\title{
Professional Learning in a School-Based Community of Science Teachers
}

\author{
Wayne Stuart Melville
}

This thesis is presented for the Degree of

Doctor of Philosophy

of

Curtin University of Technology

February 2005 


\section{DECLARATION}

This thesis contains no material which has been accepted for the award of any other degree or diploma in any university. To the best of my knowledge and belief this thesis contains no material previously published by any other person except where due acknowledgement has been made.

Signature:

Date: 1 


\section{ABSTRACT}

This thesis investigates professional learning in a school-based community of science teachers. Transcripts of science staff meetings were analysed using two frameworks. These frameworks relate to the notions of community and professional learning. The school-based community is interpreted in terms of three metaphors of understanding: meanings, practice and identity. Professional learning is interpreted in terms of how the teachers learn the episteme, techne and phronesis of their science teaching. I propose that professional learning occurs when teachers engage in virtues-based personal reflection and/or public discourse around episteme, techne and phronesis in the spaces 'in-between' the metaphors of community. This proposition raises implications for the accessibility of professional learning and the relationship between community and organisational boundaries. 


\section{ACKNOWLEDGEMENTS}

A heartfelt thankyou to Rosemary, my wife, for the sacrifices that you have made as I have pursued my dream. Without your support, this thesis would not have been possible. It is as much yours as mine.

For my children, Bethany, Bryce and Joshua, a huge thankyou for your understanding and patience over the past few years. You can have the computer now.

To my Co-Supervisors, Professor Bevis Yaxley and Professor John Wallace. Teachers, mentors, colleagues and friends, I have been privileged to be under the tutelage of such scholarly gentleman.

To my colleagues, peers and friends who form the Hobart seminar group of the Science and Mathematics Education Centre, Curtin University of Technology. You have contributed more richly to my life and work than you will ever recognise.

To my science teaching colleagues to whom I owe so much. To teach with you is an honour, to learn from you is a privilege. 


\section{ACKNOWLEDGEMENTS}

\section{ABSTRACT \\ TABLE OF CONTENTS}

\section{CHAPTER 1 - INTRODUCTION}

1.1 INTRODUCTION

1.2 METHODOLOGY AND METHOD

1.2.1 Narrative

1.2.2 Method

1.2.3 Data collection

1.3 ETHICAL CONSIDERATIONS

1.4 TRUSTWORTHINESS CRITERIA

1.5 CONCLUSION

\section{PREFACE - LITERATURE REVIEWS}

\section{CHAPTER 2 - TEACHER PROFESSIONALISM}

2.1 INTRODUCTION

2.2 A KNOWLEDGE BASE

2.3 A MORAL BASE

2.4 PROFESSIONALISM IN PRACTICE

2.5 CONCLUSION

\section{CHAPTER 3 - TEACHER PROFESSIONAL LEARNING}

3.1 INTRODUCTION

3.2 THE NATURE OF PROFESSIONAL LEARNING

3.2.1 Cognitive learning 
3.2.2 Values and purposes

3.2.3 Emotional learning

3.3 PROFESSIONAL DEVELOPMENT AND PROFESSIONAL LEARNING

3.4 METHODS OF PROFESSIONAL LEARNING

3.5 THE DEVELOPMENT, TRANSFERABILITY AND APPLICABILITY OF PROFESSIONAL

LEARNING

3.6 THE SCHOOL CONTEXT OF TEACHER PROFESSIONAL LEARNING

3.7 LEADERSHIP

3.8 CONCLUSION

CHAPTER 4 - THE SUBJECT DEPARTMENT

4.1 INTRODUCTION

4.2 COMMUNITY

4.3 SUBJECT DEPARTMENTS AND COMMUNITIES

4.4 BOUNDARIES

4.5 CHARACTERISTICS OF THE DEPARTMENT

4.5.1 Social interactions in the department

4.5.2 The department as an administrative unit

4.5.3 The department as a reference group

4.6 THE IMPORTANCE OF THE DEPARTMENT FOR PROFESSIONAL LEARNING

4.6.1 School and department

4.6.2 The department as the context for professional learning

4.7 CONCLUSION 


\section{EPILOGUE - REVIEWS OF THE LITERATURE}

\section{CHAPTER 5 - MEANINGS}

5.1 VIGNETTE 1 - 'WE TEACH MATHS, THAT'S OUR POLICY'

5.2 VIGNETTE 2 - 'THEY ARE WALLIES, ABSOLUTE WALLIES'

5.3 VIGNETTE 3 - 'SO DOES INFORMAL LEARNING COUNT?'

\section{CHAPTER 6 - DISCUSSION OF MEANINGS}

\section{CHAPTER 7 - PRACTICE}

7.1 VIGNETTE 4 - 'THE FOUR BASICS?'

7.2 VIGNETTE 5 - 'THEIR OWN CURIOSITY. THAT'S WHERE YOU START FROM'

7.3 VIGNETTE 6 - 'THE RICHNESS OF THE SCIENCE EXPERIENCE'

7.4 VIGNETTE 7 - 'I JUST PICK OFF THE TOP ONES, OR WHAT HAPPENS?'

7.5 VIGNETTE 8 - 'THAT IS NOT GOOD CHEMISTRY'

7.6 VIGNETTE 9 - 'THEY LIKE PUTTING LAB COATS ON'

CHAPTER 8 - DISCUSSION OF PRACTICE

\section{CHAPTER 9 - IDENTITY}

9.1 VIGNETTE 10 - 'WHAT'S THAT STORY, I DON'T KNOW THAT STORY'

9.2 VIGNETTE 11 - 'APPARATUS ... THE NAMES OF THE BITS AND PIECES'

9.3 VIGNETTE 12 - 'YOU WOULD NOT HAVE THE WOODWORK TEACHER TEACHING SCIENCE'

\section{CHAPTER 10 - DISCUSSION OF IDENTITY}

\section{CHAPTER 11 - ANALYSIS}

11.1 INTRODUCTION

11.2 PROFESSIONAL LEARNING AND 'IN-BETWEENNESS' 
11.4 ANALYSIS OF THE NARRATIVES

\subsubsection{MEANING - IDENTITY}

11.4.2 Meaning - Identity: Episteme 11.4.3 Meaning - Identity: Techne 1 1.4.4 Meaning - Identity: Phronesis 11.4.5 Meaning - Identity: Epilogue

\subsubsection{IDENTITY - PRACTICE}

11.4.7 Identity - Practice: Episteme 11.4.8 Identity - Practice: Techne 11.4.9 Identity - Practice: Phronesis 11.4.10 Identity - Practice: Epilogue

\subsubsection{PRACTICE - MEANING}

1 1.4.12 Practice - Meaning: Episteme 11.4.12 Practice - Meaning: Techne 11.4.14 Practice - Meaning: Phronesis 11.4.15 Practice - Meaning: Epilogue

\subsubsection{COUNTERPOINT}

11.5.2 Counterpoint: Episteme 11.5.3 Counterpoint: Techne 11.5.4 Counterpoint: Phronesis 11.5.5 Counterpoint: Epilogue

11.6 SUMMARY

\section{CHAPTER 12 - CONCLUSION AND IMPLICATIONS}

12.1 INTRODUCTION

12.2 BOUNDARIES

12.3 INSIGHTS AND CONCLUSIONS

12.4 IMPLICATIONS

\section{REFERENCES}




\section{APPENDICES}

APPENDIX 1: STUART'S GUIDELINES FOR POLICY DEVELOPMENT

APPENDIX 2: DRAFT SCIENCE POLICY

APPENDIX 3: ESSENTIAL LEARNINGS FRAMEWORK, VALUES AND PURPOSES

APPENDIX 4: TOPICS FOR THE YEARS 8 TO 10 SCIENCE SYLLABUS

APPENDIX 5: TEACHER CONSENT FORMS 


\section{CHAPTER 1 - INTRODUCTION}

\subsection{INTRODUCTION}

Australia, along with most of the English-speaking world, faces an increasing shortage of secondary school teachers; in particular, teachers with a university science qualification (Goodrum, Hackling \& Rennie, 2001). While the full extent of this shortage is unclear, the number of non-science trained teachers who teach science may be "masked by the numbers of teachers without adequate specialist backgrounds teaching in these areas - that is, the numbers of teachers teaching 'out of field' hides true shortages" (Committee for the Review of Teaching and Teacher Education, 2003, p. 8). Moreover, the number of non-science trained teachers teaching science is increasing, a situation that will not alter in the near future, given the lead-time in training teachers (Goodrum et al. 2001). Such a situation has obvious and profound implications for the quality of science education. The President-elect of the Science Teachers Association of Victoria was reported in The Age newspaper as saying that non-science trained teachers "may not understand basic concepts and, as a result, students develop misconceptions" (Cook, 2003, p. 3).

Given that the teacher is the single most important factor in the improvement of teaching and learning, professional development is a high priority for teachers of lower secondary science (Goodrum et al. 2001). In particular, it has been suggested that "professional development must involve all of the science staff within the school ... professional learning must be school-based and directly related to the classroom" (pp. 174-175). This statement reflects the growing realisation that teacher professional learning is "situated, specific and practical in character" (McCullough, Helsby and Knight, 2000 , p. 90). It is in this context of decreasing numbers of science-trained teachers, and increasing emphasis on school-based teacher professional learning, that I situate my research.

My purpose in this research is to examine the professional leaning that occurs within a school-based community of science teachers. This is an important purpose for the reasons referred to by Goodrum et al. (2001) and McCullough et al. (2000), who both stress that professional learning should be situated in the context of teachers' work. 
From his review of professional learning, Ingvarson (2003) believes that the focus of teacher professional learning will be on the school, with an emphasis on teachers meeting professional standards of practice. I do not believe, however, that this focus on the school is the most appropriate level at which to study the professional learning of teachers. After 16 years as a secondary science teacher, my intuition tells me that a more appropriate focus of study is the subject department. Upon reflection, I believe that research at the subject department level is more relevant for three reasons. The first is that the teachers who comprise the department are the people with whom a teacher spends a good proportion of their working day. The opportunity to develop personal and professional relationships is clearly higher when people spend more time in close proximity to each other. The second is that these people are the ones that a teacher will turn to when they have a problem with the teaching of the subject; in this case, science. It would be illogical to ask an English teacher for assistance in teaching Newton's Laws of Motion. Third, one would assume that the people who are trained in, and teach, a subject have a passion for the subject that draws them together. If I am correct in my intuition and subsequent reflection, there are profound implications for understanding teacher professional learning.

The participants in my research are the ten members, including myself, of a coeducational secondary school science department. This science department teaches from the first year of secondary school, Year 7, through to the two senior secondary years, Years 11 and 12. Science is compulsory until the end of Year 10, after which students can choose science subjects that are either pretertiary, qualifying them for university entrance, or non-pretertiary. The school follows the syllabus documents prepared by the Tasmanian Secondary Assessment Board for Years 9 to 12 (http://www.tassab.tased.edu.au). The Secondary Assessment Board is a statutory authority charged with providing syllabuses in Tasmanian schools, the between school moderation of these subjects, and the public examination of pretertiary subjects. The syllabus for Years 7 and 8 is developed by the school, and is usually designed to dovetail into the Secondary Assessment Board Year 9 science syllabus. Classes are homogeneous in Years 7 and 8, and heterogenous in Years 9 and 10.

Having stated that $\mathbf{l}$ believe that the department is the most appropriate context for the study of teacher professional learning, I am now in a position to outline the structure 
of my research and this thesis. In this introductory chapter, the ethnographic methodology and narrative method that I will employ in order to research teacher professional learning within a school-based community will be described.

\subsection{METHODOLOGY}

It is the purpose of this section to describe and justify the methodology and method that will be used in the development of this research. As my research is about the community of school-based science teachers, I believe that an ethnographic research methodology is the most appropriate. Ethnographic research "focuses upon the study of a culture or community" (Isaac \& Michael, 1997, p. 218) for the "purpose of describing their socio-cultural activities and patterns" (Burns, 1995, p. 246). The science teachers in this study form a community, so as a process of social description ethnographic research is appropriate for this study. It is qualitative and interpretative, and is therefore suited to the study of people's "ability to interpret their own actions and the actions of others, to act on their understandings and to endow their lives and actions with meaning" (Burns, 1995, p. 249). Such interpretations accept the political, economic and social processes that shape the context of human activities (Burns, 1995). In my research, the context is the community of science teachers, which operates within the wider contexts of both the school and the wider education community. Specifically, I will employ the methods of narrative analysis and analysis of narratives in my interpretation of the data that has been collected (Polkinghorne, 1995).

\subsubsection{Narrative}

Narrative offers an appropriate approach for considering professional learning in a school-based community of science teachers. Narratives as stories hold "significant promise for qualitative researchers" (Polkinghorne, 1995, p. 7). For qualitative researchers, narrative "is a way of characterising the phenomena of human experience and its study is appropriate to many social science fields" (Connelly \& Clandinin, 1990 , p. 2). For Polkinghorne (1995, p. 5), narrative descriptions "exhibit human activity as purposeful engagement with the world. Narrative is the type of discourse 
composition that draws together diverse events, happenings and actions of human lives into thematically unified goal-directed purposes". Czarniawska (2004, p. 3) states that the rise of narrative in humanities research is due to the belief that narrative is the "most typical form of social life". Given that I am considering the professional learning of a school-based community, such references support the choice of narrative as a suitable approach to my research.

Narrative is a way of knowing that is both different from, yet complementary to, logical-scientific knowledge - the predominant form of knowing in western societies. Lyotard (1979/ 1984, p. xxv, cited in Czarniawska, 2004) discussed the differences between and the complementarity of narrative and logical-scientific knowledge. Lyotard stresses that logical-scientific knowledge requires narrative for its own legitimation yet, at the same time, denies narrative knowledge any sense of legitimation, demanding that the differences in "knowledge status and legitimation remains taken for granted, unexamined" (Czarniawska, 2004, p. 7). Following Lyotard's work, Bruner (1986) compared logical-scientific knowledge, which he described as "paradigmatic cognition", with the narrative form of knowledge, which he referred to as "narrative cognition", with the intention of examining their relationship. For Bruner, both forms of cognition, paradigmatic and narrative, generate useful and valid knowledge (Polkinghorne, 1995, p. 9). Thus, they both have a place in the researcher's repertoire. Polkinghorne (1995) describes two types of narrative that each employs the specific form of cognition best suited to their particular ends. Analysis of narratives employs paradigmatic cognition in the analysis of stories in order to identify common elements within those stories. Narrative analysis utilises narrative cognition in synthesising data into a story, or stories, through the use of a plot or framework. It is my intention to use both methods of narrative in the construction of my thesis, as I believe that they both offer advantages for the analysis of the data that I have collected.

Within the literature on teachers and teaching, narratives are a way of telling stories about teachers that are both "personal - reflecting a person's life history [and] social reflecting the milieu, the contexts in which teachers live" (Connelly \& Clandinin, 1999 , p. 2). Stories, as the "linguistic form in which human experience as lived can be expressed" (Ricoeur, 1991, cited in Polkinghorne, 1995, p. 7), draw together events 
and actions "into an organised whole by means of a plot". As narrative cognition "consists of organizing experience with the help of a scheme assuming the intentionality of human action" the plot[s] is [are] of fundamental importance to the development of narrative (Czarniawska, 2004, p. 7). Indeed, Aristotle differentiated "between a simple story 'a narrative of events arranged in their time sequence' and a plot that arranges them according to a sense of causality" (Czarniawska, 2004, p. 124). Plots act as a "type of conceptual scheme by which a contextual meaning of individual events can be displayed" providing a structure "through which people understand and describe the relationship between the events and choices of their lives" (Polkinghorne, 1995, p. 7).

For the researcher, the structure that plots provide also assists in the separation of the narrative's essential information from information that is extraneous to the narrative. Further, the act of writing itself is a reflective activity, encouraging the growth of "consciousness out of the unconscious" (Ong, 1982, p. 150). A single plot, however, is unlikely to capture the complexity of a social situation that a researcher is interested in. For this reason, "most social science texts ... contain more than one plot, which must be connected to each other ... by one of two strategies, linking and embedding" (Czarniawska, 2004, p. 125). Plots need to connect the narrative elements in more than a temporal sense; they also need to relate the elements by transformation, which gives the narrative causality (Czarniawska, 2004). This transformation gives the narrative both a syntagmatic dimension, that is, a systematic order, in addition to a paradigmatic dimension, which serves to classify the narrative elements as "belonging to a category or concept" (Polkinghorne, 1995, p. 9).

Narrative as an approach to research is of value to the ethnographer, as the researcher attempts to "understand the fullness of human existence by including in their inquiries the unique characteristics that differentiate human existence from other kinds of existence" (Polkinghorne, 1995, p. 8). Specifically, when investigating teachers and teaching, teachers tell stories of their practice, of other teachers and of schools; stories that thread together teacher identity, knowledge and context (Connelly \& Clandinin, 1999). Czarniawska (2004) suggests that to take these stories and employ them is a three-step process. These three steps are: constructing characters, attributing functions to events and actions, and finding an interpretative theme. The process is non-linear, 
with an interpretative theme becoming clear, and then dominant, through the construction of characters and the attributing of functions. The emergence of a dominant theme is cause for the researcher to re-examine the text and "tighten up" the story (Czarniawska, 2004, p. 126). This close-knit relationship between the story and the data is described by Bruner (1986):

It is not that we initially have a body of data, the facts, and we then must construct a story or theory to account for them ... instead ... the narrative structures we construct are not secondary narratives about data but primary narratives that establish what is to count as data (p. 142-143).

This section has provided a justification for the use of narrative in my research. The methods that I will employ in the actual research, specifically narrative analysis and analysis of narrative, are drawn from this methodology. Through the use of these two methods, which rely on both paradigmatic and narrative cognition respectively, I believe that the research will provide a trustworthy understanding of the professional learning that occurs in a school-based community of science teachers.

\subsubsection{Method}

The methods that have guided the planning and conduct of this research are based on the methodology outlined above. The use of the two specific methods, narrative analysis and analysis of narrative, has evolved as the work of data collection, synthesis and analysis has proceeded. As such, the methods described here have, through a circuitous route, moulded the final structure of the thesis. The overall structure of the thesis is divided into three sections, each of which is intrinsically connected to the other.

The first task is the development of the theoretical frameworks, which will be employed in the interrogation of the data. Specifically, my research requires frameworks for the notions of community and teacher professional learning. This development will occur through literature reviews on teacher professionalism, teacher professional learning and the subject department. Without these frameworks the thesis would lack structure and coherence. These frameworks are described in chapters 2, 3 and 4 . 
Second, there is a requirement to collect the raw data and transform that data into a field text. The raw data for the research was gathered by tape recording the science department staff meetings over a period of two years. These recordings were transcribed to provide the field text for the research. Other data collected included written material produced in response to the departmental meetings and a school newsletter.

Interpretation is the third task. The initial interpretation of the data is based on the narrative analysis strategy described by Polkinghorne (1995). Under this strategy, the events and actions described within the data were synthesised into a series of Vignettes. The framework for these Vignettes was my theoretical understanding of the notion of community. This understanding was based on the metaphors of understanding developed from the literature: meanings, practice and identity. Produced according to this strategy, the Vignettes were interpreted using the analysis of narrative method outlined by Polkinghorne. This interpretation of the Vignettes was conducted using the second of my frameworks developed from the literature. This second framework was developed from my understanding of teacher professional learning, in terms of episteme, techne and phronesis. From this second interpretation, a proposition emerged that integrates my understanding of community and teacher professional learning into a coherent argument.

The key to this method being cogent in the interrogation of the data is the extent to which the literature reviews can provide suitable theoretical frameworks around which the interpretation can be constructed. For this reason, the reviews of the literature form a foundational component of this thesis. These reviews also shape the frameworks that will be employed in this thesis, frameworks that will be described and justified at the conclusion of each of the three literature reviews. Through the use of these methods, I believe that the data can be organised and interpreted in such a way as to produce an understanding of professional learning within a school-based community of science teachers. 


\subsubsection{Data collection}

Ethnographic research is based on the "observation, organisation and interpretation of data" (Burns, 1995, p. 258). The principal method of data collection is participantobservation, in which the observer is "part of the context being observed ... the end result is an analytical description and interpretation of a highly complex system" (p. 258). In order to achieve such an analytical description, Wolcott (1988, p. 192) states that the participant-observer "would never for a minute rely solely on a single observation, a single instrument, a single approach". Consideration of these two aspects of ethnographic data collection, participant-observation and non-reliance on a single observation, moulded my approach to the collection and interpretation of the data for my research.

As a member of the community of science teachers involved in the meetings, I am not a neutral observer. My role is that of participant as observer, a role in which I am involved closely with my colleagues. In such a role, I needed to be mindful of my potential to both modify, and be modified by, the context of the meetings. One strategy for dealing with this concern was to write my contributions to the meetings in the third person, and to maintain that distance throughout the analysis and interpretation. When analysing and interpreting the data $\mathrm{I}$ had to be mindful of grounding my analysis and interpretation in the collected data. In order to do this, it was important to be aware of the danger of subconsciously introducing my background knowledge of the context without proper acknowledgement. If such knowledge were to be introduced in order to develop the interpretation, such an introduction would need to be explicitly explained. As Guba and Lincoln (1989, p. 154) state, "the inquirer's own construction may be introduced for critique". With these considerations in mind, it is now possible to move to the actual process of data collection.

The data was collected in two forms, audiotape and documentation. Recording the science department staff meetings over a period of two years provided the audiotape data for the research. These meetings were programmed by the school to occur approximately every six weeks throughout the school year. In addition there was one meeting organised by the teachers to discuss changes to the syllabus. Release time 
was given to the teachers involved in this meeting, which was held towards the end of the first year of the data recording. There was also meeting time provided for planning at the start of the second year of data collection. In total, there were fourteen meetings over the course of the two years. Audiotape was used as it was considered less intrusive in the meetings, and satisfied my concerns about the effect videotaping may have had on the teachers' level of self-consciousness.

The method of recording all of the science staff meetings over the two-year period of the research capitalised on the advantages of participant-observation, while also ameliorating the major limitations of the method. The recording of all of the meetings made it possible to produce a record of teacher behaviour. This has the very real advantage of negating the tendency of some research techniques to depend "entirely on people's retrospective or anticipatory reports of their own behaviour" (Burns, 1995 , p. 262). By recording the meetings programmed as part of the teachers work, teacher non-participation in other data collection techniques, such as interviews, was avoided. As a result, all teachers had the opportunity to participate, and thus have their voices heard in the context of their work. The major limitation of observation, that of the impossibility of predicting the "spontaneous occurrence of an event" (Burns, 1995, p. 263) is also avoided by recording all of the meetings.

The second method of data collection was to gather the documentation that the teachers produced as a consequence of the staff meetings. These included the new syllabus outlines for Years 7 to 10 , the draft science policy, a letter seeking authorisation for the Science Expo, and the reporting of the Science Expo in the school's newsletter. All of these documents are provided as appendices and, in the case of the latter, in full. This is important, as the documentation provides textual evidence to support the analysis.

\subsection{ETHICAL CONSIDERATIONS}

The major ethical issues that need to be addressed in this research are those that relate to permission from the participants and the school where the research occurred. As far as the school was concerned, written permission was obtained from the Principal 
before approaching the staff. The informed, written consent of the participants was obtained before the research began. The information in this consent process included the method of data collection, how the data were to be analysed and stored, and assurances that no one individual would be capable of being identified from the text. The consent form is reproduced as Appendix 5.

With regard to the data that were collected for this research, the original recordings and transcripts will be kept secure, in accordance with the Regulations of Curtin University of Technology, for a minimum of five years. In accordance with Section 2.4 of the Australian Vice-Chancellors' Committee 'Joint National Health and Medical Research Council / Australian Vice-Chancellors Committee Statement and Guidelines on Research Practice' (2004), I have organised for the National Key Centre for School Science and Mathematics at Curtin University of Technology to retain a copy of the data in addition to my personal copy.

\subsection{TRUSTWORTHINESS CRITERIA}

Four criteria have been proposed by Lincoln and Guba (1985) in order to establish trust and confidence in the conclusions of qualitative research. The trustworthiness criteria are summarised as credibility, transferability, dependability and confirmability. These four trustworthiness criteria parallel the criteria usually assigned to ensure the soundness of quantitative research: internal validity, external validity, reliability and objectivity (Isaac \& Michael, 1997). It must be kept in mind however, that not all authors accept that validity is a criterion pertinent to qualitative work. Some authors do not accept the notion of validity in assessing the quality of their qualitative work, referring to it as a "burden" (Wolcott, 1990, p. 148), or by asking if the question "is it valid?" should be replaced with the question "is it interesting ... relevant ... beautiful?" (Czarniaskwa, 2004, p. 136). Denzin and Lincoln (2003, p. $69)$ in their discussion of qualitative research state that "qualitative researchers do not claim that there is only way of interpreting an event" for the reason that "qualitative research has to do with description and explanation and whether or not the explanation fits the description". With these questions in mind, the purpose of this 
section is to highlight how the Lincoln and Guba (1985) criteria will be satisfied in my research.

Credibility in a qualitative study can be considered through five techniques proposed by Lincoln and Guba (1985) and described by Isaac and Michael (1997, p. 221-222). These techniques are integrity of the observations, peer debriefing, negative case analysis, referential adequacy and member checks. All five of these techniques have been employed in my research. Integrity of the observations involves two features: prolonged engagement and persistent observation. Prolonged engagement was ensured through the recording, on audiotape, of the departmental staff meetings for a period of two years, thus this "prolonged engagement [was] sufficient to gain an overview of the social entity and its context to minimise sources of misinformation and distortions" (Isaac and Michael, 1997, p. 222). In addition to this, persistent observation of the data in the production of the Vignettes from the raw data will sort the "significant from the superfluous" (Isaac and Michael, 1997, p. 221). Peer debriefing involves "engaging a disinterested outside party to ask searching questions ... and generally to explore the breadth and depth of one's approach by identifying its strengths and weaknesses, as well as its implications, oversights and choice of options" (Isaac \& Michael, 1997, p. 221). In my research, peer debriefing has been achieved in doctoral seminars organised through Curtin University of Technology, in conversations with fellow doctoral students and academics, and in the many conversations that I have had with my Supervisors. All have contributed to the process of deepening my understanding of the issues involved in my research. Negative case analysis involves the recasting of "hypotheses until they fit the observed reality" (Isaac \& Michael, 1997, p. 221). In the case of my research, Vignette 11, Apparatus ... the names of the bits and pieces - A struggle to identify, fulfilled the role of the negative case analysis through its portrayal of the difficulties that a non-science trained teacher had in accessing the professional learning opportunities within the school-based community of science teachers. Referential adequacy involves the:

... recording and setting aside of unanalysed data ... so that at a later time, when tentative findings are being formulated, these reserve recordings can be examined for fit with the emerging findings from the principal data sources (Isaac \& Michael, 1997, p. 221). 
In the case of my research, the recordings of each science staff meeting have been copied. I have retained the original recordings, and the copies have been given to my Supervisors. Finally, member checks are regarded as the "most crucial technique ... in establishing credibility" (Isaac \& Michael, 1997, p. 221). For my research, the transcripts of the recordings have provided a means of keeping track of the development of the teachers' ideas over a period of months, as well as allowing an understanding of the difficulties that arose with a non-science trained teacher in Vignette 11. Through informal conversations with the participants, I believe that they trust the veracity of my analysis and conclusions.

Transferability is the questioning of similarities between the context of this research and other contexts where similar conclusions are possible. I believe that transferability is achievable for two reasons. First, my research is constructed from a grounded theory developed from the reviews of the literature that I have undertaken into teacher professionalism, teacher professional learning and the subject department. This construct provides a clear framework, which other researchers could use when trying to replicate this research. Second, the use of the Vignettes provides a rich description of the context of this research: the major participants as individuals, as a community and the organisational constraints under which they operate. Taken together, I believe that the framework and contextual description would allow replication of my research.

Dependability asks the question "If it were done over again, would one arrive at essentially the same findings and conclusions?" (Isaac \& Michael, 1997, p. 223) When addressing this criterion, it must be remembered that repetition of this research within a different context and with different participants would produce transcripts that address different issues and concerns of the community. This illustrates that teaching is not a static profession in the way it responds to a variety of needs, challenges and personalities. That said, I believe that the criterion of dependability has been met in a number of ways. The first is that the development of my proposition regarding professional learning within a school-based community of science teachers is fully detailed and considered in this thesis. My proposition was also scrutinised by my Supervisors as to its grounding in the literature and its theoretical robustness. The second is that the teacher dialogue in the Vignettes is, with very few exceptions, 
verbatim from the audiotapes. The only changes that were made were for the purposes of readability. 1 am confident that my conclusions are dependable.

Confirmability is the "most ambitious and demanding of the four criteria" (Isaac \& Michael, 1997, p. 223), as it involves a full audit of the data and records. Given that the original and copies of the audiotapes have been retained, along with the full transcripts of each tape, the data and records of my research are complete. From the data, there is a clear audit trail to the Vignettes, discussions and eventually the analysis and conclusions. Throughout the development of this research, I have constantly requested critical feedback from my Supervisors and peers as to the verisimilitude of the Vignettes and the linkage of the analysis and conclusion back to my theoretical framework and the data. With the feedback that I received and consequent reflection on my work, I believe that the trail from literature to theory, from audiotape to Vignette, and from analysis to conclusion, is clear. I am confident that my research would stand the test of the confirmability criterion.

\subsection{CONCLUSION}

In this chapter I have delineated the purpose of my research and the methods that I intend to use in order to fulfil my purpose. I believe that an ethnographic methodology that utilises a narrative approach, with both narrative analysis and analysis of narratives, is the most appropriate method for the conduct of my research. I have outlined how I intend to collect the data on audiotape, and how that data is to be interpreted from raw data, through field text to research text. I have also addressed the questions of ethics, and how I intend to justify the trustworthiness of my research, using the trustworthiness criteria developed by Lincoln and Guba (1985). Having outlined the foundations of my research, I am now in a position to outline the structure of this thesis. Chapters 2, 3 and 4 provide the reviews of the literature that will be used to develop the frameworks that will be employed in the analysis of the data. With these frameworks in place, the Vignettes that describe critical incidents in the life of the community will be presented, together with a narrative analysis of each collection of Vignettes. The Vignettes and their narrative analyses are to be found in chapters 5 to 10 . Chapter 11 , the penultimate chapter, will outline my proposition 
regarding teacher professional learning in a school-based community of teachers. I will use this proposition to undertake an analysis of narrative on my data. Chapter 12 , the final chapter, will detail the insights I reached from my research, and detail the implications of those insights for both teacher professional learning and further research. 


\section{PREFACE - LITERATURE REVIEWS}

Cresswell $(2003$, p. 32) suggests that the form of review of the literature that I am employing is "integrative [as it involves] summarizing broad themes in the literature". In undertaking an integrative review of the literature, I will be summarising the broad themes of teacher professionalism, teacher professional learning and teacher communities, for two purposes. The first purpose is to relate my research to the larger context of what is currently understood around the notions of teacher professional learning and teacher communities. My second purpose is to use these literature reviews to develop the theoretical frameworks that will be employed in interpreting the data that I have collected. Specifically, my research requires a framework for understanding the notions of teacher communities and professional learning.

At the conclusion of each of the three reviews, the major themes will be summarised, and their role in the developing frameworks briefly explored. At the conclusion of all three reviews, the salient themes that emerge will be integrated to form the frameworks and strategies that will be employed in the construction and subsequent analysis of the recorded data. These frameworks and strategies will be summarised in the epilogue at the end of chapter 4. 


\section{CHAPTER 2 - TEACHER PROFESSIONALISM}

\subsection{INTRODUCTION}

It is the purpose of this review of literature to develop an understanding of what is meant by the term 'professional' in the context of teacher 'professional' learning. This review, and the next on teacher professional learning, is intrinsically linked by the term 'professional'. The understanding that I develop from the literature needs to be appropriate for the conduct and context of this research. As the term 'professional' appears to be contextually bound, it is not the intention to develop an understanding that will necessarily be appropriate for other contexts that require an understanding of the term. However, many of the salient points regarding my understanding of teacher professionalism will reflect aspects of a wider understanding of the concept.

My understanding, gained from the literature, will guide the development of the theoretical frameworks that will be utilised in the analysis of the data that is collected from the science staff meetings. To facilitate this development, I have divided the chapter into four sections. The first two sections review the literature on the concept of teacher professionalism. Section 2.2 reviews the literature from the perspective of its knowledge base, while section 2.3 reviews the literature from the perspective of its moral base. Section 2.3 concludes with a definition of teacher professionalism that will be used in this research. Section 2.4 examines various ways in which a framework could be developed that explores the implications of this definition. Section 2.5 is the conclusion to this chapter in which the major themes will be summarised, and their role in the developing frameworks briefly explored.

\subsection{A KNOWLEDGE BASE}

Professionalism is a profoundly difficult concept to understand. This is not to say that the literature on the topic is sparse; rather, there is a vast literature on the topic that is "characterised by sophistication, variety and rigour" (Boston, 2002, p. 10). This literature has provided insights into the various components of the work of teaching, 
and into the lives of exemplary teachers. Within this extensive literature, however, definitions of professionalism often appear to lack clarity of meaning. This is a situation that can be exacerbated by the many definitions of teacher professionalism and the multiple interpretations that can be put on the meaning(s) that it is given when used in differing contexts. So problematic is any notion of professionalism, with its "conceptual difficulties and ambiguities" that even its "value as a tool for analysis" is called into question (McCulloch et al. 2000, p. 13). The sociologist Freidson (1994, p. 27) states that "the concrete, historical character of the concept [of professionalism] and the many perspectives from which it can legitimately be viewed, and from which sense can be made of it, preclude the hope of any widely accepted definition of general analytical value". The difficulties of developing a "widely accepted definition' increase again when one attempts to consider the concept of teacher professionalism, as this adds another layer of ambiguity, namely the multiple meanings that can be applied to teachers, their purposes, actions and knowledge. Given these difficuities of definition, what is it that gives the term 'teacher professionalism' "considerable resonance for teachers, one that both incorporates them into state service, and yet gives them strength to resist external controls?" (Ozga, 1992, p. 7)

Teacher professionalism can be understood in two ways. The first understanding is that it is a concept that must be located in "relation to changing historical, political and social contexts" (McCulloch et al. 2000, p. 14). As such it is a concept that is open to modification over time due to the "contestation between rival groups and interests" over its meaning (McCulloch et al. 2000, p. 14). Clandinin and Connelly (1995) describe the shifts in the meaning of words like teacher and knowledge as:

Teachers become active agents, pulling themselves into the future with their own inevitable social agendas, rather than passive agents pushed into the future by others' social agendas ... knowledge becomes the embodied forms (e.g. images, metaphors, personal philosophy, rhythms, rules and principles) by which teachers interact with the world, rather the knowledge of things (e.g. subject matter, children and instructional knowledge) that teachers need to fulfil their social function (p. 26).

The second understanding proposed by McCulloch et al. (2000) is that teacher professionalism is a form of ideology which both provides teachers with some 
autonomy of action, while also legitimating controls over them. These two ways of attempting to understand the term have lead to what Coulter and Orme (2000, p. 4) describe as the "professionalism paradox" in which people's confusion as to the meaning of the term "does not seem to prevent them from using it as a verbal weapon to exert power over others". This paradox has also seen the teaching profession described as a "mass" profession (Fitzgerald, 2002, p. 32), a term that Boston (2002) defines as existing when the profession is:

... liable to be perceived (and likely to perceive itself) as being without an independent sphere of either individual or collective authority, and hence without capacity for ownership of its ideas and tools ... a 'mass' profession needs someone else - employers, unions, academic, government, parties, even media - to contest for hegemony - leadership and ownership of its knowledge - on its behalf (p. 11).

Using the two understandings of context and ideology, McCullough et al. (2000), describe an 'ideal' of teacher professionalism that has developed in England and Wales over the past six decades. This ideal is based on the historical assumption that teachers should control both what is taught, and how it is to be taught. In short, teachers control the curriculum. The curriculum in this ideal is the term being used in its widest interpretation. It includes curriculum content, curriculum method, curriculum form, and curriculum assessment (McCullough et al. 2000). Taking this meaning of curriculum, it can be argued that the curriculum is "a definition of teachers' work" (Connell, 1985, p. 87). Freidson (1994, p. xvii) supports the notion of an ideal, stating that professions are occupations that acquire control over the "determination of the substance of its own work" to gain autonomy over the essential character of their work. This autonomy is characterised by the profession having "sufficient authority over work to be free to take discretionary action as a matter of course" (Friedson, 1994, p. 166).

The importance of a professional group controlling a knowledge base, in this case, the teachers controlling the curriculum, is emphasised by Torstendahl (1990). Alongside this recognition, Torstendahl argues that professionals must recognise that such control has "never been characterised by total autonomy" (p. 5). Professional groups 
are "granted 'jurisdiction" of their problem areas by employers, collaborators, clients or indirect financiers (the tax payers in many cases), which can be withdrawn or changed in scope when the surroundings demand a change" (p. 5). Professionalism for teachers, therefore, relies on the limited control and jurisdiction over a knowledge base that is comprised of the curriculum at its broadest definition.

There are two forms of knowledge that make up this knowledge base; knowing about teaching and knowing how to teach (Coulter \& Orme, 2000). These two forms relate directly to the contextual and ideological ideal of teacher professionalism as described by McCullough et al. (2000). Using an Aristotelian typology, Coulter and Orme (2000) describe these two forms of knowledge as episteme and techne. There are, however, qualifications in the use of these words. It has been argued that episteme and techne may be closer in their meanings than is often thought, and that no modern translation "quite fits the bill" (Squires, 1999, p. 114). Episteme can be "roughly" interpreted as "knowledge about the world" (Coulter \& Orme, 2000, p. 6), while Squires (1999, p. 112) interprets the word as "knowledge, scientific knowledge, deduction, induction". For my purposes, I will use the term episteme in its narrow sense as proposed by Coulter and Orme; that is, as an understanding of the content knowledge that a teacher is expected to cover in a subject.

However it is interpreted, episteme is a form of knowledge that is highly valued in industrialised, technologically advanced societies. This form of knowledge has directed much governmental education policy. Indeed, there have been claims that "industrial models influenced schools in our present century because of the successes of early twentieth century manufacturing" (Sockett, 1996, p. 22). Teachers, however, seem to be of the persuasion that episteme, or knowing about teaching through preservice teacher education, the teaching practicum or through the multitude of inservice professional development programs on offer, is not tightly coupled to the practice of teaching. This kind of practical knowledge about teaching is the Aristotelian techne (Coulter \& Orme, 2000). 
Techne is described as "knowing how to do something (for example, a skill, craft or art)" (Coulter \& Orme, 2000, p. 6). Squires (1999, p. 113) argues that techne might be more appropriately interpreted as "know-how" or "procedural knowledge", for to interpret techne as craft is "too limiting" and as art "too vague". Techne is better interpreted as "something that is cognitively complex and informed by its own kind of knowledge" (Squires, 1999, p. 114). For my purposes, I will use the term techne in its broad sense as proposed by Squires, that is, as an understanding of the "procedural knowledge" of teaching, "informed by its own kind of knowledge" (Squires, 1999, p.114).

Techne as a form of knowledge is an explanation of why some people, while not formally qualified, are still perceived to be very talented teachers. Further, while episteme is obviously present or absent, techne is often tacit. This quality of techne is described in the Organisation for Economic Co-operation and Development (OECD) Report Teacher Demand and Supply (2001):

The quality of teachers matters, but is hard to predict who is going to be a good teacher just by considering observable characteristics. Unobserved, or unmeasured factors, such as verbal ability, pedagogical skills, ability to convey ideas in clear and convincing ways, ability to work in teams, ability to use a wide range of teaching strategies, enthusiasm and motivation are all extremely important (Cited in Boston, 2002, p. 11).

Sockett (1993, p. 47) describes this tacit form of knowledge as being demonstrated when "someone knows how to do when - not merely spontaneously". The importance of techne in teaching is not to be underestimated; as Coulter and Orme $(2000$, p. 6$)$ state, "we learn how to teach largely by actually teaching" and teachers prize "experience as the currency of credibility". Sockett writes:

We tend to leave this extraordinary human power and other areas of teachers' actions in the limbo of tacit knowing, ineffable, elusive by definition. Even how far we can describe it remains to be seen. Its importance for teacher professionalism is that our understanding of tacit knowing can provide a reservoir for understanding excellence: perhaps it can only be emulated, but teaching skill may actually be as much caught as taught. To ignore tacit knowing as irrelevant to the description of something called the "knowledge 
base of teaching" is as neglectful as ignoring counterevidence to a theory (p. 47).

It is not enough, however, to possess mastery of techne or episteme either individually or concurrently. For, taken either individually or concurrently, both techne and episteme fail to capture the "essence of good teaching" (Coulter \& Orme, 2000, p. 6). This missing essence is a moral base for teaching, a point that is made by Coulter and Orme (2000) and Sockett (1993, 1996). As Fenstermacher (1990) states:

Thus, the knowledge base helps teachers teach more effectively than they could before, but it does not clarify what it is that teachers ought to teach or at what purposes this improved teaching is aimed ... expertise alone is not the best foundation if one's intent is to educate as broadly as possible (pp. 139 141).

This literature review, focussing on a knowledge base for teaching, provides valuable insights into what it means for a teacher to be 'professional'. From my interpretation of the literature, it seems that teachers need to possess both episteme, knowledge of the subject, and techne, a specific knowledge-based form of procedural knowledge, if they are to be even considered remotely 'professional'. Just as importantly, the review of the literature highlights the need for teachers to possess more than just episteme and techne, important as these are. Teachers also need to have an "essence of good teaching" (Coulter \& Orme, 2000, p. 6). It is at this point that I commence section 2.3 of this review, concerning myself with this "essence" - a moral base of teaching.

\subsection{A MORAL BASE}

Over the past decade there has been much written about the nature of the professions. From these writings it would appear that at the heart of the concept of a profession is the notion of a particular, essential 'social good' that a profession attempts to provide for the benefit of society. This notion is important in terms of teaching, as it allows the development of a deeper understanding of teaching in terms of both a knowledge base and a moral base. As described in section 2.2, there is a need to pursue an understanding of the moral base of teaching, as the possession of both episteme and techne will not guarantee that a teacher will act in a 'professional' manner. 
In 1986, the American Bar Association stated that a profession:

... refers to a group ... pursuing a learned art as a common calling in the spirit of public service - no less a public service because it may incidentally be a means to livelihood. Pursuit of a learned art in the spirit of public service is the primary purpose (p. 10).

The Australian Council of Professions (1993) stated that professional practitioners must:

$\ldots$ at all times place the responsibility for the welfare, health and safety of the community before their responsibility to the profession, to sectional or private interests, or to other members of the profession (p. 1)

Such writings point to a moral purpose for every profession, a purpose that is, perhaps, best exemplified by the Hippocratic Oath of the medical profession. This moral purpose for every profession is the point made by Davis and Elliston (1996) that:

One of the tasks of the professional is to seek the social good. It follows from this that one cannot be professional unless one has some sense of what the social good is. Accordingly, one's very status as a professional requires that one possess this moral truth. But it requires more, for each profession seeks the social good in a different form, according to its particular expertise: doctors seek it in the form of health; engineers in the form of safe efficient buildings; and lawyers seek it in the form of justice. Each profession must seek its own form of the social good. Without such knowledge, professionals cannot perform their social roles (p. 18).

If professions are underpinned by a moral imperative that seeks to define their own form of the social good, education professionals, be they in academia, schools or administration, must also seek to define and actively express their form of the social good. For this to be allowed to happen, teachers would, out of necessity, require the trust of the general population, through - in democratic societies - the populations' elected representatives. It must also be kept in mind that the moral principles that would guide such a definition of the social good may also be expressed differently "depending on religious or ethnic background" (Kilbourn, 1998, p. 44). Thus, what may be considered morally repugnant in one society may be considered acceptable in another. For this reason, the understanding developed for my research is contextualised within a western, multicultural democracy. 
Making the first attempts at the definition of this social good is a task that has already been accepted by some authors in the field of education. Sockett $(1993$, p. xi) writes that "teaching is an ideal of service" while Brock (1999) states that:

Through addressing the needs, taking account of the interests, and challenging the capacities, of each individual student - the essential 'social good' pursued by the profession of teaching is to maximise the learning opportunities to help enable each individual student to achieve personal excellence in the intellectual, personal, social, cultural, emotional, physical, moral, spiritual and other aspects of human development (p. 16).

If, at its core, a profession is concerned with the social good, it would follow that the teaching profession, "the knowing and caring profession", as described by the OECD Centre for Educational Research and Innovation (1994), cited in Brock (2000, p 8), would seek to concern itself with both the 'knowing' and 'caring' sides of teaching. This returns the discussion to the forms of knowledge discussed in section 1, and to the need to understand the moral base of teaching. The teaching profession would be rightly concerned with the episteme and techne aspects of teaching: those things that can be learnt, or developed, such as content knowledge, pedagogy and classroom management. It would also be concerned with the moral obligations and duties of those who teach, as the moral development of "every learner is of fundamental importance in every teaching situation" (Sockett, 1993, p. 13). These obligations and duties are demonstrated in good teachers making "the right decisions in the right circumstances for the right reasons" (Coulter \& Orme, 2000, p. 6). This third form of expertise is not described by either episteme or techne.

Aristotle described this kind of wisdom or understanding as phronesis and it is both related to, and distinct from, episteme and techne (Coulter \& Orme, 2000, p. 6). Squires (1999, p. 112) interprets phronesis as a form of "practical wisdom, practical sense or prudence". Squires (1999) argues that phronesis is:

... distinct from episteme and techne but may nevertheless draw on them and deploy them in the right course of action ... episteme and techne are thus drawn into the service of phronesis but the latter is not reducible to either of them (p.116). 
For my purposes, 1 will use the term in the sense that Squires describes, in which phronesis draws on episteme and techne and deploys "them in the right course of action". This is despite some concerns that such an interpretation "implies a relationship between the three forms of thinking that goes well beyond what Aristotle actually said" (Squires, 1999, p. 116).

Phronesis is seen in the judgements that teachers make about the treatment of the students in their care, and in the ways in which students are helped in their learning. Regnier (1994) has made the claim that to reduce teaching quality to a question of subject knowledge or technique is illusionary. Eisner (1988) speaks of the politics of inquiry in which values and knowledge are intertwined. Clandinin and Connelly (1995, p. 27) state that "teachers' knowledge, whether in or out of the classroom, is morally inclined" and that "dilemmas of knowledge are also moral dilemmas". In discussing the dilemmas faced by teachers and the contradictory nature of teachers' work, Lampert (1985, p. 183), describes the importance of a teacher being able to balance the need to act with integrity while "maintaining contradictory concerns" about student progress. Professionals are constantly "called on to make decisions in unique circumstances without certain knowledge" (Loucks-Horsley, Hewson, Love and Stiles, 1998, p. 31). In these cases, professional practice relies on the teacher reflecting on both past and current actions. In undertaking this reflection, a professional will demonstrate expert knowledge in their decision-making (LoucksHorsley et al. 1998).

Phronesis provides teachers with a deeper understanding of the moral base of their profession. Such an understanding is necessary, as an understanding of teaching in terms of just episteme or techne is unhelpful and unproductive (Fenstermacher, 1990). Specifically referring to the ongoing conflict between the teaching profession and policy makers, he states:

As one examines the battles ... that have occurred over the last few years, an uneasy feeling begins to emerge. It may be best if neither side wins this war, for neither side appears to have a morally grounded sense of the meaning of teaching. (p. 131) ... It is as if the moral dimensions of teaching were lost, forgotten about, or - to put the best possible light on the matter - simply taken for granted (p. 132) ... The rhetoric of the professionalization of teaching is 
grounded primarily in the knowledge base of teaching, not the moral base ( $\mathrm{p}$. 132).

There are a number of authors who have explored the moral basis of education. Aristotle believed that the overarching value was the moral value, and that all other values were sub-classes of this (Kenny, 1978). Teaching is a moral activity because it is essentially involved with relationships between teachers and students, and the quality of those relationships. Fenstermacher (1990, p. 133) describes teaching as a moral activity as it is a "human action undertaken in regard to other human beings. Thus, matters of what is fair, right, just and virtuous are always present". Coulter and Orme (2000, p. 6) describe the relationships between teachers and students as ones in which teachers "agree to share responsibility with parents and the community generally to help children learn the knowledge, attitudes and dispositions that will help them lead good and worthwhile lives now and in the future". Aspin (2002, p. 22) states that it is schools that help students to "learn to become persons in mutual association with other members of their school community and of the community more broadly conceived".

The use of such value-laden words as fair, right, just, virtuous, good and worthwhile in these citations clearly delineate teaching as a moral activity, for these words must be described, explained, acted upon and enacted in a consistent manner if students are to learn what it is to lead a life that is to be judged as good. As Fenstermacher (1990, p. 133) writes, "the teacher's conduct, at all times and in all ways, is a moral matter". To add further weight to the argument that teaching is, at its core, a moral activity, Coulter and Orme (2000, p. 6) suggest that "to teach is to influence the present and future by affecting the lives of particularly vulnerable others' children". In a similar vein, Smith and Blase $(1988$, p. 8) state that education is ultimately concerned with who "we are as human beings and about how we are to lead our lives". Sockett (1996, p. 23) writes that "at the heart of teaching are moral and ethical relationships, because the teacher takes responsibility for the upbringing of the young". Kilbourn (1998, p. 44) has stated that moral principles not only contribute to learning, they are "ends in themselves", which "emphasize the question of how children are to be treated rather than the question of how to help them learn". It is the dual focus on the quality of a teacher's professional 'knowing' and 'caring' practice that is the key to the notion of 
professionalism. Sockett $(1993$, p. 9) reiterates this duality by referring to teacher professionalism as a description of the "quality of practice" that a teacher demonstrates.

This review of the literature about the moral base for teacher professionalism highlights the importance of the notion of phronesis and its relationship with knowledge-based notions of episteme and techne. Integrating the three notions together allows me to understand the term 'professional' and begins to provide a strong framework for the analysis of my data. Teacher professionalism is centred on the quality of the practices that teachers engage in within the framework of episteme, techne and phronesis.

\subsection{PROFESSIONALISM IN PRACTICE}

In section 2.3 of this review of the literature I stated that my understanding of teacher professionalism is that of teachers' quality of practice within the framework of episteme, techne and phronesis. It is the purpose of this section to review the literature as it relates to the practical outworking, and enunciation of this understanding in the context of teachers' work. In particular, I intend to explore the use of virtues as a method of expressing both the knowledge and moral bases of teacher professionalism. With this intention in mind, I will use Sockett's (1993, p. 16) "dimensions" of teacher professionalism to give structure to this section, as I believe that the dimensions provide a solid philosophical basis for this review. Sockett outlines four dimensions of teacher professionalism. These dimensions are: the professional community, professional expertise, professional accountability, and the profession's ideal of service.

The first of Sockett's (1993) dimensions is that of the professional community. The development of a teacher professional community must, at its core, be based on the moral consideration of the purpose(s) of education. As an outworking of that common moral understanding, a professional community must allow for individual teachers to negotiate the quality of common practice that aims to achieve the common purpose. Negotiation of purposes is also seen as foundational in Wenger's (1998) discussion on 
communities of practice. The development of a professional community, and the autonomous collaboration that underlies it, requires a morally justifiable basis, due to its power to "strengthen professional development and increasing professional dignity as a basis for wiser, more skilled activity and is the central condition of teacher excellence" (Sockett, 1993, p. 25). The importance of teacher professional development in improving the quality of teacher practice has been stated by Costello (1991, pp. 138-139), who writes "the quality of a school [system] ... is powerfully influenced by the extent of professional development occurring within it". Further, he asserts that "successful schools exhibit strong commitment to teamwork and in the pursuit of common goals".

The development of a professional community depends on the professional development of the individuals concerned, as they develop the understandings and knowledge that are needed to achieve the common educational goals that the community has agreed upon. There is a serious problem, however, with current conceptualisations of teachers' professional development (Clandinin \& Connelly, 1995). The first of these problems relates to the source of the impetus for teacher professional development. If the main impetus for professional development comes from those external to the teaching profession, it could be argued that the reason for that impetus is that teachers have an incomplete form of professional knowledge (Clandinin \& Connelly, 1995). Under such a view, teachers have been taught that they have incomplete knowledge, and that they will need to continue to learn through professional development offered by "experts" in universities, central education offices or in other schools. Teachers, of themselves, are not seen to be "knowers who can teach one another" (Clandinin \& Connelly, 1995, p. 126), but rather as learners who need to be taught by experts. Lampert (1985, p. 191) discusses the same conceptualisation of teacher learning as arising "out the work of social science researchers and government policy makers". The result of this conceptualisation is that a teacher is seen as "a technical-production manager who has the responsibility for monitoring the efficiency with which learning is being accomplished" (Lampert, 1985, p. 191). The most effective way for learning to be improved, under this view, is for teachers to find out "what researchers and policymakers say should be done with or to students, and then do it" (Lampert, 1985, p. 191). The implications of such a 
conceptualisation for the professional learning of teachers in the department will be reviewed in more detail in chapters 3 and 4.

In terms of the individual teachers' professional development, there are four categories to an individual's professionalism (Sockett, 1993): the character and commitment of the teacher, which together form the moral dimension of the teaching; and knowledge and pedagogy, which form the intellectual dimension of teaching. This definition of the professional community, as both moral and intellectual, provides a very strong link to the concept of the professional knowledge landscape that is described by Clandinin and Connelly (1995). It also requires that these terms, the moral and intellectual dimensions of teaching, are described more fully to develop an appreciation of their importance for teacher professional learning.

Teachers work with people, so their character and commitment is vitally important. Teachers help shape what a person becomes. The moral good of each learner is of fundamental importance in every teaching and learning context. As virtues are strongly related to moral betterment, for example courage, honesty, and kindness, a discussion into the moral virtues that teachers possess is required. This moral dimension of the teacher must also apply to the techne aspects of teaching, with these aspects being subservient to the moral condition, that is, the means do not justify the ends. For example, the learning of multiplication tables by students could be regarded as fundamental to the students' future mathematical development. This perceived importance, however, would not justify the use of corporate punishment in teaching tables.

Such a discussion of the moral virtues of teachers reflects the fact that teachers are not just learners of the episteme and techne of teaching, they are also learners of the phronesis of teaching, or in the words of Hargreaves (1994, p. 11) they are "social learners". By describing teachers as "social learners", Hargreaves points to both the capacity for teachers to change, and their desire to change those practices that require change and conserve those practices that are valued. In using the word "desire", Hargreaves echoes the fundamental human desires of telling stories, relationship and 
reflection described by Clandinin and Connelly (1995). Desire provides the basis for teachers' "creativity, change, commitment and engagement" (Hargreaves, 1994, p. 12) to teaching. Desire is at the heart of all good teaching, as it is desire that connects good teachers "emotionally and sensually (in the literal sense of feeling) with their students, their colleagues and their work" (Hargreaves, 1994, p. 12).

The intellectual dimension can be developed within the professional community, as teachers desire to tell the stories of their practice, and use opportunities to learn from their colleagues and other members of the profession. Teachers need to have the autonomy to frame the questions regarding specific predicaments that are susceptible to change, and that need to be addressed, within their specific context. Change for teachers is an issue of practicality: an ethic of "what works and what doesn't [for] this teacher in this context" (Hargreaves, 1994, p. 12). This ethic of practicality is a "distillation of complex and potent combination of purpose, person, politics and workplace constraints" (Hargreaves, 1994, p. 12). This means that potential changes must be congruent with the teachers' desire to change if the change is to proceed successfully in the current context. This also means that teachers need to be given the opportunity to develop their thinking about their practice. Ridden (1996) summarises these opportunities as:

Finding ways to challenge their thinking; to assist them to evaluate their own practice; to encourage them to take risks with new behaviours, new practices and new ideas; to assist them through the process of working with those new practices; to celebrate with them the successes and reflect with them on the failures that will probably be part of the process; to help them set and achieve personal goals (p. 27).

These opportunities also reflect each of the desires outlined by Clandinin and Connelly (1995): telling stories, relationship and reflection. Within such opportunities for discussion there is also the need to be aware of how teachers 'fit' within a learning community. Are teachers an occupant within a role, which is a form of empowerment? Or are teachers individuals who develop a way, or ways, of interpreting their role, which is a form of personal emancipation? To use the Clandinin and Connelly desires: are teachers permitted to tell the stories that are 
important to them about their teaching practices and the roles that they fulfil in the out-of-class place? Or are they constrained into telling the stories that they believe 'fit' in with what is expected of their roles? Sockett $(1993$, p. 56) makes the point that the relationship between a person and their role is one that should be viewed as that of "a free social individual who creates his or her own social identity by acting rationally within a consistent role set of his own choosing and becomes what he has chosen by accepting his duties as his duties". The implication of this is that the individual is, conceptually and morally, primary, regardless of the socialisation of the institution. As Angus states (1986, p. 6) "people do not make an organisation, they are the organisation". Therefore, any discussion centred on the roles of the individual and their willingness to tell their stories must turn to the concepts of power and leadership in the out-of-class place.

To empower individuals or a group of people, effective leadership, which requires power, must be exercised (Bybee, 1993). If individuals, or groups, are to develop their ideas, make decisions or carry out the tasks set before them, they need power to fulfil their visions or obligations. Bybee (1993, p. 157) cites the psychologist Rollo May's (1972) description of power as the "ability to cause or prevent change", and considers the various forms that power can take in the relationship between those who are leading and those who are led. These forms of power can include the exploitive, manipulative, competitive, nutritive and integrative. In each case the leader's use of their power is a moral question. Bybee argues that the last two are the most relevant when discussing teachers. Nutritive power is described as a form that exists on behalf of another person, for example in the parent-child or teacher-student relationship. Integrative power is the form that arises when two or more people work together, such as in cooperative learning.

Bybee's (1993) emphasis on power and leadership is important as it focuses on the empowerment of science teachers in their work. Empowered teachers are those who are prepared to adapt science education materials, regardless of their origin, to "enhance the teaching and learning of science" (Bybee, 1993, p. 159). Empowerment 
has five qualities: significance; knowledge, skills and attitudes; community; enjoyment; and responsibility (p. 159).

Significance is described as the development of a substantial and transcendent vision that aims to improve science education. The second quality, that of knowledge, skills and attitudes results in a "greater sense of competence and mastery" (Bybee, 1993, p. 159). The third quality is community, achieved through teachers working collaboratively and collegially in the common task of improving science education. The fourth is enjoyment, and is based on the needs of teachers to "know and understand, engage in meaningful work and develop personal and professional efficacy" (Bybee, 1993, p.159). The final quality is responsibility, where teachers assume the responsibility of improving science education in their classrooms. In accepting this responsibility, teachers also use the power that they possess in a positive manner. These qualities, attributed to empowerment, reflect several of the key themes raised by Clandinin and Connelly (1995) and Sockett (1993). All five, to a greater or lesser extent, embody the basic desires that Clandinin and Connelly describe: desires for relationship, story telling and reflection. Sockett's dimensions of professionalism: professional community, professional expertise, professional accountability and the ideal of service are also seen in these qualities.

The second of Sockett's (1993) dimensions is that of professional expertise. This expertise has two parts. First, is the knowledge base that underpins the subject disciplines, and the acquisition of skills that are integral to those disciplines. The second is the pedagogical knowledge of teaching. Professional expertise can be discussed using the moral language of virtues such as honesty, courage, care, fairness and practical wisdom (Sockett, 1993). An understanding of these virtues is central to understanding the professional practice of teaching, and the importance of the individual teacher in the task of teaching. The reason for this belief is that professional virtues are "those acquired moral qualities that are embedded in the social practice of teaching and that are necessary to the particular professional task" (Sockett, 1993, p. 62). 
The link between the virtues and practice is important as it clearly commits a professional teacher to both acquire and live out the professional virtues. This linking of theory and practice in the transmission of virtues in education is, to cite Lovat, Schofield, Morrison and O'Neill (2002), consistent with Aristotle's (1985) bearing on eudaemonia and Aquinas' (1936) notion on synderesis. Both Aristotle and Aquinas stress that the seeking of truth, and a commitment to its practice, are "inextricably linked" (Lovat et al. 2002, p. 129). This position is also seen in the work of Habermas (1972). Noddings (1984) writes that moral education, from a caring perspective, involves four components: modelling, dialogue, practice and confirmation. These components also reflect the basic human desires at the heart of Clandinin and Connelly's (1995) work: relationship, story telling and reflection. The continuing importance of values education in schools is demonstrated within the Australian education literature by several recent papers; Buckskin (2002), Carr (2002), Cawsey (2002), Connors (2002), Forgasz (2002), Forster and Masters (2002), Kennedy (2002), Quisumbing and de Leo (2002), Salman (2002), Tarlington and O'Shea (2002) and Toh (2002).

There is a problem, however, in using virtues in a post-industrial society. The problem is that moral qualities may no longer be seen as "embedded in the social practice" that Sockett (1993, p. 62) suggests, but they may have already been decontextualised and supplanted by government mandate. This is the point that Wells (1998) makes:

These classical virtues had always been thought about in relation to the community in which a person lived. To act justly was not an internal attitude, but the practice of what was upright in a context where that moral virtue had been put to the test. When we come into the modern period, and as communities begin to disappear, the virtues come to stand alone, out of the social context in which they had formerly been understood (p. 15).

The process of decontextualising the virtues, begun during the Age of Enlightenment in the $18^{\text {th }}$ and $19^{\text {th }}$ centuries, came to see them lose their pre-eminent role in the conduct of the civil society, and to be replaced by rules, and finally, by government regulation:

When the virtues were thus privatised, when they were disengaged from private life, that life had to be governed, not by morality, but by social rules that became etiquette. It was these rules that replaced the virtues, and these 
rules have now been replaced by government regulation and by litigation (Wells, 1998, p. 15).

In his later work, Sockett (1993, p. 22) acknowledges the replacement of the virtues by mandate, by stating that "in loco parentis has been replaced by due process". This does not mean, however, that virtues have lost their potential as descriptors of professional practice.

Kidder (1994) describes eight universal values that he believes are essential for the development of moral conditions in the $21^{\text {st }}$ century. These values are love, truthfulness, fairness, freedom, unity, tolerance, responsibility and respect for life. Newell and Rimes (2002, p. 94) state that these values - or virtues - "apply regardless of the religious or secular tradition in a school". Lovat $(1994,1995)$ argues that the biomedical ethics of autonomy, justice, non-maleficence and beneficence have a role in shaping the practice of teachers. These ethics, described as "definitive" in Lovat et al. (2002, p. 128), can only be effectively communicated to students if the teacher demonstrates "consistency of theory and practice, ideas and action" (p. 129).

The first virtue that Sockett (1993) discusses is honesty, and it's opposite, deceit. Honesty is the basis on which social life is constructed (Sockett, 1993). Bok (1978) argues that there is an important distinction between truth and truthfulness. This distinction is based on:

... the moral domain of intended truthfulness and deception, and the much vaster domain of truth and falsity in general. The moral question of whether you are lying or not is not settled by establishing the truth or falsity of what you say. In order to settle this question, we must know whether you intend your statement to mislead (p. 6).

The virtue of honesty contains several components, each of which is important for the professional teacher to demonstrate. The first of these components is an understanding of the difference between fact and fiction, the ability to distinguish the real from the imaginary, and a willingness to teach this understanding to children. This understanding can be difficult to acquire and teach, as it covers a range of potential areas in which the distinction between fact and fiction, real and imaginary, can become blurred for a variety of reasons. These include a neglect of those facts that may be considered, rightly or wrongly, to be inconsequential or unpalatable to the 
teacher. It may also include a failure to explore alternative perspectives on the topic that is being taught, although this would depend on the developmental stage of the child. The personal bias of a teacher may also come into play, as well as a deliberate or unintentional misrepresentation of the truth. In all teaching, teachers should avoid deceiving the learner.

Secondly, teachers need to display a concern for the truth, as opposed to falsity in any situation, and for how the truth is to be sought after. It is not enough to simply question, it is a case of which question will most decisively facilitate the search for the truth in the content (Sockett, 1993). Obviously, there will be times when there is no position that could be described as the truth, and in this situation it is important to rigorously examine what information is known. In such a case, questions should be deployed that vigorously examine different positions, with the express aim of facing hard choices and making decisions about what is considered truthful.

However, attempts to support this notion of what is true, is difficult in an increasingly pluralistic society. Children, therefore, need to be taught an "ethic of belief" (Sockett, 1993, p. 67) that is based on evidence, if they are to face the moral complexity of the world as autonomous moral agents. Such evidence should fulfil two criteria. First, the evidence needs to be factually true and morally acceptable. Second, the evidence should help the child develop the connection between belief and truth; that is, the child should learn to believe in what is true, or in what has good evidence. The aim of teaching such an ethic based on evidence, is to permit students to function as citizens in "a complex democratic society that is riddled with hard choices demanding attention to evidence" (Sockett, 1993, p. 67). The principle of autonomy comes into this aim, as it is a principle that "assumes that the individual is responsible for, and should therefore determine the direction of, his or her own life" (Lovat et al. 2002, p. 128). If an individual is to function in a difficult, complex society, autonomy is crucial, as autonomy allows for the authentic knowing that is needed in such a society. This link between autonomy and authentic knowing has been widely discussed in the literature (de Bono 1970; Habermas 1972, 1974; Stenhouse 1975; Costa, 1981; Biggs, 1987; Salomon, 1994). 
In teaching such an 'ethic of belief' and developing the autonomy of the student, it is not simply a case of presenting information to a child; the teacher must also model and live such an ethic in all their teaching. Lovat et al. (2002, p. 128) states that there is "a particularly strong responsibility on a profession charged with the teaching of morality to be seen as practising it as well".

Trust is another component of honesty. Trust is totally dependent on the absence of deceit if it is to be regarded as authentic (Sockett, 1993). Trust can be lost through a failure to state the truth, for whatever reason, or through the misuse of authority to gain control. Professional teachers who care about the truth will not misrepresent the status of knowledge, they will recognise that there are other ways of questioning knowledge, and pass this on to their students. To do this, however, often requires the second virtue of courage.

Courage as a moral quality can be defined as "deliberate, practical reasoning in circumstances of difficulty, turbulence or trouble" (Sockett, 1993, p. 71). Courage, as such, can exhibit a variety of characteristics (Sockett, 1993). It may include a longterm commitment to ideals that are closely held. Hence, it is not related solely to fear or to physical action. Finally, courage will be evident in many different social and institutional practices. Within education, courage is needed in the pursuit of the truth in - at times - difficult circumstances. Learners, when operating in a difficult context, often need to be encouraged. Such a context may be the learning of new material, learning a new skill, or learning to concentrate to resolve a difficulty. To encourage a student is a moral act, with a purpose to "get children to learn whatever is to be learned and also to summon up their will in those situations of difficulty" (Sockett, 1993, p. 74). Teachers are also required to demonstrate courage in the out-of-class place described by Clandinin and Connelly (1995). Teachers are often confronted with changes imposed by those who desire to implement "new and imaginative educational reforms". In these confrontations, teachers have the ability to rise to the challenge and take charge of their "moral professional landscape" or to be subversive and tell "cover stories" that agree with what the reformers in the conduit want to hear (Clandinin \& Connelly, 1995 pp. 162-3). Which path is taken depends, in large part, on the congruency of the reforms with the teachers' desire to change (Hargreaves, 1994). 
The third virtue that Sockett describes is care, a notion that has become a "staple of educational scholarship" (Schultz, 1998, p. 373). Noddings, in particular, has made several contributions to the discussion of this virtue. There are three major tenets to Nodding's conceptualisation of care. The first of these is that each human being is unique. Secondly, building on this individual uniqueness, there is a unique relation between two people (the carer and the cared-for) in which each maintains the otherness of the other (Noddings, 1995). Thirdly, in caring, we "treat each situation and each cared-for (person) as unique" (Schultz, 1998, p. 375). In a caring relation, which is a dynamic, but equal relation, there is no judgement of the other person, and the carer has the responsibility to respond to the cared-for "in a way that furthers the others' purpose or project" (Noddings, 1992, p. 16). Caring requires action and the development of an attitude by those who are cared-for to become, in turn, carers (Schultz, 1998). Finally, Noddings argues that caring has a naturalistic base, others such as Schultz disagree, seeing it as a social practice that can be learned.

In relating caring to communities in general and schools in particular, there are a number of features that characterise an authentic community (Noddings, 1996). Authentic communities, avoid "tendencies towards parochialism, conformity, exclusion distrust (or hatred) of outsiders and coercion" (Noddings, 1996, pp. 258). Authentic communities also offer individuals the opportunity to "be part of something significant" (Noddings, 1996, p. 260). This conceptualisation of caring is in contrast to ethics, which are based on principles, which, while not unimportant, are fundamentally masculine in nature and treat individuals as comparable and classifiable (Noddings, 1989). Critics of Noddings believe that caring, without an ethic, such as justice, to support it, is unable to provide protection against oppression or a make commitment "to those who cannot be cared for directly" (Schultz, 1998, p. 373). Justice is the fourth virtue discussed by Sockett (1993). This leads to a need for the examination of other virtues that impinge upon Noddings' conceptualisation of caring, non-maleficence and beneficence.

Non-maleficence and beneficence are two biomedical ethics that Lovat et al. (2002) believe have a powerful role to play in the guidance of teacher practice. Nonmaleficence reflects a requirement that the conduct of a profession does not harm or 
injure another person. For teachers, this includes not just the physical wellbeing of students, but also the intellectual health of the student. This being the case, it is possible that teachers are in a position to cause "intellectual harm" through poor pedagogy, poor subject knowledge and poor, or unfair assessment (Lovat et al. 2002, p. 129). Beneficence is a general ethical principle under which the ethical person has a "duty to engage in conduct that is aimed at the good and wellbeing of others" (Lovat et al. 2002, p. 129). For teachers, this involves a duty to develop both the physical and intellectual wellbeing of those students in their care (Peters, 1972).

Sockett (1993) defines care through two lenses. The first of these lenses, which includes both non-maleficence and beneficence, is the extent and limit of the care that is to be found in a school. The care of a professional teacher is demonstrated in their practice. Professional teachers desire their students to care for what they learn and to care for each other. Teachers, especially in secondary schools, want their students to show some commitment to the traditions and disciplines of learning. This particular lens on virtue, as well as the virtues of courage and truth, is demonstrated in the Ontario College of Teachers' 'Standards of Practice' (1999), whose first statement reads:

Members ... demonstrate care for and commitment to students. They are dedicated in their efforts to teach and to support student learning. They treat students equitably and with respect. They encourage students to grow as individuals and as contributing members of society (p. 5).

The second lens is the social climate of the school, and the role that care takes on within it. Through this lens, care is seen as being active in permitting teachers to critique the climate of the school in which they work, with the aim of striving to improve the level of care provided to all the individuals within the school. The climate of a school is generally regarded in the literature as those things that give a school a personality or a culture (Fisher \& Fraser, 1991). There are many influences on the climate of a school, some external, such as government-mandated policies, and some internal, such as organisational policies, history, and school personnel. Rosenholtz (1989), in her study of the teaching workplace and teaching quality, argued that those teachers who believed that they were supported in their ongoing learning and development of teaching practices were more committed and effective than those who did not feel the same level of professional support. Supporting 
teachers in their work allows for a more caring school climate, as it presupposes a greater opportunity to work towards the development of the moral skill of dialogue and the modelling of caring behaviours, both of which are necessary for an improvement in the level of care in a school (Sockett, 1993; Clandinin \& Connelly, 1995).

The fourth virtue described by Sockett (1993) is fairness. This virtue, also called justice is, along with truth, described as being "uncompromising" (p. 81). The essence of fairness is found in Aristotle's axiom that justice consists of treating equals equally and unequals unequally - but in proportion to their relative differences (Sockett, 1993). Justice also gives a clear expectation of what a society believes is appropriate for the relationships between members of that society (Lovat et al. 2002). There are also two types of justice to consider (Sockett, 1993). The first is distributive justice, where consideration is given to the distribution of benefits, and secondly, retributive justice, where the consideration is to right a wrong, or punish a law-breaker. Relating these notions to teaching, there are three questions that need to be addressed: the distribution of time and attention to students' intellectual and social needs (Lovat et al. 2000) in a way that is fair to all within the class; the imposition of sanctions and discipline: and the monitoring of the deployment of teachers in a way that can be considered fair to both teachers and students, irrespective of their status (Lovat et al. 2000).

The fifth and final virtue is that of practical wisdom. Wisdom is described as a quality of reflectiveness and judgement that assists in answering the question 'what to do and why?' In Sockett's view (1993) it includes subject knowledge, or episteme (content), and pedagogical skills, or techne and phronesis (method). The Ontario College of Teachers' 'Standards of Practice' (1999) express the same belief:

Professional knowledge is the foundation of teaching practice. Members of the Ontario College of Teachers know the curriculum, the subject matter, the student, and teaching practice. They know education related legislation, methods of communication, and ways to teach in a changing world (pp. 5-6).

The United States National Board of Professional Teaching Standards 'Policy Position' (1989) makes a similar statement in the second of five core propositions: 
National Board Certified teachers have a rich understanding of the subject(s) that they teach and appreciate how knowledge in their subject is created, organized, linked to other disciplines and applied to real world settings. While faithfully representing the collective wisdom of our culture and upholding the value of disciplinary knowledge, they also develop the critical and analytical capacities of their students (p. 1).

In concluding this discussion on the dimension of professional expertise, I believe that it is hard to go past what Sockett (1993) writes concerning the moral imperatives of both teaching and learning:

... just as we have lost some of our moral sensibilities because we have stopped using a moral vocabulary, so we will lose much more if we ignore our world culture, its history, artefacts, conventions and styles; and settle for some empty hybrid like critical thinking. A teacher cannot understand many practical issues within teaching without being learned (p. 86).

The third of Sockett's (1993) dimensions is professional accountability. This dimension has within it four major components that need to be addressed if the desired level of accountability is to be achieved. These components are: accountability is akin to moral obligation; trust is the primary condition for professional accountability; a professional code of practical guidance provides a potential vehicle for accountability; and a moral stance toward professional accountability is central to professional development (Sockett, 1993).

Within educational research circles the notion of professional accountability, as opposed to managerial accountability, appears to have gained much ground over the past decade. As a consequence of that movement, much of the academic writing on topics such as professional development and school improvement over the past decade is, to a large degree, underpinned by the components of accountability. For example, authors such as Darling-Hammond (1990), Fullan (1992), Hargreaves (1992), Hord (1997 a, b), Wallace (1997), Wallace and Wildy (1997) and Loucks Horsley (1998), suggest a moral basis to professional accountability. Sockett's (1993) definition of accountability cuts straight to the moral heart of the matter, by referring to the importance of relationships. The definition that "accountability is not just acting independently, or under orders, it defines the character of the relationship between the parties involved" (Sockett, 1993, p. 110) reiterates the Clandinin and Connelly (1995) contention that relationships are a basic human desire. If accountability is about the 
relationship between different parties, there is obviously a moral dimension to that relationship, as it involves people and/or institutions. This means that teachers, as educators, are accountable to a range of interests for the maintenance and improvement of their professional practice, that is, their professionalism. These interests include students, parents, the public, their employers (either private or the state), their professional peers and the state, which mandates compulsory education.

Potentially, these interests will each have different conceptions of the role of education in meeting both the public interest and private wants. Since there is no clear set of extant moral principles that may help to resolve this dilemma, professional accountability based on the concept of trust between the interests mentioned above and professional educators may be a way of partially reconciling these competing demands (Sockett, 1993). Sockett (1993, p. 113) goes on to suggest that the development of such a trust may allow for the development of a practical "code of standards" for education. It is interesting to note in the Ontario College of Teachers' 'Standards of Practice' (1999), the first point of the key element 'Leadership and Community' is that "members of the Ontario College of Teachers build trust with students, parents and the community [and] exercise professional integrity and judgement" (p. 10).

The United States National Board of Professional Teaching Standards 'Supporting Statement' (1989) states, with regard to professionals, that:

Essential to their work is the trust of clients. What warrants that trust is the obligation, upheld within the community of professionals, to pursue an ethic of service and to employ special knowledge and expertise in the interests of their clients (p. 2).

Trust, therefore, must be acknowledged as a fundamental component of any conception of teacher professionalism. Hence, it must be discussed and explored in terms of its meaning and its constituent parts. To understand trust is to aid in understanding teacher professionalism.

Trust requires two conditions to be met (Nias, 1975). The first of these conditions is that trust implies that a person can make an accurate prediction about the attitude, reactions, technical competence and consistency in both other individuals and in 
organisational procedures. The development of trust in colleagues is particularly important in the development of a reflective community of teachers (Gulledge, 1998). This development is, however, difficult in teaching, which tends to be an individualistic profession. Ball (1996) summarises the dilemma of developing trust in an individualistic profession as:

The common view that each teacher has to find his or her style is a direct result of working within a discourse of practice that maintains the individualism and isolation of teaching. This individualism not only makes it difficult to develop any sense of common standards, but it also makes it difficult to disagree. Masking disagreements hides individual struggles to practice wisely and so removes a good opportunity for learning. Politely refraining from critique and challenge, teachers have no forum for debating and improving their understandings. To the extent that teaching remains a smorgasbord of alternatives with no real sense of community, there is no basis for comparing or choosing alternative practices, no basis for real or helpful debate. This lack impedes the capacity to grow (p. 13).

While this failure to develop trust may, or may not be, true for the profession as a whole, there are definite signs in the research literature that within small communities of teachers, trust is developed, and teaching and learning are improved as a result. Rosenholtz (1989), in her study of the teaching workplace and teaching quality, argues that those teachers who believed they were supported in their ongoing learning and development of teaching practices were more committed and effective than those who did not feet the same level of professional support. These forms of support include: the development of teacher networks; collegial cooperation; and the expansion of professional roles for teachers. McLaughlin and Talbert (1993) support Rosenholtz's findings and suggest that teachers developed and shared a body of teaching wisdom based on their experiences, when they were given an opportunity to participate in collaborative inquiry and learning. It was these findings, amongst others, that began to popularise the notion of the professional learning community. Astuto, Clark, Read, McGree and Fernandez (1993) defined such a community as one in which both school teachers and administrators share learning and act on that learning. Rowan (1991) describes learning communities with distinguishing features, which include: the sharing of a common core of educational values; a strong sense of collegiality and collaboration, which both support continuing professional development and improved mastery of teaching; and a strong commitment to improving the work setting. This description of learning communities by Rowan leads 
back to Nias' (1975) contention that trust towards organisational procedures must also be developed.

This inclusion of organisational procedures is interesting; Fullan (1992) believes that trust in individuals is no longer sufficient, particularly in large schools. Rather, trust in organisational processes is a prerequisite for organisational growth and problem solving in a dynamic educational environment. The processes that need to be trusted are those that improve organisational "expertise and problem solving capacities", such as "improved communication, shared decision making, opportunities for collegial learning, networking outside the school environment, experimenting with new ideas and practices, commitment to continuous enquiry and so on" (Fullan, 1992, p. 74). It would seem that schools with organisational procedures that allow teachers the opportunity to develop a professional learning community are also encouraging both personal and organisational trust. This theme will be returned to in chapters 3 and 4 on professional learning and the subject department.

The second condition required for trust is that there needs to be perceived agreement over the means and ends of any relationship (Nias, 1975). If there are disagreements over means, or ends, then there is a greater need for formalised procedures within the relationship. This is a key point in regard to education and the question of professional accountability. Professional accountability, if it is to be seen as a moral obligation, must, at its core, be seen to improve the 'social good' that the profession seeks to define, and teachers must accept the responsibility for that moral obligation. This is the purpose behind the goal statement of the National Board for Professional Teaching Standards (1989) and the 'Standards of Practice' of the Ontario College of Teachers (1999). The National Board for Professional Teaching Standards states that:

Our goal is to improve student learning by strengthening teaching ... We make a difference in how communities view teachers; in how teachers view themselves; and in how teachers go about strengthening their practice throughout their careers (p. 1).

The Ontario College of Teachers' 'Standards of Practice' (1999) sets out five standards for the teaching profession. These are: commitment to students and student 
learning; professional knowledge; teaching practice; leadership and community; and ongoing professional learning.

Both sets of standards attempt to reduce possible disagreements over the means and ends of a professional teacher's work within the jurisdiction of these two teacher organisations. Measures of their success, or otherwise, would be the extent to which teachers themselves, and the wider community, trust such standards, and the teachers' individual and corporate commitment to the integrity and maintenance of the values that they extol.

The fourth dimension that Sockett (1993) discusses is that of professionalism possessing an ideal of service. This dimension of professionalism was reviewed in section 2.3 of this chapter. There are, however, several points that need to be drawn together. The first is the importance of the notion of an 'ideal'. Ideals have three characteristics: they are subject to different interpretations, they are unattainable, and they can guide and sustain us.

These characteristics mean that, while teachers might accept Brock's (1999) definition that the ideal of teaching is about providing a service that aims to "maximise the learning opportunities to help enable each individual student to achieve personal excellence in the intellectual, personal, social, cultural, emotional, physical, moral, spiritual and other aspects of human development" (p. 16), or something similar, those same teachers need to understand what the ideal means to them. This understanding is important for two reasons.

The first is that it helps teachers to shape their professional practice around an ideal that will provide direction for their efforts. An understanding of the ideal allows teachers to develop their own voice in the development of teacher professionalism (Sockett, 1993), and also provides an ideal image against which to reflect on their actions. Secondly, an understanding of the ideal will help determine how they respond to alternative interpretations of it, to interpretations that provide new perspectives to be considered, and to interpretations that are miseducative and must be vigorously defended against. Clandinin and Connelly (1995) discuss the need for teachers to be engaged in educative conversations with their colleagues. These 
conversations should focus on "teachers learning from their students ... teachers learning from each other ... teachers learning the limits of their own expression on the out-of-classroom place on the professional knowledge landscape" (Clandinin \& Connelly, 1995, p. 161). Ridden (1996, p. 270) expresses the same sentiment in that "each teacher has something to offer colleagues - experiences, strategies, knowledge, creative ideas, classroom management procedures".

Sharing about practice and conversations about ideals also indicate the principal responsibility that teachers have for developing their own professionalism. Mandated changes and regulations, which often appear to fail in their objectives, do so because they are "political and administrative devices for bringing about educational change [that] usually ignore, misunderstand or override teachers' own desires for change" (Hargreaves, 1994, p. 11). Educational improvement relies on teachers' desire to make a difference, in this sense; teachers possess real power (Hargreaves, 1994). To use this power ethically in the pursuit of the 'social good' of education means that teachers need to demonstrate a measure of "learned optimism" (McCullough et al. 2000 , p. 118) and be prepared to "take charge of their moral professional landscape" (Clandinin \& Connelly, 1995, p. 163) by way of "creating spaces, taking initiatives, making partnerships, proclaiming their work and achievements" (McCullough et al, 2000 , p. 118). In this way, teachers will develop a professionalism that will improve the quality of their practice.

This section has reviewed the literature on teacher professionalism as it relates to teachers' practice. As such, it has touched on notions of community, expertise, accountability and a profession's ideal of service. For the purposes of my research, this review has highlighted several salient points. A major point that has emerged from this review is the importance of teachers negotiating their sense of meaning, or purpose in education using the language of virtues. These virtues are trust, care, practical wisdom, courage, honesty, truth and fairness. A second major point has been the continuing impact of episteme, techne and phronesis as focal points for this ongoing negotiation of meanings or purposes. Taken together, these two points begin to provide a powerful theoretical framework for the understanding of teacher professional learning. 


\subsection{CONCLUSION}

This chapter has reviewed the literature on teacher professionalism, with the aim of developing an understanding of the term. This will be used to guide the development of the theoretical frameworks that will be utilised in the analysis of the data that is collected from the science staff meetings.

From this literature review I understand that teacher professionalism can be described in terms of improving the quality of practice of teachers, within a framework of episteme, techne and phronesis. This understanding can be perceived, principally, as a moral understanding. While teachers must understand the episteme and techne of teaching, these aspects by themselves, or in concert, are insufficient to describe the real essence of teaching. What is needed is an understanding of the phronesis of teaching, an understanding of the importance of moral relationships in teaching. Teaching is a moral activity, as it concerns people, and thus, the moral foundations of practice need to be examined. Fundamental to any examination of the professional learning of teachers is an understanding of a language of virtues to negotiate the meanings that teachers bring to their work. With these understandings of episteme, techne and phronesis, and a language of virtues, in place, the next chapter will review the literature on teacher professional learning to continue the development of the theoretical frameworks for my research. 


\section{CHAPTER 3 - TEACHER PROFESSIONAL LEARNING}

\subsection{INTRODUCTION}

The previous chapter developed understandings of teacher professionalism that will be useful for this research. Teacher professionalism, as a contextually bound concept, refers to a teacher's quality of practice within the framework of episteme, techne and phronesis. This provides a strong theoretical framework for understanding the nature of the negotiations that teachers undertake if they are to shape the meanings that they bring to their practice. The language of virtues conveys a richer, more human, sense of meaning to my understanding of teacher professionalism. The language of virtues also provides a strategy for understanding the negotiations into meanings that teachers undertake. It must be noted that my understanding of the concept of teacher professionalism is contextually bound, and that I do not preclude other conceptualisations being proposed for other contexts.

This chapter provides a review of professional learning research that focuses on how teachers can continue to develop their professionalism throughout their careers. This is an important area for teachers, as the quality of both teaching and student learning can be substantially improved through teachers' continuous professional learning (Darling-Hammond, 2000). Despite this importance, teacher professional learning appears to be a largely "voluntary activity", a status that is unusual amongst the professions (Ingvarson, 2002, p. 17).

This review of the literature is divided into seven sections. The first considers the nature of teacher professional learning, including cognitive and emotional learning, and values and purposes. The second considers the current notions of professional development and professional learning. The third discusses the development, transferability and applicability of professional learning. The fourth reviews current methods that are available for teacher professional learning. The fifth focuses on the school as a context for teacher professional learning. This fifth section leads into a third literature review about the central role the school academic department plays in teacher professional learning. The sixth section examines the role of leadership, including teacher leadership in professional learning. The seventh section offers a 
conclusion to this chapter in which the major themes will be summarised, and their role in the developing frameworks briefly explored.

\subsection{THE NATURE OF PROFESSIONAL LEARNING}

The terms "knowledge based society [and] knowledge based economy" are often used interchangeably (Misko, 2002, p. 65). They are generally accepted to mean the extent to which "the production, distribution and use of information is the main driver of growth, wealth creation and employment across all industries" (Asia-Pacific Economic Cooperation Secretariat, 2000, p. viii). Due to the economic imperatives imposed on individuals by a rapidly developing knowledge society, it will become increasingly important for the individuals of that society to be capable of constantly developing the knowledge, skills and personal qualities that will be needed to take full advantage of emerging technologies. These personal qualities, such as the ability to be "autonomous, self-organising, networking, entrepreneurial, innovative [should give the individual] the capability, constantly, to redefine the necessary skills for a given task, and to access the sources for learning these tasks" (Hargreaves, 2000, p. 224). The Dean of the Australian Council of Deans of Education, Mary Kalantzis, believes that even "traditional industries such as manufacturing will be transformed by the rise of information and communications technologies, greater collaboration, and the need for interpersonal and problem solving skills" (Elson-Green, 2002, p. 1). Moreover, in such a rapidly changing society, "educators will play an increasingly important role in the well-being of nations and individuals" (p. 1).

For teachers, the challenge of responding to these societal changes is amplified by the challenges that they already face in dealing with the changes imposed by the career stages through which teachers pass (Huberman, 1992). Given the scale of changes that teachers face, it has been argued that teacher professional learning should not just be seen as a constant 'updating' of teachers' knowledge, skills and personal qualities; rather, teachers should be lifelong learners whose professional learning should be based on "developing and enhancing in-depth content and instructional knowledge" (Cibulka, Coursey, Nakayama, Price \& Stewart, 2000, p. 21). 
Given the purpose of this research, there are two questions that arise: What is actually meant by the term 'professional learning'? And what professional learning should teachers undertake during their careers? Another way to ask this second question is to ask if teachers should be:

... directed to improving their technical skills at delivering curricula developed by others, or should it be professional learning, encouraging creativity, reflection and consideration of the best forms of education for the different needs of the children who they teach? (McCullough et al. 2000, p. 78).

Teacher professional learning does not revolve around the continuous acquisition of information. Rather, it involves "expanding the ability to produce the results we truly want in life. It is lifelong generative learning" (Senge, 1990, p. 142). Generative learning allows a person to expand their ability to create, and only occurs "when people are striving to accomplish something that matters deeply to them" (Senge, 1990, p. 206). For Ingvarson (2002), generative learning enhances teachers' professional knowledge and understanding. Thus, professional learning is essential to teacher professionalism as described in chapter 2 - a teachers' 'quality of practice' can only be developed if teachers value, understand and enhance not just the episteme and techne aspects of teaching, but they must also understand the importance of moral relationships in teaching; the phronesis of teaching. Teachers need to have a highly developed sense of the episteme of their subject area(s), the techne of student learning, and phronesis before they can begin to develop their professionalism. Teachers' professional learning, therefore, needs to be directed towards the coverage of a large area of knowledge. This includes discipline knowledge, knowledge of their students, knowledge of instruction and assessment, and knowledge of the wider context of their teaching (Coble \& Koballa, 1996; National Research Council [NRC] 1996). Earlier, I asked what professional learning should teachers undertake during their careers. If teacher professional learning is centred on expanding teachers' ability to develop their professionalism in a deeply meaningful way, then the answer to this question must centre on what teachers need to learn if they are to undertake the demanding role of the teacher.

McCullough et al. (2000, p. 82) ask a simple question: "What are professionals to learn?" To answer this question, professionals need to learn in two profoundly 
interconnected areas - the cognitive and the affective. This makes a powerful link between the Aristotelian typology of the episteme, techne and phronesis of teaching, and teacher professional learning. This connection is: teaching and learning are not activities that can even begin to be understood, or described, in terms of any of these types of knowledge in isolation. All three types of knowledge about teaching need to be explored together if the complex nature of teaching is to be examined and described. For the same reason, these three types of knowledge will provide the frames of reference for discussing two essential characteristics of teacher professional learning, cognition and affect. The cognitive aspect of professional learning can be subdivided into two major areas: pedagogy and curriculum content, and values and purposes.

\subsubsection{Cognitive learning}

The cognitive aspect of teacher professional learning is discussed thoroughly in the contemporary literature (Ball, 1993; Cohen \& Hill, 2000; Kennedy, 1998; Lampert, 1985; Schifter \& Fosnot, 1993; Shulman, 1987; Sykes, 1999, 2001; Wilson \& Berne 1999). Cibulka et al. (2000, p. 27) state that "teachers must have deep disciplinary understandings". Teachers need to have a deep understanding of the conceptual structure and epistemology of their subject, as well as knowledge of the methods that will assist their students to understand the subject (Bransford, Brown and Cocking 1999). Smith (2002) writes that "the expert knows that different disciplines are organised differently and have different approaches to inquiry and they explicitly teach the skills of their discipline" (p. 26, author's emphasis). In his review of contemporary research into teacher professional learning, Ingvarson $(2002$, p. 6) indicates that the "content of professional learning matters as much, if not more, than the process". Ingvarson's review of the research stresses that increases in student learning outcomes are more likely to occur if teachers increase their understanding of: the content they teach; how students learn that content; how to represent and convey that content in meaningful ways; and how well their students are doing in relation to how well they should be doing.

The United States National Board for Professional Teaching Standards "Policy Position' (1989, p. 1) makes similar statements in its "core propositions". The second, 
of five propositions, states that "teachers know the subjects they teach and how to teach those subjects to students". The third proposition states that "teachers are responsible for monitoring and managing student learning". The Ontario College of Teachers' (1999) 'Standards of Practice' stresses the importance of seeing teachers' episteme and techne together with phronesis. This standard is summarised as:

Professional knowledge is the foundation of teacher practice. Members of the Ontario College of Teachers know the curriculum, the subject matter, the student, the teaching practice. They know education related legislation, methods of communication, and ways to teach in a changing world (p. 5).

The importance of teachers possessing a highly developed understanding of the content that they teach is also demonstrated in the findings of two recent reports. An evaluation of the United States Eisenhower Professional Development Program by the American Institutes for Research (1999, p. 7) recommended that future activities should concentrate on "deepening teachers' content knowledge and knowledge of how students learn particular content" as well as developing better indicators of student learning. A 2001 report into teaching and learning, the Queensland School Reform Longitudinal Study, concluded that improvements to student learning were associated with higher levels of teacher use of "productive pedagogies and productive assessment" (Smith, 2002, p. 24). These pedagogies cover "four overarching dimensions: intellectual quality; connectedness; supportive classroom environment; and recognition of difference" (Smith, 2002, p. 24).

For Ingvarson $(2002$, p. 8 ) the term 'productive pedagogy' appears to "be a set of generic principles or standards for teaching". Specific training of teachers in the use of these pedagogies is, however, insufficient unless that training is "embedded in the context of teaching and learning specific content knowledge" (Ingvarson, 2002, p. 8).

Shulman (1987) states that teachers' certification could only be legitimised if:

... they be closely tied to the findings of scholarship in the academic disciplines that form the curriculum (such as English, physics and history) as well as those that serve as foundations for the process of education (such as psychology, sociology or philosophy); they must possess intuitive credibility (or 'face validity') in the opinions of the professional community in whose interests they have been designed: and they must relate to the appropriate normative conceptions of teaching and teacher education (p. 5). 
Thus, changing and/or improving the pedagogical skills of teachers (techne), must be seen as integral with, and not divorced from, the content (episteme) or the moral dimension (phronesis) of teaching.

In the United States, changing and improving teachers' pedagogical skills are regarded as fundamental to reforming that nation's schools (Cibulka et al. 2000). This reformation involves the reconceptualisation of teachers' work, the learning of new skills and knowledge, the construction of new teaching practices and unlearning some common teaching practices. There is also evidence in the research to suggest that in order to assist students more fully in their learning, teachers need to change their pedagogical skills, as for example, in mathematics (Ball, 1993) and literacy (Calkins \& Harwayne, 1991; Short 1990). Achieving such changes without concomitant changes in how teachers view their students as learners is, however, accepted as being difficult (Smith, 200, p. 26; Cibulka et al. 2000).

Smith (2002, p. 26) believes that expert teachers can assist their students' learning "by understanding their students as learners, having a clear picture of an individual student's current state of understanding and targeting their instruction activities accordingly". Part of this "understanding" comes about through teachers being engaged in student learning and seeing the role of the teacher as part coach, part mentor or as a friend to a student (Louis \& Smith, 1992). One finding of the Queensland School Reform Longitudinal Study (2002) was that teachers who were effective in raising student outcomes considered themselves responsible for student outcomes. These teachers viewed all students as capable of learning and saw it as their "responsibility to provide opportunities for student learning" (Smith, 2002, p. 25).

Eraut (1995) proposes that teachers have three roles. The first is that teachers know their students and know how those students learn best. The second role focuses on teachers' involvement within the wider school community, serving the needs of those students and the public. The third role is to undertake a moral commitment to serving the interests of the students. Using his descriptions of these roles, Eraut connects all three components of Aristotles' typology; episteme, techne and phronesis. Such a 
description also points to the second part of cognitive learning, as proposed by McCullough et al. (2000): values and purposes.

Much has been written in the literature about organisational values, vision and leadership in education (Cibulka et al. 2000). Teaching is a moral undertaking because it is essentially centred on the relationships between teachers and students, and the quality of those relationships. Fenstermacher (1990, p. 133) describes teaching as a moral activity as it is a "human action undertaken in regard to other human beings. Thus, matters of what is fair, right, just and virtuous are always present". As a moral activity, it is entirely appropriate that teacher professional learning should involve asking moral questions about the aims and purposes of education. Asking moral questions are, by themselves, not enough. There is also a need to lead the debate on the aims and purposes of education. Ridden (1996, p. 25) uses the analogy of teachers feeling "themselves being swept along on a vessel over which they have no control, and in which nobody seems to be exercising any leadership. They perceive that they have no opportunity to contribute to the dialogue".

It is the role of those in authority, as well as teacher leaders, to provide the leadership in such debates. Hord (1997b, p. 3) refers to the need for schools to develop a creative climate in which staff "conduct conversations about students and teaching and learning, identifying related issues and problems", Fitzgerald (2002) stresses a similar point:

The best of teachers lead, share, and inspire. They do not regard good ideas, practices and methodologies as private property to be shielded from public gaze but rather as an asset to be shared around, analysed, adapted and improved upon (p. 33).

While the same sentiment is expressed by Goodrum et al. (2001):

... teachers need to have time to develop ideas, reflect, discuss and be more collaborative. To assist teachers in this way, it will be necessary to acknowledge the importance of giving teachers time to think about their work ... relating to improved teacher knowledge and teaching strategies (p. 91). 


\subsubsection{Values and purposes}

The literature gives many insights into values and purposes as important dimensions of professional learning. These dimensions are important in establishing, maintaining and nurturing school organisations that promote teacher professional learning. As Ingvarson (2002) states:

Organisations that improve do so because they create and nurture agreement on what is worth achieving, and they set in motion the internal processes by which people progressively learn how to do what they need to do in order to achieve what is worthwhile (p. 13).

In his work on learning organisations, Senge (1990) emphasises the importance of vision, both personal and shared, as a driving force behind learning. Personal visions derive their efficacy from the individual's concern for the vision. Shared visions derive their power from a common concern for the vision. Visions are vital as they provide a focus for learning, while meeting the desire for people to be "connected in an important undertaking" (Senge, 1990, p. 206). The use of the word desire is important, as desire provides the basis for a teacher's "creativity, change, commitment and engagement" to teaching (Hargreaves, 1994, p. 12). Vision, therefore, has an important role in teacher professional learning, as it engenders many attributes crucial to teacher professionalism.

The first of these attributes is that an intrinsically shared vision "uplifts people's aspirations" as work becomes part of a larger purpose (Senge, 1990, p. 207). The Queensland School Reform Longitudinal Study (2002) found that there were strong links between school philosophy and the frequent use of productive pedagogies in higher achieving schools. Hord $(1997 \mathrm{a}, \mathrm{b})$ reported that one dimension identifying a professional learning community within a school was the existence of shared values and visions that focussed school improvement on student learning and which were constantly referred to by teachers. Teachers, in this case, are encouraged not only to be involved in the development of these values and visions, but also to use those values and visions "as a guidepost in making decisions about teaching and learning in the school" (Hord, 1997b, p. 4). In her description of collegial support groups for teachers in Alberta, Canada, Parquette (1987, p. 39) states that "nothing in a school is 
more powerful than teachers who have achieved agreement on what is truly important". Bybee (1993, p. 151) writes that visions must be in the "context of the individuals' own environment, organisation or institution". This contextual boundary on shared visions is important as it leads to another attribute of visions: developing commitment.

Commitment to a vision is a long-term proposition (Senge, 1990). Schools that demonstrate the qualities of a professional learning community engender a high level of commitment to their vision through "purposeful decision making" (Huffman, Hipp, Pankake \& Moller, 2001, p. 457). This means that when decisions are made supporting the schools' vision, those decisions must not appear to be fragmented and must not destabilise the balance between organisational and individual teacher needs. Since the development of visions is a long-term proposition, visions cannot be seen as a "statement of the status quo; they are new, they are substantial, and they look to the future" (Bybee, 1993, p. 151). As they look to the future, they also require a plan as to how the goals are to be achieved, and the personal qualities that are required to achieve that plan. These personal qualities include motivation and responsibility. Also important is "a well developed sense of humour and ... language that signals [the] understanding, valuing and inclusion of others" (Loucks-Horsley et al. 1998, p. 201). The importance attached to personal qualities leads to the final three of Senge's (1990) attributes of visions: exhilaration, courage and a willingness to experiment.

Exhilaration creates the "spark, the excitement that lifts an organisation out of the mundane" (Senge, 1990, p. 208). Exhilaration with a shared vision permits interpersonal mistrust to be replaced with a common identity, and "the most basic level of commonality" (Senge, 1990, p. 208). The psychologist Maslow (1965), cited in Senge (1990, p. 208), observed that in high performing teams "the task was no longer separate from the self ... but rather he identified with this task so strongly that couldn't define his real self without including the task". This observation has echoes in Siskin's (1994) description of one of the four aspects of school departments. An academic department in a high school can act as a "knowledge category [that] influences the decisions and shapes the actions of those who inhabit it" (p. 5). 
Visions can command courage, as a person who is committed to a vision will be emboldened to undertake whatever is required to pursue the vision, whatever the cost (Senge, 1990). Courage as an intellectual and moral quality can be defined as "deliberate, practical reasoning in circumstances of difficulty, turbulence or trouble" (Sockett, 1993, p. 71). Finally, visions can encourage "risk taking and experimentation" (Senge, 1990, p. 208). Such activity is vital if teachers are to improve their practice (Loucks-Horsley et al. 1998). If they are to develop strong professional cultures in their schools, teachers must "examine assumptions, focus their collective experience on solutions, and support efforts on the part of everyone to grow [and develop] skills and dispositions towards inquiry, norms that recognise and support failure, and ideas with which to experiment" (Loucks-Horsley et al. 1998, pp. 195-196). Underpinning these efforts at experimentation is the need for teachers to be involved in active conversations about their own practice, and the practice of others, with the aim of improving learning for both teachers and students. These conversations should involve teachers in "applying standards of effectiveness to their and others' practices; in gathering, analysing and explaining the evidence for their convictions; and in communicating criticisms to each other, both positive and negative" (Loucks-Horsley et al. 1998, p. 198).

Taken together, these attributes of vision are discussed in Clandinin and Connelly's (1995) narrative description of the "teacher professional landscape", which can be discussed in terms of three intrinsically human desires. These desires are the "desire to tell stories, the desire for relationship and the desire to think again, to reflect on actions taken and things thought" (p. 154).

\subsubsection{Emotional learning}

Emotional learning is the second component of teacher professional learning, discussed by McCullough et al. (2000). It would appear that the emotional, or affective, component of teacher professional learning has been largely ignored, despite the importance that intrinsic motivation and personal relationships have in a person-oriented profession such as teaching. Cooper and Sawaf (1997) argue that emotional learning is more important in life and work than the level of intelligence measured in IQ tests. To ignore the emotional component of teacher professional 
learning is, therefore, to the detriment to teachers. In the words of Hargreaves (1998, p. 850), "without attention to the emotions, educational reform efforts may ignore and even damage some of the most fundamental aspects of what teachers do". Goodrum et al. (2001, p. 87) found that in "many cases [teachers felt] tired, disillusioned, disheartened and burnt out" through a lack of recognition and support from their school systems. These teachers felt that they were given insufficient time to attend to "the core business of teaching". Emotions are particularly significant in peopleworking occupations where the rewards are commonly the emotionally satisfying, intrinsic, rewards that come from working with people, rather than the extrinsic rewards of pay or status (McCullough et al. 2000). While extrinsic rewards can "produce or reduce dissatisfaction" it is only the intrinsic factors such as "enjoyment, satisfaction, belief in the value of the work, that can produce feelings of fulfilment" (McCullough et al. 2000, p. 82-83).

Intrinsic motivation, therefore, is crucial to teachers' professional growth (Cibulka et al. 2000). Little (1990) stresses the importance of teachers' motivation to work and motivation to learn as being intrinsically linked. Improving the emotional working conditions of teachers can be seen as "central to teachers improving their teaching, thereby improving student achievement" (Cibulka et al. 2000, p. 31). This links emotional learning with the development of teaching communities in which teachers provide their colleagues with the support required to pursue their professional learning. These links are discussed by Loucks-Horsley et al. (1998) and McCullough et al. (2000) who stress the importance of groups of teachers as potential sites for professional learning within a school. Other examples include Senge's (1990) description of personal mastery, and three of Siskin's (1994) definitions of a high school department, each of which has a bearing on emotional learning. Departments provide: a context for teacher social interaction, micro-political decision-making, and decisions as to pedagogy.

This section has highlighted the importance of both cognitive and emotional learning in the professional learning of teachers. It would seem that the heart of teacher professional learning is the engagement of teachers in virtues-based private reflection and/or public discourse around the episteme, techne and phronesis of teaching. This is an important strategy to bear in mind when analysing the data, as it provides a method 
of linking professional learning with the notion of community. In the following sections it is my intention to focus on the current ambivalent relationship between professional development and professional learning; the transferability of teacher professional knowledge; and the role of the school in encouraging both teacher professional learning and teacher leadership.

\subsection{PROFESSIONAL DEVELOPMENT AND PROFESSIONAL LEARNING}

Science teachers are required, possibly more than in other curriculum areas, to deal with "subjects, topics, issues and boundaries that are continually changing" (Council for Science and Technology, 2000, p. 10). For this reason, science teachers need to be involved in developing a "culture of continuous or ongoing professional development" (Goodrum et al. 2001, p. 174). This statement raises two questions: What is meant by the term professional development? And is there a difference between professional development and professional learning, as discussed in section 3.2 of this chapter?'

In order to answer the first question, it is necessary to consider the current conceptualisation of professional development. This conceptualisation has changed greatly over the past thirty years. Loucks-Horsley et al. $(1998$, p. 37) in a review of the literature, found that professional development from the early 1970's was centred on the importation of "outside expertise" into schools, with the purpose of increasing teacher knowledge about a particular program. While the early 1970's model has continued, professional development has tended to become more sophisticated in its delivery as it has recognised "the importance of self-reflection and personal growth as major determinants of staff morale and job satisfaction" (Ryan, 1996, p. 7). One result of these changes is that many lists are available that detail "principles for effective professional development" (Ingvarson, 2002, p. 6). Darling-Hammond and Sykes (1999, pp. 136-144) put forward eight "Design Principles for Effective Professional Development". These theoretical principles can be summarised as: 
Goals and student performance;

Teacher involvement;

School -based;

Collaborative problem solving;

Continuous and supported;

Information rich;

Theoretical understanding; and,

Part of a continuous change process.

Taken together, these principles for professional development largely reflect the nature of professional learning discussed in section 3.2 of this chapter. They do not, however, reflect the current practice of professional development in many schools, a practice that suggests teachers have little positive comment regarding the usefulness of professional development (Bacharach, Bauer \& Shedd, 1986).

The second question I asked at the beginning of this section was: Is professional development different from professional learning, as discussed in section 3.2 of this chapter? The answer appears to be yes. Many authors believe that the current practice of professional development does not reflect the current theoretical understanding of best practice. Darling-Hammond and Sykes (1999, p. 134) refer to critics of professional development who believe that current practices are "shallow and fragmented". Ryan (1996, p. 7) describes current professional development practice as the "two or three days that were student free - where staff gathered together to listen to a keynote address from a visiting expert ... the mandatory discussion groups ... followed and that was that until next term". Cibulka and Nakayama (2000, p. 6) describe one of "the most grievous faults" of current professional development efforts is that "the goals and content of these efforts is prescribed for teachers, rather than by them". Darling-Hammond and Sykes (1999) comprehensively fault current practices as: 
Focusing on district-mandated, generic instructional skills of teachers "trained" as individuals by an outside "expert" away from their job site. Because this training is fragmented, piecemeal, and often based on instructional fads, it is viewed as a frill, easily dispensed with in tough financial times. Perhaps most damaging, these workshops, although they often respond to expressed teacher needs, are seldom explicitly linked to what schools expect students know and be able to do (p. 134).

These authors express dismay with the commonly held notion that current professional development practices should be externally controlled because teachers have an incomplete form of professional knowledge (Clandinin \& Connelly, 1995). As was stated in section 2.4 , this view of professional development proposes that teachers have been taught that they have incomplete knowledge, and that they will need to continue to learn through professional development offered by "experts" in universities, central education offices or in other schools. Teachers are not seen to be "knowers who can teach one another" but rather learners who need to be taught by experts (Clandinin \& Connelly, 1995, p. 126). Lampert (1985, p. 191) discusses the same conceptualisation of teacher learning as arising "out the work of social science researchers and government policy makers". The frequent result of this research is a teacher is seen as "a technical-production manager who has the responsibility for monitoring the efficiency with which learning is being accomplished". Such a notion of professional development is at odds with the notion of professional learning that was considered in section 3.2 .

If such a notion of current professional development practices were accepted, the notion of professional development may be seen as not being 'professional' in the full sense of the word (McCullough et al. 2000). Rather, such development would tend to undermine the professionalism of the teachers involved, as externally imposed knowledge and prescriptions could "reduce teachers' power to decide on goals and methods and effectively make them technicians following someone else's designs" (McCullough et al. 2000, p. 82). This is not to say that teachers do not learn from undertaking current professional development practices, but it would indicate that professional development is distinct from, and not synonymous with, professional learning. This distinction is far from clear in the literature. For this reason, the remainder of this literature review on professional learning will assume that where 
authors refer to forms of professional development that encourages the development of both teachers' cognitive and emotional learning, and the development of learning communities, they are referring to professional learning.

With this review into the current conceptualisations of teacher professional learning in place, it is necessary to discuss the methods of professional learning that have been proposed by various authors. This forms section 3.4 of this review of the literature.

\subsection{METHODS OF PROFESSIONAL LEARNING}

Teacher professional learning is an important part of the professional life of a teacher. Thus the methods deployed for encouraging teacher professional learning must be appropriate to the "goals and context ... of the professional development program" (Ingvarson, 2002, p. 9). These methods include: the forms of professional learning referred to by McCullough et al. (2000); the fifteen strategies that Loucks-Horsley et al. (1998) refer to; the three main strategies that Cibulka et al. (2000) discuss; and the interactive professionalism of Fullan (1991). The purpose of this section is to briefly describe these methods and the assumptions that underpin their usefulness in encouraging teacher professional learning.

McCullough et al. (2000, p. 88) refer to five forms of professional learning, each "capable of provoking that reflection that is necessary if fresh understandings are to emerge". This reflection is at its most powerful as a form of professional learning when "it involves sharing emergent understandings with peers, whose enquiries can support their refinement and consolidation" (McCullough et al. 2000, p. 88). These forms, with their potential strengths and weaknesses, can be summarised as:

Offsite courses and conferences. This form has the potential to share expert knowledge with a wide range of teachers. The potential drawbacks of offsite courses and conferences include the cost, content and detachment from the context of teachers' work; 
On-site, non-contact days. The ability to deal with the learning context firmly in mind is a potential strength of this form. The potential weaknesses include a collegiality that is contrived (Hargreaves, 1994), a failure to address serious concerns and a lack of external expertise and perspectives;

Staff, departmental and other school meetings, subject associations. The potential strengths of this form include those listed for on-site, non-contact days, and the opportunity for the display of expert, teacher centred advice on curriculum and pedagogical knowledge. The potential weaknesses include those listed for on-site, non-contact days and four others. Firstly, not all teachers are members of specific groups. Secondly, some groups of teachers can be under-represented. Third, learning tends to be based on print media and individually focussed. Finally, there are problems in translating individual learning into practice;

Reading. There is much that can be learnt from written media, and allowing access to other perceptions of teaching practice and education programs. The potential weaknesses are the individual nature of this form of learning and the difficulties of applying the learning to new situations. In addition to this, there is the tendency for written material to appear after the need for an innovation has occurred; and,

Daily work practices. The potential strengths of this form are that the learning is contextualised, collegial and continuous, rather than being seen as a single event. The informal nature of much professional learning is discussed by several researchers (Shapero, 1985; Blackler, 1993; Becher, 1996 and Eraut, 1997). The potential weaknesses of this form are seen as including the possibility of a group achieving no real change, and a tendency to "reinvent the wheel, and little validation of the norms and routines that the group works under" (McCullough et al. 2000, p. 88).

McCullough et al. (2000) state that these professional learning methods are built on four important considerations. These are: 
Professional learning is situated, specific and practical in nature;

Most professional learning takes place in the normal working of activity systems, such as departments;

The main form of professional learning is not through courses and conferences, although they have their place; and,

The improvement of professional learning is contingent upon the improvement of activity systems (p. 90).

As these four considerations focus on the need for professional learning to be contextualised in the work environment, they have a direct impact on the usefulness of much professional learning. They support Ingvarson's (2002) contention regarding the need to develop the capacity of the school or system in order to build up the professional learning capacity of teachers. The implications of contextualising the professional learning of teachers for this study will be explored more fully in section 3.6 , and in chapter 4 , which focuses on the school subject department.

A strategy is a "kind of learning experience that has identifiable characteristics that make it recognizable when implemented" (Loucks-Horsley et al. 1998, p.42). LoucksHorsley et al. (1998) suggest fifteen strategies, together with their underlying assumptions, key elements and implementation requirements for professional learning. These strategies are, however, not to be seen in isolation from each other, a variety of strategies will be needed to achieve particular professional learning purposes. Loucks-Horsley et al. (1998) also stress the importance of the context in which professional learning occurs as "teachers learn in their work settings, which support that learning and, consequently, become a stronger and richer source of learning for all" (Loucks-Horsley et al. 1998, p. 195). In highlighting the importance of the professional community to the teaching and learning that occurs in classrooms, Loucks-Horsley et al. (1998) refer specifically to the academic department as the professional community:

Classroom practices and conceptions of teaching ... emerge through a dynamic process of social definition and strategic interaction among teachers, students, and subject matter in the context of a school or a department community. The character of the professional community that exists in a school or a department-collegial or isolating, risk taking or rigidly invested in best practices, problem solving or problem hiding-plays a major role in how teachers see their work and their students and in why some teachers opt out, figuratively or literally, while many teachers persist and thrive even in exceedingly challenging teaching contexts (p. 195). 
With the importance of the context in mind, the selection of the most appropriate strategies depends on the particular purposes that are to be achieved. Loucks-Horsley et al. (1998) describe some of these purposes as:

Focussing on developing teacher awareness of new approaches or content;

Focussing on building knowledge about science and mathematics content and teaching practice;

Assisting teachers to translate new information into personal teaching practice;

Focussing on the transfer and transposition of new professional knowledge; and,

Providing opportunities for teachers to reflect deeply on the teaching and learning that occurs in both their own classrooms, and the classrooms of their colleagues (p. 45).

These goals allow for the selection of appropriate professional development strategies, as summarised in the following table, taken from Loucks-Horsley et al. (1998, p. 46):

\begin{tabular}{|c|c|c|c|c|c|}
\hline Strategy & $\begin{array}{c}\text { Developing } \\
\text { awareness }\end{array}$ & $\begin{array}{c}\text { Developing } \\
\text { knowledge }\end{array}$ & $\begin{array}{c}\text { Translating } \\
\text { into } \\
\text { practice }\end{array}$ & $\begin{array}{c}\text { Practicing } \\
\text { teaching }\end{array}$ & Reflecting \\
\hline $\begin{array}{c}\text { Immersion in } \\
\text { inquiry }\end{array}$ & $\mathrm{X}$ & $\mathrm{X}$ & $\mathrm{X}$ & & \\
\hline $\begin{array}{c}\text { Immersion in } \\
\text { Maths/Sci } \\
\text { world }\end{array}$ & $\mathrm{X}$ & $\mathrm{X}$ & $\mathrm{x}$ & $\mathrm{X}$ & \\
\hline $\begin{array}{c}\text { Curriculum } \\
\text { implementation }\end{array}$ & & $\mathrm{x}$ & $\mathrm{x}$ & $\mathrm{X}$ & \\
\hline $\begin{array}{c}\text { Curriculum } \\
\text { replacement }\end{array}$ & $\mathrm{X}$ & $\mathrm{X}$ & $\mathrm{X}$ & $\mathrm{X}$ \\
\hline $\begin{array}{c}\text { Curriculum } \\
\text { adaptation and } \\
\text { development }\end{array}$ & $\mathrm{X}$ & $\mathrm{x}$ & & & \\
\hline $\begin{array}{c}\text { Workshops and } \\
\text { Institutes }\end{array}$ & $\mathrm{X}$ & & & \\
\hline $\begin{array}{c}\text { Action } \\
\text { research }\end{array}$ & & $\mathrm{x}$ & & \\
\hline $\begin{array}{c}\text { Case } \\
\text { discussion }\end{array}$ & & & & \\
\hline
\end{tabular}




\begin{tabular}{|c|c|c|c|c|c|}
\hline Study groups & $X$ & & $\mathrm{x}$ & & $\mathrm{X}$ \\
\hline $\begin{array}{l}\text { Examining } \\
\text { student work }\end{array}$ & $\mathrm{X}$ & $\mathrm{x}$ & $\mathrm{x}$ & & $X$ \\
\hline $\begin{array}{l}\text { Coaching and } \\
\text { mentoring }\end{array}$ & & $\mathrm{x}$ & $\mathrm{x}$ & $X$ & $\mathrm{x}$ \\
\hline Partnerships & $X$ & $X$ & & & \\
\hline $\begin{array}{c}\text { Professional } \\
\text { networks }\end{array}$ & $\mathrm{X}$ & $X$ & $\mathrm{x}$ & & $\mathrm{x}$ \\
\hline $\begin{array}{c}\text { Developing } \\
\text { professional } \\
\text { developers }\end{array}$ & & $\mathrm{x}$ & $\mathrm{x}$ & $\mathrm{X}$ & $\mathrm{x}$ \\
\hline Technology & $\mathrm{X}$ & $X$ & X & & $\mathrm{x}$ \\
\hline
\end{tabular}

In this table, purposes are italicised, and $X$ represents the primary purpose for each strategy, while $x$ indicates a secondary purpose(s).

Cibulka et al. (2000) distinguish between strategies for the professional learning of individual teachers, and strategies that are directed toward the potential for corporate change in teachers' knowledge, behaviour and beliefs. The strategies that affect individual teachers' professional learning can be subdivided into three main strategies: the sequencing of knowledge acquisition; providing opportunities for participatory learning; and the individual needs of the teacher (Cibulka et al. 2000).

Sequencing of knowledge acquisition consists of four conditions that need to be met if teachers are to adopt new teaching practices. In the National Center for Research on Teacher Education Report (1991), the first of these conditions gives teachers an opportunity to investigate the potential value of new practice, compared to their existing practice. The second condition is the provision of images of the new practice. Third, teachers need to be provided with the opportunities to learn examples of the new practices. Finally, teachers need the support and guidance of the school if they are to learn how to teach the new practice. The difficulties that arise with the 
dissemination of new practice are not discussed by Cibulka et al. (2000). This is surprising given the difficulties of teacher professional knowledge creation outlined by Hargreaves (2000).

The second strategy: providing opportunities for participatory learning, is centred on giving teachers responsibility for their own learning through activities like action research, and allowing closer collaboration with colleagues within their school. This strategy, in part, revolves around the reconceptualisation of professional development to include more than the formal and structured methods favoured at present, such as conferences and seminars.

By tailoring professional learning to the individual needs of the teacher, the third strategy aims to improve the effectiveness of professional development. These needs change throughout a teacher's career and include, for example: pre-service, induction, competency building, enthusiasm and growth, career frustration, career stability and career wind down (Cibulka et al. 2000). Huberman (1995) claims that current professional development practices are geared more to the needs of schools, rather than balancing the legitimate needs of the school with the needs of individual teachers. The result of this is that the difficulties of instructional change are not fully comprehended (Cibulka, et al. 2000). As a result, there is a need to match professional learning activities to the individual teachers' career needs.

Fullan (1991) also develops the notion that professional learning needs for individual teachers will change during the course of their careers, and indeed, in different stages of their careers. Fullan develops the notion of interactive professionalism, with the aim of redefining the work of teachers and their working conditions, so as to "sustain and motivate teachers throughout their careers" (Fullan, 1991, p. 61). In order to achieve the notion of interactive professionalism, he suggests twelve guidelines that must be seen as an integrated whole. It is suggested that these guidelines, together with the systematic changes that their widespread adoption will bring to the context of teachers' work, will produce "more fundamental and effective change than existing reform strategies do" (Fullan, 1991, p. 64). Fullan's twelve guidelines are:

Locate, listen to and articulate your inner voice; 
Practise reflection in action, on action and about action;

Develop a risk taking strategy; trust processes as well as people;

Appreciate the total person in working with others;

Commit to working with colleagues;

Seek variety and avoid balkanisation;

Redefine your role to extend beyond the classroom;

Balance work and life;

Push and support principals and other administrators to develop interactive professionalism;

Commit to continuous improvement and perpetual learning; and,

Monitor and strengthen the connection between your development and your students' development (p. 64).

Taken together, these twelve guidelines reflect the desire "to tell stories, the desire for relationship and the desire to think again, to reflect on actions taken and things thought" as described by Clandinin and Connelly (1995, p. 154). The guidelines are also heavily influenced by the context in which teachers work, a theme that has been repeated throughout this literature review. The school context, and its importance for teacher professional learning, will be considered in section 3.6. First, however, it is necessary to consider the development and dissemination of professional knowledge for individual teachers, individual schools, and across school systems. Such a review is important as it highlights aspects of professional learning that assist in developing the theoretical frameworks for this research. This consideration of the development, transferability and application of professional knowledge forms section 3.5 .

\subsection{THE DEVELOPMENT, TRANSFERABILITY APPLICABILITY OF PROFESSIONAL LEARNING}

Section 3.2 of this literature review discussed the current conceptualisation of professional learning as "expanding the ability to produce the results we truly want in life. It is lifelong generative learning" (Senge, 1990, p.142). Under this conceptualisation, teacher professional learning consists of two important components, cognitive learning and emotional learning that teachers need to address if they are to improve their quality of practice. Professional development, in its theoretical conceptualisation, appears to acknowledge, and support, the need for teachers to become life-long learners. Current professional development practices, however, appear to have the potential to undermine teachers' professional learning 
through the reduction in "teachers' power to decide on goals and methods and effectively make them technicians following someone else's designs" (McCullough et al. 2000 , p. 82). Section 3.4 examined the various methods by which teacher professional learning can be pursued, from the forms of McCullough et al. (2000) to the strategies of Loucks-Horsley et al. (1998) and Cibulka et al. (2000) to the interactive professionalism of Fullan (1991). Each of these authors highlights the importance of the context in the work of teachers. The importance of the school context is discussed more fully in section 3.6. Chapter 4 will focus on the subject department, providing a review on the role of the subject department and the specific importance of the department context in the professional learning of teachers.

The development of professional learning and the professional knowledge that develops from that learning continues to be important for research. There is literature suggesting that sufficient knowledge already exists to allow schools to become more effective, and that the most pressing task is to disseminate this knowledge to all teachers. If this diffusion were comprehensive enough student educational outcomes would improve. Such a view, however, repeats a major flaw of current professional development practice: teachers possess an incomplete professional knowledge and, therefore, others should direct the purposes and content of teacher professional learning. The diffusion of existing practices is insufficient for the improvement of student outcomes. What is needed is the generation of "better knowledge and practices" (Hargreaves, 2000, p. 225).

The generation of new knowledge, which includes practical knowledge, is fundamental to professions undergoing change (Hargreaves, 2000). Senge (1990) develops a similar notion of generating new knowledge in his discussions of mental models as a method of exposing assumptions about business issues. This exposition of assumptions allows managers to develop new mental models of their company and permits corporate learning to become institutionalised. Specifically referring to education, Ingvarson (2002) writes of increasing the capacity for professional learning of both individual teachers and of schools and systems, while Hargreaves (2000) describes the features of the knowledge creating school, and Loucks-Horsley et al. 
(1998, p. 204) discuss the "building capacity for professional learning". Despite different terminologies, all these authors appear to be developing the same basic concepts.

Ingvarson (2002) grounds his notion of professional learning capacity on a foundation of four elements:

The capacity to build strong normative structures in the profession that provide teacher leadership and standards from entry to highly accomplished teaching across the profession;

The capacity to provide a credible professional certification, based on a rigorous system for assessing teacher performance in relation to standards;

The capacity to develop a new infrastructure to support professional development towards standards for each career stage; and,

The development of new career structures and pay systems that provide incentives for professional development and tangible recognition of professional certification (p. 18).

Ingvarson (2002) describes the teaching profession as weak regarding this level of professional learning capacity. The other levels at which Ingvarson proposes that the teaching profession can develop its professional learning capacity are at the school and system levels. At these levels, professional communities and leadership are the key contributors to capacity building, as schools and systems support teacher professional development and pre-service education.

Similarly, Loucks-Horsley et al. (1998) identify the "components of capacity, which can be present at any system level" as:

People who can work with teachers in supporting their learning and teaching;

Support systems for professional development providers;

A knowledge base of professional development theory and practice;

Supported subcultures in which professional development flourishes; and,

Policies, resources, and structures that make professional development a central rather than a, marginal activity (pp. 204-205). 
Hargreaves (2000) proposes that, in the ideal form, a professional knowledge creating school should: audit its professional working knowledge; manage the process of creating new professional knowledge; validate the professional knowledge created; and disseminate the created professional knowledge.

The common threads linking these three descriptions of teacher professional knowledge creation are the development of a common knowledge base for the teaching profession, and the development of the social context of the school as a method of focussing on the continual learning needs of teachers (Cibulka et al. 2000). These common threads are grounded in the discussion of the Aristotelian typology of episteme, techne and phronesis found in chapter 2.

The auditing of teacher professional knowledge has the purpose of exposing the "social distribution of knowledge so that planned and co-ordinated action on the sharing of existing professional knowledge, and the creation of new knowledge, may be undertaken" (Hargreaves, 2000, p. 225). This auditing of professional knowledge is based on two of the features of teacher professionalism that were described in chapter 2: the desire of teachers to tell stories about their practice; and the nature of professional knowledge, which is both explicit and tacit. Allowing teachers to utilise the knowledge that is found within their own school also gives teachers the opportunity to develop new knowledge. As Scribner (1998, p. 33) notes "teachers working in the same context as their peers are much more likely to address critical teacher issues, and peers are much more willing to listen". If teachers are not given the opportunity to tell their stories, their colleagues cannot draw upon the professional knowledge that they possess. The result is that knowledge is "locked in the heads of individual teachers" (Hargreaves, 2000, p. 225).

The importance of explicit and tacit knowledge is found in the creation of professional knowledge through the interactions of these forms of knowing (Hargreaves, 2000). Hargreaves bases this importance on his analysis of the work of Nonaka and Takeuchi (1995). Nonaka and Takeuchi discuss the creation of knowledge in four modes: socialisation, internalisation, externalisation and 
combination. Each of these modes has direct relevance to the development of teacher professional knowledge, and has implications for the development of the school context as one that supports knowledge creation.

Socialisation is concerned with "the shared experience through apprenticeship and onthe-job training that generates tacit knowledge" (Hargreaves, 2000, p. 228). This acquired tacit knowledge can become explicit knowledge through the process of externalisation, which is based on "dialogue and collective reflection among community members" (p. 228). Explicit knowledge can also become tacit knowledge, such as in the acquisition of skills through the process of internalisation. Finally, the process of combination relies on teachers coming together for the process of "systemising and elaborating explicit knowledge by combining different bodies of knowledge" (p. 228). The development of a professional community, as described by Ingvarson (2002) and Hord (1997a, b), provides the conditions that are necessary to allow these processes to occur, and for stories of practice to be told. The primary conditions that must be met if these interactions are to occur are "a willingness to accept feedback and work toward improvement ... respect and trust" (Hord, 1997a, p. 5 ). With these conditions in place a sharing of personal practice becomes possible (Hord, 1997a). Sharing can encourage the development of an environment that "values and supports hard work, the acceptance of challenging tasks, risk taking, and the promotion of growth" (Midgley \& Wood, 1993, p. 252). Thus, the context of teachers' work is intimately interconnected with the development of teacher professional knowledge, a connection at the school level that will be more fully discussed in section 3.6 and at the department level in chapter 4 . The net result of such developments at the school level is the creation of shared knowledge that can become "a shared language with which to communicate and improve" the professional knowledge base (Loucks-Horsley et al. 1998, p. 206).

However, the creation of shared knowledge is, by itself, insufficient to guarantee improvements in the professional knowledge base. Validation of the new knowledge is also required (Hargreaves, 2000). Validation of knowledge in the professions is the process through which knowledge becomes a practice that "demonstrably and 
repeatedly works" (p. 228). There are many forms of validation, most of which are rarely used in the education profession. The result of this is, that in many schools:

... knowledge validation is in a primitive state, consisting largely of the ipsative form with elements of the social, in which teachers informally exchange experiences but with relatively little analysis or concern to identify and agree upon what might be effective practice (Hargreaves, 2000, p. 229).

Before discussing the implication of validation on the conceptualisation of teacher professionalism, it is also necessary to examine the dissemination of professional knowledge.

The dissemination of teacher professional knowledge is a difficult area, referring specifically to problems in science education, Bybee (1993), refers to the problems associated with the presentation of either incomplete programs, inadequate programs and/or inappropriate programs to science teachers. Dissemination is difficult because it often involves "knowledge or practice ... becoming transposable and transferable" (Hargreaves, 2000, p. 230). Knowledge transfer is the movement of knowledge or practice between persons. Knowledge transposability refers to the movement of knowledge and practice between places. Knowledge or practice is transposable if the individual with that knowledge or practice is able to use the knowledge or practice in a new context. An example of this may be teaching the same topic to different classes. Transferable knowledge or practice is where a second teacher can use knowledge or practice from another teacher and use that knowledge in its original context. It is apparent that the problems associated with transposability and transferability are a major impediment to traditional forms of professional development delivery.

One obvious implication of this notion of transferable and transposable knowledge and practice is that the basic human desires described by Clandinin and Connelly (1995) cannot be considered in isolation. The desire to tell stories, by itself, will not improve the knowledge base of teaching for two reasons. The first is that telling a story only provides information to another teacher, it does not provide knowledge. This means that transfer is difficult (Hargreaves, 2000, p. 230). The recipient must take the information and make it into their personal knowledge before transfer can 
occur. Secondly, the desire to tell stories must be seen in concert with the desire to reflect on thoughts, words and actions, and a willingness to act on those reflections. It is through thinking and doing that teachers learn about teaching.

Action in trying out new approaches is imperative, for it is through "informed experiments, pursuing promising directions, and testing out and refining new arrangements and practices that we make the most headway" (Fullan, 1991, p. 63). Huberman (1992) stresses that a craft model is the best scenario for teachers' development. Under such a scenario:

... teachers are artisans working primarily alone, with a variety of new and cobbled together materials, in a personally designed work environment. They gradually develop a repertoire of instructional skills and strategies, corresponding to a progressively denser, more differentiated and well integrated set of mental schemata; they come to read the instructional situation better and faster, and respond to it with a greater variety of tools. They develop this repertoire through a somewhat haphazard process of trial and error, usually when one or another segment of the repertoire does not work repeatedly. Somewhere in that cycle they may reach out to peers or even to professional trainers, but they will typically transform those inputs into a more private, personally congenial form (p. 136).

More succinctly, Huberman (1992, p. 137) states that teachers "spontaneously tinker with their classrooms". It is through tinkering that "an individualised embryo of knowledge creation [which if] more systematic, more collective and explicitly managed ... is transformed into knowledge creation" (Hargreaves, 2000, p. 231). Tinkering is the process through which teachers can take a good idea and develop it into "something worth subjecting to more systematic validation" (p. 231). Tinkering with ideas, in the form of personal reflection and/or public discourse amongst teachers, is an important consideration in professional learning. It is the context of that learning to which this review of the literature now turns. 


\subsection{THE SCHOOL CONTEXT OF TEACHER PROFESSIONAL LEARNING}

The purpose of this section is to review the significance of the school as a context for teacher professional learning. It is a precursor to chapter 4 , which will focus specifically on the importance of the academic department as both a site of professional learning, and as the subject of this research.

Scribner (1998, p. 3) notes that "our knowledge of the influence of work context on teacher learning is limited". There are two possible explanations for this limitation. One possibility is to be found in the deeply contextualised nature of teachers' work, which is related to a second explanation, found in the work of Senge (1990). For Senge (1990), there has been a diminution in the meaning of the word 'learning', which has become a synonym for 'taking in information'. If this diminution is the case, and teacher learning is regarded as the taking in of information outside the context of teachers' work, the inherent link that exists between teacher professional learning and the context of teachers' work is broken. Scribner (1998) describes this connection:

The functional relevance of a piece of theoretical knowledge depends less on its presumed validity than on the ability and willingness of people to use it. This is mainly determined by individual professionals and their work context, but it is also affected by the way in which the knowledge is introduced and linked to their ongoing professional concerns (p. 6).

Taking this description into account, Scribner believes that current teacher professional learning practices, rather than acting as a catalyst for personal reflection and use, often occur in a manner divorced from the context of the teacher. It is this failure to take into account the context of work that Senge (1990) addresses in his conceptualisation of the learning organisation. As Senge (1990) states, learning which is 'real' is learning that: 
... gets to the heart of what it means to be human. Through learning we become able to do something that we were never able to do. Through learning we reperceive the world and our relationship to it. Through learning we extend our capacity to create, to be part of the generative process of life (p. 14).

If this richer meaning is given to learning, Senge (1990, p. 14) argues, the learning organisation is a system that is "continually expanding its capacity to create its future". It is this emphasis on the system, as a whole, that may be a helpful conceptualisation of the school context, and an important tool for facilitating teacher professional learning. This argument is echoed by Ingvarson (2002) who, writing specifically about education, states that:

Organisations that improve do so because they create agreement on what is worth achieving, and they set in motion internal processes by which people progressively learn how to do what they need to do in order to achieve what is worthwhile (p. 13).

Given the importance of the connection between teacher professional learning and the context of teachers' work, it is necessary to consider the use of systems thinking in examining the school context.

In his work on systems, Senge (1990, p. 12) argues that systems thinking is a way of integrating the disciplines of "shared vision, mental models, team learning and personal mastery" in such a way as to permit understanding of the new way in which individuals perceive themselves and the world. It is the understanding of this new perception that takes people from "seeing themselves as separate from the world to being connected to the world [to] a place where people are continually discovering how they create their reality ... and how they can change it" (Senge, 1990, pp. 12-13). Such a conceptualisation is powerful for teachers, as "each teacher is part of a system" (McCullough et al. 2000, p. 90). The reasoning behind this statement is that, although much of what teachers do is isolated from their colleagues (Hargreaves, 1994), the "expectations, practices and nature of the learning that they foster in children all affect what other teachers do and can do" (McCullough et al. 2000, p. 90). Ingvarson $(2002$, p. 12$)$, in a similar discussion, argues that policy should aim to 
develop schools which are defined by the "collective power of the school staff to improve student achievement school-wide".

Teachers can simultaneously belong to several different systems within a single school. These may include subject departments, curriculum development groups, or administrative groups. Each of these groups could possess different perceptions of their work, and the individual's role within the group. In learning organisations, as proposed by Senge (1990), it is entirely possible that some groups within a school could be seen as possessing the characteristics of a learning organisation, while others may not. McCullough et al. (2000) refer to these different groups as activity systems. It is the impact of change on these activity systems that produces, in teachers, "new conceptions of their activities and ... new activity systems" (Blackler, 1993, p. 875). It is through changes to activity systems that teachers' professional learning occurs (McCullough et al. 2000). While these changes may facilitate teacher professional learning, they also contextualise the professional knowledge that is produced. Scribner (1998, p. 8) states the "ability to acquire and use knowledge are highly dependant on context ... for knowledge to be acquired it must be used in some form, thus becoming part of the user". It is this contextualisation of professional knowledge that limits its transferability and transposability, as discussed by Hargreaves (2000).

If the work of teachers is so heavily contextualised, it is necessary to consider the various elements that constitute the context of their work, and the impact of those elements on professional learning. The importance of this contextual knowledge for educational leaders is to allow them to "create contexts and use any methods that increase the frequency and quality of conversations that teachers can have with each other about the content of what they are teaching and the learning that is going on in their classrooms" (Ingvarson, 2002, p. 12).

The context of teachers' work is multi-dimensional (Scribner, 1998), which means that changes imposed on an activity system can affect different dimensions at different times. Eraut (1994) describes teachers' work as occurring in three interdependent contexts: the academic, the classroom, and the school. The academic 
framework of their work generates theoretical knowledge on topics such as pedagogy, curriculum design, and subject knowledge that is usually communicated through specialised language (Scribner, 1998). As such it covers the episteme and techne of the Aristotelian typology. The second perspective that Eraut (1994) identifies is that of the classroom. The classroom is characterised by the teachers' necessity to act, and react, quickly, with "minimal time to reflect on past knowledge or memory [relying] proportionally more on personal knowledge - i.e. knowledge acquired through experience, often in isolation and routinised into tacit behaviours" (p. 8). The result of this is that the transferability of knowledge from academia to schools and classrooms is extremely difficult to achieve. The third context of teachers' work is the organisational environment of the school. This environment "generates knowledge that socialises members to the existing norms, through vehicles such as policies and procedures that guide the members' conduct and organisational directions" (p. 8). It is this environment that is the subject of this section.

Developing the context of the school so that it facilitates teacher professional learning is often described in terms of fostering schools as professional learning communities. McLaughlin and Talbert (1993, p. 18) believe that "the path to change in the classroom core lies within and through teachers' professional communities". Fullan $(2002$, p. 6) states that increases in teacher learning in the school context are a function of five components: "individual teacher knowledge, skills and dispositions, professional learning community, program coherence, technical resources and the leadership of the principal".

Building on the foundation of enhancing professional capacity, Ingvarson (2002, p. 18) believes that the professional learning capacity of schools and systems can be enhanced through developing professional communities and exercising educational leadership. This echoes the findings of Hord (1997a), who highlighted the importance of five key attributes of professional learning communities. These attributes, which are seen as necessary to increase both teacher effectiveness and student outcomes, can be summarised as: supportive and shared leadership, collective creativity, shared values and visions, supportive conditions and shared personal practice. 
In their discussion of the contextual factors that affect learning communities, Cibulka et al. (2000) refer to many local features that are unique to individual schools. These include:

Structures for collaboration (scheduling time, personnel and funds), support for effective professional development, performance standards and expectations, the culture of classrooms and schools, the availability of access to outside networks, resources and community services, the degree to which the school has a trusting and supportive climate, and the presence of an ethic of caring for all members of the community (p.44).

In addition to these school specific features of a professional learning community, there are two other features of learning communities: the policy context in which the school operates and the role of leadership found at all levels in a school (Cibulka et al. 2000). The role of leadership is discussed in greater detail in section 3.7. While the broad policy environment in which a school operates is outside the scope of this literature review, Cibulka et al. (2000, p. 45) argue that policy, which is defined as an "array of forces - formal and informal; regulatory and voluntary; proximate; and which impinge on schools" has a considerable potential to assist, or retard, the ability of individual schools to establish and maintain learning communities.

\subsection{LEADERSHIP}

An integral part of managing the creation and sustenance of professional learning communities is the role of leadership. Ingvarson (2002), Fullan (2002), Cibulka et al. (2000), Loucks-Horsley et al. (1999), Scribner (1998) and Hord (1997a and b) all specifically recognise the importance of leadership in the development of both school and system professional learning capacity. Scribner (1998, p. 32) believes that educational leaders must "place professional development at the core of teacher work [in order] to ingrain the value of continuous professional learning throughout teachers' careers". However, for this conceptualisation of teachers' work in schools to occur, leadership will be required. The reason for this is that teachers may well regard any proposal for continuous professional learning as still more work, especially if it is seen as being mandated (Scribner, 1998). This requirement for educational leadership 
in developing professional learning communities raises the question: What does this leadership look like?' In asking this question, it is not my intention to attempt a review of the literature on leadership, rather it is to focus on the role of leadership as it relates to the development and maintenance of professional learning communities.

The salient point regarding leadership in professional learning communities appears to centre on the redefinition of leadership away from a paradigm that equates leadership with a hierarchical position of authority, to one in which leadership is based on collegiality (Wallace \& Wildy, 1995a; Hord, 1997a). This means that those in authority in schools who "have received their authority and power from their position" would be required to accept, and act on, a redefinition of leadership (Ridden, 1996, p. 28). This redefinition requires that "sources of authority for leadership are embedded in shared ideas, not in the power of position" (Hord, 1997a, p. 3). For principals and others in positions of authority, this means that any notion of omnipotence must be replaced by a notion of becoming learners themselves, "questioning, investigating and seeking solutions themselves for school improvement" (Hord, 1997b, pp. 2-3). Fullan (2002) identifies five core components of a new conceptualisation of leadership: moral purpose, understanding change, relationship building, knowledge creation and sharing, and coherence making.

If such a change in the conceptualisation of leadership occurs, school-based bureaucratic administrators will become educational leaders who can adopt a systems approach to the development of their school as a professional learning community (Wallace \& Wildy, 1995a). Under such an approach, different tasks, and authority, within the school can be shared amongst staff with expertise in particular areas and the teaching and learning work of teachers can be facilitated (Hord, 1997a). Such a development also allows the educational leader to concentrate their energies on those activities that are central to the teaching and learning that occurs in schools (Cibulka et al. 2000; Wallace \& Wildy, 1995a). These changes in the work of those in authority present a challenge to the types of new skills and abilities that are required to build and sustain a professional learning community (Cibulka et al. 2000). Leithwood, 
Leonard and Sharratt (1998), describe such leadership as transformational, a term also used by Bybee (1993) in his discussion on the dimensions of leadership.

Transformational leadership consists of eight dimensions, which appear to have a positive correlation with the promotion of professional learning in schools. Transformational leaders need to develop their skills and abilities in these dimensions, described by Cibulka et al. (2000) as:

... including practices aimed at identifying and articulating a vision, fostering the acceptance of group goals, and providing individualised support for staff members. Transformational leadership practices also aim to stimulate organisational members to think reflectively and critically about their own practices, and to provide appropriate models of the practices and values considered central to the organisation. Holding high performance expectations, building shared norms and beliefs (culture), and structuring the organisation to permit broad participation and decision making also can have important consequences for organisational learning (p. 62).

Discussion on leadership in professional learning communities has, so far, related mainly to those who occupy positions of authority with a school, and the challenges that they face in developing and sustaining a professional learning community. Teacher leadership is also crucial in developing professional learning communities (Silva, Gimbert and Nolan, 2000; Wallace \& Wildy, 1995a; Fullan, 1994). This topic is of profound importance to the literature review on the academic department that is to follow in chapter 4 , it is within the academic departments of secondary schools that the "requisite conditions [for becoming a] socially cohesive community" exist most fully (Huberman, 1990, p. 32). Hence, the notion of teacher leadership must be considered, as "each teacher has something to offer colleagues - experiences, strategies, knowledge, creative ideas, classroom management procedures" (Ridden, 1996, p. 27).

Silva et al. (2000) discuss three waves of teacher leadership. The first of these waves was characterised by a desire to maintain an efficient and effective educational system rather than a desire to improve leadership. In order to achieve this first wave, various roles were created for teachers such as Department Head, Master Teacher and Head 
Teacher. A possible outcome of this wave was the undervaluing of teachers' professionalism. The second wave centred on the creation of positions for teachers that "capitalised on teachers' instructional knowledge" (Silva et al. 2000, pp. 779780). This change resulted in teacher leaders working in isolation from the daily work of the teachers that they were to lead. This deficiency in the second wave did, however, highlight the importance of empowering teachers in the work that they undertake within the classroom. This recognition led to the third wave on teacher leadership.

This third wave of teacher leadership, as described by Silva et al. (2000) has parallels in the professional learning community literature. It revolves around the reculturing of schools in order to provide for the meaningful participation of teachers in the school as an organisation (Evans, 1996). Wasley (1991) defines teacher leaders as:

Those who enable colleagues to improve professional practice by doing things that they would not ordinarily do on their own ... [they] help redesign schools, mentor their colleagues, engage in problem solving at the school level and provide professional growth activities for their colleagues (p.5).

Thus, teacher leadership is actively grounded in the daily work of teachers. Silva et al. (2000) believe that teacher leaders, in their classroom and school contexts, actively seek to:

Collaborate with other teachers, discuss common problems, share approaches to various learning situations explore ways to overcome the natural constraints of limited time, space, resources, and restrictive practices, or investigate motivational strategies to bring students to a deeper engagement with their learning (p. 781).

In order to understand the purposes and actions of teacher leaders within their school and classroom contexts, five assertions regarding teacher leaders have been proposed by Silva et al. (2000). These assertions, based on their case study of three selected teacher leaders, are that teacher leaders navigate the structures of schools, nurture relationships, encourage professional growth, help others with change, and challenge the status quo by raising children's voices. 
Such assertions reflect the sentiments of one of the attributes of a school-based professional learning community, "shared personal practice," described by Hord (1997a):

Teachers share their practice and enjoy a high level of collaboration in their daily work life. Mutual respect and understanding are the fundamental requirements for this kind of workplace culture. Teachers find help, support and trust as a result of developing warm relationships with each other. Teachers tolerate (even encourage) debate, discussion and disagreement. They are comfortable sharing both their successes and failures. They praise and recognise one another's triumphs, and offer empathy and support for each others' troubles (p. 5).

While Silva et al. (2000), Hord (1997a and b) and Ridden (1996) stress the importance of teacher leaders, there has been little research into the "roles and responsibilities ... or the knowledge, skills and abilities that they possess" (Silva et al. 2000 , p. 781). This deficiency in the knowledge base applies to both the whole school and the academic department contexts.

\subsection{CONCLUSION}

In this chapter, I have sought to review literature to develop a broader and deeper understanding of the nature of professional learning as it applies to both schools as institutions and teachers as individuals within those institutions. This review has covered topics such as the cognitive and emotional aspects of professional learning; the ambivalent nature of the relationship between professional learning and professional development; professional knowledge creation and dissemination; methods of professional learning; and the context of professional learning. Key points emerge that add shape to the theoretical frameworks that I will employ in the analysis of the data.

Professional learning stresses the importance of both cognitive and emotional learning in the overall leaning of teachers. Teachers clearly need to continue to keep abreast of development in their particular subject area(s). They also need to ensure that they 
continue to reflect on the pedagogies that they employ in the classroom, and to reflect on the moral implications of their practice. Teachers cannot, however, be expected to undertake these tasks of reflection on their own. Within the teachers' workplace, teachers need to be given the opportunity to engage in tinkering with ideas and to negotiate what is important to them, their teaching and their students. To engage in such tinkering and negotiation is to give meaning to one's work, and it is in meaning that motivation is maintained, and teacher leadership encouraged.

To engage in negotiation is also to encourage innovation in practices that improve student-learning outcomes. Linking these insights back to the definition of teacher professionalism developed in chapter 2 , it would seem that the heart of teacher professional learning is the engagement of teachers in virtues-based private reflections and/or public discourses around the episteme, techne and phronesis of teaching. This is an important theoretical framework for my thesis, as it provides a process for professional learning that can be investigated in the data.

It must be noted here that these reviews have dealt almost exclusively with the system that is the whole school, and has not ventured into the different systems that can, and do, make up schools. It must be remembered that teachers can simultaneously belong to several different systems within a single school. For my research, the focus is the activity system of the science department, the members of which also belong to other departments or administrative groups. It is for this reason that the next chapter must focus on the dynamic nature of the academic department as an activity system; its definition, constitution and impact in shaping, and being shaped by, the episteme, techne and phronesis of its members. This impact on the teachers who constitute the department shapes the quality of the professional learning that the teachers undertake, and so directly affects the quality of the teaching and learning that occurs in the science classroom. 


\section{CHAPTER 4 - THE SUBJECT DEPARTMENT}

\subsection{INTRODUCTION}

Within the literature on science education there appears to have been little work on the importance of the subject department in the professional learning of teachers. This lack of attention is intriguing, as I believe that the study of the subject department provides new insights into teacher professional learning. Due to this lack of attention to the subject department as a subject for study, I have expanded the scope of this review of the literature to include the notion of 'community'. Such an expansion opens several new insights into the importance of the subject department for teacher professional learning. Introducing the notion of 'community' into my research offers a greater depth of understanding than would be possible if this review was limited to the school subject department.

As a consequence of this decision to review the literature on 'community', I must state here that, throughout the thesis, I will use the term department in reference to a school's organisational structure, and community when referring to the teachers who are the focus of this research This is an important point to consider, as the definition that is applied to a group of people involved in a line of work can be influenced by the "presumed dichotomy between communal or collegial and rational or administrative forms of work organisation" (Van Maanen \& Barley, 1984, p. 287). In this review I will examine two overlapping concepts, community in the broad sense of the word, and subject departments in the school-based, organisational sense of the word. As much of the education literature concerns itself with subject departments in a generalised sense, there will be only limited references to the particular subject of this research, the science department. These references will be noted where they exist.

This review is divided into seven sections. The first section reviews the literature on communities. The second section considers the school subject department as a community. The third delineates the boundaries of the department. The fourth investigates the characteristics of departments. The fifth examines the importance of the community as a site for teacher professional learning. The sixth studies the department within the context of the school, and the importance of the department as 
a site for teacher professional learning. The seventh and final section concludes the chapter, and provides a summary of the major themes and their role in developing frameworks.

\subsection{COMMUNITY}

Community, as it is used in the educational literature, is a notion that has become "an obligatory appendage to every educational innovation" (Grossman, Wineburg \& Woolworth, 2000, p. 6). As a result of this overuse, there is a multitude of theoretical conceptualisations as to the meaning of the term. Despite the plethora of meanings, there are no accepted criteria to "distinguish between a community of teachers and a group of teachers sitting in a room for a meeting" (Grossman et al. 2000, p. 6, author's emphasis). Such comments provide clear guidance for researchers to provide a definition of community that is appropriate for their research. As Westheimer (1998, p. 148) writes, "researchers could benefit from a stronger conceptualization of communities based in empirical research". The first purpose of this literature review is to provide a conceptualisation specific to my research.

The understanding of community that forms the foundation for this research was developed from the work of Wenger (1998) on communities of practice, Siskin (1994) on school academic departments, and Van Maanen and Barley (1984) on occupational communities. Taken together, these authors provide a framework for understanding the school-based community of science teachers. Such an understanding is important for two reasons. The first is the need to develop the stronger conceptualisation demanded by Westheimer (1998). The second is because, if "we wish to promote teacher led professional development ... we need to understand how to create workplace environments that respect, support and nourish the efforts of those involved" (Mayer-Smith, 2003, p. 96). Such an understanding must involve a sense of what constitutes a community for a particular group of teachers.

In their paper studying the formation and development of a teacher community, Grossman et al. (2000) review many of the aspects of community. For these authors, "face to face interactions, dialogue, and trust are necessary ingredients in building cohesion" in teacher communities in schools (p. 8). More particularly, community is 
"a group of people who are socially interdependent, who participate together in discussion and decision making, and who share certain practices that both define the community and are nurtured by it" (Bellah, Madsen, Sullivan, Swidler, \& Tipton, 1985 , p. 333). The development of such personal interdependence, decision-making capacity and common practices is a process that requires time for the members of the community to "become a 'community of memory' where public discussion revolves around members retelling the 'constitutive narrative' of the group" (Grossman et al 2000, p. 9). The practices of the community also represent sharing in the community's moral life, in which members are mindful of how they respond to their colleagues (Carter, 1998). These observations highlight many important aspects of the notion of community: relationships, virtues, reflection, discourse, shared practices and time. It is these characteristics that Wenger (1998), Siskin (1994), and Van Maanen and Barley (1984) discover in their work.

The practices of a community provide the coherence that defines that community as unique (Wenger, 1998). These practices, however, are built on the foundation of the meanings that a community negotiates for itself. These meanings are crucial, as the practices of the community are "about meaning as an experience of everyday life" ( $p$. 52). This negotiation of meaning involves two mutually dependent processes, participation and reification. The active involvement between the members of a community in an enterprise is seen as participation. Participation is a "complex process that combines doing, talking, thinking, feeling and belonging. It involves our whole person, including our bodies, minds, emotions and social relations" (Wenger, 1998, p. 56). Participation has a strong link to the relationships and identities developed by the members of a community. Ritchie and Rigano (2002) also discuss the value of professional conversations in supporting changes to the practice of teachers, changes that are often driven by a deep moral concern for student learning. In the teacher's words:

We talk about what we are doing in the staff room a lot. There is a lot of dialogue that occurs in the staff room about professional issues ... I guess that we are always evaluating what we are doing and trying to come up with a better way to do it. People are prepared, no matter how long they have been teaching to put in a lot of effort, to make it right for the kids, to give a good product to the kids, or to give the kids the best opportunities (p. 1090). 
Reification, or the making of the abstract into a concrete form, is the second of Wenger's (1998) processes involved in the negotiation of meaning. Reification creates focal points around which negotiation can occur. There is a danger in not recognising the duality inherent in participation and reification. To give precedence to participation over reification, and vice versa, is to risk endangering the entire enterprise. As Wenger states:

If participation prevails - if most of what matters is left unreified - then there may not be enough material to anchor the specificities of coordination and to uncover diverging assumptions. If reification prevails - if everything is reified, but with little opportunity for shared experience and interactive negotiation - then there may not be enough overlap in participation to recover a coordinated, relevant or generative meaning (p. 65).

Effective science departments appear to have dealt with this apparent tension through the development of robust relationships that allow for the adoption of contextuallybased solutions (Harris, Bennett \& Preedy, 1997). The methods deployed in building these relationships all centre on taking sufficient time to constantly interchange "professional information at a formal and informal level" (Harris et al. 1997, p. 151). The result is that these effective departments, through their recognition of the importance of participation and reification, open new possibilities for learning.

The practices of a community are derived from the meanings that a community has negotiated for itself. Wenger (1998) describes practices as belonging to one of three interconnected dimensions: mutual engagement, shared repertoire, and joint enterprise. Mutual engagement consists of, for example, the diversity within a community and the relationships that exist between those members. Shared repertoire includes discourses, stories, artefacts and concepts. Joint enterprise is made up of characteristics such as accountability, interpretations, and responses to circumstances. Each of these three dimensions of community can shape the identity of individuals already within the community, individuals who join the community, and the community itself. This issue of identity is a constant theme in much of the literature around both community and subject departments. 


\subsection{SUBJECT DEPARTMENTS AND COMMUNITIES}

Within the literature, Siskin (1994) has defined four aspects of the school-based subject department that she believes are crucial to the delineation of the subject department in contemporary American high schools. These four aspects were based on work undertaken by the Stanford University Centre for Research on the Context of Secondary School Teaching, at three high schools in the United States. The four aspects of departments identified by Siskin (1994) are that they:

... represent a strong boundary in dividing the school ... provide a primary site for social interaction ... [are] an administrative unit, [with] considerable discretion over the micro-political decisions affecting what and how teachers teach, and as a knowledge category influences the decisions and shapes the actions of those who inhabit it (p. 5).

Siskin's (1994) four aspects of the department, when considered in concert with the work of Wenger (1998) on communities of practice and Van Maanen and Barley (1984) on occupational communities, form a powerful definition of a school-based community for this research.

Van Maanen and Barley's (1984) definition and development of the concept of an occupational community provides a strong theoretical foundation for understanding Siskin's (1994) definition of a subject-based community. In her work, Siskin states that teachers identify themselves not just as teachers; rather, they see themselves as teachers of their subject. Helms $(1998$, p.831) argues that the identities of science teachers, "to greater or lesser degrees, are defined by" the subject matter. Thus, given the definition that Van Maanen and Barley (1984) propose, subject departments in secondary schools can be seen as occupational communities, in which:

... a group of people who consider themselves to be engaged in the same sort of work; whose identity is drawn from the work; who share with one another a set of values, norms and perspectives that apply to but extend beyond work related matters; and whose social relationships meld work and leisure (Van Maanen \& Barley, 1984, p. 287).

Such a definition arises from two sociological premises. The first of these is that "people bound together by common values, interests, and a sense of tradition, share bonds of solidarity or mutual regard and partake in a communal way of life" (Van 
Maanen \& Barley, 1984, pp. 292-293). Despite the dilemmas that such a conceptualisation caused for theorists such as Weber, who argued for a more rational, utilitarian form of organisation, it was generally accepted that these relationships were of great value. From this realisation came the second premise that serves as a foundation for the notion of an occupational community. This is the premise that "the work that we do shapes the totality of our lives and, to a great extent, determines who we think we are" (Van Maanen \& Barley, 1984, p. 293). This implies that work in the modern society is rationally structured vertically, as well as structured horizontally by occupational communities. This means, according to the Chicago School of Sociologists, cited by Van Maanen and Barley (1984), that:

The meaning of a line of work is socially constructed and validated in practice by members of an occupation; that an occupational career is decipherable only by reference to occupationally specific meanings; that occupations foster particular categorization schemes which structure work worlds as well as the larger social environment; and that work roles provide incumbents with a social identity and a code of conduct, both within and without the workplace (p. 294).

This line of thought, serving as it does to provide the foundations for Van Maanen and Barley's (1984) definition of an occupational community, Siskin's (1994) definition of the subject department and Wenger's (1998) argument for the process of negotiation of meaning, is also important in the context of this research. It encompasses not just the community as a place for the work of the teaching of science, but also the professional learning requirements of the teachers in the community. It achieves this through its focus on the work of a community that possesses the characteristics of the Aristotelian typology of episteme, techne and phronesis. The occupational community, therefore, provides the context in which teachers can seek to improve the quality of their practice.

If the definition of a subject-based department for this research is accepted as the same as that put forward by Siskin (1994), it is also necessary for me to examine the implications of this definition for my research. These implications include: the reasons for the departmental boundaries; the importance of the department in social relationships; and the role of the department in the practice of its member teachers. In examining these, I believe that this section of the review will provide important information that will allow for a much richer interpretation of the collected data. This 
belief is based on the notion that "commonality and connection across specific domains of thought and action ... reflects integrative themes or ordering assumptions that are held by the membership [of a community]" (Van Maanen \& Barley, 1984, p. 308). It is these themes and assumptions that are of fundamental importance to my research.

\subsection{BOUNDARIES}

School subject departments "represent a strong boundary in dividing the school" (Siskin, 1994, p. 5). There are two questions that flow from this statement: What is the reason for the existence of these boundaries? And who maintains these boundaries, and for what reason(s)?

The answer to the first question is not difficult to locate in the literature. Departmental boundaries are found in the ways that subject teachers view the world through the lens of their particular subject. Effective subject departments are characterised by "a clear and shared sense of vision ... [which] embrace the nature of the subject and how it should be organised for teaching purposes" (Harris et al. 1997, p. 151). Wildy and Wallace (2004, p. 100) note the role of the subject in "filtering and shaping the way teachers plan their work and interact with students". Siskin $(1994$, p. 153) states, that the "subjects give departments their very reason for being". Teachers in Siskin's research found that their professional identity lay not in teaching, "but in the teaching of their subject [which] plays an active role in influencing teachers' actions and attitudes" (p. 153). The reasoning behind this statement is that a teacher's academic discipline is fundamental in an individual teacher's - often subconscious - "choice of words, the structure of their arguments, or the goals that they hold" and how they "construct their norms of community, their standards of practice-their professional identity and behaviour" (Siskin, 1994, p. 153-154).

A notable caveat to the perceived importance of the subject and its role in defining boundaries is found in the work of Wildy and Wallace (2004, p. 100), who, citing their earlier work (Wildy \& Wallace, 1994; Wallace \& Wildy, 1995a, 1995b), state that "teachers within the same discipline do not always share the same views about 
what constitutes good teaching" or the same views as to the "nature of science itself". Science can be described as "a set of universal truths that describe the operation of the natural world". Under this view the purpose of school science "is to deliver that knowledge" (Wildy \& Wallace, 2004, p. 109). An alternative description of science is "as a process of personal sense making that helps people survive in their environment" (Wildy \& Wallace, 2004, p. 109). School science, from this perspective, has many, frequently competing goals.

Flowing from these two descriptions of the discipline of science come two conceptions of work in the science department. Under the first description of science, the science department "is a tightly organised and orderly place to work. There is one best way of teaching and a single best way of assessing students learning" (Wildy \& Wallace, 2004, p. 109). Alternatively, the second description of science perceives the science department as one in which "the goals of inquiry, individuality and freedom sought for students in the classroom are also sought for teachers in the department" (p. 109). Effective science departments appear to have dealt with these apparent tensions through the development of robust relationships within the department that allow for the growth of contextually-based solutions (Harris et al. 1997). The methods employed in developing these relationships all centred on taking sufficient time to constantly interchange "professional information at a formal and informal level" (Harris et al, 1997, p. 151). Departmental meetings were frequent, more frequent than were scheduled by the school, leading to higher levels of communication. Effective time management is crucial in making possible these professional learning opportunities for teachers (Huffman et al. 2001).

The strategies that effective departments developed included, firstly, a shared "vision of the subject and how it should be organised for teaching purposes" (Harris et al. 1997, p. 151). Secondly, the students' learning of the subject underpinned the work of all teachers, with each student's learning progress being monitored and evaluated. These strategies did not include prescriptive details regarding pedagogy, as it was considered that given proper support mechanisms "all departmental members could work to their individual capacities and strengths" (p. 153). The converse was also considered true, that without the proper support mechanisms "there was a greater 
danger that the department would suffer from a greater amount of idiosyncratic teaching" (p. 153).

Who maintains the boundaries dividing the school, and for what reason(s)? The answer to this second question builds on the importance of subject in defining teachers' identity that was crucial to answering the first question. The boundaries of a community are set by the members of that community (Van Maanen \& Barley, 1984, p. 295); this is based on Gusfield's (1975) idea that a 'consciousness of mind' is the foundation of a community. For secondary school teachers this means that those trained in a discipline can describe themselves in terms of their subject, because they share, along with similarly trained teachers, a set of values, norms and perspectives based around their subject discipline (Siskin, 1994). Such a situation also provides prerequisite conditions for the development of a professional learning community, one that closely mirrors the occupational community. If professional learning allows a person to expand their ability to create, professional learning only occurs "when people are striving to accomplish something that matters deeply to them" (Senge, 1990 , p. 206). If teachers describe themselves in terms of what they teach, it would be, I believe, entirely reasonable to assume that what they teach is something that matters deeply to them.

Thus, an occupational community is made up of people who consider themselves "to be" the members of an occupation, rather than those people who "are" members of the same occupation (Van Maanen \& Barley, 1984, p. 295). This delineation is critical in the context of subject departments, as teachers are often found to be teaching in subject disciplines other than the one[s] that they were initially trained in. In specific regard to science education, the report by Goodrum et al. (2001, pp. 62-63) stated that "it would seem that there are a decreasing number of science teachers being trained for the profession". As a result, there is currently "a serious shortfall in science teachers". The net result of this is that there could well be large numbers of teachers teaching science who, because of their lack of science background, are members of science departments, but are not members of the community of science teachers within a school. This situation has serious implications for the future quality of science teaching in Australia. 
Van Maanen and Barley (1984) make note of the difficulties associated with the accurate delineation of an occupational community. It is necessary, in their opinion, not only to discover a functioning occupational community, but also to describe the "dimensions along which they are formed" (pp. 297-298). These dimensions are the extent to which the department possesses the characteristics of an occupational community, and are described by Van Maanen and Barley (1984) as: boundaries, social relations, reference group and social identity. All of these characteristics are present in the other reviewed literature, invariably under different titles.

With this understanding of the reasoning behind the existence and maintenance of departmental, and community boundaries, it is now necessary to examine the second aspect of Siskin's definition of the department: the department's role in providing a primary site for social interaction.

\subsection{CHARACTERISTICS OF THE DEPARTMENT}

\subsubsection{Social interactions in the department}

As I have described in the previous chapters on teacher professionalism and on teacher professional learning, relationships have an important role in the professional life, and learning, of the teacher. Aristotle was concerned with the moral obligations and duties of those who teach, and described "this kind of practical wisdom or understanding" as phronesis (Coulter \& Orme, 2000, p. 6). Gray, Hopkins, Reynolds, Wilcox, Farrell and Jesson (1999), in their research on school improvement and the role of departments in those processes, make little reference to the social relations that are found in departments, reporting that most schools they researched assumed that school-wide initiatives would lead to improvements in departments.

Considering the department as a community, however, reinforces the importance of phronesis. For Siskin (1994, p. 5) departments are a "primary site for social interaction", while social relationships are considered one of the attributes of an occupational community (Van Maanen \& Barley, 1984). Harris et al. (1997), in their 
discussion of departments, state that one of the crucial features of an effective department is this sense of collegiality. It has been argued that the whole school, with its inherent complexities, especially secondary schools, possesses few of the "requisite conditions [necessary for a] socially cohesive community" (Huberman, 1990, p. 32). The size of secondary schools tends to work against collegial decisionmaking. Secondary schools, in North America at least, are characterised by images of anarchic shopping malls and a divided staff and curriculum (Siskin, 1994, p. 90). The conditions necessary for the development of a professional learning community in a secondary school are more likely to be found within academic departments. Bush (1997) advocates that collegiality is more likely to be found in subunits of the institution such as subject departments. This is due to the individuals in a particular department developing strong personal and professional relationships with colleagues, and "through these connections shape and reshape their own teaching - and bring it into line with local practice" (p. 95). Siskin's argument is important, as it leads into the area that is explored by Clandinin and Connelly (1995), that of the "professional knowledge landscape' of teachers.

The 'professional knowledge landscape' is the knowledge context in which teachers work. As a 'landscape' it relates space, place and time, and is filled with diverse people, objects and events, both in and out of the classroom. The in-class place is seen as one in which teachers teach and the curriculum is made. The out-of-class place (which is the focus of this study) is one that is filled with visions of what is 'right' in terms of the students' education. As such it is a place that develops certain expectations about actions and behaviours that will fulfil those visions of what is educationally 'right'. Within this out-of-class place teachers learn to live and tell stories that fit with the expectations of the place (Clandinin and Connelly, 1995). This description of the landscape echoes one of Siskin's aspects of departments, as a "knowledge category it influences the decisions and shapes the actions of those who inhabit it" (1994, p. 5). Thus, between these authors, there is a recognition that the department both shapes, and is shaped by, its membership. This recognition highlights a deep connection between the definition of the department and the importance of the department in the context in which it operates. That connection is the notion that the department operates in the 'professional knowledge landscape', and as such the 
department is in relationship with the people, places, and objects in that landscape. It is in the relationships that exist amongst people, places and objects that define the landscape as both an intellectual and moral landscape. This definition of the professional knowledge landscape, as both moral and intellectual, provides a very strong link to the concept of teacher professionalism that is described by Sockett (1993).

The importance of social interactions in defining the department does not, however, mean that all members share in these interactions to the same extent. Siskin (1994) has classified departments using the dichotomy of inclusivity and commitment to the purposes of the department. Using these classifiers, four types of departments can be described: bonded, bundled, fragmented and split. Bonded departments have a high degree of commitment toward departmental goals. Bundled departments are characterised by high inclusion, but low commitment. Fragmented departments are those that are low in both commitment and inclusion. Split departments have a strong commitment to goals, but their members are divided into factions.

One indicator of department type is the amount of task delegation that occurs. This indicator is to be found in departments in which heads of departments trust their colleagues and undertake the "lead on behalf of the whole department" (Harris et al. 1997 , p. 151). Another indicator of the level of collegiality, and thus the type of department, is to be found in the personal style of the departmental head. All of the departmental heads observed by Harris et al. (1997) exhibited a mode of practice in their teaching that could be regarded as an example for other members of the department to follow. This mode of practice, described as being a "leading professional" included an enthusiasm for the subject and a concern for students' learning, as well as a willingness to "safeguard their colleagues from inappropriate developments and unnecessary additional work by carefully scrutinising the latest developments" (Harris et al. 1997, p. 151). Of equal importance, all of the departmental heads were described as very skilled in managing interpersonal relationships, a skill that engendered a trust and confidence in their leadership and decision-making. Inexperience, a lack of ability or a lack of time in managing 
relationships, can also contribute to tensions within the social relationships within a department, as shown by the tensions between the teacher and the head of department in a study by Wildy and Wallace (2004).

Given the inherent importance of social interactions in the department, and the importance of the subject itself in influencing how teachers "construct their norms of community, their standards of practice-their professional identity and behaviour" (Siskin, 1994, p. 154), it is important to consider the relationship between academic departments and the whole school. The reasoning behind this statement is that departments, as administrative units within schools, have "considerable discretion over the micro-political decisions affecting what and how teachers teach (Siskin, 1994 , p. 5). As such, they have the capacity to add, or detract, from the quality of teaching and learning offered by a school. It is this aspect of the department that will be examined next.

\subsubsection{The department as an administrative unit}

Departments have boundaries that are, to a large extent, shaped by the nature of the subject itself and the sense of purpose that is engendered in the teachers of that subject. These boundaries are reinforced by the department's pre-eminent position as the site of most teachers' social interactions, interactions that allow teachers to "teach each other the practice of teaching" (Little, 1982, p. 331). Organisationally, however, departments are also the administrative units into which secondary schools are divided. Although there has been relatively little work done on the effectiveness of the department as an organisational component of the whole school, the department appears to occupy one crucial organisational position of power within the school (Harris et al. 1997, p. 148). This is the political role that departments play in "affecting what and how teachers teach" (Siskin, 1994, p. 5).

Departments are the engine room of secondary schools, "in most schools ... what went within subject departments was central" (Gray et al., 1999, p. 122). But "just as the powerful subcultures of subject departments can oppose curriculum reform efforts, so they can operate to impede efforts to reform leadership within schools" 
(Wildy \& Wallace, 2004, p. 110). Thus, subject departments in schools have political power that can be exercised in either a positive, or negative, manner. This raises the question: What gives departments this political power?

Blenkin, Edwards and Kelly (1997, p. 222), in their discussion of the micropolitics of schools, describe the politics of schools as being concerned with the "control of territory, the distribution of resources, the acquisition of status, and participation in the decision-making process". Subject departments, viewed from the micropolitical perspective tend to confer on their members "a sense of common identity in relation to space, epistemology and pedagogy" (Blenkin et al. 1997, p. 222). The result of this is that subject departments are "seen as a most significant organisational and political division within the secondary school" (Blenkin et al. 1997, p. 222). It must be stated, however, that subject departments are not discrete units in terms of their membership, and that subject departments are the only units of a school to which teachers can belong.

If subject departments are described from the perspective of being a community, they derive their political power from the nature of the work that their members undertake. As community members share amongst themselves "occupational practices, values, vocabularies and identities", there is also the supposition that only members of the community are in possession of the "proper skills, knowledge and orientations necessary to make decisions as to how the work is to be performed and evaluated" (Van Maanen \& Barley, 1984, p. 308). Ingvarson (2002, p. 8) stresses the importance of teacher training that incorporates pedagogy in the "context of teaching and learning specific content knowledge". To teach science proficiently, therefore, it is necessary to be trained in both pedagogy and the discipline of science.

The degree of self-control that an occupation has is a distinguishing feature of a community. Apart from some professions, such as medicine and law, most occupational communities operate within an organisation. At a superficial level, this would appear to reduce the opportunity for the community to maintain some sort of occupational self-control. However, communities are capable of operating within the hierarchical structure of an organisation, thus meeting the criteria of self-control, whilst also serving the organisation's goals (Van Maanen \& Barley, 1984). If this dual 
role of the department, as a community and as an administrative unit, is the source of the department's political power, how does the department exercise this power? The answer lies in the notion that, while membership of the department provides a place for social interactions, support and a teacher's identity, the department, as "a formally sanctioned administrative unit, has the authority to command and dispense far more tangible rewards and sanctions" (Siskin, 1994, p. 114). These tangibles, within the department, can include class allocations, resource allocations, and course offerings.

In their study of effective departments, Harris et al. (1997) outline two important features that allowed departments to play a role in shaping what, and how, teachers teach. The first feature of effective departments was the possession of detailed schemes of work. These schemes generally contained the following features:

They were consistent with the general vision of the subject within the department; they were very detailed with clear guidance; they were regarded as important documents; and they were easily accessible in the department; and they had been agreed by all the department after a discussion (p. 152).

In addition to this level of organisation, there was a commitment to the management of resources in such a way as to promote teaching and learning opportunities for all students.

Second, each department was capable of producing a record of any individual student's progress in the subject, complete with "detailed assessments of their strengths and weaknesses" (Harris et al. 1997, p. 152). These records, and their monitoring, identify potential student underachievement, and were found to be well entrenched. These records also assisted the departments in assessing their own progress. One powerful advantage of the use of student records, together with the detailed schemes of work, would be to allow for one of Hawley and Valli's (1999) principles of effective professional learning. Professional development should be based on differences between actual student performance, and the goals and standards for student learning (Hawley \& Valli, 1999). These records were also of use to the senior management team in accounting to track the effectiveness of the department. Heads of department did not view this use of records as a threat; rather, they saw the inherent accountability in the record use as "a necessary and justifiable route to further departmental improvement" (Harris et al. 1997, p. 150). 
It was noted in section 4.4 of this chapter that the subject itself plays a crucial role in determining the boundaries that divide secondary schools. Importantly, the subject also has a crucial role in, amongst other influences, the decisions and actions of departmental members. It is this final characteristic of academic departments to which I now turn.

\subsubsection{The department as a reference group}

A defining feature of occupational communities is the "reference group", the means by which members "take other members as their primary reference group such that the membership comes to share a distinct pattern of values, beliefs, norms and interpretations for judging the appropriateness of one another's actions and reactions" ((Van Maanen and Barley, 1984, p. 303). This common set of values includes the moral standards for, what can be described as, the genuine work of the community, as well as the rules that govern conduct, and the language that delineates the world (p. 303). The value system that develops around the reference group is a powerful influence in the development of the individual's social identity, which is the last of Van Maanen and Barley's defining characteristics of the community. This value system gives members a "collective perspective in everyday matters" (p. 303) and permits self-evaluation not just within their work, but also away from their work.

The social identity that members of communities draw from their work is contextually derived, and is not easily shed, for it is "central to the individual's self-image" (Van Maanen \& Barley, 1984, pp. 298-299). For secondary teachers, this social identity is not centred on the fact that they teach, the social identity is centred on "what they teach [as] subjects are an important aspect of who they are" Siskin (1994, pp. 155156). Gulledge (1998, p. 3) refers to the members of a group feeling that "indeed we 'belonged' together because we all worked in the same content area discipline". Identification with a particular occupationally derived social identity can take the form of the jargon or language which establishes the codes that members of an occupational community are socialised into. Identification can also come from dress, as in the case where a science teacher is identified in a group photo as the "one ... with a pair of safety goggles dangling around her neck" (Gulledge, 1998, p. 4). Within 
subject departments, there appears to be subject specific codes that define the membership of the department, as Siskin (1994, p. 152) describes "the disciplines [of] language and epistemology are interwoven in the ways teachers-as subject matter specialists-conceptualise the world, their roles within it, and the nature of knowledge, teaching and learning".

Subject specific codes, developed by subject specialists, reinforce the boundaries that exist within secondary schools. It would also be entirely reasonable to expect that those not trained in the subject discipline would have difficulty gaining acceptance within the community (Van Maanen \& Barley, 1984). Such failure to gain acceptance within a department that is operating as an occupational community has implications for the professional learning of the individual concerned. The reason for this is that an individual, outside the full social and micro-political boundaries of a department, is unlikely to develop the important interpersonal relationships with existing members of the department that are seen as the precursors that "allow professional relationships to proceed" (Siskin, 1994, p. 169).

Having established an understanding of what constitutes a department, and the significance of the department in teachers' relationships and social identity; it is now my intention to examine the import of the department in the professional learning of teachers.

\subsection{THE IMPORTANCE OF THE DEPARTMENT FOR PROFESSIONAL LEARNING}

Within the literature on teacher professional learning, it is frequently the case that the whole school is the appropriate level of organisation at which professional learning programs should be developed and implemented (Harris et al. 1997; Gray et al., 1999). It is the purpose of this section to examine the importance of the department as a context for teacher professional learning, within the larger context of the whole school. 


\subsubsection{School and department}

There is little doubt within the literature on school management and leadership that the style of school level management and leadership are pivotal to the perception of a school's effectiveness in achieving its expectations (Huffman et al. 2001; Gray et al., 1999; Harris et al. 1997). This relationship questions the nature of the impact of whole school management policies on departmental effectiveness. Both Gray et al., (1999) and Harris et al. (1997) believe that there are three areas in which whole school policy could been seen to improve the work of departments: mission and ethos; student achievement; and management. Departments that were operating successfully within effective schools did "not feel that they were operating in structures and cultures that were particularly supportive of their specialist endeavours" (Harris et al. 1997, p. 150). The reason for this feeling is, I believe, is found by using the notion of the department as a community, as discussed in the previous section.

Given this observed relationship between the whole school level of organisation and the department, it is not surprising to find that most school managements tend to lack explicit strategies for changing the operations of departments. Gray et al. (1999) found that strategies for departmental improvement in the studied schools included: the appointment of a new head of department; the assumption that school-wide initiatives will bring about departmental improvement; the dissemination of the practice of 'well running' departments to others; and the development of departments that are 'ticking over' with the help of external support.

These strategies tend to be modestly used in schools, with the majority of senior management in schools assuming that departmental members would eventually adopt school-level initiatives. Where strategies for departments were implemented, they tended to focus on senior managers either taking personal responsibility for an ineffective department and leading it forward or "pinning their hopes for change on key personnel" (Gray et al., 1999, p. 121). As a result of such overly optimistic assumptions, many senior managers "retained rather pessimistic views about what it was possible and appropriate to do at departmental level" (Gray et al., 1999, p. 121). 


\subsubsection{The department as the context for professional learning}

As I noted in the conclusion to chapter 3, it is the importance of different groups of individuals, possessing different perceptions of the work of their group that shapes the professional learning of teachers. These groups of individuals are referred to as "activity systems" by McCullough et al. (2000, p. 91) and now, given the definition developed in the previous section of this chapter, referred to as departments in my research. It is the impact of change on departments that produces, within teachers, "new conceptions of their activities" (Blackler, 1993, p. 875). It is through the impact of changes in departments that teachers' professional learning occurs, rather than changes at the whole school level.

This conceptualisation of the subject department as being the primary context for teacher professional learning relies on two premises. These are the importance of the subject department as the primary site for the development of both relationships and teachers' social identity as a teacher of their subject. McCullough et al. (2000) also develop the vital role of the subject department in teacher professional learning. In their discussion on activity systems, they base their argument on four strands:

Professional learning is situated, specific and practical in character;

Most professional learning takes place in the normal workings of activity systems, such as departments;

The main form of professional learning is not through courses and conferences, although they have their place: and,

The improvement of professional learning is contingent upon the improvement of activity systems (pp. 90-91).

Huffman et al. (2001) support the notion that teacher professional learning is context specific. In their study, teachers placed great value on professional learning that was "job-embedded" (Huffman et al. 2001, pp. 457-8). Such learning was based on corporately identified and executed professional learning that was in accordance with the school's vision. The achievement of such a climate within a school also depends on the willingness of, and opportunity for, teacher leadership. Teacher leadership in schools, as discussed in chapter 3 , is reflected in the extent to which teacher expertise is acknowledged and productively deployed to solve problems. 
The ways in which teachers in subject departments can demonstrate leadership and collaborative learning that improve student learning outcomes are discussed by Harris et al. (1997). Subject departments that are considered effective develop strategies in five areas that focus the work of the teachers in the department on teaching and learning. These five areas are; the provision of structure and feedback to student learning; the correct matching of a student with the most appropriate syllabus for their ability; assessment of students; the development of productive classroom routines; and the encouragement of a teacher's individual teaching styles within the of the department. Professional learning within such a department is "contexted and necessarily specific, concerned with particular practices and possibilities" (McCullough et al. 2000, p. 91). A concern about possibilities resonates with the belief that learning organisations, through their efforts, work to expand their ability to produce the results that they want.

\subsection{CONCLUSION}

In this chapter, I have developed the work of Wenger (1998), Siskin (1994) and Van Maanen and Barley (1984) into an understanding of the school-based community of science teachers, the focus of this research. This understanding of the school-based community has produced, for me, three powerful metaphors of understanding that will shape my thesis: meanings, practice and identity. The first metaphor sees the community as the site of teachers' meanings. Practice clearly resonates throughout the literature that has been reviewed. The third metaphor sees the department as being defined by, as well as defining, the identity of its members.

Meanings serve as one of the foundations of education. They are developed when teachers discuss with each other the issues of subject matter, pedagogy and the moral values and imperatives that are important to them in the context of their work. Meanings are the basis for the episteme, techne and phronesis of the teaching.

The second metaphor of practice is heavily influenced by the nature of the subject. Members of a community who are trained in a particular occupation set the standards of acceptable practice for each other, and act as a reference group to which concerns, 
or innovations, can be expressed for consideration. Further, the common training gives members of the community a common vision of what they consider to be important in their occupation, and how they should go about their work. In the specific case of the teacher, this includes both content and pedagogical knowledge.

The third metaphor for the department is that teachers identify themselves as teachers of their subject. For science teachers, their training in the sciences gives them a sense of purpose as to what is important in their subject content, how it should be taught, and why it should be taught. The discipline of science is important to teachers of science, as it provides direction and values to guide both their teaching, and their lives. This social identity as science teachers is a powerful determinant of their view of the world, and their place in it.

Taken together with the concept of teacher professional learning as teachers' practice within the framework of episteme, techne and phronesis, the three metaphors of understanding provide two powerful theoretical frameworks for my research. By including the idea that teacher professional learning occurs when teachers engage in virtues-based private reflection and/or public discourse, I believe that I have justified the tools needed to undertake the narrative analysis to develop the raw data into the Vignettes. 


\section{EPILOGUE - REVIEWS OF THE LITERATURE}

The chapters on teacher professionalism and professional learning provide me with an understanding that teacher professionalism can be described in terms of improving the quality of practice of teachers, within the framework of episteme, techne and phronesis. This understanding, based on the reviewed literature, can be conceived of, principally, as a moral question. While teachers must understand the episteme and techne aspects of teaching, these aspects by themselves, or in concert, are insufficient to describe the real essence of teaching. What is needed is an understanding of the phronesis of teaching, an understanding of the importance of moral relationships in teaching. Teaching is a moral activity, as it deals with people, and as such the moral foundations of practice also need to be examined. Teacher professional learning, therefore, is concerned with how teachers learn the episteme, techne and phronesis of their work and improve the quality of that work. Teachers learn the episteme, techne and phronesis of their work through the telling of stories "to live by" (Connelly \& Clandinin, 1999, p. 4), stories that link their knowledge, context and identity. Episteme, techne and phronesis provide one strong theoretical framework around which to discuss teacher professional learning.

The chapter on the subject department provides a second theoretical framework for my research. The second framework involves an understanding of the notion of community. This understanding of the school-based community has produced three powerful metaphors of understanding that will shape my thesis: meanings, practice and identity. Meanings serve as one of the foundations of education. They are developed when teachers discuss with each other the issues of subject matter, pedagogy and the moral values and imperatives that are important to them in the context of their work. Meanings are the basis for the episteme, techne and phronesis of the teaching.

Practice is heavily influenced by the meanings and identities that science teachers develop from their work. The subject shapes their identity and the meanings that they develop in their working lives. The third metaphor of understanding for the 
department is that teachers identify as being teachers of their subject. For science teachers, their training in the sciences gives them a sense of purpose as to what is important in their subject content, what is important in how that content should be taught should be taught, and why it is important that it should be taught. The discipline of science is important to teachers of science, as it provides direction and values to guide both their teaching, and their lives. This social identity as teachers of science is a powerful determinant as to how they view the world and their place in it. Meanings, practice and identity provide a strong theoretical framework around which to understand community.

For my research, virtues provide the connection between the two frameworks of professional learning and community. Virtues can describe the episteme, techne and phronesis of teaching, as well as being foundational to the meanings, practice and identity of the community. Virtues are the glue that binds together the two theoretical frameworks of my research.

In this brief epilogue, I have summarised the two frameworks that will guide the development of my thesis. My initial analysis of the data is based on the narrative analysis strategy described by Polkinghorne (1995). Under this strategy, the events and actions described within the audiotaped data are synthesised into a series of Vignettes. These Vignettes are constructed around the metaphors of understanding that have been developed from the literature: meanings, practice and identity. Having been produced using the narrative analysis strategy, the Vignettes will be interpreted using the framework of episteme, techne and phronesis of narrative and the language of virtues. 


\section{CHAPTER 5 - MEANINGS}

\subsection{VIGNETTE 1}

This Vignette relates to the negotiation of the boundaries of the science department as a community. It does this by describing the attempted development of a school-based science policy, and through the meaning that teachers give to this conversation. The Vignette is composed from the transcripts of the departmental meetings held in March and April of 2002.

\section{'WE TEACH MATHS, THAT'S OUR POLICY'}

The development of a school science policy

Another day of teaching over, and the science teachers had gathered together for the first of their scheduled departmental meetings for the year. This meeting was the first that Rob was to chair, having been appointed as Head of Department at the end of 2001. What was his view of where the department should go under his leadership? What would be the dynamics within the department, given that Jenny and Maddie had also served as previous Heads of Department? How would the department maintain the academic standards for which it was so highly regarded, both within the school, and in the wider community? All these questions awaited the new Head of Department and the teachers in the department.

It was also the first formal meeting that Stuart was attending since accepting a position at the school. Having taught secondary science for 13 years, and also knowing several of the teachers personally, he had slotted into the department easily, and had already been introduced to all the members of the department.

"Come on, get on with it, a good meeting is a short meeting" said Jack, preferring action to reflection. Over the obligatory cups of coffee, the meeting started at $3.15 \mathrm{pm}$ with the usual agenda items. The first item on the agenda was a report from the school-level faculty heads meeting regarding the cleanliness and security of the science labs. Following convention, the next few agenda items considered the 
constant stream of competitions, activities and product brochures that come before most science departments. This stream was regarded as more of a nuisance than a help to the progress of the meeting.

Zoe spoke from her experience as the Head of Mathematics. "Bit of a paper warfare, isn't it?"

Rob was exasperated. "Yeah, oh gees; this activity, do we want to be involved?"

Maddie, who had been the Acting Head of Department in 2001, gave an answer, "We were the year before."

Jenny, who regularly and actively involved students in competitions and research activities, gave her assessment of the activity. "It's very good, but it is very time consuming."

To save meeting time it was decided to place all of the correspondence regarding competitions, activities and products in an envelope that teachers could look at in their own time.

Coming in at number four on the agenda was, according to Rob, the most important item. This was the development of a school-based science department policy. Rob and Stuart had recently attended a meeting organised as part of the Federal Government funded Quality Teacher Program, and Rob, as Head of Department, believed that the development of a policy would be beneficial for the science department.

"That's why I've been asking about the science policy here at school, because obviously, if we are looking at revamping our science program, which we are sort of doing, from my point of view I'd like to know what the policy states, so we know what our aims of the science program are, so that we can design our science program 
to fulfil those aims and objectives of our policy. I can't seem to lay my hands on the policy. Is there one?"

"Have you got a maths policy?" Maddie asked Zoe.

Zoe's response was lucid, and in a tone of voice that indicated that a written policy was superfluous to good teaching. "We teach maths, that's our policy."

Rob ignored this and continued explaining his rationale for developing a policy, "Do we want to have a policy so that we've got overall aims and objectives for the science department that say why we teach science here? The Principal Curriculum Officer for Science says all schools should have a policy, that we must enthuse kids in science and that we must get them interested. The science policy should, I suppose, reflect the community as well. For example, Marine Biology at Channel District High and West Coast High concentrate on mining and the environment. Do we need to look at writing a science policy so that we can design our program to fit the policy, or do we design our program and not worry about the policy?"

It was here that Maddie moved the discussion along in her usual business like manner. "If we are going to redesign our program we should have a policy, so why don't you, or Stuart, or someone get a couple of examples and put something together, and we have a look at it next meeting. It's entirely up to you if you want to do one. How's that?"

"That's what I was thinking," answered Rob.

At this point, Stuart sought to allay Zoe's concerns about producing a meaningless document based on educational jargon, the sort of document that every one can agree with due to the vagaries of the wording.

"From what we saw at the meeting, we don't need to go overboard with it - a page or so to basically say what we believe is important in science education, and these are 
the ways that we are going about making sure that we meet these values. That's basically all it is, we don't want to get carried away with jargon, do we Zoe?"

Seeking to draw the discussion to a close, Rob agreed to gather together the examples of other schools' policies and a draft statement of values. "We'll try and get that done for the next meeting, so we can look at that."

The meeting continued on with a discussion of the state government review of the science curriculum. By $4.15 \mathrm{pm}$, the teachers had had enough, Rob asked, "Anything else?" No one had anything else to add. "Okay, that went too long," said Rob, as the meeting closed.

By late April, the time of the next departmental meeting, the school year was well and truly up and running. The school administration was requesting dates for excursions in all subjects, so that the calendar of events could be filled in. Money needed to be collected by the science teachers from the 353 students who had entered the Australian Science Competition. Planning was underway for the science teachers' participation in the Conference of the Australian Science Teacher's Association in Hobart. The first of the year's progress reports for Years 7 to 10 would also need to be completed in the near future.

For the second meeting, Stuart had put together a series of guidelines as to what he saw a draft policy should contain (Appendix 1). This document formed the basis of the discussion about the proposed policy.

Recapping the previous meeting, a science policy would, according to Rob, "Be a good tool so that we could have a focus on how to make changes, and what our units of work should be focussing on. What we would like to have done would be to get some ideas from you guys about what we should include in each of these sections, so that we can go away and write something up." Referring to the guidelines, he asked, "Did anyone have a look at that?" 
"What sorts of things are you looking for?" asked Dennis, who almost exclusively teaches Year 7 science, with one middle syllabus Year 9 class.

"Well" said Rob, "the first point says that the policy needs to clearly articulate what we consider to be important in the teaching and learning of science. So to us, what is important? For example, how do we take the Department of Education, Science and Technology statement about scientific literacy? Their aim is to make students science literate. That means being able to read something in the paper, something scientific in the paper, some sort of scientific study or some sort of scientific argument; be able to understand the terms that are in that article; and be able to formulate some sort of opinion, because they have some background themselves. Or is our aim in science to teach them enough stuff to get them through Year 11 and 12 science, or is it to give them skills to design and develop experiments, and, you know, what is our aim?"

Maddie's reaction to the notion of scientific literacy was supportive. "I like your first point, I think that we should be educating people to be able to make informed decisions based on what they see on television or read in the paper, and to see that to every story there are two sides to it, and to be able to critically make a decision."

"So if that is one area that we consider important, well then, do we need to start designing our science program so it is one of the outcomes?" asked Rob latching onto this support.

"We already have it don't we?" asked Maddie, who was also the school's Director of Studies, "A fairly good focus on science in everyday life."

Dennis, given the range of classes that he taught, wasn't so sure. "I'd say that in the middle syllabuses it is, in the top syllabus, I don't know."

Rob answered Dennis' uncertainty. "The Year 10 science that I teach in top syllabus is really focussed on knowledge and theory, because they are the students who are going to go onto Year 11 and 12." 
Maddie continued, "And if we want them to go on with science in 11 and 12, we need to give them enough background in science, we need to see what the syllabuses say, but the main thing is that they need to be interested in it. If they are interested in the subject, provided that they have a certain level of ability, then they will be able to handle it in 11 and 12."

Dennis provided the link between the needs of the top syllabus students, those who were "going to go onto Year 11 and 12" and the middle syllabus students whom he teaches. "Well, I think that if we state something about them making informed decisions, based on some sort of understanding of the processes involved, then you can go from there ... if you put the word processes in there, then there is the scientific method for your top syllabus. I suppose that if we are doing a process then students do some sort of experiment and they are testing a hypothesis, then we can do as we have always done and relate the data to the hypothesis, and in that way get them to think critically, just based on the data that they have got. But then we need fairly simple experiments for some of them."

With this connection between scientific literacy and the academic needs of years 11 and 12 apparently made, Rob continued, "What about these other points down here? The policy should give practical guidance to teachers of science as to what is expected of them, and what they can expect of the science faculty, in their teaching of science. Is there anything in there that we need to include?"

Putting this point in the context of the individual, Stuart added, "In many ways it is actually going to vary with the individual, like someone who is fresh out of uni is going to be different to someone who has been around for a while." As there were no suggestions as to possible ways in which the proposed policy could address the expectations of teachers, Rob continued onto what was to become the final point of discussion for the afternoon, "How assessment is to be conducted and reported, I suppose that is straight forward." 
From this point, the conversation drifted towards the topic of criterion-based assessment, never to return to the development of the policy. In a fleeting return to prominence, the science policy was mentioned in a later discussion about the Years 7 and 8 program, and Rob produced a draft policy for the June meeting. It was not discussed at that meeting, and still exists today in draft form only (See Appendix 2). 


\subsection{VIGNETTE 2}

This Vignette regards the delineation of this science department's boundary from other communities that are also engaged in science education. It does this through describing the relationship between the school-based department and the state's Department of Education and Secondary Assessment Board, which is mandated to accredit syllabus documents in all subject areas. The Vignette is composed from the transcripts of the departmental meetings held in June 2002 and February 2003.

\section{'THEY ARE WALLIES, ABSOLUTE WALLIES'}

\section{Boundaries and brokering}

In late 2001 the state government's Secondary Assessment Board called for expressions of interest from serving classroom teachers to work on committees that were to produce new science curricula in both general science (Years 7 to 10) and in the senior secondary sciences (Years 11 and 12). Zoe and Stuart, both of whom already served as Subject Moderators for the Secondary Assessment Board, were accepted onto the committees for 2002. Zoe was to help develop the Life Science and pretertiary Biology curriculum, and Stuart was to help develop the General Science syllabus. Another member of the department, Maddie, continued to be closely involved with the examination process for the pretertiary Physical Science curriculum. This level of involvement with the Secondary Assessment Board is one indication of both the depth and calibre of the science teachers in this department.

The third item on the agenda for the June 2002 department meeting was information from the Secondary Assessment Board regarding the development of the new science syllabuses. The proposed date for the introduction of the syllabi was set for 2004. A student's progress against a syllabus was to be measured against a series of Levels. The achievement requirements for Level 1 were minimal, while Level 8 was designed as a pretertiary level. Zoe was involved in the development of two syllabi in the biological sciences. The first was the Level 4 to 7 Life Sciences, and the other was the 
Level 7 and 8 pretertiary Biology. Stuart was involved in the Level 1 to 6 General Science syllabuses

Stuart informed the other teachers of the progress of the syllabus-writing group that he was involved with.

"This is the content that we think is essential to get the top award at Level 6 . In chemistry, people would need to have an understanding of the language of chemistry, the structure of the subject, and also the basic ideas. In physics, the main things there were motion and energy changes. With rates of change, we were especially interested in the maths, the simple maths such as changing equations around. We were going to talk to the maths people as well, so that in maths they can look at science equations, and so develop those cross-subject links. In biology, the three areas that we are looking at so far are diversity and the function of living things, cell biology, and processes including respiration and photosynthesis, as well as ecosystems. To get to Level 6 you would need to have those basic things. Up to and including Level 4, what we are looking at is students having a good understanding of scientific literacy, which we came across at the last meeting here. That would include an understanding of the terminology and language of science, because it is a very precise language, as well as a large number of the basics, your scientific method, and methodologies and also your general knowledge of the science that they see around them, or don't see around them. So that is where we are at the moment. At the next meeting, we are going to flesh out some of these a bit more."

As well as producing the syllabus document, Stuart also outlined a wider objective of the syllabus writers, all of whom are experienced science teachers. The new syllabus, Stuart said, would also assist science teachers across the state to:

"Strengthen the position of science in schools. A lot of schools are having science as an option for Years 9 and 10. Or they are having it as a short course for six months. To get to Level 6 , there is no way that you could do these things if you just had a short course. The plan is that, if parents see that science is important, the direction that Dr. Nelson (the Federal Education Minister) is also pushing from, then there is 
going to be a large push on making sure that science gets covered in the school curriculum."

After a brief discussion regarding a comparison of the new Levels with the current biological sciences syllabi, Zoe outlined the progress of the syllabus-writing groups that she was involved with.

"I'm on the Life Sciences Level 4 to 7 and Biology Level 7 to 8,8 being the pretertiary, and we spent a lot of time trying to delineate what would go in our subjects. We also needed to decide on what would go into the new subjects of Environmental Science and the Science of Natural Resources. We had to have a clear dividing line as to the content in each subject. It was one of those areas that we intrinsically knew what it was, but you have simply got to get it straight in your head and make it obvious for other people. I don't see senior Biology, Level 7 and 8 being dramatically different from what we currently do, because it is a syllabus that a lot of teachers are really happy with the way that it is, and we seem to have a fairly consistent number of kids doing it. So it is not as if we are losing kids because the syllabus is inappropriate. It is then a case of coming up with Life Sciences Level 4 to 7 , and it is actually quite hard because we can't develop too much of that until these guys get their Level 1 to 6 stuff done. So I can't tell you much about ours yet. We've had one meeting and another one next Sunday, and we will go from there. The ultimate plan for the Science of Natural Resources, if they can get together, is to put things like aquaculture, agricultural science and geology together so it would be like a framework syllabus that people could do it from the point of view of a local industry that worked for them. I'm not on that writing committee, thank goodness, because it is a bit of a nightmare, but I think that they have made some progress. I don't know if there is any chance of us being interested in that, Maddie. Maybe for some Year 11 's, you know the sort of project science that Jack has been doing, that is probably where some of those students might fit."

The work that Zoe and Stuart were involved in continued until February 2003, much of it in their own time. The work involved various meetings at both ends of the state, and keeping in contact with their fellow science teachers in other schools. The Secondary Assessment Board did not pay for their extra hours of work. The progress 
that had been achieved, however, was all brought to a sudden and, for the people involved, discouraging halt.

In early February 2003, before the students returned for the new school year, the department gathered for its first meeting of the year. Most of the department had been at an earlier mathematics meeting, where Stuart had been informed by Zoe that the entire science syllabus writing process had been "pigeon-holed somewhere" within the Secondary Assessment Board. He was still angry at the later science meeting. His colleagues were incredulous.

"So what is going on with the science syllabus writing, Stuart?" asked Rob as a way of informing those teachers who had not been at the mathematics meeting.

The response was measured, although he was obviously discouraged. "I've just been told this morning that the science syllabus writing has been pigeon-holed somewhere. I haven't been told officially and I'm on it."

Jack's comment was direct. "Sensational, Jesus, science have got their act together haven't they. Wonderful!"

"So, what do we think of the Secondary Assessment Board, Jack?" asked Stuart.

"They are wallies, absolute wallies, incompetent morons. The reason that they are at the Secondary Assessment Board is that they can't teach."

Zoe also expressed her feelings about the decision. "It is enormously frustrating for us. Endless days working on a Life Science syllabus that doesn't look like it is going to exist anymore, despite everything that we have done. Although the Education Department's Science Curriculum Officer did say that the work was not wasted, because people will dip into the proposed syllabus for getting their Essential Learnings right."

Essential Learnings is the name given to the new Education Department curriculum framework that was in the process of being introduced in 2002 and 2003 . The 
Essential Learnings and their foundational Values and Purposes are shown in Appendix 3.

Stuart was dismissive of this suggestion. "Who listens to Curriculum Officers anyway?"

Jack was unrepentant. "Stuart, what I said earlier on the tape still stands, okay."

At this point Zoe attempted to point out that the Secondary Assessment Board might not be entirely at fault in the shelving of the science syllabus writing. "The Assessment Board isn't driving the agenda anymore, it is all this Essential Learning stuff coming from the Minister, and whoever advises the Minister."

"They must be an ex-teacher who can't teach, that's why they are there with the Minister," fired Jack from across the table.

Zoe continued, despite Jack's anger, "They have decided that the Essential Learnings are the only thing that they want in schools up to grade 10 , by 2005.

Stuart's anger had turned to sarcasm. "That's very interesting because the bloke who actually set up the New Basics in Queensland, which is similar to the Essential Learnings, it's almost exactly the same, he did a review of the New Basics in Queensland and came up with the brilliant conclusion that they made a serious mistake by chopping out disciplines, like science and maths."

"And he developed it" stated Jack rhetorically.

"He developed it Jack, you ask the TCE Coordinator about it." The school's Tasmanian Certificate of Education (TCE) Coordinator has the role of disseminating information to and from the Secondary Assessment Board.

"Geez, have we got something to look forward to." 


\subsection{VIGNETTE 3}

This Vignette relates to the department's consideration of the school's mandates for teacher professional learning. The school is itself caught in transition between its own practices and the requirements of the Tasmanian Teacher Registration Board, established by Parliament in 2000. The Vignette is composed from transcripts of the departmental meetings held in November 2002 and February and July of 2003.

\section{'SO DOES INFORMAL LEARNING COUNT?'}

\section{School -based professional learning}

In 2000, the school adopted a professional development policy that was supposed to encourage teachers to undertake 20 hours of professional development a year. Up to eight of these hours could be undertaken in school time, by for example, attending a school-based meeting that involved a presentation by a visiting expert. The remaining 12 hours were to be made up in the individual teacher's own time. Accountability was fairly loose, with teachers to submit a list of their professional development activities to the Principal in December of each year. The trade-off for undertaking the 12 out-of-school hours of professional development was to finish the school year two days earlier than those who had not fulfilled the requirement. Towards the end of the year, teachers would start looking at what they could include on their list.

It was November 2002, and teachers were beginning to count up their out-of-hours professional development. "We have to do 20 hours all up, but we have done some stuff at school that brings that down to 12 hours" said Rob, opening the discussion about what the teachers could include for professional development. "For example, the maths department started some curriculum work in the last two periods of a few days, and then stayed on until five or six o'clock. Those couple of hours after three o'clock will count onto your out-of-hours PD."

"Sounds good" said Dennis as he added a few extra hours to his list. 
Jill, being part time, had not been to all of the department's meetings. She was not certain as to what actually counted, and what did not count. "Is there anything that we've done at school that will count towards, you know how we've stayed on a bit later, is there anything else?"

Rob started to reply, "No, the stuff that we've done at school ..." Jenny finished the sentence, "Is within hours." Therefore, whatever "the stuff" was, it did not count as professional development.

From the start there were no guidelines as to what actually constituted professional development. Many teachers felt that it was simply easier to just turn up for the two days at the end of the year, and socialise with their colleagues, as no formal program was organised for these days. Several teachers used the two days in 2002 to finish off their own woodwork projects in the school's Materials, Design and Technology workshops. The school's workshops were better equipped than their own home workshops. Widely regarded as a 'non-policy' the policy was quietly dropped at the end of 2002. It was not mourned.

Under the Tasmanian Teachers Registration Act (2000) schools in Tasmania can only employ teachers who are either fully or provisionally registered with the Tasmanian Teachers Registration Board. Starting in 2002, there were suggestions from the Board that continued teacher registration would depend on teachers providing evidence to the Board of ongoing professional development. This external change, combined with the dropping of the school's policy at the end of 2002 and the appointment of a new Principal in 2003, caused a shift in thinking about professional development, or to use the new jargon, 'professional learning'. Once again, it was never articulated at the school-level just what the new term 'professional learning' actually meant.

Despite this lack of meaning, professional learning was to be the focus of departmental meetings. Rob made this clear at the science department's February 2003 meeting.

"Our department meetings, our science ones, are to be more along the lines of professional learning, rather than information dissemination. As Department Head, I 
have to disseminate information through notes in pigeon-holes, rather than waste time in our meetings going through stuff. The Principal is going to speak to the whole staff, there's an expectation that the meetings will be from 3.15 to 4.15 minimum, and during that time we do some professional learning, and that may be logged onto our little sheets to satisfy teacher registration. That might mean that we take turns in presenting something. You only need to talk about something that you might do in class, an experiment that you might do."

Stuart had experience in this form of departmental meeting from his previous school. "We sort of did that sort of system a couple of years ago, where each person took a meeting, and one person who was new to science teaching brought in their Year 8 prac books, and then people went through and discussed: why did you give this person a $\mathrm{C}$ and this person a $\mathrm{B}$, which helped moderate things very nicely. One person did something on teaching about models, using models in science and some of the problems that you run across in using models. It doesn't need to be much, and if it is addressing problems that people have already mentioned, well, it helps everybody. Rather than passing around the latest stationery catalogue. Who wants to buy this Lego?"

"That's right, yeah, that would be PD" said Rob, agreeing with Stuart's description of how the meetings could function. Even if Rob had used the old jargon of PD, rather than the new jargon of professional learning.

There was still the question, however, of what professional learning actually was, and how it could be recorded in case it was needed for teacher registration. The lack of clarity, at both the school and Teacher Registration Board level, was a source of frustration for some teachers.

Rob added, "Another thing that I think is relevant is that any professional learning that we do in departmental meetings, we can get approved to go onto our ongoing PD file for teacher registration." It seemed that professional learning and professional development were synonymous. 
Jenny was confused as to what actually counted as professional learning. "It has never been perfectly clear what counts for that."

Rob tried, unsuccessfully, to explain the situation. "We put in what we have done to the Director of Staff and he okays it."

Zoe had experienced organisational difficulties with this system. "We don't get a response back when we put it in to tell us if it was okayed or not."

Rob was on the defensive. "No, we have to wait" was his response.

Jenny was not impressed by the vagueness of this answer. "Till when?"

Rob was becoming increasingly flustered by the direction of the conversation. "Until we do get a response, what do you mean you don't get a response?"

Jenny explained the reason for her frustration, "One does this, one gets a certificate to say that one has done this, one submits the certificate to the administration to say that one has done that, and one should get a response saying, yes we are accrediting you two hours, one hour, half an hour, whatever PD time. That hasn't happened; I've submitted things and had no response. I've done something at the library that has given me a professional development certificate for a set amount of time that I have done there. Now, I am not sure what that is worth to my registration, and if it is worth something, as Zoe has just said, shouldn't that be documented and then evidence of that documentation provided for us?"

Rob's instruction reflected little faith in both the Teachers Registration Board and the school's system. "If I was you, I would document it myself on my own CV, because the amount of PD that you have to do for re-registration, that hasn't been decided yet."

Zoe had heard that the Board would require evidence of ongoing professional learning in 2004. "This year you don't, but they reckon that next year you will have too." 
Jenny was clear as to what she felt the school's responsibility was. "Therefore, admin need a system whereby they can amass whatever we submit to them, but also respond back to us. Because if there is a benchmark, say you need 28 hours, or whatever, we need to know whether our work has been accepted or not in order to determine how much more we have to do in order to qualify."

Once again the importance of what was meant by professional learning had come to centre stage. "The essential nature of what you do is going to have to be spelt out too. Like, I'm on a syllabus-writing committee, which takes a fair bit of time, does that count?" This was a perfectly valid question for Zoe to ask.

Rob was not certain as to whose responsibility it was to define professional learning for teachers. "They haven't worked that out, the Registration Board, have they?"

Zoe shared Rob's uncertainty. "So that comes from the Registration Board, not the school's administrative system?" she asked.

Rob's response did not clear the uncertainty. "Well, who knows at the moment?" was all he could say.

At the request of the school's Board of Management, Stuart had looked into teachers' perceptions of the school as a workplace earlier in the year. He referred back to this work.

"The Registration Board doesn't know what they are doing. But in the survey that we did before the holidays, one of the areas that people were concerned about was developing their professional interest, which is what we are talking about here, what counts, what doesn't count, how do I go through making sure that it does get counted, and also when it occurs. Some of the best stuff occurs when you are talking to people over lunch. Like that conversation the other day about vectors, and making sure that the kids were doing the same style with their vector work. Does that count? It should."

Jenny was sceptical. "I would say probably not." 
Zoe had a reason for her scepticism. "I bet it won't. It's got to be formalised with evidence."

Rob promised to raise the issues involved at the next meeting of the Heads of Department that he went to. "I'll bring that up at the next Faculty Heads meeting."

Dissatisfied with this, Stuart asked Rob a direct question, "So does informal learning count?"

Rob's answer was to the point and somewhat surprising. "The Principal said last night, 10 minutes here and there is not going to count, even though she said that she recognises that it is probably more beneficial than the other stuff."

Zoe noted that such a statement was an attempt to put administrative structures around teachers' professional learning in order to facilitate management and accountability. "That is more for administrative reasons than for devaluing the informal learning." 


\section{CHAPTER 6 - DISCUSSION OF MEANINGS}

In the foregoing Vignettes, I have described three critical incidents. The first Vignette describes the attempt at developing a school-level science policy that would have acted as a reference point for future departmental decision making. The second Vignette describes the involvement of some of the teachers in state-wide science syllabus-writing parties, and their sense of betrayal at the cancellation of their work. The third Vignette describes the difficulties that the science teachers had in understanding, and adhering to, new professional learning accountability procedures being proposed by both the school and the Teachers Registration Board.

Looking out over these incidents, there is one key theme that emerges: the importance of the virtues that are displayed within the community. This section on meanings is composed of three Vignettes that are heavily redolent with the importance of virtues in the life of the community. Virtues underpin all of the relationships found in the community. Virtues provide the context for teacher leadership within the community, and they provide the foundations for the discourses, and actions, of the community and its members. Given their importance in the life of the community, it is appropriate to discuss the virtues in the context of the other two issues: teacher leadership and the importance of the subject. It must be remembered, however, that there are shades of many of these virtues in all of the situations discussed below. Virtues are not to be found as discrete units in the complex life of the community.

Teachers, like people everywhere, can have trust in both people and processes. Indeed, trust is fundamental to the running of an ordered society, and this community of teachers is no different. In these Vignettes, there are examples of trust in both individuals and processes, and the exasperating effects of realising that one's trust has been misplaced. In these Vignettes, there are also examples of trust both within, and without, the school-based community that is the focus of this study.

Trust is observed in the manner in which the teachers accept that Zoe and Stuart are working on the new science syllabuses for the Tasmanian state government's Secondary Assessment Board, a statutory authority responsible for the syllabuses used 
in Tasmanian schools. Both demonstrate leadership in undertaking these roles, being prepared to undertake the extra work for little remuneration. For Stuart, it is important to be involved in order to "strengthen the position of science in schools" (Vignette 2). Clearly, to be asked to develop a new syllabus is to be trusted that they understand the subject and how it is to be taught. This trust is well founded, and also reciprocated, as both Zoe and Stuart report back to the meeting on their progress:

\begin{abstract}
Zoe: "I' $m$ on the Life Sciences Level 4 to 7 and Biology Level 7 to 8,8 being the pretertiary, and we spent a lot of time trying to delineate what would go in our subjects... We had to have a clear dividing line as to the content in each subject. It was one of those areas that we intrinsically knew what it was, but you have simply got to get it straight in your head and make it obvious for other people ... The ultimate plan for the Science of Natural Resources, if they can get together, is to put things like aquaculture, agricultural science and geology together so it would be like a framework syllabus that people could do it from the point of view of a local industry that worked for them ... I don't know if there is any chance of us being interested in that, Maddie. Maybe for some Year 11's, you know the sort of project science that Jack has been doing, that is probably where some of those students might fit."
\end{abstract}

Stuart: "This is the content that we think is essential to get the top award at Level 6 ... people would need to have an understanding of the language ... the structure of the subject, and also the basic ideas." (Vignette 2)

Both Zoe and Stuart are prepared to share their syllabus work with their colleagues, and also ground this work in the community. Both clearly understand their own areas of science teaching, and also trust in the expertise that their colleagues possess. Zoe raises the notion that the school should be involved in the development of the Science of Natural Resources subject syllabus, as it is in Jack's area of interest. Stuart refers back to the notion of scientific literacy that was discussed at a previous meeting, demonstrating trust in the value of that discussion. While there is a high level of trust between the teachers, their trust in the process is about to be shattered:

In early February 2003, before the students returned for the new school year, the department gathered for its first meeting of the year. Most of the department had been at an earlier mathematics meeting, where Stuart had been informed by Zoe that the entire science syllabus writing process had been 'pigeon-holed somewhere' within the Secondary Assessment Board. He was still angry at the later science meeting. His colleagues were incredulous.

"So what is going on with the science syllabus writing, Stuart?" asked Rob as a way of informing those teachers who had not been at the mathematics meeting.

The response was measured, although he was obviously discouraged. "I've just been told this morning that the science syllabus writing has been pigeon-holed somewhere. I haven't been told officially and I'm on it."

Jack's comment was direct. "Sensational, Jesus, science have got their act together haven't they. Wonderful!"

"So, what do we think of the Secondary Assessment Board, Jack?" asked Stuart. 


\footnotetext{
"They are wallies, absolute wallies, incompetent morons. The reason that they are at the Secondary Assessment Board is that they can't teach."

Zoe also expressed her feelings about the decision. "It is enormously frustrating for us. Endless days working on a Life Science syllabus that doesn't look like it is going to exist anymore, despite everything that we have done." (Vignette 2)
}

To have the syllabus writing process cancelled after they had put a considerable amount of work into their respective syllabuses, for little tangible reward, was clearly a blow to both Zoe and Stuart. To "rub salt into the wounds", the Secondary Assessment Board did not even officially inform them of the decision to "pigeonhole" their work. Neither Zoe, nor Stuart, has accepted any further work with the Secondary Assessment Board since February 2003, despite being asked. They no longer trust in the syllabus writing processes of the Board.

Jack's reaction is interesting as it shows a strong bond of collegiality between himself, Zoe and Stuart. For Jack's colleagues to be treated in this way is unforgivable, and it reflects poorly on the competence of the Secondary Assessment Board. Jack trusts his colleagues in a way that the Board cannot be trusted:

"They are wallies, absolute wallies, incompetent morons. The reason that they are at the Secondary Assessment Board is that they can't teach." (Vignette 2)

This strong trust in one's colleagues, but limited trust in those outside the community is understandable. Trust is based on relationships and a constancy of action in such a manner that people know what to expect from both each other and from processes. Trust is built up over time, and can be lost through inconsistency of word and action. In a close-knit community in which teachers work together and share a common view of the world based on their subject, trust has ideal conditions to grow and prosper. Those conditions do not necessarily exist between the community and those outside it. Certainly, the community lost trust in the Secondary Assessment Board.

The discussions in Vignette 3 around professional learning highlight these differential levels of trust between those within the community, and those not in the community. In discussing professional learning, as requested by the Principal, there is uncertainty about what is actually required of the teachers. The Principal has not specified what she means by professional learning, nor has the Teacher Registration Board, a state government statutory authority charged with the registration of teachers and their 
continuing professional development. In this definitional vacuum, the teachers develop their own notions of what constitutes professional learning. For the community, one possibility is the use of meeting times to share their practices with their colleagues:

Rob: "That might mean that we take turns in presenting something. You only need to talk about something that you might do in class, an experiment that you might do."

Stuart had experience in this form of departmental meeting from his previous school

"We sort of did that sort of system a couple of years ago, where each person took a meeting, and one person who was new to science teaching brought in their Year 8 prac books, and then people went through and discussed; why did you give this person a $\mathrm{C}$ and this person a $\mathrm{B}$ which helped moderate things very nicely. One person did something on teaching about models, using models in science and some of the problems that you run across in using models. It doesn't need to be much, and if it is addressing problems that people have already mentioned, well, it helps everybody." (Vignette 3)

While this was seen as a positive way to proceed, integrating such a system into the school's professional learning accountability system was seen as problematic, primarily due to a lack of trust in that system:

Rob added, "Another thing that I think is relevant is that any professional learning that we do in departmental meetings, we can get approved to go onto our ongoing PD file for teacher registration." It seemed that professional learning and professional development were synonymous.

Jenny was confused as to what actually counted as professional learning. "It has never been perfectly clear what counts for that."

Rob tried, unsuccessfully, to explain the situation. "We put in what we have done to the Director of Staff and he okays it."

Zoe had experienced organisational difficulties with this system. "We don't get a response back when we put it in to tell us if it was okayed or not."

Rob was on the defensive. "No, we have to wait" was his response.

Jenny was not impressed by the vagueness of this answer. "Till when?"

Rob was becoming increasingly flustered by the direction of the conversation. "Until we do get a response, what do you mean you don't get a response?" (Vignette 3 )

Clearly, the teachers within this community have trust in each other, a solidarity that allows them to raise concerns and issues with each other, and have those concerns and issues dealt with. The same level of trust does not appear to extend far beyond the community in areas that impact on the work of the community, such as syllabus writing and accountability for professional learning. 
Care within these Vignettes is expressed between the teachers within this community, seen in the way they support each other in difficult times, such as in the cancellation of the science syllabus writing. It is also evident that the teachers care for their students and their learning. As important as theory is, science education is not simply a case of providing theory for the students. Science education is about educating students in order to be able to make informed decisions in the use of science. This care is clearly demonstrated in the conversations about the proposed science policy:

\footnotetext{
"Well" said Rob, "the first point says that the policy needs to clearly articulate what we consider to be important in the teaching and learning of science. So to us, what is important? ... is (our aim) to make students science literate."
}

\begin{abstract}
Maddie's reaction to the notion of scientific literacy was supportive. "I like your first point, I think that we should be educating people to be able to make informed decisions based on what they see on television or read in the paper, and to see that to every story there are two sides to it, and to able to critically make a decision ... We already have it don't we? ... A fairly good focus on science in everyday life."
\end{abstract}

Dennis, given the range of classes that he taught, wasn't so sure. "I'd say that in the middle syllabuses it is, in the top syllabus, I don't know."

\begin{abstract}
Rob answered Dennis" uncertainty. "The Year 10 science that I teach in top syllabus is really focussed on knowledge and theory, because they are the students who are going to go onto Year 11 and 12."
\end{abstract}

Maddie continued "And if we want them to go on with science in 11 and 12, we need to give them enough background in science, we need to see what the syllabuses say, but the main thing is that they need to be interested in it. If they are interested in the subject, provided that they have a certain level of ability, then they will be able to handle it in 11 and $12 . "$ (Vignette 1)

The teachers believe that they are educating their students in the wise application of science even though the emphasis may vary between students of different levels of ability. This recognition of different abilities is evidence of the care that the teachers have for their students. It is also evidence of the virtue of practical wisdom that these teachers, all experienced teachers of science, demonstrate.

Practical wisdom in one's life, a virtue centred on reflection and judgement, is evident in the discussion on the proposed science policy. Despite the fact that the policy was never implemented, its discussion raised many important issues for the teachers. The first was that it forced the community to reflect on its purposes: 
Rob: "I'd like to know what the policy states so we know what our aims of the science program are, so that we can design our science program to fulfil those aims and objectives of our policy ... say what we believe is important in science education, and these are the ways that we are going about making sure that we meet these values." (Vignette 1)

Despite Zoe's lucid response of "We teach maths, that's our policy", Rob's question did prompt conversation into scientific literacy, based on the definition given in The status and quality of teaching and learning of science in Australian schools (2000) report, the provision of learning opportunities for students of various abilities in science and the involvement of the wider community in science education; an involvement that became reality in the Science Expo some eighteen months later (see Vignette 6). One area which Rob's proposed policy touched on, but was not discussed, was the issue of teachers themselves as:

Teachers are life-long learners who are supported, nurtured and resourced to build the understandings and competencies required of contemporary best practice (Appendix 2).

This issue was to re-emerge in the following year, when Dick, a teacher who was not trained in the sciences, was employed to teach Year 8 science. As the learning needs of Dick, in terms of the knowledge that he was required to teach, were not identified, there were problems that led to Dick relinquishing his class (see Vignette 11).

The importance of the subject as a foundation for the practical wisdom of the community is also clearly demonstrated in these Vignettes. The involvement of both Zoe and Stuart in the Secondary Assessment Board syllabus writing was strongly focused on the content knowledge that they, along with their fellow syllabus developers, believed to be important:

\footnotetext{
Zoe: "I don't see senior biology, Level 7 and 8 being dramatically different from what we currently do, because it is a syllabus that a lot of teachers are really happy with the way that it is, and we seem to have a fairly consistent number of kids doing it. So it is not as if we are losing kids because the syllabus is inappropriate."

Stuart: "This is the content that we think is essential to get the top award." (Vignette 2)
}

For both these teachers, content was crucial to effective science teaching. In Zoe's case, the senior Biology syllabus already stressed the importance of content, and hence there was little need for change. For those students seeking to undertake a 
senior secondary, but not necessarily pretertiary science course, the new 'Science of Natural Resources' syllabus would cater for their needs:

In Stuart's case, the insistence on content endpoints for students seeking a solid knowledge of science at the end of Year 10 was also a method of defending science as a subject which was seen to be under threat:

\begin{abstract}
Stuart: "Strengthen the position of science in schools. A lot of schools are having science as an option for Years 9 and 10 . Or they are having it as a short course for six months. To get to Level 6 , there is no way that you could do these things if you just had a short course. The plan is that, if parents see that science is important, the direction that Dr. Nelson (the Federal Education Minister) is also pushing from, then there is going to be a large push on making sure that science gets covered in the school curriculum." (Vignette 2)
\end{abstract}

The teachers in these Vignettes seek to reflect on the nature of their subject and their teaching. In doing so they make mistakes and fail to achieve some of the objectives that they set themselves, but the intention is clear, they are seeking to improve on their practices as teachers of science.

Courage and honesty are virtues that exist in this community, and are shown in a number of contexts. It is a courageous and honest person who can admit that they have an uncertain understanding of a situation. In the discussion on scientific literacy in Vignette 1, Maddie poses a question that elicits an answer from Dennis that highlights his uncertainty:

\footnotetext{
"We already have it don't we?" asked Maddie, who was also the school's Director of Studies, "A fairly good focus on science in everyday life."

Dennis, given the range of classes that he taught, wasn't so sure. "I'd say that in the middle syllabuses it is, in the top syllabus, I don't know."

Rob answered Dennis' uncertainty. "The Year 10 science that I teach in top syllabus is really focussed on knowledge and theory, because they are the students who are going to go onto Year 11 and 12."

Maddie continued "And if we want them to go on with science in 11 and 12 , we need to give them enough background in science, we need to see what the syltabuses say, but the main thing is that they need to be interested in it. If they are interested in the subject, provided that they have a certain level of ability, then they will be able to handle it in 11 and $12 . "$
}

Dennis provided the link between the needs of the top syllabus students, those who are "going to go onto Year $1 \mathrm{I}$ and 12" and the middle syllabus students whom he teaches. "Well, I think 
that if we state something about them making informed decisions, based on some sort of understanding of the processes involved, then you can go from there ... if you put the word processes in there, then there is the scientific method for your top syllabus. I suppose that if we are doing a process then students do some sort of experiment and they are testing a hypothesis, then we can do as we have always done and relate the data to the hypothesis, and in that way get them to think critically, just based on the data that they have got. But then we need fairly simple experiments for some of them." (Vignette 1)

Dennis was prepared to be vulnerable, and admit he was uncertain as to the importance of scientific literacy in classes, and student ability levels, different from the one in which he taught. In making himself vulnerable, Dennis demonstrated courage, honesty and trust in his colleagues. As a result of his actions, and the caring responses of his colleagues, Dennis was able to learn from the conversation, as well as contributing to the learning of his colleagues.

Courage and honesty are also evident in the manner in which members of the department are prepared to criticise the administration of the school. In Vignette 3, there is discussion about the professional learning accountability requirements that the school wished to introduce. Given the previous experience of some teachers, there were a number of concerns with the system that the administration needed to be aware of if the new system was to function for the benefit of all. The excerpts from Vignette 3 that cover these concerns appear in the discussion on trust above. As a result of a preparedness to honestly raise and pursue issues that are important to their work as teachers, the members of the community demonstrate courage and honesty. If the teachers were not prepared to raise issues that affect them with the administration of the school, then there is no one else who will raise those issues on their behalf.

Fairness in the treatment of others is clear in the Vignettes. Faced with the discouragement, anger and frustration of the cancellation of the Secondary Assessment Board's syllabus-writing parties, it would have been easy to simply accept Jack's description of the Board as "wallies" and "incompetent morons". Zoe, however, attempted to explain how the situation in which she and Stuart now found themselves might have arisen. In doing so, despite her stated frustration, she acted with fairness towards the Secondary Assessment Board: 
At this point Zoe attempted to point out that the Secondary Assessment Board might not be entirely at fault in the shelving of the science syllabus writing. "The Assessment Board isn't driving the agenda anymore, it is all this Essential Learning stuff coming from the Minister, and whoever advises the Minister."

"They must be an ex-teacher who can't teach, that's why they are there with the Minister" fired Jack from across the table.

Zoc continued, despite Jack's anger. "They have decided that the Essential Learnings are the only thing that they want in schools up to grade 10 , by 2005." (Vignette 2)

Zoe again demonstrated fairness when the teachers were discussing the professional learning accountability requirements of the school. When Rob mentioned that the Principal had stated that informal learning was not going to count in assessing the professional learning of teachers, Zoe spoke up in order to attempt to put the comment in context:

Zoe: "That is more for administrative reasons than for devaluing the informal learning." (Vignette 3)

Zoe clearly demonstrates the virtue of fairness in both of these examples.

Virtues clearly play a substantial role in the life of this community of science teachers. In their negotiation of meanings for their work as science teachers, they demonstrate the virtues of trust, care, practical wisdom, courage, honesty and fairness. Behind all of these virtues, however, there is the virtue of truth. Truth appears foundational in teachers' dealings with each other, with those outside their community, with their students, and with their subject, Science is, according to the Shorter Oxford English Dictionary (1980) definition, a "branch of study which is concerned with a connected body of demonstrated truths". In negotiating their meanings of science education, the community seems to have internalised this definition, and applied it to their work as science teachers. 


\section{CHAPTER 7 - PRACTICE}

\subsection{VIGNETTE 4}

This Vignette details the development of the science syllabus for Years 7 to 10 . The development of the syllabus was undertaken in order to ensure that the major concepts in physics, chemistry and biology were being covered in a systematic manner for Years 7 to 10 . The Vignette is composed from the transcript of one of the departmental meetings held in December 2002.

\section{'THE FOUR BASICS?'}

\section{Developing the science syllabus}

What to include in the science syllabus for 2003 and beyond? What to exclude in the science syllabus for 2003 and beyond? What were the core scientific concepts that the department wanted to promote? As 2002 drew to a close, the department's interest in these questions increased. The catalyst for asking these questions was provided by the new science syllabus being developed by the Tasmanian Secondary Assessment Board. With these questions in the background, the department met in mid-December 2002 to discuss the topics that were to be taught in 2003 .

Given the lack of a firm agenda for the meeting, there was little direction to the initial conversation, which had focussed on mapping the current content of the Year 7 science course. The major questions remained in the background. What was important to include, and by definition, exclude? What differences in topic or pedagogy were necessary between the top and middle syllabuses? Jack's blunt interjection brought the questions out of the shadows and into the light, forcing them to be acknowledged and discussed.

"I think that we should probably change the whole system. I'm probably throwing a spanner in the works here. I would pull geology out of grade 10 , so that we could spend more time on physics, chem, maths and biology. I say that we take all the 
geology out of Year 10, put it over Years 7, 8 and 9, only have the four basics in 10, and put aside the time ..."

This comment changed the course of the whole conversation. Rob was surprised at the sudden change in direction. "The four basics?" he asked.

"Yeah, chemistry, biology, physics and maths" answered Jack, before outlining his idea of what the syllabus should include. "I think that it would be good for the top syllabus, but we need to have something flexible for the bottom syllabus, and for the middle syllabus kids. I think we should have a flexible syllabus based on themes or something, and it is totally and utterly up to the teacher to decide on with those groups of students. I don't know, maybe I'm coming from left field, perhaps it might be worth rethinking."

No one seemed to be of the opinion that Jack was coming from "left field". Indeed, the teachers seemed to be of the opinion that what he had proposed was reasonable and workable. There appeared to be two reasons for this agreement. First, the proposal appeared to fit the proposed new science syllabus, with its content endpoints for physics, chemistry and biology. Second, the proposal also appeared to offer a method of focussing the work of teachers on the core concepts of the three branches of science, as well as mathematics, rather than attempting to crowd content into the syllabus. At the time of the meeting there were 14 topics in the Year 8 syllabus and a similar number in Year 7. Jack's "left field" suggestion would help to overcome this common problem teachers faced, as Jack highlighted in this exchange:

"We do cover all those" Jack said, referring to the subject endpoints in physics, chemistry and biology. "There is no doubt about that. But not having taught 7 and 8 for a while, how do you go for time in that area?"

Jenny answered for all of the Year 8 teachers. "We didn't get our last unit on machines done."

"So you struggled with time, did you?" enquired Jack. 
Jenny's explanation as to why the last unit on machines was not covered reflected the difficulties in having some 14 topics to cover in a school year. "I think that I could have tightened up a few topics; I kind of went over, with a couple of the units early on. If I had kept to the time table ..."

Stuart also expressed concerns about the large number of topics that were in the Year 8 syllabus at the time.

"The problem that I had was that you would just be getting into something with the kids, they would just be showing some understanding, and that is the point where you can stretch it and do all sorts of wonderful things, and bang, sorry, we've got to go off and do something different."

Rob was busily noting these concerns, and looking at ways in which the Years 7 and 8 syllabuses could be reorganised to deal with these difficulties. The syllabus for 2003 , and into the foreseeable future, was about to take shape from these hastily scribbled notes. The new syllabus would bear little resemblance to the mass of topics that had characterised the syllabus in the past. It would, however, cover the major concepts in the major branches of science. This would permit the development of common tests for each unit of work. It would also, for the first time, explicitly focus on the professional judgement of the teacher. Rob outlined his ideas.

"What I was thinking of was, we just have our four units, chemistry, physics, biology and geology, we work out what we want to teach in each of those areas, and then leave it up to the teacher, to structure their unit themselves in Years 7 and 8. If you want to do a whole 10-week block on chemistry, go for it. But if you want to split your chemistry unit up into a couple of units on chemistry, it's up to you. As long as we all cover the same endpoints, we'll be right. What we could do would be to list the units in a booklet like this one from my previous school, and hand that out at the beginning of each year. Have a look; is there enough depth to be prescriptive enough, so that everybody is covering similar things?" 
Rob passed examples of the booklet around. The booklets contained the lists of topics to be covered, as well as the aims and objectives of each topic. Jack was not convinced that the booklet was the best method of ensuring that core concepts were covered. For him, the judgement of the teacher, and the ability of the department's teachers to share their concerns, was more important. As Jack said,

"If people have any questions about depth or perception in terms of their work, they can talk to anybody and we can make a decision then and there. Is there a need to be so prescriptive? We can have common tests, particularly for the better kids that will cover the core units that everybody does and if anyone wants to do anything else, that's fine. There needs to be some professional judgement there, so that these are covered. It's probably just my nature, but I think that the booklet is overly prescriptive. Whereas a checklist may not be as prescriptive, it may give you a little more flexibility, perhaps that is enough, that's for me, maybe for a new teacher coming in, being first year out might need a bit more guidance."

"Yeah, I was thinking that for Years 7 and 8 , but for 9 and 10, it would need to be like we had this year" Rob replied.

Jack was enthusiastic about the idea of units that teachers could develop, even though he did not teach Year 7 or 8 Science. "I like that idea, you see in physics, if I was teaching physics in grade 8 , I would do a big chunk on astronomy, because there is so much physics in astronomy."

Stuart was quick to see the connections between what was being proposed and the new science syllabus that he had been involved in at the state level.

"This also fits in with the new science syllabus, because one of the recommendations in that is that you do themes. So, Jack, you might do astronomy to cover physics, I might do light, that's fine, as long as we cover the same basic ideas. If people know where they have to get to, and then you leave it up to the professionalism of the teacher, I mean, we trust each other. For everyone around this table, the units and their endpoints would be enough. I think that you would be confident that everything would be covered." 
With that affirmation of their work, the teachers proceeded to map out the topics that would be covered in physics, chemistry, biology and geology for the Year 7 to 10 classes in 2003. At the end of the meeting, the units of work shown in Appendix 4 had been agreed. 


\subsection{VIGNETTE 5}

This Vignette details the development of a research component within the Year 10 science syllabus. The development of this component was, in part, a response to the external challenge by the Essential Learnings Framework to the department's sense of meaning, as discussed in chapter 6. The Vignette is composed from the transcript of the departmental meetings held in December 2002.

\section{'THEIR OWN CURIOSITY. THAT'S WHERE YOU WORK FROM'}

The development of a research component

The school was winding down at the end of a busy year, and summer was approaching. The senior students' examinations had finished and the Year 10 students had finished for the year. The student body had been reduced to just Years 7, 8 and 9. To take advantage of this situation, Rob had requested that time be made available for the science teachers to meet. The Principal had agreed to the request, and the teachers were given a morning to plan for the following year.

The morning went quickly, and the meeting had gone through the topics that were to be taught in Years 7 to 10 . The major disciplines of chemistry, physics, biology and geology had been divided into topics, which had then been arranged to provide continuity across all four year groups. Several times the teachers had considered stopping for a break, but had felt that it was better to continue working while they were making such good progress. Besides, the products of Jack's fermentation 'experiment' were still chilling in the prep room fridge, and would be better served in the afternoon.

In Year 10, the curriculum contained a chemistry unit based on titrations, a physics unit based on Newton's Laws, and a biology unit based on genetics. The geology unit had been moved to Year 9, leaving a nominal 10 weeks available for a fourth unit. In reality, the 10 weeks was closer to seven weeks by the time interruptions, both planned and unplanned, were removed. It was for this block of time that Jenny proposed the introduction of a research topic. Jenny had built a formidable reputation 
on the back of the number, and quality, of her students' research entries into various state and international competitions.

Jenny proposed her idea of a research topic, and how it could be organised.

"It could be organised by a couple of different methods. One way would be that you go unit one, research block, unit two, and unit three. That means that they have their research finished half way through the year. So then it is ready to go into the science competition. The other option would be, or one of the other options would be that, you start out doing unit one, and you take a day a cycle, which is probably a better way to go, and that becomes the research day, and then next cycle has another research day."

Rob was already looking at the implications of this proposal. "And that work goes all the way through. It would be a major part of their assessment; you could just about assess every criterion."

Jenny continued her proposal, highlighting the importance of student accountability in the completion of their research. "The work goes all the way through the year and then at the end of it, you end up with a research investigation. That's quite good because they've been working on it all year. It's like an advanced science class running in your regular science class. There would have to be an expectation on those kids that they will have to complete it, because, overseeing them, that is tedious work, you know. That is going to be part of their assessment that they have to complete."

As teachers are quick to do, concern was expressed about how students of different scientific abilities would handle a research topic.

Rob's question was directed to Jill, who had the lowest syllabus Year 9 class. "Would your weak kids be alright with this?"

"Extended task?" asked Jill. Her answer to Rob's question sought to clarify what would be expected of her students. An extended task, for her, implied less structure than a project, in which the students were generally given a question, and then given assistance in gathering and organising the information. 
Rob picked up on this cue. "No, just a project, one day a fortnight for the whole year."

"They just won't do what you say, just sit around ... if you're talking about their ability, no" Jill replied.

Given this assessment of the ability and motivation of the bottom syllabus students, the teachers sought to provide a feasible alternative to the proposed research topic.

Stuart suggested that an answer could be found in the amount of structure that was provided to the students. "With kiddies like that you need to keep it fairly structured, you basically give them the question."

Rob was caught between the idea of the research topic and the practicalities of such an idea with students who were in the bottom syllabus. "Would the weaker kids be better off doing a project over a block of time? Or not a project, and just do another unit of work?"

Jill's response, borne of experience in teaching lower ability classes over a number of years, was blunt. "Another unit of work"

In this, Jenny supported Jill's position. "Yeah, plus they could all be doing different things at the same time. And since they are probably in groups, then if you've got one in a group that has got data, and is not at school, it mucks up the whole group, you know you have got to be ready for problems with this. I would say that the weaker kids would probably not be as interested in the outcome."

With this, it was decided that an investigative topic be developed for the bottom syllabus students. The selection of this topic was to be at the discretion of the teacher, based on their knowledge of the students' interests and abilities. In 2003, the topic was the Spaghetti Bridge Building Competition, organised by the Institution of Engineers, Australia. 
With this outcome in place Dennis expressed concern for the middle syllabus students who struggled, for whatever reason, in science.

"And what about the weaker middle syllabus kids?" Dennis asked.

For these students, it was decided that the best option would be to give them the opportunity to develop their research skills, but to provide the extra support that they would require. Stuart believed that structure was important for these students, and shared the methods that another teacher used for research topics in her class.

"She has got reams and reams of research questions. If we asked her nicely, she's got chemistry and physics and biology, and she is one of the sharpest operators that you would meet anywhere. Basically, the way that she sets it up is to give the kids a log book, they have to come up with the question, when they have done that they have to get her to sign off on it and they sign off, work out the variables, everyone signs off, so that is all very structured."

With this in mind, it was agreed that a structured project, rather than an open-ended piece of work would be more appropriate. With that course of study decided, Rob opened a brief discussion on suitable projects.

Rob's question was for everybody at the meeting, and was a reflection of the experience of the teachers. "What would be some projects that the weaker kids could do that we could structure?"

There were several possibilities mentioned, and it was readily decided that the final choice of project would be the responsibility of the class teacher, again based on their knowledge of the students' interests and abilities. In 2003, the topic that was taught was forensic science.

With the outline of Jenny's proposal for a research topic taking shape, the teachers decided to continue working. This was despite a series of interruptions to the meeting. Some teachers were asked to take phone calls during the meeting. A member of the school's administration team wanted some information about a group of students 
'now'. And the school's public address system offered all kinds of useful reminders and notices to anyone who cared to listen.

Jenny introduced two new dimensions into her proposal at this stage. The first dimension was the explicit introduction of the importance of community involvement into the research process. There were two components to her conception of community involvement. The first component was drawn from her own experience. And the second came from the work of a science teacher in New South Wales that Jenny had met at a conference. Regarding her own experience in teaching research topics, she explained that: "The very nature of research, it involves extending yourself out into the greater community. And very often they (the students) have to do something that then has to be the data that is not on the premises. It is very hard to coordinate, it is very rewarding when it works."

Jenny shared the ideas of the New South Wales teacher she had met. "I was talking to a woman from New South Wales who was going off on a bursary overseas to a university overseas to learn how to put on a science fair. She won an award to do this ... what she wants to do now is to set up firstly in their school, and then extend it through New South Wales in general, a science fair where they stand and talk to the project that they have done. And be evaluated on it, and get a prize and all."

The response to this idea was spontaneous, and the publicity value for the science department was recognised. Rob's statement was typical of the response. "If we get all these projects completed early enough, we'll have them for Open Night as well ... the kids could do that at Open Night, speak about their project at Open Night."

The second dimension of Jenny's proposal was to link the research topic to the Essential Learnings Framework. In December 2002 the teachers had spent little time acquainting themselves with the Framework; hence the hostility at the February 2003 meeting that was evident in Vignette 2. Jenny, however, had already begun looking at the Framework, and had reached the following conclusion:

"You know where this would fit perfectly, it would fit in that Essential Learnings thing, because the whole idea of that Essential Learnings is that they (the students) 
have got data that is applicable to them, and that they can analyse it and display and talk about it. And that is the whole focus of the Essential Learnings. So you'll be doing something for the science department that they'd be interested in."

The implications of this statement were not understood at the time, nor would their full importance be understood for close to a year, with the development of the Science Expo, which is the critical incident described in Vignette 6.

The meeting had achieved its purposes of placing the topics that flowed from the major branches of science into a coherent curriculum structure from Years 7 to 10 . Although it was recognised that there was still fine-tuning to be done, the department now also possessed the genesis of a research topic for Years 9 and 10 . A most productive meeting was called to a close. And in the near future the products of Jack's fermentation 'experiment' would be chilled and ready to serve. 


\subsection{VIGNETTE 6}

This Vignette describes the culmination of the development of the research topic proposal that was discussed and developed in Vignette 5. It also marks a significant shift in the thinking of the science department with regard to the new Essential Learnings Framework that was described in Vignette 2. The Vignette is drawn from a letter that was sent to the school's administration, the departmental meeting of October 2003, and the school newsletter dated October 29, 2003.

\section{'THE RICHNESS OF THE SCIENCE EXPERIENCE'}

The Science Expo.

\section{Administration Meeting Tuesday 23 September 2003}

Dear Administration Team,

I write to seek your permission and support in the running of a Science Expo at the School on Tuesday October 21 from $6.30-9.00 \mathrm{pm}$.

The purpose of the expo is:

- To showcase the scientific research work being conducted by grade 9 and 10 students at the school.

- To allow students an opportunity to "speak to" their research before judges and the general public (their parents and friends).

- To raise public awareness of the importance and relevance of science to our lives today.

- To demonstrate the ways in which the school is addressing the new curriculum Framework for Essential Learnings through science.

- To create models and exemplars of students' work to assist teachers embarking upon this approach to curriculum delivery and the establishing of moderation standards.

- To provide a set of research dossiers from which to select entries for the Open Research Section of the Tasmanian Science Talent Search (due 3 days later).

As we know, 2004 sees the introduction of the Essential Learnings Framework for grade 7-10 students. The new curriculum is organised into fives areas with key elements as follows:

Thinking: - Inquiry 


\section{- Reflective thinking}

$\begin{array}{ll}\text { Communicating: } & \text { - Being Literate } \\ & \text { - Being Numerate } \\ & \text { - Being Information Literate } \\ & \text { - Being Arts Literate } \\ & \\ \text { Personal Futures: } & \text { - Building identity and relationships } \\ & \text { - Maintaining wellbeing } \\ & \text { - Being ethical } \\ & \text { - Creating and pursuing goals } \\ & \text { - Building social capital } \\ \text { Social Responsibility: } & \text { - Valuing diversity } \\ & \text { - Acting democratically } \\ & \text { - Understanding the past and creating preferred futures } \\ & \text { - Investigating the natural and constructed world } \\ \text { World futures: } & \text { - Understanding systems } \\ & \text { - Designing and evaluating technological solutions } \\ & \text { - Constructing sustainable futures }\end{array}$

It is my belief that conducting independent scientific research allows students an opportunity to address all of the above key elements.

- In order to decide upon a topic for research, students must demonstrate some curiosity and sense of inquiry in relation to some scientific phenomenon and reflect deeply upon the best pathway to pursue to answer their questions.

- When communicating with one another during the process, or with the public when completed, students need to utilise all listed modes of communication.

- Numeracy, in relation to their quantitative evaluations

- Literacy, in verbal and written communication

- Information technology, in compiling their dossiers

- Arts, in presenting their summary poster as background for the presentation.

- In personal terms, while conducting the research, students need to: set firm goals (both short and long term) and pursue them; be ethical in presenting 'true' results; avoid plagiarism; and maintain good relationships with coworkers.

- In social terms, students need to value the diversity of their working groups and allow equal representation. They must show understanding and act democratically toward one another. Only in this way can a future that will hold benefit for all, emerge.

- With view to our world, hopefully they will come to understand the systems already in place, their benefits and limitations and how these can be modified to create more sustainable futures. 
Technical Issues:

These issues will be dealt with in the next submission to administration (next meeting) if agreement in principle is reached at this meeting.

Basically the issues are:

- Preparation time for stall set up (3 - 4 pm on that evening)

- Judging (4-5.30 pm)

- Sausage Sizzle for participating students $(5.30-6.30 \mathrm{pm})$ ?

- Wine and cheese for judges?

- Arrival of parents at $6.30 \mathrm{pm}$ and formal address (hall)

- Exhibition: parents circulate among entrants $(7-8.30 \mathrm{pm})$

- Formal announcement of "Young scientist of the year", and prize?

- Coffee, Tea snacks/Biscuits for audience?

I would be grateful if you could let me know at your earliest convenience if this project can go ahead, so I can make continuing arrangements.

Yours in Science,

Jenny.

Initially, it appeared that Jenny had caught everybody in the department by surprise. The letter reproduced above was drafted and sent to the administration of the school before the members of the department had seen it. At the administration meeting the proposal for a Science Expo was enthusiastically endorsed by the Principal and the other members of the school administration. In her handwritten comments back to Jenny, the Principal was effusive in her praise of the idea, and also noted that the proposal would require a high level of 'team cooperation' by the members of the science department. Only after approval did Jenny bring the proposal back to a hastily arranged lunchtime meeting of the department.

Like Nelson raising his telescope to his blinded eye at the Battle of Copenhagen, the action of Jenny could be seen as reckless or inspired, irresponsible or brilliant. To gain approval for her idea of a Science Expo, and then to seek the 'team cooperation' of the science department was a calculated risk. It was a risk that Jenny, in her energetic way, was prepared to take. At the lunchtime meeting of the department, Jenny outlined her plan, pointing out that it had been flagged at the end of 2002 . The result of the meeting was that the department was fully supportive of the idea, and each member was given a role in the organisation of the event. Jenny maintained overall control, Rob being more than happy to let her take that responsibility. Rob 
had to coordinate the venue, organise food, and notify other staff members. Dennis and Jack had the responsibility to prepare the barbeque tea for both the participants and the judges - they both like to cook. Stuart was given the responsibility to look after communications for the evening, taking photographs and so on. Anna, the laboratory technician, was to help Jenny in the overall organisation. The other members of the department pledged to assist their colleagues in any way they could.

The organisation of the Expo was also discussed at a later department meeting. At that meeting, concerns were expressed about the number of Year 9 students involved in presenting the research projects to Years 7 and 8 . The use of the hall for the displays was also seen as a difficulty for the Year 9 physical education classes if the weather was inclement. These concerns were regarded as minor compared to the potential benefits of the Expo.

The day of the Inaugural Science Expo arrived, Tuesday, October 21, 2003. At 2pm, approximately ninety Year 9 and 10 students descended on the school hall to set up their displays. An increasingly stressed Jenny accompanied them. "Give them weeks to get organised" she said, clearly exasperated, "and they will still leave it to the last." Each of the 39 groups was given a large table on which to base their display. Each group had to present a $1 \times 0.8$ metre poster of their work, a document folder presenting their method and findings, and their actual apparatus and / or experiment. Given that the Science Expo commenced at $3.30 \mathrm{pm}$, time was short.

The range of topics was immense. From a student carrying hovercraft to the effectiveness of anti-bacterial cloths. From the effectiveness of stomach antacids to the effects of computer monitor screens on eye fatigue. From a photosensitive robot to a solar oven that reached $265^{\circ} \mathrm{C}$ on a cloudy day, all of the major branches of science were represented. For the next five hours, the students spoke of their work to their colleagues and over 200 visitors and family members who came to look at their work. Many found it exhausting work, and were more than happy to be fed at Dennis and Jack's barbeque. Many also found that they grew in confidence in presenting their project to the diverse audience of friends, family and, of course, the judges. 
The three judges were drawn from the state government's Department of Primary Industry, Water and Environment (DPIWE), the University of Tasmania, a national paper manufacturing company that operates in the local area, and the Tasmanian Science Talent Search, an initiative of the Australian Science Teachers Association. The four judges spent four hours going to each display and listening to the students describe their work. They also asked questions as to the experimental design, the variables that were involved in the study, and the applicability of the results to the wider community. The science teachers did not envy the judges' role in deciding the prize-winners as they sat down for a meal together. At $8.30 \mathrm{pm}$, the judges took to the stage to award the 2003 Inaugural Science Expo prizes. The winners were reported in the school's newsletter as:

First Prize: Water Rehabilitation Project.

A research investigation entitled "Potatoes to the Rescue" presented by Year 10 students, Jane Emerson and Jess Callaghan took first place in the Science Research Expo held over Tuesday and Wednesday, October $21^{\text {st }}$ and $22^{\text {nd }}$. The project, which researched the use of potatoes to absorb heavy metals, particularly iron, from industrial residues mirrors closely the process currently used by ICI Tasmania in their rehabilitation of their local industrial site. The students, who were mentored throughout their research by Mr. Bob Harris of ICI Tasmania, devised some innovative tests never before attempted in a laboratory. Using standard iron solutions in excess of $1000 \mathrm{ppm}$, they set up a series of potato variables to establish the best conditions under which potatoes can mop up the iron. The process has application not only to residual waters from pigmentation industries, but also to tailings water from mines which must undergo treatment before release. The Senior Environmental Officer for DPIWE, one of three judges assessing the research, was very complimentary toward the students' work saying it "showed innovation and problem solving at its best."

Second prize: Beach Sand Formation.

Second prize was awarded to Bruce Simons (Year 9) who conducted extensive research into the particle size of sands from over 20 different beaches in the North West. In an exceptionally well-presented report, Bruce went on to map all beaches with a view to sand type and particle size. He was then in a position to draw comparisons between beaches and make some deductions regarding their formation. In presenting Bruce's prize, judge Mr. Nigel Scrimgeour (Industrial Chemist) praised the quality of the report and Bruce's capacity to 'speak to' the project, thus selecting him as the 'Best Science Communicator' at the Expo.

Merit awards were awarded to the following research projects. 
'Is The Weight of the World on Your Shoulders?' (Year 10): Research into the weight of schoolbags being carried by current Year 7 students.

'Catalase Activity in Liver and Celery' (Year 10): Explored the capacity of liver and celery to act as antioxidants, mopping up dangerous free radicals in the body.

'The Water Rocket' (Year 9): This demonstration and video showed how to launch a water rocket. The boys were very impressive in their presentation and have been invited to demonstrate their rocket to local primary school students.

'Break it Down' (Year 9): This research explored the break down rates of various waste products that normally go to land fill dumps. The girls are now working on establishing a recycling facility at the school.

'Artificial Wetlands' (Year 9): This project researched the impact of wetlands at a mine site in reducing the acidity of mine water.

By $8.30 \mathrm{pm}$ the awards had been presented, and the students and their families were ready to go home. The students were to present their work the next morning to the Year 6 class of a neighboring primary school. Parents, based on the feedback that they gave to their children and some of the science teachers, were impressed by the work that they had seen.

Jenny was delighted with the success of the school's Inaugural Science Expo, saying in the school's newsletter that: "This presentation demonstrated 'teamwork' not only from science personnel, but generous help offered right across the board". In terms of the relevance of this kind of approach to science teaching she commented, "it is clear that there are many experts in our local community who are willing to share their scientific know-how with our students. This can compliment our classroom teaching and make the study of science more relevant to our students. By engaging students now, hopefully we will encourage more to pursue careers in science".

The Principal was also impressed by the standard of the students' research. The evening had also been a public relations coup for the introduction of the Essential Learnings Framework in 2004. As she wrote in the newsletter:

"By exhibiting the products of their own investigations, students are fulfilling the main criteria of the Essential Learnings Frame work about to be adopted by 
Tasmanian Schools. We are glad to have an opportunity to showcase the manner in which we approach Essential Learnings."

The science department also built on its reputation through the experience of the Science Expo. The event, in the eyes of the one of the judges, demonstrated the "richness of the science experience that is available to students at the school". The members of the department were equally enthused by the potential of the Expo to highlight science education to the community. As Jack told the department meeting on the day before the Expo "we are going to gear the whole school around the Science Expo. If we are going to take the Essential Learnings to the nth degree, everything that we do in science could be the centre point, and every thing else comes into it. Computing to English to maths. The whole lot." The principal did not disagree with this view of the centrality of science. "I have heard that science is the focus and that every thing else radiates out from it."

So it was that with the Inaugural Science Expo judged a success by all and sundry, the hall was cleared of the displays, and Jenny began to plan for a larger event in 2004. 


\subsection{VIGNETTE 7}

This Vignette describes the changes to the processes that the science department used to allocate students to different ability classes. Within these processes, ideas to assist students at both ends of the ability continuum were discussed. The Vignette is drawn from the departmental meetings of April and November 2002 and March, July and October of 2003

\section{'I JUST PICK OFF THE TOP ONES, OR WHAT HAPPENS?'}

\section{Allocating students to classes}

The mathematics department in the school has a reputation for being organised. Ruthlessly organised! Organised to a degree that intimidated some other staff members. Handbooks for each year level are colour coded and list the topics that are to be taught, and the order that they are to be taught in. The learning objectives for each topic are explicitly stated, together with a time allocation, teachers' notes and a resource list. Common tests exist for each topic, and a teacher is rostered to mark each topic test. No other department comes close to this level of organisation. Zoe is the Head of Department.

When assessing a student's mathematical ability in Years 7 and 8, the mathematics department rely on the common topic tests and three common tests in each year group. These tests are administered on the same day to all classes, and marked by a small group of teachers to ensure that the tests are internally moderated. These tests cover all the topics that have been covered through the year, and hence become progressively harder. The results for the three tests are averaged to produce a summative list of student ability from number 1 to number 127 in 2003 . Teacher consultations centred on this list determines a student's class into the following year, Year 7 into Year 8 and Year 8 into Year 9. In Year 9, the school uses the government syllabus and assessment regimes to maintain class groupings.

Almost all of the science teachers also teach mathematics, and so are familiar with the mathematics department modus operandi. Despite their knowledge of the process, and 
their participation in it, the members of the science department had never adopted a similar process. Indeed, the science department process bore no resemblance to the mathematics process. This was clearly evident in the November 2002 meeting.

Rob started the conversation "... so that we can work out who is in what level and in what class in the 2003 Years 9 and 10. I don't know what the process is, but obviously, do we get together and talk about it, or do you just give me your results and I just pick off the top ones in each class, or what happens?"

Jenny, as a previous faculty head, outlined her method. "That's what I used to do, and hope that an OA (Outstanding Achievement award) coming from one class was equivalent to an $\mathrm{OA}$ from another."

Rob found this reassuring "Yes, and then I'll probably come up with some draft lists and we'll sit down and talk about it all as a team, and say 'no or yes'. And the same with the Year 8's as well. Okay, so I reckon that we will do that in the last week of school ... because you'll have all your results done by then. Just keep a copy of them."

This process was to come under challenge throughout 2003, mainly due to the efforts of one teacher. Dennis, throughout the year, kept the issue of student achievement on the agenda of the staff meetings. Dennis' concern was for the students' achievement, and how he, as a teacher in the early years of secondary schooling, could help them progress in science. All through the year he had reminded the teachers of their responsibilities for student learning.

At the February 2003 meeting, during a discussion about the perception that girls were achieving better results than boys in Years 7 to 9 , Dennis made a plea to look at the way in which science was taught in Years 7 and 8.

"If you are looking at Years 7 and 8, when you look at the swing in assessment criteria and so on, how subjects have become touchy feely, it is no wonder that boys are disadvantaged in that area. You are looking at a lot of written work, and poster 
drawing and what ever is going on, then of course the boys are going to be disadvantaged compared to the girls."

At the March 2003 meeting in which the role of mathematics in science classes was being discussed, Dennis continued to reflect on the work of his students.

"Perhaps we need to do more science with maths in it lower down, so that we teach them how to use the calculators, what the numbers mean." (Dennis' own emphasis)

At the August meeting, Dennis touched on the same theme of concern for the progress of his students. "What about the kids? Teaching all four Year 7 classes, I see the same problems coming up with the students. Like organisational skills, you can see it's not just one; it is across all the classes."

At the October staff meeting, Dennis seized an opportunity that arose from the Principal's decision to begin implementing the Essential Learnings Framework in 2004. The Principal had outlined how changes in the organisational structure of Year 7 would commence in 2004 .

"The Essential Learnings are a platform that we follow ... what that means is entirely up to our own community. The significant word is Framework, and certainly the way that I see it is that we use it to use it as a framework to evaluate our own curriculum and our pedagogy. So things like the rigour of the disciplines is something that we don't want to tamper with. But it is an opportunity for us to see if we ensure that what we are teaching is relevant and isn't being duplicated."

Dennis saw these organisational initiatives as being intimately connected to his own concerns for the Year 7 classes that he taught. He was more than prepared to put forward his ideas, prompting a discussion about the best forms of assistance for students at both ends of the ability continuum.

"I've had some ideas in Year 7, that we can take out students that have, shall we say, difficulties, and put them into one class, they would probably end up doing less, but 
perhaps, if we concentrate on those students they might be ready, or better prepared for Year 8. And then they can go back into normal classes. I was thinking that in the classes I teach, I reckon that you could probably fill up a class with students who are having a few difficulties of one sort or another. I also think too that some of the brighter kids, many of them just seem to be treading water. Because we tend to teach to that middle lot. There are classes in which we spend a fair amount of time on the middle students, the ones at the bottom; they need a lot of help, so you don't see them very often, and the good ones you just tend to leave. I wonder also if some of the good kids were getting bored, because of the repetition, having to do so much over and over again."

Jack was supportive of Dennis" ideas, backing them fully. "Dennis made the point that they don't cover as much, but does that matter if what they do cover they cover well?"

Dennis was quick to capitalise on this support, and also link the 'brighter kids' to the success of the Science Expo

"That's right, just imagine also, if you take out those high flyers they don't necessarily cover more, but can you imagine what you could do with them by the time that they reach Years 9 and 10 for the Science Expo or whatever. You could do quite a lot with them by that stage."

It was at this point that Jack suggested that the science department, almost all of whose members also taught mathematics, adopt the same structure as the mathematics department.

"I think that we should adopt the same system as the maths department, now Zoe will probably jump up and down about this, but if my understanding is correct, mixed ability in 7 and then they have a better class of 8's, based on the common test, work your way down. Now if we had something similar, also during third term, Jill suggested it, and the Special Ed teacher has organised it, that the top five or six kids in each class are doing extension maths twice a fortnight. They come out of maths to be extended a little further; perhaps we could adopt a similar principle. Because I 
think that the good kids are going to do it in spite of us, it is our less able kids that we are not helping by teaching the middle ground. The good kids are going to succeed anyway, it is ideal if we can push them by teaching the middle road, I think that the less able kids are more disadvantaged than the other kids. By doing what you are suggesting, Dennis, I think that we can help those less able."

Zoe pointed out that the science department would need to be very careful, as the mathematics department was, when deciding on class allocations. "What we haven't necessarily always done very well is this within-school moderation. If you do head down that path, you do need to have quite effective ways of allocating kids to these classes." And, she continued, "I think that that has been the problem with science in the past. We do need to address that a bit better." No one disputed this criticism.

Maddie, a member of the school's administration, came in at this point. "If you think that it is really valuable, then put in your suggestion, and we will see if it can be arranged."

Postscript: Dennis' suggestion was acted on by the school's administration. The process of class allocations in science now mirrors that of the mathematics department. Implementation of programs to assist students at both ends of the ability continuum commenced in 2004. 


\subsection{VIGNETTE 8}

This Vignette describes the perceived challenges to science teaching from school level changes in the area of examination scheduling, and the department's response to that challenge. The Vignette is drawn from the department meeting of August 2003.

\section{'THAT IS NOT GOOD CHEMISTRY'}

School-level changes.

As opposed to the content in the Years 7 to 10 syllabuses, the Secondary Assessment Board, a state government instrumentality, mandated the content for the Years 11 and 12 syllabuses. At the end of each year, externally assessed examinations were set in each of the pretertiary subjects, which partially determined students' eligibility for university entrance. The process of internal assessment of students' work throughout the year by their teachers was also used to assess university eligibility.

Part of the internal assessment process of the school is the examination that is usually held in August or September. Having the examinations later in the year gave many teachers the opportunity to cover most of the required syllabus before the school examinations. Other teachers thought that the lateness of the examinations was a hindrance to learning, as there was insufficient time after the school examinations to assist those students struggling with either the content, or their examination technique, or both.

In 2003, the school examination was moved to early August, due to other cultural events that were happening within the school. At the August 2003 meeting of the Heads of Departments, it was decided to ask teachers how they had found the change of date, and how they would feel if the change was made permanent.

Jenny, the senior chemistry teacher, was not impressed. "I am in the middle of a very big section; I don't finish organic chemistry until the end of July. And then I would have to leave a whole criterion off. I'm not happy with that." 
Rob, who did not teach any Year 11 and 12 science classes, offered a solution. "Can you do organic chemistry earlier, as the first unit?"

"I could, but that is not good chemistry. And if I do, then I miss out on my electrochemistry, so I leave a different criterion off." Jenny was highly regarded by both her colleagues and students for the quality and rigour of her chemistry teaching. This regard extended further than the school grounds. The Royal Australian Chemistry Institute does not hand out citations for excellence in chemistry teaching to anybody. Jenny taught chemistry, and chemistry was her subject.

Maddie teaches Physical Science, the Year 11 subject that is a prerequisite for chemistry in Year 12. She was sympathetic to Jenny's concerns. "It is better to do electrochemistry first, and you can't do organic chemistry until you have done electrochemistry, because you have a lot of oxidation."

'Good' chemistry, as taught by Jenny, followed a clearly defined sequence of topics. It was the perceived threat to this sequence that Jenny was concerned about. "I have a sequence worked out, I have done it for five years, and I have changed various bits and pieces, but it is good." She had not appreciated the earlier examination this year. "It was disastrous for me this year, because it was very difficult to set the paper because I had to make up a lot of my own organic questions, as I hadn't gone deep enough into the topic to be able to use any of the exam paper types of questions. So I had to write a lot of stuff myself."

Jenny had made her point, and there was no challenge to that point. Indeed, following Jenny's concerns, the entire issue of an over-crowded school calendar was raised as an impediment to covering the course content in Years 11 and 12. The timing of the school examinations, in the view of the department, should have precedence over other activities. 


\subsection{VIGNETTE 9}

This Vignette describes the discussions that went into the development of chemistry units of work that would cater for the different levels of ability possessed by students in Years 9 and 10. In particular, it highlights the difficulties of providing learning opportunities for all students, from those looking at going onto chemistry in Year 12 to those who like to put on lab coats so that they 'look the part'. The Vignette is drawn from the meetings held in March and December 2002 and February 2003.

\section{'THEY LIKE PUTTING LAB COATS ON'}

\section{Real science}

"So what about Year 9 chemistry?" Rob asked, as the discussion continued as to the content that could be covered by students of different ability.

Dennis, who taught the lowest ability class, was determined to ensure that there was a heavy emphasis on practical work for his class. He had found, through his long experience that practical work was something that his students could achieve. "Just something of a practical nature, I don't think that my kids would be capable of some of the maths."

This statement initiated a discussion as to the importance of practical work in science, particularly in Years 7 to 10 . Dennis continued, referring back to the earlier discussions about the role of practical work in the department's draft science policy.

"Yeah I think that if we're going to look at basing things on practical work, it might be an idea to train the kids in 7 and 8 , so that by the time they get to 9 and their looking at the criteria involved with practical work they know how to do it and we don't have to re-teach it."

Rob was in full agreement with this. "Yeah, yep. Isn't that what we're doing in Years 7 and 8 this year?" 
Dennis related to his colleagues his concerns about the practical abilities of students in his Year 7 classes.

"Well the first unit, I'm just concentrating on practical work, and what I'm finding is interesting in that I'm getting to the stage now where I'm wondering what practical work, not necessarily to do with school, but anything practical, that students do. When it comes to tightening and untightening clamps, clearly they haven't got any idea which way they turn. It's just those little things ... so I don't think we can expect the kids to have the same skills that they used to have, because I don't think that they do."

With these concerns fresh in their minds, the teachers turned to the content that was currently being taught in Years 9 and 10. Jenny was quick to offer her opinion as to the standard that should be reached in the early part of the chemistry unit. "A very quick review of what they have done, and then you go into writing formulae for various other types of reactions. You know, acid plus carbonate to produce carbon dioxide that kind of thing, writing an equation from it as opposed to a word."

Stuart agreed. "Your middle syllabus kids, say you did acid plus carbonate, you can do the word equation, you can do the experiment, and you can separate out the salt from the water. If you want to try and push on in the direction of writing the chemical equation, that's fine."

Jill was sceptical about the progress that some students would make with equations. She asked, "Do you see the bottom kids doing it that way?"

"Certainly getting the products of the reaction" said Stuart, as that was as far as he would have taken a lower ability class with the acid reactions. "Although there is the problem that if we chop out the theory too much some students may be disadvantaged in the longer term."

Jill was quick to point out that such a standard would, in her opinion, quickly lose a large number of students. "That equation work is alright for the top syllabus, but for the middle and bottom syllabus kids, they haven't made enough progress in Year 8." 
Jenny was quick to defend her position. "I'm going on what's here."

Rob pointed out that, as the content was currently written, "The bottom kids would be spending three weeks reviewing the chemistry that they did in Year 8."

"And loving it." Jill remained cynical as to how the less able students would find the first three weeks of Year 9 chemistry. In this, she was supported by Jack.

Looking over the list of content for chemistry in Years 9 and 10, Jack had two major concerns. The first was a concern for the perceived lack of interest in the content that the students would display.

"But, you see, my view is that there should be some practicals that you do purely and simply for the enjoyment of science. You don't necessarily have to write up everything ... if I was looking at this, in terms of a less able science student, I'm not going to enjoy it in Year 9. You need something, you need some enjoyable science there that can, let's face it, it's not enjoyable. So in 9, we need some whiz bang stuff."

In Jack's opinion, there was a great need for less able students to, at the least, engage in what they perceived as 'real science'. Real science involved doing experiments that involved apparatus that they didn't otherwise have access too, as well as looking like a stereotypic scientist. A comment Rob made about Year 10 chemistry gave Jack a way to express the second of his concerns.

Rob asked about the weaker classes. "Are the weaker classes going to bother doing titrations?"

Jack: "They love to. They do them; they don't understand anything about the molarity, that doesn't matter. They think that they are doing science. In Year 10 they probably will end up doing titrations. They just have to fill in the boxes," Jack said, referring to the calculations that went with titrations. "Unless we just get onto the titrations and not worry about the theory, because they like putting lab coats on," he concluded. 
Rob had taken this path with some previous classes. "Just the mechanics of it, that's what I used to do with the other group. They could use all the gear, but had no idea about the calculations. They can't do the maths and stuff, they can't write the equation."

Dennis was unequivocal about the value of the equation compared to the value of the practical. "They can still do the prac though. Forget about the equation."

Jenny was concerned for the wellbeing of her chemistry burettes, in the hands of lower ability students. "Yeah, you could give them the plastic burettes as well."

"Oh no, you have to give them the glass ones, how would they break the plastic ones?" asked Jack, who was fishing for a bite from Jenny. The bait was not taken.

"Swordfights?" offered Stuart, referring back to an earlier incident in which two burettes had been broken in a duel between two students.

"Mine have difficulty with lab coats and things like that," said Jenny, changing the conversation back to the need for some students to look like scientists before they thought they were doing science. It just wasn't science without a lab coat and, preferably, a pair of safety glasses.

"Lab coats?" asked a slightly incredulous Rob.

"You've got to look the part," Stuart explained.

There was a chorus of agreement. "You do," said Jack, "the better groups don't care about the lab coats."

"Oh yeah" added Jenny, before continuing. "Who did I have doing titrations, and all he used to do was go out into the corridor, up and down, in his lab coat and his glasses, so that everyone could see him?" 
The conversation eventually resolved that, for the lowest ability students, practical work in chemistry that related to, or extended, their experiences was the way to proceed. In explicitly deciding this course of action, the teachers formalised what had been their individual practices into the collective practice of the department.

There was no shortage of examples of work that could be incorporated into this practical chemistry, as Jenny quickly pointed out:

"Well, see that acid base definition and $\mathrm{pH}$ ? I have had them over the years bring in all sorts of body stuff like shaving foam and soap and shampoo and conditioner. Everything and go and get the $\mathrm{pH}$ of it all ... and they are shocked, some of them, at the acidity of some of the things that they are putting on their faces. You know. Like, they say that 5.5 is about as low as you should go and we had pHs of 2 and 3."

"Cleans you, cleans you up no problems. Takes off the layers of skin" observed Jack dryly. Stuart could relate to the $\mathrm{pH}$ practical work.

"We made some soap once and I told the kids that it might be wise not to use it because if you haven't rinsed out all of the $\mathrm{NaOH}$, it will take a couple of layers of skin off. And this kid took some home, his old man is a mechanic, and he came back the next day and said "My dad wants the recipe for that. He said that it removed the grease and everything else as well. He reckons that it is the best stuff that he has ever used." But you could do things like making soap. You can test which soaps or dishwashing liquids are the most effective. There are all sorts of bits and pieces that you can throw in." 


\section{CHAPTER 8 - DISCUSSION OF PRACTICE}

In the foregoing Vignettes, I have described six critical incidents. The first Vignette describes the development of the science syllabus from Years 7 to 10 . The second Vignette describes the development of a research topic within the Year 9 and 10 science syllabus. The third Vignette describes the development of the Year 10 research topic into the school's inaugural Science Expo. The fourth Vignette describes the changes in the department's practices for streaming students into homogenous ability groups. The fifth Vignette describes the reactions of some members of the department to school level changes that are seen to affect science teaching. The sixth Vignette describes the discussions that went into the development of chemistry units of work that would cater for the different levels of ability possessed by students in Years 9 and 10. Looking out over these incidents, three key themes emerge. These themes are the importance of the virtues that are displayed within the community, teacher leadership, and the importance of the subject to the members of the department. As in the previous discussion on meanings, it is virtues that underpin both the teacher leadership that occurs within the community and the importance of the subject to the teachers.

Trust is a virtue clearly evident to the members of the department; it is explicitly named within the transcripts: "we trust each other". Such a level of trust reflects on the strong relationships that exist within the department, relationships built up over a period of years. In dealing with the content that should, and by implication, should not, be included in the syllabus there was general agreement with Jack's suggestion to cover the major concepts in the major branches of science. This agreement was firmly grounded in the common belief that the existing list of topics was unwieldy, and that the syllabus needed to focus on the core concepts. In making his suggestion, Jack has identified a concern of the teachers, and he acted in a way to bring that concern, as well as a potential solution, into the open. Even though he believed that he was "throwing a spanner in the works" Jack had demonstrated both leadership and a high level of trust in his colleagues. His potential solution, centred on a non-prescriptive list of the core concepts, relied on the professional judgement of his colleagues to cover those core concepts. Further, if any of the teachers had any questions about 
"depth or perception in terms of their work, they can talk to anybody and we can make a decision then and there" (my emphasis). In Jack's opinion, any of his colleagues could ask for assistance from anyone else in the department with the expectation that a decision could be made. Stuart, who had only been a member of the department for 11 months, shared Jack's opinion:

\footnotetext{
"If people know where they have to get to, and then you leave it up to the professionalism of the teacher, I mean, we trust each other. For everyone around this table, the units and their endpoints would be enough. I think that you would be confident that everything would be covered." (Vignette 4)
}

Clearly, there exists a high level of trust in the ability, knowledge and personal relationships that exist in the department. Further, there is also a high level of trust in the department as an organisation, as Dennis demonstrated in Vignette 7.

Throughout the departmental meetings of 2003, Dennis had raised his concerns about student achievement in the early years of secondary school. These concerns ranged from an assessment system that, in his view, disadvantaged male students to the organisational skills of many students. "What about the kids?" was his heartfelt plea. In October 2003, Dennis was more than prepared to raise the issue again, using the discussion about the Essential Learnings Framework and the streaming of students to push his case:

\footnotetext{
"I've had some ideas in Year $7 \ldots$ we tend to teach to that middle lot. There are classes in which we spend a fair amount of time on the middle students, the ones at the bottom; they need a lot of help, so you don't see them very often, and the good ones you just tend to leave. I wonder also if some of the good kids were getting bored, because of the repetition, having to do so much over and over again." (Vignette 7)
}

Dennis took his opportunity to both state his opinion and to offer a way forward, through which his concerns could be addressed. In this, Jack supported him. "Dennis made the point that they don't cover as much, but does that matter if what they do cover they cover well?" When Maddie suggested that "If you think that it is really valuable, then put in your suggestion, and we will see if it can be arranged", Dennis trusted the organisation enough to pursue his concerns. He also demonstrated a great deal of leadership by being prepared to argue the merits of his beliefs, and to persevere until he achieved a positive result for the students in his care. As a result of his perseverance, his concerns were acted on in the 2004 school year. 
Care is another virtue that is illustrated within these Vignettes on practice. Dennis' concern for his students is a prominent example of this virtue. Dennis was concerned for the progress of students of all abilities in science. He expressed care for "the ones at the bottom, they need a lot of help ... there are classes in which we spend a fair amount of time on the middle students ... I wonder also if some of the good kids were getting bored, because of the repetition, having to do so much over and over again". Dennis was also concerned with the "weaker middle syllabus kids" and how they would cope with a research topic. In demonstrating his care and concern, he was not alone.

In the discussions on developing a research topic for students, there is recognition within the department that students of different abilities require different levels of support if they are to achieve to their potential. For the weakest of students, research was not seen as a suitable pedagogy.

\footnotetext{
"Would the weaker kids be better off doing a project over a block of time? Or not a project, and just do another unit of work?"

"Another unit of work." (Vignette 5)
}

For students in the middle syllabus, research was seen as appropriate, provided that the necessary levels of support were provided at all stages of the research work.

Stuart: "With kiddies like that you need to keep it fairly structured, you basically give them the question." (Vignette 5)

For students with more ability in science, research was seen as a valuable experience that could be used to extend the students out of the classroom.

\footnotetext{
Jenny: "The very nature of research, it involves extending yourself out into the greater community. And very often they (the students) have to do something that then has to be the data that is not on the premises ... they (the students) have got data that is applicable to them, and that they can analyse it and display and talk about it ... It is very hard to coordinate, it is very rewarding when it works." (Vignette 5)
}

The care that the teachers show for their students is based on their individual and communal understanding of their students' abilities and attitudes. These different abilities and attitudes required different pedagogies if the students were to progress in science. In developing and using these different pedagogies, the teachers demonstrated not just the virtue of care, but also the virtue of practical wisdom. 
Practical wisdom can be described as a quality of reflectiveness and judgement that assists in answering the question 'what to do and why?' In selecting the pedagogies that they chose in relation to research, the teachers not only demonstrate care for their students, but also the value of understanding their subject and how best to organise it for teaching and learning. Developing a research topic for Years 9 and 10, however, is not the only area where such wisdom exists. It is also to be found in the specialist pretertiary subjects, as evidenced by Jenny in Vignette 8 .

When confronted by changes in the scheduling of the school's examinations in Year 11 and 12, Jenny was decidedly unhappy. The reason was simple. By moving the examination forward, Jenny was forced to develop examination questions in areas of the course in which she had not gone "deep enough into the topic to be able to use any of the exam paper types of questions". The result was that her carefully planned sequence of teaching had been affected, "I have a sequence worked out, I have done it for five years, and I have changed various bits and pieces, but it is good". The results her students had achieved in the past had demonstrated to all the benefits of Jenny's "good chemistry".

The importance of a solid understanding of the subject to be taught is also clearly highlighted in this Vignette. When Rob, who did not teach pretertiary science classes, suggested that the order of the syllabus content could be altered, both teachers who taught the physical sciences in Year 11 and 12 rebuffed him:

\footnotetext{
Jenny: "I could, but that is not good chemistry. And if I do, then I miss out on my electrochemistry, so I leave a different criterion off."

Maddie: "It is better to do electrochemistry first, and you can't do organic chemistry until you have done electrochemistry, because you have a lot of oxidation."(Vignette 8)
}

Practical wisdom can assist in the evolutionary moulding of both the syllabus and the pedagogy that teachers adopt for different students. As teachers reflect on their practice and make judgements as to the value of different aspects of their practice, incremental changes will inevitably occur. It had taken Jenny five years to develop what she could call "good chemistry". For any evolutionary change in practice, practical wisdom is an essential starting point. Practical wisdom in concert with the virtue of courage, however, can result in revolutionary changes in practice. 
Courage can be expressed in many different ways. It may be seen in the pursuit of something worthwhile under difficult circumstances. It may be seen in a long-term commitment to a worthwhile goal. Within this department it was seen in Dennis' continued efforts on behalf of those students whom he considered to be struggling with science. Dennis was prepared to keep raising his concerns for an extended period of time, and was also prepared to elaborate on his views when an opportunity presented itself. The result of Dennis' courage was to see the department adopt a series of measures specifically designed to assist students to achieve their best in science.

Courage was also to be seen in the development of the Science Expo, from an idea to reality, under the leadership of Jenny. The department's reaction to the state government curriculum reform, the Essential Learnings Framework, was negative. In the face of such opposition, it would require a courageous person to frame a proposal for an event such as the Science Expo in terms of the Essential Learnings Framework. Yet, this was how Jenny went about her task. In the letter to the school's administration, Jenny phrased her beliefs about science education in the language of the Essential Learnings Framework:

It is my belief that conducting independent scientific research allows students an opportunity to address all of the key elements (of the Essential Learnings Framework).

In order to decide upon a topic for research, students must demonstrate some curiosity and sense of inquiry in relation to some scientific phenomenon and reflect deeply upon the best pathway to pursue to answer their questions.

When communicating with one another during the process or with the public when completed, students need to utilise all listed modes of communication.

- Numeracy, in relation to their quantitative evaluations

- Literacy, in verbal and written communication

- Information technology, in compiling their dossiers

- Arts, in presenting their summary poster as background for the presentation

In personal terms, while conducting the research students need to set firm goals (both short and long term) and pursue them, be ethical in presenting 'true' results, avoid plagiarism and maintain good relationships with co-workers.

In social terms students need to value the diversity of their working groups and allow equal representation. They must show understanding and act democratically toward one another. Only in this way can a future that will hold benefit for all, emerge.

With view to our world, hopefully they will come to understand the systems already in place their benefits and limitations and how these can be modified to create more sustainable futures. (Vignette 6) 
Such was the strength of Jenny's conviction regarding the importance of student research, and with her superb organisational skills, when the Science Expo was discussed at a hastily convened meeting; the entire concept was enthusiastically accepted.

With the full backing and participation of the members of the science department, the Science Expo was an outstanding success. The event had taken the school's science syllabus into the wider community, and also brought the wider community into the school's science syllabus, as Jenny described in the school's newsletter:

\footnotetext{
"It is clear that there are many experts in our local community who are willing to share their scientific know-how with our students. This can compliment our classroom teaching and make the study of science more relevant to our students. By engaging students now, hopefully we will encourage more to pursue careers in science." (Vignette 6)
}

Jenny's courage, commitment and leadership also changed the attitude of the department towards the Essential Learnings Framework. As Jack, a vociferous critic of the framework said the day before the Expo:

"... we are going to gear the whole school around the Science Expo. If we are going to take the Essential Learnings to the nth degree, everything that we do in science could be the centre point, and every thing else comes into it. Computing to English to Maths. The whole lot." (Vignette 6)

Jenny's combination of practical wisdom and courage had, through the experience of the Science Expo, revolutionised the conduct and reporting of student research within the department.

Despite its many successes, the department is not immune to criticism from its members. Criticisms are not, however, seen in the pejorative sense of the word. Rather, criticisms demonstrate the virtue of honesty in challenging assumptions that underpin the workings of the department. And in challenging those assumptions in an honest manner, opportunities for learning are created.

The first example is seen in the honest assessment of the Year 8 syllabus. To attempt to cover 14 topics in a year was simply too difficult:

\footnotetext{
Jenny answered for all of the Year 8 teachers. "We didn't get our last unit on machines done." Jack enquired "So you struggled with time, did you?" (Vignette 4)
} 
The result was that both teachers and students were frustrated:

"The problem that I had was that you would just be getting into something with the kids, they
would just be showing some understanding, and that is the point where you can stretch it and
do all sorts of wonderful things, and bang, sorry, we've got to go off and do something
different." (Vignette 4)

Given the honest appraisal of the difficulties of the situation, the teachers were willing to consider alternatives that were presented within the meeting. By identifying the problem themselves, within the context of their work, the teachers were also able to assess the merits of potential solutions. For this reason, Jack's "left field" suggestion was seen as a workable solution to the problems of a crowded syllabus that did not encourage student learning.

In the decision on the streaming of classes, Zoe's criticism is directed at the management processes of the department over a number of years:

\footnotetext{
"What we haven't necessarily always done very welt is this within school moderation. If you do head down that path, you do need to have quite effective ways of allocating kids to these classes." And she continued, "I think that that has been the problem with science in the past. We do.need to address that a bit better." (Vignette 7)
}

Based on the dual membership of most of the science teachers, as many are members of the mathematics department as well, they could understand where the criticism was coming from, and the solid practice of the mathematics department that underpinned it. The process was seen to work in mathematics, and hence was seen as a model for the science department.

Truth is mentioned only once in the Vignettes, but it is positioned at the heart of science as the subject. In her presentation to the school's administration, Jenny stated that students participating in the Science Expo would need to "be ethical in presenting 'true' results (and) avoid plagiarism". By placing 'true' in inverted commas, Jenny acknowledges both the objective search for 'truth' that underlines science, as well as the subjectivity that underpins much research. The implication for teaching is clear: Students must be taught to undertake science with an understanding of the importance of those factors such as variables and bias that may lead them to results that are not justifiable and 'true' in a scientific sense. 
The essence of fairness is found in Aristotle's axiom that justice consists of treating equals equally and unequals unequally - but in proportion to their relative differences. The Vignettes present a picture of a department that recognises that different groups of students have different needs, and therefore are to be treated differently. There are three clear examples of the virtue of faimess in action.

The first example of fairness is in the decision making around the research topic for Years 9 and 10, which is also an example of the care that the teachers have for their students. Which option was the most beneficial for the students, a research topic, or a more tightly controlled topic?

\footnotetext{
"Would the weaker kids be better off doing a project over a block of time? Or not a project, and just do another unit of work?"
}

Jill's response, borne of experience in teaching lower ability classes over a number of years, was blunt. "Another unit of work." (Vignette 5)

Given the experience that various teachers had with lower ability groups, and the students' interests and abilities, it was the teachers' perception that another unit of work was of more value to these students in terms of achievement and interest. This perception mainly related to the organisational abilities of the students, and the difficulties that many of them experienced with the higher order thinking required of research. The actual topic was left to the discretion of the teacher for example, the Year 10 class undertook the Spaghetti Bridge Building Competition organised by the Australian Institution of Engineers. The Year 9 class studied undertook work on forensic science. From talking to the students, these units of work appeared to be popular, and they did not feel that they had been sidelined.

Allied to this concern was the discussion into encouraging all students to participate in science, and to benefit from the experience. The department clearly values the academic success that it has enjoyed with the most capable students in its care. However, the department also appears to understand, that for some students, science is not an interesting subject.

Jack: "But, you see, my view is that there should be some practicals that you do purely and simply for the enjoyment of science. You don't necessarily have to write up everything ... if I was looking at this, in terms of a less able science student, I'm not going to enjoy it in Year 9. You need something, you need some enjoyable science there that can, let's face it, and it's not enjoyable. So in 9, we need some whiz bang stuff." (Vignette 9) 
Jack's statement clearly shows that the department is prepared to consider new methods of engaging students in a subject that the teachers are passionate about. The passion for ensuring that students enjoyed their science meant that even content knowledge, a core part of the subject, could be diminished in stature if it meant that students could participate in "real science". As Dennis said, "They can still do the prac though. Forget about the equation". To engage the lower ability students, the teachers were prepared to shift the emphasis of what they taught, and how they taught it, in order to engage as many students as possible.

Fairness is also evident in the concerns that Dennis raises regarding the criterion based assessment system that is used throughout science. In Dennis' opinion, the criteria are, unintentionally, weighted against the boys. The reason for his belief is that the criteria are weighed towards the presentation of work, an area in which boys in the junior years of secondary school are not renowned for achievement in.

Dennis: "If you are looking at Years 7 and 8 , when you look at the swing in assessment criteria and so on, how subjects have become touchy feely, it is no wonder that boys are disadvantaged in that area. You are looking at a lot of written work, and poster drawing and what ever is going on, then of course the boys are going to be disadvantaged compared to the girls." (Vignette 7)

In Dennis' opinion, the assessment criteria should emphasise practical work, which is more in keeping with boys" interests and abilities "in doing things". The question of assessment is an ongoing discussion.

These Vignettes about practice highlight three important issues in the life of the department and its members. These issues are: the importance of virtues to the teachers; the role of teacher leadership in promoting discussion and change; and the importance of the subject as a foundation for considering both individual and departmental practices. 


\section{CHAPTER 9 - IDENTITY}

\subsection{VIGNETTE 10}

This Vignette describes some of the stories about practice that the teachers shared in order to increase their subject knowledge. Some of the stories refer to experiments that have been conducted, some refer to excursions that have been beneficial to student learning, and some refer to the connections between school science and the wider world. All of the stories, however, are directly related to the work of the science teachers. The Vignette is drawn from the transcript of the November 2002 meeting.

\section{'WHAT'S THAT STORY, I DON'T KNOW THAT STORY' \\ Departmental story telling}

Geology is one area of the science curriculum that the science teachers did not feel that they taught particularly well, partly due to the rather 'dry' nature of the subject. After all, there was only so much practical work that could be done with colour, lustre, streak, cleavage and hardness. In an attempt to address this, Stuart and Rob had poached an idea from a science teacher who had attended the 2002 Conference of the Australian Science Teachers Association. This unit involved students setting up mining companies, prospecting for, and then mining minerals (pieces of polystyrene foam) in an area of the school grounds. The topic also included investigations into the formation of ore deposits, prospecting methods, mining techniques and mineral processing. The unit had proved quite successful in raising the interest of the students, and was to be developed further in 2003. The unit had not, as yet, been publicly shared with the other teachers. The other science teachers were to have a look at the full unit for the first time today. The conversation that followed added to the unit, and also added to the knowledge base of individual teachers.

"In mining we have got minerals and ores, prospecting, mining techniques ..." Rob began, as he introduced the unit to the meeting. Before he could finish outlining the content Jenny made an enquiry. "Distribution of mines around the state as well?" she 
asked. Jack took this as a cue to push for the inclusion of knowledge about the geology of western Tasmania, one of the most mineralised areas in the world.

"Make sure they know that the volcanic arc is unique in the world, bar one place," Jack said.

Rob's tone of voice was one of surprise. "Really? What's it called again?" he asked.

Jack explained the global geological significance of the area. "The Mount Read Volcanic Belt" he said, "You've got seven kilometres between the Hellyer silver lead zinc mine to the Renison Bell tin mine, which is unheard of, anywhere else, except in Quebec in Canada. They are the only two that we know of."

Jenny was intrigued. "And is that the result of volcanic action?"

Jack explained the mineralisation. "Over three different periods, quite unique, exceptionally unique. Now you can throw in a gold mine down there as well." Not recognising that the teachers had learnt from this brief exchange, Jack apologised for the interruption. "Sorry, keep going" he said.

Stuart continued to expand on the topic content. "We've also got the environmental side, such as rehabilitation. This covers assessment criterion 7, which is social issues. There is also prospecting, geological mapping, and mineral processing processes such as separation and froth floatation. The kiddies were impressed with the story about the bloke at Broken Hill with the beer."

"What's that story? I don't know that story," interrupted Jack.

Stuart told the story of the metallurgist who, according to legend, had developed froth floatation by observing the bubbles in his beer. 'He had a beer poured after a big day at the office, and he watched all the bubbles float up, and he noticed the foamy bit on top and thought that if he bubbled oxygen through the solution of minerals and bits and pieces, then the lighter ones should be carried to the top. So he did it." 
"Who was it?" asked Jack, clearly impressed by the story.

"Can't remember the blokes name, but he made a fortune," replied Stuart. With that the talk turned to the biology unit.

Throughout 2002 there had been an ongoing debate in Tasmania as to the merits of genetically modified (GM) crops. The state government had placed a moratorium on the production of GM food crops, but not on fibre and pharmaceutical crops. These categories included trees for pulp production and the lucrative opium poppy crop. The teachers saw the ongoing debate as an important issue for the science department to address.

Stuart described a proposal that he and a representative of the Forest Education Foundation, an industry-funded organisation, had discussed.

'For the 9 biology course, Eric of the Forest Education Foundation has done a whole stack of work on forests, ecology and forestry industries. He took five of us up to a plantation area and laboratory for Science Week. He said that he would be more than happy to come into a school and help set a unit of work based on forestry. This would include ecology, industry, conservation, preservation, the whole box and dice. And he has got the money to do it. So he would be quite happy, and he said that the school would be the one place to do it as we are close to the major forestry areas, just up the back here."

Jack was keen to extend that idea further. "That's a wonderful idea, but I have also said that I would like to see the better groups do a GM discussion, as there is a very large debate in relation to organic and non-organic, it's all related."

"We could do the GM one, because up there we went to the tree nursery and had a look at the propagation work out there. They grow 15 million trees a year and spend a fortune on developing 'super' trees" Stuart said.

Jack had also heard of the scale of the propagation work. "They ship a lot out to the mainland now." 
Rob had been listening to this exchange, and now changed it slightly to include the recently announced trials of GM canola in the mainland state of South Australia. "On Saturday there was talk about canola, the GM canola trials that they were doing in South Australia."

Jack was unimpressed by the concept of controlled open-field canola trials.

"You cannot isolate a crop, it is physically impossible out in an open space, of course the canola is going to cross. But then you go to a debate in Zimbabwe, there are millions of people starving, because the government has made a decision that they are not going to let them eat genetically modified corn. I'd take the risk if you are starving to death, you're going to die, I'd take the risk of eating the GM corn. See that is the sort of debate you could go into with the better kids."

At this point, Rob brought economics into the discussion. "Did you know that in Canada, they plant the area of Tasmania in canola? It's unbelievable."

"It's big business" Jack concurred.

Jenny was concerned by the economic muscle of large companies in a relatively small economy such as Tasmania. "You see, if a company is big enough and employs enough, and has a big amount of the state's GDP, as alkaloid companies do, they call the shots."

Rob agreed. "Yeah, well they did with poppies."

Jenny continued her argument. "They'd pull out if they were not allowed to go ahead with GM poppies."

Jack though had a different view on the reason why the GM poppy was not included in the government's moratorium.

"No, it is a security issue. That's what has come about. Purely and simply, these new crops are too toxic, and you can't pick them by looking at them. By spreading 
rumours that half the crop is more toxic, no one will touch them. That's the security. And there are probably only 10 percent of them are toxic. But the rest, you can't tell. If you had the toxic crop and the non-toxic crop, you can't tell the difference, only through analysis. So I think that is a security matter more than a political matter."

Jenny maintained her position on the issue. "But they are still modified in comparison with other strains ... they are having a lot more difficulty in having them legislated." Jack explained that the company's research was well advanced before the issue of GM had become a mainstream issue in the media. "Agreed, but I think that the company has been doing it for about 10 years already. They had a foot in the door beforehand."

"Also the government's moratorium is only on food crops, it doesn't cover the pharmaceutical crops" concluded Stuart, as the discussion moved onto physics.

Speed and motion experiments using ticker times, inclined planes, rockets powered by carbon dioxide, water or solid fuel and strobe light photography are all commonly used by the teachers in this department. No one, however, had heard of an experiment to measure the speed of insects. Jenny explained the work of one of her students.

"Sam measured the speed of insects. He got himself a scorpion and a slater and a snail and one of those ... can't remember. And then as they took off, he got the video camera and he went along after them with chalk, and then he got string along the chalk, and he had to help some of them along a bit, and got the comparative speeds."

"Painstaking" was all Jack could say. 


\subsection{VIGNETTE 11}

This Vignette describes the difficulties that a new, non-science trained teacher, Dick, had in shaping an identity as a teacher of science, and the difficulties that the department had in assisting Dick in the process of identity formation. The Vignette is based on the transcripts of the science department meetings of February and March 2003.

\section{'APPARATUS ... THE NAMES OF THE BITS AND PIECES'}

\section{A struggle to identify}

The summer holidays were over, and the teachers had returned a week before the students. Apart from the obligatory whole school staff meetings, the school had also organised a day at a local lake for the staff to catch up socially with their colleagues. Each department was also given time to organise meetings for its own members. The first science department meeting for the year was also a chance to formally meet the newest member of the science department.

Dick had joined the teaching staff as both a mathematics and science teacher. He had previously worked in the engineering division of a large manufacturing plant that had been progressively downsized and restructured over the past 15 years. During this time the workforce had been dramatically reduced, causing serious economic dislocations in the surrounding area. Dick had left the company and studied for a Bachelor Degree in Adult and Vocational Education. It had been some 25 years since he had formally studied either mathematics or science. This was his first teaching position in a secondary school.

The first departmental staff meeting was designed to ensure that everyone had the correct syllabus information and were updated on the resources that had arrived in the school over the summer. The booklets that outlined the syllabus content, assessment criteria and attendance registers had been handed out to each teacher earlier in the week. The school appointed Stuart to mentor Dick - Stuart was in his second year at the school with 15 years of teaching experience - and they had already gone through 
the syllabus that Dick was to teach: one lower secondary science class, Year 8. But from the start Dick did not exude a great level of confidence. This was clear in the first meeting.

"Any comments?" asked Rob, the Head of Department, as the discussion turned to the Year 8 syllabus outline. The question was directed to the other teachers of Year 8 for that year: Stuart, Dick and Jenny. Rob was also taking a Year 8 science class.

"No surprises" replied Stuart.

Dick's first question surprised Stuart, as they had gone through the syllabus that morning. "Is there a book that goes with Year 8?" Dick asked.

"No, we don't have text books" replied Rob, who went onto explain that the usual practice was to select relevant material from any text and use that when appropriate. At this point Stuart realised the enormity of the task that awaited him in mentoring Dick. The "usual practice" that Rob had just referred to might work well for those with a deep understanding of the subject that they were to teach, but would probably not be a great deal of assistance to someone lacking that understanding. Even as this realisation was dawning on Stuart, the conversation had moved on, highlighting Dick's lack of knowledge.

"I bought a Year 7 book, a whole lot of them" Dick said, "I had the idea of photocopying that and testing them on ... on ...on ..."

"Apparatus" offered a somewhat bemused Jenny.

"The names of the bits and pieces and going over safety again" continued Dick. "Given that I haven't done any science teaching before, I thought I should know what they can do. That's what I'm here to find out, I haven't looked at anything, I haven't seen the assessment criteria or anything yet." 
Rob, knowing that Stuart had spent time with Dick that morning, pointed out where the materials could be found. "The assessment criteria would be in with the notes with this" he said, referring to the booklet. Dick did not respond.

The teachers for Year 8 moved onto the order that they would teach the topics in. The idea was to avoid too many classes seeking to use the same equipment at once, due to some perceived shortages. Dick would start the year with the unit of work on Chemistry, which included acid-base, acid-metal and acid-carbonate reactions, word equations, corrosion and its prevention. Stuart, in his capacity as mentor, offered to work in tandem with Dick.

"It might be worth, Dick, if we work together."

"Yeah, I'd be happy with that. My weak area is chemistry" replied Dick.

"I'll give you a hand with that, I've got some resources in that" offered Jenny, who was highly regarded for her teaching of chemistry.

"Meet the chemistry guru" said Stuart, showing his respect for Jenny's abilities.

Dick's response did not inspire confidence. "Chemical formulae and that used to scare me" he said. The return of the students was only six days away.

The return of the students in the following week gave Dick the opportunity to see Stuart and Rob at work in their classrooms, before he took his first science class. He made notes on how the teachers organised and managed their classes. The majority of his notes, however, referred to the content that was being taught, to the extent of taking the students' notes from the board. In Stuart's class, these notes initially included revision on the properties of acids and bases and their uses. The notes made in Stuart's class were to form Dick's lesson plans.

Rob, as Head of Department, and Stuart, as the school-appointed mentor, made an effort to sit in on Dick's science classes, in order to offer feedback on his progress and ideas for future lessons. The Head of Mathematics also supervised Dick's 
mathematics classes. All three expressed concerns about Dick's depth of subject knowledge.

Dick's lack of subject knowledge, as perceived by the department, was brutally exposed during the March science staff meeting. The school's administration had requested that departments consider the potential dates and costs for excursions during the year. Suggestions were put forward for astronomy, geology and biology, the same as in previous years. Dick suggested a visit to the school by an organisation promoting creation science. To the science staff, Dick asked:

"Have you heard about the creation science van that travels around schools, to give a scientific presentation of creation?"

"Scientific presentation would be one definition of it" was Stuart's curt response.

"One description of it" was Jack's sarcastic contribution to the discussion.

Stuart continued. "The creation science bus is fairly dogmatic. If you disagree with ..."

At this point Dick was back-pedalling rapidly from his initial question, "I've never seen one, I just heard about it." The damage had already been done.

Stuart finished his sentence. "It's not terribly scientific, if you don't go along with them, then, you're wrong. There is no space for disagreement with those people." The meeting moved on to the next agenda item.

\section{POSTSCRIPT}

Over the following seven weeks, Stuart and Rob continued to support Dick's teaching. Both occasionally took Dick's class in order to model classroom management, both helped with the development of lesson plans, and both went through resources and experiments with him. Their direct observations of his 
teaching, and concerns raised by students, however, forced Rob to act on Dick's perceived failure to develop as a teacher.

Within a week of Rob taking his concerns to the school's administration, another science teacher, Jill, was assigned to Dick's class. Jill had been teaching part-time before this, and the increased teaching load almost brought her up to a full teaching load. Dick was told by the school's administration to use the extra time allocation to concentrate on his mathematics classes. Rob's main concern as he expressed it to the Deputy Principal was that "he doesn't understand the core concepts well enough to teach them. He goes off with explanations that are not correct, and the kids' eyes glaze over. They know he doesn't know." Rob had acted to protect the status of the subject from what he saw as an inappropriate standard of teaching. If the subject had not had the profile of science, then it would have been interesting to see the response of the administration to the concern. 


\subsection{VIGNETTE 12}

This Vignette describes the teachers' view of themselves as science teachers. They recognise that science education across the state is struggling with falling enrolments, especially within the physical sciences. They are also aware of the declining numbers of science-trained teachers, and the deleterious effect that this is having on science education. The Vignette is drawn from the transcript for the June, November and December 2002 meetings and the March and August 2003 meetings.

'YOU WOULD NOT HAVE THE WOODWORK TEACHER TEACHING SCIENCE'

Identity and the subject

The discussion that afternoon had centred on what science knowledge to teach in Year 10. The question of who would teach it was just around the corner, as the teachers recognised that they were in the fortunate position of being in a department of teachers trained in science. As Stuart put it, "The point about who is teaching science is an important one, because for everyone around this table, that list of content would be enough. I think that you would be confident that everything would be covered." There were many nods of agreement.

This situation could not be said to exist in all other science departments across the state. In meeting after meeting with other science teachers, a grim picture was emerging. The syllabus-writing group that Stuart was involved in had highlighted a case in point:

"Every year there are a whole stack of schools where the head of science is being asked to justify the existence of science as a subject at all. Because they have to do an hour of physical education a day or every two days, an hour of numeracy, an hour of literacy, you have to do health, all those are compulsory. Take those out of the day, and it doesn't leave a lot of time for maths and science ... as a result you could have 
students going through Year 10 at the moment, and depending on the school, depending on the teachers who they have, how trained they are and all the rest of it, they can get by with doing very little physics, or very little chemistry, or whatever."

Rob, who has many contacts with other schools in his role as Head of Department, added to the discussion, "That is my understanding, yeah. I think that the trend is going to get worse as well, because of the shortage of science teachers; the quality of science teaching in 7,8 and 9 is going down. You know, some schools have Year 10 science as an option." He continued facetiously, "that's why we're not going to have science in 7,8 and $9 . "$

"What, that's awful" said a shocked Dennis.

"We'll have everybody doing projects, and saying that they are doing science" concluded Rob.

"We are seeing the dumbing -down of science" observed Jack.

This concern about the "dumbing-down of science" was expressed by many of the teachers present at the meeting. Jenny was concerned that the standards within the school may be far higher than in other schools across the state. Her concern was that the students within the school might be disadvantaged, in the short term, in comparison with their peers in other schools.

"So does mean that a top award at this school is going to be worth more than a top award at a school that doesn't teach the same knowledge? For example, all our chemical analysis in grade 10 is probably off the scale compared to some other schools."

Jenny continued on with her concerns, using the content outlines from two neighbouring schools to push her case that standards within the school were more rigorous than in the neighbouring schools. She went so far as to demean the efforts of teachers in the neighbouring schools. 
"Well, what I'm saying is that both that and that are lightweight in comparison to what we do in grade 10. In chemistry, but you see I guess that a lot of the high schools haven't the problem of knowing that their kids are going on to their own school in grade 11, so they don't care if they don't know about molar calculations. Because it is not their problem. They go off to a pretertiary college somewhere else where people there teaching physical sciences have got to deliver."

Jenny continued, "Because I tend to think that we are overcharging our kids, and whilst they're staying in our system, that's okay. But it worries me if they transfer out of our system into another system. They will end with a less high standard if they go to a school where they haven't done the same."

Stuart was quick to defend the efforts of the science teachers in other schools, and used his work as a subject Moderator at a district level to make his point.

"I think that is stretching it a bit. From what was said at the last moderation meeting, teachers know what their top-level kids should be able to do, which includes the sorts of things that you've said. So teachers basically know what they need to teach. For Year 10, calculations will be there, titrations will certainly be there, all that sort of stuff. We are not short-changing anybody."

Stuart knew, however, that with the number of science-trained teachers falling it was not just a case of knowing what the "top-level kids should be able to do". Schools also needed the teachers who could teach to that level. And, as Jenny soon reaffirmed, that was becoming increasingly problematic. Jenny was focussing on many students' lack of specific content knowledge when they were enrolling in Year 11 Physical Science classes.

"A certain amount of knowledge should be compulsory, because they were coming in and they know nothing. And it is a big, big problem. We hear it at moderation all the time. I mean it is so big a problem that they are talking about having a subject called Introduction to Physical Science as a non- pretertiary." 
Dennis had heard of this development as well in a senior secondary college. "Bowen College have already done that."

Jenny continued, pointing out the difficulties that this also created for students.

"Yeah, now that is a sad state of affairs for the rest of the state's 7 to 10 schools, I think. It's an indictment of very poor levels of achievement, and then they can't do their matriculation within the two years of senior college because they've got to do Physical Science in Year 12 and then they've got to come back for 13 too for physics and chemistry. So we're not helping them, I would have thought. So, from my point of view, the knowledge should be very subject specific, so that in all schools they are doing exactly the same."

It was against this background for concern that a new organisational model for Year 7 was released. The proposal came via the Faculty Heads meeting, and Maddie, a member of the schools' administration, introduced the proposal. The main changes to the current practice were to have teams of teachers in Year 7 and to also streamline the number of subjects being taught.

"To adopt the middle school approach for the Year 7 basic subjects. To limit the number of teachers that students have, and in English and social sciences, to allow for more integration of the syllabuses. It is an easing in process, better for the kids."

Rob moved quickly to fill in how science, and science teachers, fitted into this model. "For example, in Year 7, have the same teacher teaching maths and science and possibly one other subject."

Dennis was impressed; as he had though that such a model was in the best interests of students for some time. "I like it."

Jenny was diametrically opposed. "When I was teaching at the other school that I taught at, we had a similar structure. I really begrudged the time that I spent teaching 
SOSE (Studies of Society and Environment). I hated it. There wasn't the opportunity to teach other grades."

Rob was quick to reassure Jenny. "You would here. The proposal was not to spend all of your time in one year level, but the majority of your time in one year level."

Jenny, however, would clearly need more convincing. "A problem that I see with this is the lack of specificity of the teacher-student relationship. Because in that sort of set up, you could have people teaching science or SOSE or English or whatever, who are predominantly trained in another area."

Maddie moved quickly to reassure Jenny, given the concerns of the department. "No, because it is only in Year 7, we ought to be able to have subject specialists."

Jenny remained sceptical of this reassurance, and repeated her position. 'In an era of declining maths and science teacher numbers, is it wise to have your science teacher teaching other things? I wouldn't want science teachers teaching SOSE, we haven't got enough maths and science teachers."

Maddie's response was clear and unambiguous. "Maths and science teachers would be teaching maths and science. You would not have the woodwork teacher teaching science."

Dennis was quick to see the irony in this statement, and use it to reduce the tension that had crept into the meeting. "It is alright for a science teacher to teach woodwork," he said, "but you would not have the woodwork teacher teaching science." Dennis, the science teacher, was also a Year 7 woodwork teacher. 


\section{CHAPTER 10 - DISCUSSION OF IDENTITY}

These three Vignettes describe three critical events in the life of the community. In the first Vignette, the teachers tell stories of practice that increase their content knowledge. The difficulties that a teacher, not trained in science, experienced in forming an identity as a science teacher dominate the second Vignette. The third Vignette describes the teachers' view of themselves as science teachers. Four key themes emerge from these incidents. The first is the preparedness of the teachers to act in the defence of their subject against threats, both real and perceived. The second is the importance of stories in shaping teachers' knowledge in both content and pedagogy. The third is the importance of virtues in the views that the teachers hold about their subject, each other, and those outside their community. This theme is most appropriately discussed in terms of the first two themes. The fourth overarching theme that is never explicitly articulated by the teachers is the importance of the subject in shaping the identity of the teachers.

The teachers in this community are all, with the exception of Louise and Dick, tertiary trained in science. This gives them a relatively homogenous view of the world, a view shaped by their education in science. They can communicate in the language of science, and share the same passion for science education. For some of these teachers, science is located at the top of the subject hierarchy, along with mathematics, and above subjects such as Studies Of Society and Environment (SOSE), English and woodwork.

Jenny: "I really begrudged the time that I spent teaching SOSE. I hated it."

Maddie: "You would not have the woodwork teacher teaching science." (Vignette 12)

The hierarchy is clear, teachers of subjects down the hierarchy cannot teach higher up the hierarchy, but one can teach a subject that is lower down the hierarchy.

Dennis: "It is alright for a science teacher to teach woodwork" he said, "but you would not have the woodwork teacher teaching science." Dennis, the science teacher, was also a Year 7 woodwork teacher (Vignette 12).

Flowing from this strong sense of identity with the subject comes a preparedness to act in the defence of the subject against threats, both real and perceived. As demonstrated in the excerpts from Vignette 12 above, one identified threat was the 
risk of non-science trained teachers teaching science. That threat was, and remains, very real, as both Jenny and Rob recognised:

\footnotetext{
Jenny: "In an era of declining maths and science teacher numbers ... we haven't got enough maths and science teachers."
}

Rob: "I think that the trend is going to get worse as well, because of the shortage of science teachers; the quality of science teaching in 7,8 and 9 is going down."(Vignette 12)

This concern was understandable, given the experience that the teachers had earlier in 2003 with a teacher who was not trained in science. Dick had been employed by the school to teach maths and one class of Year 8 science. It had not been a positive experience for Dick or the community, despite the efforts that had been put into assisting Dick to become a teacher of science.

Dick was not university trained in science, and because of this had difficulty in assuming the identity of a science teacher. A key component of identity is the ability to communicate in the same language as others who also share the identity. Dick clearly did not possess this language:

\footnotetext{
"I bought a Year 7 book, a whole lot of them" Dick said, "I had the idea of photocopying that and testing them on ... on ... on ..."

"Apparatus" offered a somewhat bemused Jenny.

"The names of the bits and pieces and going over safety again" continued Dick. "Given that I haven't done any science teaching before, I thought I should know what they can do. That's what I'm here to find out, I haven't looked at anything, I haven't seen the assessment criteria or anything yet." (Vignette 11)
}

The difficulty with the language of science is not just that it is a highly specific language; it is also a highly symbolic language that one is trained into understanding. Dick's lack of background in science precluded him from this symbolic aspect of the language as well:

"Chemical formulae and that used to scare me." (Vignette 11)

Another component of identity that Dick did not possess was the ability to negotiate an understanding of the meanings that the science teachers had developed for their work. Of primary importance amongst these negotiated meanings was an 
understanding of the nature of science itself. The inability to participate in the negotiation of meanings was exposed in the March 2003 staff meeting.

Dick's lack of subject knowledge, as perceived by the department, was brutally exposed during the March science staff meeting. The school's administration had requested that departments consider the potential dates and costs for excursions during the year. Suggestions were put forward for astronomy, geology and biology, the same as in previous years. Dick suggested a visit to the school by an organisation promoting creation science. To the science staff, Dick asked:

"Have you heard about the creation science van that travels around schools, to give a scientific presentation of creation?"

"Scientific presentation would be one definition of it" was Stuart's curt response.

"One description of it" was Jack's sarcastic contribution to the discussion.

Stuart continued, "The creation science bus is fairly dogmatic. If you disagree with ..."

At this point Dick was back-pedalling rapidly from his initial question, "I've never seen one, I just heard about it." The damage had already been done.

Stuart finished his sentence. "It's not terribly scientific, if you don't go along with them, then, you're wrong. There is no space for disagreement with those people." (Vignette 8)

Clearly, Dick did not understand the negotiated meaning that the community attached to 'science'. Dick's lack of knowledge in science made it close to impossible for him to assume the identity of a science teacher. This difficulty did not mean, however, that the teachers did not attempt to help Dick in his teaching. There were several ways in which individuals attempted to help Dick. These attempts, although not successful in the end, are reflective of the virtues of teacher professionalism.

Dick would start the year with the unit of work on chemistry, which included acid-base, acidmetal and acid-carbonate reactions, word equations and corrosion and its prevention. Stuart, in his capacity as mentor, offered to work in tandem with Dick:

"It might be worth, Dick, if we work together."

"Yeah, I'd be happy with that. My weak area is chemistry" replied Dick.

"I'll give you a hand with that, I've got some resources in that" offered Jenny, who was highly regarded for her teaching of chemistry.

"Meet the chemistry guru" said Stuart, showing his respect for Jenny's abilities. (Vignette 11)

The return of the students in the following week gave Dick the opportunity to see Stuart and Rob at work in their classrooms, before he took his first Science class. He made notes on how the teachers organised and managed their classes. The majority of his notes, however, referred to the content that was being taught, to the extent of taking the students' notes from the board. In Stuart's class, these notes initially included revision on the properties of acids and bases and their uses. The notes made in Stuart's class were to form Dick's lesson plans. 
Rob, as Head of Department, and Stuart, as the school-appointed mentor, made an effort to sit in on Dick's Science classes, in order to offer feedback on his progress and ideas for future lessons. The Head of Mathematics also supervised Dick's mathematics classes. All three expressed concerns about Dick's depth of subject knowledge. (Vignette 11)

Trust is clearly demonstrated in these excerpts. Stuart trusts in Jenny's ability to assist Dick with the provision of resources that will help his teaching of the unit on chemistry. Dick trusted Rob and Stuart, he believed that the strategies they employed in presenting the topics and the way they managed their classrooms would be ones that he could transfer to his own class. Rob and Stuart trusted in Dick to learn from the observations that he made of their classes. In all of these situations, the members of the community: Jenny, Rob and Stuart, also demonstrate a care both for the progress of Dick as a teacher, and for the way in which science is taught in Dick's classroom. Given the strength of their negotiated meanings for science education: critical thinking, relevance, knowledge and theory, interest and understanding, it is no surprise to see them actively engaged in Dick's teaching.

Other virtues are also seen in the ways in which the community responded to Dick's lack of training in science. Practical wisdom saw Rob and Stuart offering guidance to Dick in how to teach the chemistry topic, including how to organise experimental lessons. This included Dick observing how they ran the same experiments in their classes before Dick ran them in his class. Honesty and truth are also evident in how willing Rob and Stuart are to:

"... offer feedback on his progress and ideas for future lessons." (Vignette 11)

The members of the community, however, made a fundamental error in the assistance that they offered to Dick. This error was not made in malice; it was made due to inexperience in dealing with teachers with no science training coming into the community. Dick was not in a position to develop an identity as a teacher of science. This made it difficult for him to place the information that he was to teach in a context that would direct his teaching. The community did not recognise Dick's lack of identity as an issue, as they had never had that experience before. To respond to a non-science trained teacher's difficulties with copious quantities of lesson plans and tips for experiments was to ignore the importance of giving the non-science trained teacher a context for using that information. If departments are in the position of having non-science trained teachers teaching science, a negotiated context for the 
material needs to be developed. Such a negotiation must be at the level of subject understanding of the non-science trained teacher, and concentrate on the core concepts of the topic being covered.

Dick struggled in his science teaching, and eventually Rob, as Head of Department was forced to act.

\begin{abstract}
Over the following seven weeks, Stuart and Rob continued to support Dick's teaching. Both occasionally took Dick's class in order to model classroom management, both helped with the development of lesson plans, and both went through resources and experiments with him. Their direct observations of his teaching, and concerns raised by students, however, forced Rob to act on Dick's perceived failure to develop as a teacher.

Within a week of Rob taking his concerns to the school's administration, another science teacher, Jill, was assigned to Dick's class. Jill had been part-time before this, and the increased teaching load almost brought her up to a full teaching load. Dick was told by the schools administration to use the extra time allocation to concentrate on his Mathematics classes. Rob's main concern as he expressed it to the Deputy Principal was that "he doesn't understand the core concepts well enough to teach them. He goes off with explanations that are not correct, and the kids' eyes glaze over. They know he doesn't know". Rob had acted to protect the status of the subject from what he saw as an inappropriate standard of teaching. (Vignette 11)
\end{abstract}

Rob displayed the virtues of courage and fairness. He was clearly concerned for the students in Dick's class, and how they were learning. In fairness to the students, he could not allow the situation to continue.

Yet to act in the way that he did required courage, for to act was to make it clear that Dick had not been successful in his teaching, that the school had not employed a suitable science teacher in the first instance, and that the school would have to pay for Jill to take Dick's class, as Dick had been employed on a full-time basis. The status that science enjoys within the school, especially with the parent community, probably meant that the administration had no option but to accede to the request that Rob made to them.

For those teachers who are trained in science, stories are a key method for their own learning. Vignette 10 makes this clear, as the teachers discuss a range of science disciplines from geology through biology to physics, with a touch of chemistry thrown in as well. The stories are stories of content, pedagogy and the relationship of science to the wider world of governments, economics and ethics. Through these stories, all members of the community are given a chance to contribute and learn from their colleagues in a format that allows issues to be explored in some detail. The 
virtue of trust underpins these stories, as it allows differences of opinion to be expressed and challenged in an atmosphere of mutual respect.

\begin{abstract}
"In mining we have got minerals and ores, prospecting, mining techniques ..." Rob began, as he introduced the unit to the meeting. Before he could finish outlining the content Jenny made an enquiry. "Distribution of mines around the state as well?" she asked. Jack took this as a cue to push for the inclusion of knowledge about the geology of western Tasmania, one of the most mineralised areas in the world.

"Make sure they know that the volcanic arc is unique in the world, bar one place" Jack said.

Rob's tone of voice was one of surprise. "Really? What's it called again?" he asked.

Jack explained the global geological significance of the area. "The Mount Read Volcanic Belt" he said, "You've got seven kilometres between the Hellyer silver lead zinc mine to the Renison Bell tin mine, which is unheard of, anywhere else, except in Quebec in Canada. They are the only two that we know of."

Jenny was intrigued "And is that the result of volcanic action?"

Jack explained the mineralisation. "Over three different periods, quite unique, exceptionally unique. Now you can throw in a gold mine down there as well". Not recognising that the teachers had learnt from this brief exchange, Jack apologised for the interruption. "Sorry, keep going" he said. (Vignette 10)
\end{abstract}

The story begins with the introduction of a geology unit that he and Stuart had worked on with their respective classes. The unit was developed from a similar unit that a teacher that they had met at a conference had run with his class. One of their objectives was to make geology interesting, and in this they believed that they had been successful. From this introduction of what the unit covered, however, the discussion turned into an opportunity for the teachers to learn more about the geology of western Tasmania. The unique geology, and genesis, of the Mount Read Volcanic Belt was discussed and used to explain the distribution of the mining operations in the area. Not only had teachers learnt something of the geology of their state, the entire conversation had been in the context of their classroom practice. After this lesson in geology, the discussion turned to the floatation method of mineral separation:

Stuart continued to expand on the topic content. "We've also got the environmental side, such as rehabilitation. This covers assessment criterion 7 , which is social issues. There is also prospecting, geological mapping, and mineral processing processes such as separation and froth floatation. The kiddies were impressed with the story about the bloke at Broken Hill with the beer."

"What's that story, I don't know that story?" interrupted Jack.

Stuart told the story of the metallurgist who, according to legend, had developed froth floatation by observing the bubbles in his beer. "He had a beer poured after a big day at the office, and he watched all the bubbles float up, and he noticed the foamy bit on top and 
thought that if he bubbled oxygen through the solution of minerals and bits and pieces, then the lighter ones should be carried to the top. So he did it."

"Who was it?" asked Jack, clearly impressed by the story.

"Can't remember the blokes name, but he made a fortune" replied Stuart.

Once again, the story was placed in the context of the classroom practice of the teachers, and also linked together the geology and chemistry units. The telling of a story that students could relate to was also seen as being a useful story to remember, as it was a fine example of the sometimes serendipitous nature of scientific discovery.

The other major story told centres on the relationship between genetically modified (GM) organisms, economics, government policy and ethics. The background to the study was the ongoing government moratorium on the growing of GM food crops. The moratorium did not extend to the growing of tightly controlled pharmaceutical crops such as opium poppies, which are worth some $\$ 120$ million dollars to the state economy, or fibre crops such as GM eucalypt trees grown for wood fibre. The discussion commenced with Stuart outlining how the school could tap into the expertise of Forest Education Foundation, a privately funded organisation, for the unit of work on biology. The discussion turned to the GM issue:

\footnotetext{
Jack: "That's a wonderful idea, but I have also said that I would like to see the better groups do a GM discussion, as there is a very large debate in relation to organic and non-organic, it's all related."

"We could do the GM one, because up there we went to the nursery out at Somerset and had a look at the propagation work out there. They grow 15 million trees a year and spend a fortune on developing 'super' trees" Stuart said.

Jack had also heard of the scale of the propagation work. "They ship a lot out to the mainland now." (Vignette 10)
}

From being centred on content and pedagogy, the discussion now turned to the science of trialling GM crops (a contentious issue at the time), and the ethics of using GM crops.

Jack was unimpressed by the concept of controlled open-field canola trials.

"You cannot isolate a crop, it is physically impossible out in an open space, of course the canola is going to cross. But then you go to a debate in Zimbabwe, there are millions of people starving, because the Government has made a decision that they are not going to let them eat genetically modified corn. I'd take the risk if you are starving to death, you're going to die, I'd take the risk of eating the GM corn. See that is the sort of debate you could go into with the better kids" (Vignette 10) 
Jack was acknowledging that there were two aspects to the use of GM crops, an acknowledgement that he believed students should explore in an honest and fair way. The use of virtues in scientific discussion are not something that teachers should keep to themselves, teachers should engage their students in order to educate their students in the relationships between science and the world. No one disputed that Jack would be right in explicitly pursuing ethical arguments with his students.

The discussions also touched on the relationships between science, economics and government policy. In this section of the discussion there was disagreement as to the nature of the relationships, but those disagreements did not limit the opportunities for the teachers to express their views:

At this point, Rob brought economics into the discussion. "Did you know that in Canada, they plant the area of Tasmania in canola? It's unbelievable."

"It's big business" Jack concurred.

Jenny was concerned by the economic muscle of large companies in a relatively small economy, such as Tasmania. "You see, if a company is big enough and employs enough, and has a big amount of the state's GDP as alkaloid companies do, they call the shots ... They'd pull out if they were not allowed to go ahead with GM poppies."

Jack, though had a different view on the reason as to why the GM poppy was not included in the government's moratorium.

"No, it is a security issue. That's what has come about. Purely and simply, these new crops are too toxic ... So I think that is a security matter more than a political matter."

Jenny maintained her position on the issue. "But they are still modified in comparison with other ... they are having a lot more difficulty in having them legislated."

"Also the government's moratorium is only on food crops, it doesn't cover to pharmaceutical crops" concluded Stuart.

Through the use of stories teachers have the opportunity to explore a number of issues and to learn from their colleagues. Stories of content, pedagogy and the relationship of science to other areas of human endeavour are important if teachers are to maintain a contemporary understanding of their subject and practices, and to challenge their thinking on both their subject and practices.

These three Vignettes highlight the importance of the subject in shaping the identity of the teachers and the importance of that identity in explaining their willingness to defend their subjects against threats. This sense of identity is not static, it is dynamic, constantly being negotiated through the use of stories in which teachers can learn 
from each other and reflect on their own practices and beliefs. For these teachers, the constant negotiation of identity is firmly grounded in the virtues of teacher professionalism: trust, care, practical wisdom, courage, honesty, truth and fairness. 


\section{CHAPTER 11 - ANALYSIS}

\section{1 INTRODUCTION}

In his discussion of the use of narrative in the qualitative analysis of data, Polkinghorne differentiates between what he refers to as 'narrative analysis' and 'analysis of narratives'. Narrative analysis requires the researcher to collect "descriptions of events and happenings and synthesise or configure them by means of a plot into a story or stories" (Polkinghorne, 1995, p. 12). Analysis of narratives involves the researcher collecting "stories as narratives and analysing them using paradigmatic processes" (Polkinghorne, 1995, p. 12). My research employs both forms of narrative inquiry in order to develop the raw data into the research text that this thesis represents. This process initially required the production of the field text from the data recorded at the science staff meetings. In order to produce the field text, the raw data was synthesised into a series of Vignettes that reflected the three major metaphors for my understanding of the notion of community: meaning (Vignettes 13), practice (Vignettes 4-9), and identity (Vignettes 10-12). In my research I am specifically referring to: the meanings that the teachers bring to their work as teachers of science; the teaching practices that they have both together and as individuals; and the identities that the teachers possess as a group and as individuals. These three metaphors of understanding community have been developed from the literature review about subject departments in chapter 4 .

By undertaking an interpretation of the twelve Vignettes in this chapter, the field text develops into my research text. My interpretation of the Vignettes is based on a proposition that has evolved from my reviews of teacher professionalism, professional learning, and the school-based subject department that constituted chapters 2, 3 and 4, as well as my personal reflections on the Vignettes. My proposition seeks to relate the understanding of community with the episteme, techne and phronesis of teaching, as discussed in chapter 2 . In seeking the means to relate the metaphors of understanding with the Aristotelian typology, two key realisations occurred that, for me, unified the theory with the stories that I was collecting. First, throughout each of the audiotapes teachers shared both their own reflections on issues that were important to them as 
teachers of science, and their stories of their work in science education. Reflecting on this observation, it became apparent that the virtues were important as a way of relating my metaphors of understanding community with the Aristotelian typology. The virtues provided a language in which to discuss the private reflections and/or public discourses of the teachers, thus linking the metaphors with the Aristotelian typology and providing a common thread for my research. Second, as I transcribed the audiotapes $I$ realised that the data was situating both teacher reflection and discourse around the metaphors of understanding: meanings, practice and identity. Initially, I was uncertain about how to resolve this conceptual difficulty. Resolution was provided when I attended a doctoral seminar in Hobart at which the notion of 'inbetweenness' was discussed. Applying the notion of the 'in-between' to the situation of reflection and discourse within my work provided the final piece of the jigsaw that was needed to link the theoretical frameworks of my research with the data that I was collecting. With my theoretical frameworks now developed, it was possible to make my proposition explicit.

My proposition states that professional learning occurs in the spaces 'in-between' the metaphors of understanding community: meanings, practice and identity. Professional learning occurs in these spaces 'in-between' when members of the community engage in virtues-based personal reflection and/or public discourse around the episteme, techne and phronesis of the specific 'in-between' space.

\subsection{PROFESSIONAL LEARNING AND 'IN-BETWEENNESS'}

I propose that professional learning occurs in the spaces 'in-between' the metaphors of understanding community: meanings, practice, and identity. The nature of the spaces 'in-between' is of critical importance to this proposition. The spaces 'inbetween' are sites of "original difficulty, of ambiguity, ambivalence and uncertainty, but simultaneously a site of general possibilities and hope" (Aoki, 2003, p 5). Bhabha (1994, p. 38) describe the spaces 'in-between' as 'the cutting edge of translation and negotiation ... that carries the burden of culture". Smith (2003, p. xvi) states that "inbetweeness was the deep ethical ground out of which it could be possible to negotiate a conversation". The language of virtues is fundamental to such a conversation. All 
three authors highlight the importance of negotiations in the shaping of the ethical and intellectual "landscape" (Clandinin \& Connelly, 1995) of the spaces 'in-between". I believe that foundational to these dynamic negotiations that shape the "landscape" are virtues. The virtues of teacher professionalism, such as honesty, truth, trust, courage, care, fairness, and practical wisdom, which were discussed in chapter 2 , are central to the relationships that exist between teachers within the community, the relationships between teachers and their subject, and the relationships between the teachers and their teaching practices. Virtues are, I believe, central to teacher professional learning.

Professional learning occurs when members of the community engage in virtuesbased personal reflection and/or public discourse around the episteme, techne and phronesis in the space 'in-between'. For example, in the space 'in-between' identity and practice, Dennis is concerned about the progress of those students in his class who are struggling with a curriculum that favours theoretical knowledge over practical work. In his concern he demonstrates a high level of care for his students:

Dennis: "And what about the weaker middle syllabus kids? ... Just something of a practical nature, 1 don't think that my kids would be capable of some of the maths." (Vignettes 5 and 9)

As another example, Jenny showed great courage in pursuing the introduction of a research topic into the syllabus, using the language of the Essential Learnings Framework. The Framework had been heavily criticised for reducing the status of science as a subject by the science teachers in the period leading up to this discussion.

\footnotetext{
Jenny: "You know where this would perfectly, it would fit in that Essential Learnings thing, because the whole idea of that Essential Learnings is that they (the students) have got data that is applicable to them, and that they can analyse it and display and talk about it. And that is the whole focus of the Essential Learnings. So you'll be doing something for the science department that they'd be interested in." (Vignette 5)
}

As a result of Jenny's courage, a research topic was introduced into the Years 7 to 10 syllabus, and the Science Expo, which developed from the research topic, was an overwhelming success for the science teachers. The importance of the virtues in both the negotiation of these developments, and the many other opportunities for professional learning that the Vignettes capture, are not to be underestimated. 


\subsection{STRUCTURE OF THE ANALYSIS}

The structure of the analysis of the Vignettes is directly derived from my proposition. There are three metaphors of community: meanings, identity, and practice, which reflect my understanding of the notion of community. As well as these three metaphors, there are also three spaces 'in-between'; the spaces between meaning and identity, identity and practice, and practice and meaning. Within each of these spaces, teachers engage in professional learning when they are involved in virtues-based personal reflection and/or public discourse around the episteme, techne and phronesis of the specific 'in-between' space. Episteme, techne and phronesis, therefore, form the structure of the analysis of the Vignettes within each of the three spaces. As an example, teachers can involve themselves in a public discourse regarding the importance of science as a discipline in the space 'in-between' practice and meaning. Through such a discourse, opportunities for professional learning are opened. It must be remembered that many reflections and discourses could be argued as occurring in more than one of the spaces 'in-between', and thus within the analysis of the Vignettes there is some degree of overlap. In recognising this challenge, I have attempted to maintain my paradigmatic structure by confining myself to what I believe is the most illustrative data for each 'in-between' space.

\subsection{ANALYSIS OF THE NARRATIVES}

\subsubsection{MEANING - IDENTITY}

The theme of the first three Vignettes is the desire of the community to articulate meanings about what it perceives as important in science education. Such an articulation of meaning is important, as these meanings shape both the practices and identities of the members of the community. The articulation that the community undertakes does not occur in isolation, it is carried out against a series of organisational backgrounds, from the school to the Secondary Assessment Board to the Teachers Registration Board. Both Boards are state government authorities. The former is charged with the provision of syllabus outlines and the organisation of public examinations for university entrance. The latter is charged with the registration 
of all teachers across the state, registration being dependant upon qualifications and character checks. There are occasions when this articulation is self-imposed, as in the case of the school science policy. In this case, there was a desire by Rob, the new Head of Department, to commit to paper the aims and objectives of the department. On other occasions, the articulation is in response to externally imposed decisions, such as teachers' reactions to the Secondary Assessment Board's decisions and to the requirements of the Teachers Registration Board. In constantly revisiting what the community viewed as important in science education, it became clear that the members of the community are also deeply concerned with maintaining, and in some cases vehemently defending, their identity as members of a school-based community of science teachers. This nexus between meaning and identity is a crucial site of professional learning, as the following introductory example highlights.

In Vignette 1, the community is asked a profound question. It is deceptively simple: "So to us, what is important?" In looking to write a school science policy, the Head of Department asks the teachers what is important to them in their field of expertise, science education. They are asked to explicitly state their understanding of what is important. If any community of science teachers were asked this question, then this community should be in a position to provide a succinct answer that describes the essence of their work. There are several reasons for this belief in the community's ability to answer the question: They have taught together for over a decade; with one exception, they are all trained in the sciences; members of the community are intimately involved with curriculum initiatives across the state; and members of the community have won, or been short-listed for, a number of teaching awards. Yet, despite the obvious strength of their commitment to science education, and the results achieved by their students, they struggled to provide an answer to the question.

What is important to these teachers is expressed in a series of statements that were never elaborated on by any of them:

\footnotetext{
Maddie: "I think that we should be educating people to be able to make informed decisions based on what they see on television or read in the paper, and to see that to every story there are two sides to it, and to able to critically make a decision... A fairly good focus on science in everyday life ... The main thing is that they need to be interested in it. If they are interested in the subject, provided that they have a certain level of ability, then they will be able to handle it in 11 and 12."
} 
Rob: "The Year 10 Science that I teach in top syllabus is really focussed on knowledge and theory, because they are the students who are going to go onto Year 11 and 12."

Dennis: "Well, 1 think that if we state something about them making informed decisions, based on some sort of understanding of the processes involved, then you can go from there ..." (Vignette 1)

Critical thinking, relevance, knowledge and theory, interest, understanding; these words are the foundations on which the community base their understanding of the teaching and learning that occurs within the laboratories and classrooms that occupy the science block.

These foundations were never formally stated in any documentation produced by the community or the school, and the proposed school science policy, which was to include the aims of science education, was stillborn (see Appendix 1). The unstated science policy was, and still is, a paraphrase of Zoe's mathematics policy: "We teach science, that's our policy". The teaching and learning of science did not suffer as a result of this inability to state explicitly what was important to the community in terms of science education. Indeed, the success of the Science Expo in 2003 would indicate that the science community was undergoing significant changes aimed at improving its practice. Professional learning, as I have defined it for this thesis, is clearly occurring for this community as they continue to negotiate their meaning and identity. The processes that enable this professional learning to occur are the personal reflections and/or public discourses that the teachers engage in around the episteme, techne and phronesis of science teaching. Engagement in these reflections and/or discourses serves to hone the teachers' sense of identity and meaning as teachers of science, as they continue to both learn from each other, and work to constantly interpret their discipline.

\subsubsection{Meaning - Identity: Episteme}

The importance of the subject cannot be underestimated in this discussion of professional learning. The teaching of a subject engenders an identity for teachers of that particular subject. This identity is crucial in the shaping of a boundary around the teacher community, as was discussed in the review of the literature on subject departments. Subject knowledge provides the members of the community with the 
words, arguments and goals that permit them to negotiate a sense of meaning for science education. An example of this is the following excerpt from Vignette 8 , in which Jenny is responding to proposed changes to her pretertiary chemistry course.

Rob, who did not teach any Year 11 and 12 science classes, offered a solution. "Can you do organic chemistry earlier, as the first unit?"

"I could, but that is not good chemistry. And if I do, then I miss out on my electrochemistry, so I leave a different assessment criterion off."

Maddie teaches Physical Science, the Year 11 subject that is a prerequisite for chemistry in Year 12.She is sympathetic to Jenny's concerns. "It is better to do electrochemistry first, and you can't do organic chemistry until you have done electrochemistry, because you have a lot of oxidation."

'Good' chemistry, as taught by Jenny, followed a clearly defined sequence of topics. It was the perceived threat to this sequence that Jenny was concerned about. "I have a sequence worked out, I have done it for five years, and I have changed various bits and pieces, but it is good." She had not appreciated the earlier examination this year. "It was disastrous for me this year, because it was very difficult to set the paper because I had to make up a lot of my own organic questions, as I hadn't gone deep enough into the topic to be able to use any of the exam paper types of questions. So I had to write a lot of stuff myself." (Vignette 8)

For Jenny and Maddie, who both teach Year 11 and 12 chemistry, there is a particular sequence in which the subject is to be taught. This sequence gives these teachers a sense of meaning for the subject that Jenny describes as "good". Other teachers, without this knowledge might suggest a different sequence, as they do not have the same sense of meaning, which in this case developed over five years. Thus, discourse and reflection around the subject provides for professional learning in the inbetween' space between meaning and identity. Three Vignettes further emphasise this point.

Vignette 2 highlights the response of the community to externally imposed government decisions. Specifically, the state government's Secondary Assessment Board is in the process of writing new science syllabuses. Both Zoe and Stuart are involved in this process. Zoe is involved in writing the pretertiary Biology and nonpretertiary Life Science syllabuses, and Stuart is involved in the General Science syllabus writing. Subject knowledge was seen as crucial to the integrity and acceptability of these new syllabuses, a point both teachers made explicit:

Zoe: "We had to have a clear dividing line as to the content in each subject. It was one of those areas that we intrinsically knew what it was, but you have simply got to get it straight in your head and make it obvious for other people ... to put things like aquaculture, agricultural science and geology together so it would be like a framework syllabus that people could do it from the point of view of a local industry that worked for them."(Vignette 2) 
Stuart: "This is the content that we think is essential to get the top award ... what we are looking at is students having a good understanding of scientific literacy, which we came across at the last meeting here. That would include an understanding of the terminology and language of science, because it is a very precise language, as well as a large number of the basics, your scientific method, and methodologies and also your general knowledge of the science that they see around them, or don't see around them." (Vignette 2)

The aims of science education that the community has negotiated for itself: critical thinking, relevance, knowledge and theory, interest and understanding are all expressed in these statements. Clear in their own minds about the crucial importance of these aims, Zoe and Stuart have interpreted these aims into the work of the syllabus-writing groups in which they were involved. The interpretation is unsurprising as this school-based community is not isolated from other communities of science teachers. Given that the other syllabus writers are also trained science teachers, there would generally appear to be a common acceptance of these aims of science education, even if they may be expressed in different ways. Ideas, strategies and meanings in science education are freely debated and negotiated, challenged and accepted, imported and exported through the many interactions that science teachers have with their colleagues in other schools and institutions. In these debates, challenges and transfers, teachers have an opportunity to learn from their colleagues in the wider science education community.

What it means to educate students in science is seen as foundational for the aims of science education that have been negotiated. Of equal importance in the identity of the teachers and their community is the foundational nature of episteme. Through reflection and discourse, subject knowledge shapes the meanings that they negotiate for their work. Through reflection and discourse, the subject shapes their identity. They teach science, and science is their subject. This sense of identity is clear when Jenny argued against a proposal that may have allowed non-science trained teachers to teach science in Year 7:

\footnotetext{
"In an era of declining maths and science teacher numbers, is it wise to have your science teacher teaching other things? I wouldn't want science teachers teaching (other subjects), we haven't got enough maths and science teachers." (Vignette 12)

Maddie's response was clear and unambiguous. "Maths and science teachers would be teaching maths and science." (Vignette 12)

Dennis: "It is alright for a science teacher to teach woodwork ... but you would not have the woodwork teacher teaching science." (Vignette 12)
} 
By making these statements Jenny and Dennis, very clearly and unapologetically, also promote science in the hierarchy of subjects. Science is more important, in their view, than subjects such as Studies of Society and Environment and woodwork. Hence, to challenge the subject is to challenge both the teachers' personal sense of identity and their position in the academic hierarchy. To challenge the subject, therefore, is to provoke a furious response. Vignettes 2 and 12 chronicle both the challenge and the subsequent response.

The response to the "pigeon-holing" of the new science syllabuses in Vignette 2 was acerbic, as typified by Jack's statement:

"They are wallies, absolute wallies, incompetent morons. The reason that they are at the Secondary Assessment Board is that they can't teach." (Vignette 2)

While this could be explained as a reaction to the wasting of teachers' time and public money, Vignette 12 gives a deeper reason for the response. The "pigeon-holing" is seen as a pre-cursor to the introduction of the Essential Learnings Framework syllabus. This syllabus was seen as "dumbing-down science", attacking the subject and its knowledge base, and so attacking the teachers' sense of identity:

Rob: "You know, some schools have Year 10 science as an option ... we'll have everybody doing projects, and saying that they are doing science." (Vignette 12)

Doing projects is something that everybody can do, and they can even call it science if they want to. Science teachers, however, will know that it is not science, because science teachers know that only science teachers can teach science:

Rob: "I think that the trend is going to get worse as well, because of the shortage of science teachers; the quality of science teaching in 7,8 and 9 is going down." (Vignette 12)

Episteme, however, is not enough to make a science teacher. A teacher also needs an understanding of the other two constituents of the Aristotelian typology, techne and phronesis. Discourse and reflection around episteme shape the meanings and identities of the members of the community. Discourse and reflection around phronesis help to make the teachers of this community aware that they are educating humans, not training technicians in science. Discourse and reflection around techne, the art of teaching, provides another avenue for professional learning as teachers share their stories and their open learning opportunities with their colleagues. 


\subsubsection{Meaning - Identity: Techne}

To be highly trained in science does not guarantee an individual the ability to teach science to others. To teach science requires an understanding of how people learn, as well as the knowledge and skills to engage the learner in the content of the subject. It also requires an understanding of the difficulties that many learners face in their learning. To teach requires sensitivity to the individual learning needs of the learner. As a result of these challenges, teaching requires skills and abilities such as communication, planning, explanation, questioning, providing feedback, assessment, motivation and classroom management. Reflection and discourse on techne provides professional learning in these skills and abilities.

Reflection and discourse on one's practice as well as the practice of other teachers is, however, more easily said than done. For to engage in reflection and discourse on practice is to make one vulnerable to understanding the limitations of oneself. The fear of understanding one's limitations can act as a barrier to reflection and discourse. Such fear can hinder, or indeed, preclude learning. Learning can only occur if individuals are prepared to make themselves vulnerable and thus overcome their fear. A prerequisite for this to occur is trust in the members of the community. The trust that the members of this community have for each other is clear from the Vignettes on meaning and identity. They are prepared to be uncertain with each other. They are prepared to tell their stories and to listen to the stories of others. They are prepared to disagree with each other and to learn from each other. By reflection and discourse on techne in the 'in-between' space between meaning and identity professional learning occurs within the community.

Vignette 1 describes a conversation about what the community values in science education. The notion of scientific literacy, as defined by Goodrum et al. (2001), is widely accepted, but there is uncertainty about what it is explicitly taught for.

\footnotetext{
"We already have it don't we?" asked Maddie, who was also the school's Director of Studies,

"A fairly good focus on science in everyday life."

Dennis, given the range of classes that he taught, wasn't so sure. "I'd say that in the middle syllabuses it is, in the top syllabus, I don't know."
} 
Rob answered Dennis' uncertainty. "The Year 10 science that I teach in top syllabus is really focussed on knowledge and theory, because they are the students who are going to go onto Year 11 and 12." (Vignette 1)

There is a dilemma here, as well as an opportunity for learning. Having decided that scientific literacy is important, the community is uncertain if they are teaching for it. Maddie believes that teaching for scientific literacy is already part of the practice of the community. And Dennis believes that teaching for scientific literacy is already part of the practice of the community, at least for the students in the middle syllabus. Rob does not appear to believe that scientific literacy is being taught for in the top syllabus, where the focus is on knowledge and theory.

Into this uncertainty Dennis provides an answer as to how the apparent dilemma can be resolved. The answer is not whether scientific literacy is being taught for or not, but rather for Dennis, it is a case of how to make it explicit:

\footnotetext{
"Well, I think that if we state something about them making informed decisions, based on some sort of understanding of the processes involved, then you can go from there ... if you put the word processes in there, then there is the scientific method for your top syllabus. I suppose that if we are doing a process then students do some sort of experiment and they are testing a hypothesis, then we can do as we have always done and relate the data to the hypothesis, and in that way get them to think critically, just based on the data that they have got. But then we need fairly simple experiments for some of them." (Vignette I)
}

In providing this linguistic connection between the needs of the top syllabus students, those who are "going to go onto Year 11 and 12" and the middle syllabus students, Dennis opened up an opportunity for professional learning to the community. The practice of the community, as it related to meaning and identity, had been made explicit.

The telling of stories is another important part of the discourse on techne in the inbetween' space between meaning and identity. These stories are a way of informing others about organisational and classroom practices that are novel, or giving other teachers ideas to develop for their own classroom teaching. As such, the stories are an avenue for teachers to undertake discourse around techne, and so they continue to negotiate both their meanings and identities. Stuart's story regarding the structure of science staff meetings at a previous school he was involved with is a case in point:

\footnotetext{
"We sort of did that sort of system a couple of years ago, where each person took a meeting, and one person who was new to science teaching brought in their Year 8 prac books, and then people went through and discussed; why did you give this person a $\mathrm{C}$ and this person a $\mathrm{B}$,
} 
which helped moderate things very nicely. One person did something on teaching about models, using models in science and some of the problems that you run across in using models. It doesn't need to be much, and if it is addressing problems that people have already mentioned, well, it helps everybody. Rather than passing around the latest stationery catalogue. Who wants to buy this Lego?" (Vignette 3 )

For Stuart, such an organisation of meeting times was beneficial. Each science teacher was given an opportunity to raise an issue that they had, or to share something that they had learnt. The aim of the meetings was to address "the problems that you run across ... and if it is addressing problems that people have already mentioned, well, it helps everybody". Nobody disagreed with the possibilities that this organisational structure offered for learning over the existing organisational structure, which was seen as little more than "information dissemination". Further, such a system offered an opportunity to satisfy the requirements for a system of state government mandated teacher registration.

One proposed criteria for ongoing teacher registration was the need for teachers seeking registration to be involved in ongoing professional learning, even though neither the Teacher Registration Board, nor the school, had ever made clear what this meant.

"It has never been perfectly clear what counts for that ... They haven't worked that out, the
Registration Board, have they?" (Vignette 3)

For organisations that were trying to document the amount of time that each teacher was involved in professional learning, this lack of clarity as to "what counts" and what, by implication did not count, had produced discord between teachers and the administration of the school. Caught in the middle was Rob, the Head of Department:

Rob: "We put in what we have done to the Director of Staff and he okays it."

Zoe had experienced organisational difficulties with this system. "We don't get a response back when we put it in to tell us if it was okayed or not."

Rob: "No, we have to wait."

Jenny was not impressed by the vagueness of this answer. "Till when?"

Rob was becoming increasingly flustered by the direction of the conversation: "Until we do get a response, what do you mean you don't get a response?"

Jenny explained the reason for her frustration:

"One does this, one gets a certificate to say that one has done this, one submits the certificate to the administration to say that one has done that, and one should get a response saying, yes we are accrediting you two hours, one hour, half an hour, whatever professional development 
time. That hasn't happened; I've submitted things and had no response. I've done something at the library that has given me a professional development certificate for a set amount of time that I have done there. Now, I am not sure what that is worth to my registration, and if it is worth something, as Zoe has just said, shouldn't that be documented and then evidence of that documentation provided for us."

Rob's instruction reflected little faith in both the Teachers Registration Board and the school's system. "If I was you, I would document it myself on my own curriculum vitae, because the amount of professional development that you have to do for re-registration, that hasn't been decided yet" (Vignette 3)

The teachers in the community, however, were specific about what they valued as important. Reflection and discourse around techne was seen as a part of professional learning, regardless of where it occurred. Stories around techne, stories that fill the 'in-between' space between meaning and identity can be told in formal meetings, and in informal discourse, such as over lunch:

Stuart: "Some of the best stuff occurs when you are talking to people over lunch. Like that conversation the other day about vectors, and making sure that the kids were doing the same style with their vector work." (Vignette 3)

The teachers saw such opportunities as important, as they offered a method of learning from their colleagues, learning that was in response to a common concern; vectors in this case. These teachers did not underestimate the importance of stories in learning. Administrators had also grasped the importance of stories, even if that importance was proving elusive to capture in an administrative form.

Rob: "The Principal said last night, 10 minutes here and there is not going to count, even though she said that she recognises that it is probably more beneficial than the other stuff."

Zoe noted that such a statement was an attempt to put administrative structures around teachers' professional learning in order to facilitate management and accountability. "That is more for administrative reasons than for devaluing the informal learning." (Vignette 3 )

Reflection and discourse around techne is an important avenue for teachers to negotiate the meanings that they bring to their work and their identity as teachers of science. For in reflection and discourse, often through stories, teachers can share their practice, learn from their colleagues, and add to the trust that underpins their sense of community. Trust allows the community to be accepting of uncertainty, into which a teacher can propose new insights from which the community can learn. Trust allows new practices to be proposed and debated, again opening up opportunities for learning. Trust also allows teachers to argue over what is important to them, reinforcing their sense of identity and community. Trust is foundational to community, meaning, and identity. Trust is foundational to professional learning in a 
school-based community. Trust, as a virtue, also underpins the third constituent of the Aristotelian typology, phronesis.

\subsubsection{Meaning - Identity: Phronesis}

The stories that are told in Vignette 10 cross several disciplines of science: geology, chemistry and biology. In geology, we have teachers sharing stories of the success of a new unit on mining that they had developed from listening to another teacher at a conference. This sharing provided an opportunity for learning about the geological history of Tasmania and the metallurgical process of froth floatation. This sharing provided an opportunity to engage in a discourse regarding the episteme and techne of teaching geology, and how geology teaching could become more than the dry study of rocks and minerals, colour, lustre, streak, cleavage and hardness. By placing geology in the wider context of the mining industry, student interest and achievement were seen to improve. It is in the stories of biology, however, in which we hear reflections and discourses on phronesis, and how it acts on both meaning and identity.

Science does not exist in an ethical vacuum; it exists in a world in which ethics determine the priorities and purposes to which science is directed. To have an understanding of science, which is limited to science as a mere process, is to be trained as a technician. To be educated in science and its ethical implications is to be human. Within this community of science teachers, it is important to educate humans about science, rather than train technicians in science. Critical thinking is one of the foundational aims that the teachers have for teaching and learning. It is also part of their identity as teachers of science.

Having trained, and worked, in both the physical and biological sciences, Jack was used to utilising data to support, or reject a hypothesis. In the discussion on genetically modified canola crops, Jack reacted critically to the issue. On the issue of the proposed open field canola trials in South Australia, he was scathing. "You cannot isolate a crop, it is physically impossible out in an open space, of course the canola is going to cross". On the evidence available to him, he was not convinced by the assurances that genetically modified canola would not cross with unmodified canola crops in the same district. 
On the question of African countries rejecting genetically modified corn from the United States, however, he was convinced that the benefits outweighed the risks:

\footnotetext{
"But then you go to a debate in Zimbabwe, there are millions of people starving, because the government has made a decision that they are not going to let them eat genetically modified corn. I'd take the risk if you are starving to death, you're going to die, l'd take the risk of eating the GM corn." (Vignette 10)
}

The core issue is the same; genetically modified food crops. On the evidence that was available to him, Jack gave two apparently contradictory responses. The safety assurances of the company proposing the open field trial were not believed. Yet, in an extreme case, the risks of eating genetically modified corn were seen as acceptable. It was part of Jack's identity, having been taught in the sciences, to critically evaluate and reflect on the information before him in order to reach an honest conclusion and to have the courage to stand by that conclusion. It was this sense of personal identity that had shaped his view on science education, and the importance of critical thinking:

"See that is the sort of debate you could go into with the better kids." (Vignette 10)

Discourse and reflection around phronesis provides for professional learning in the 'in-between' space between meaning and identity, as teachers deal with the virtues that underpin their sense of identity and meaning. The meanings that the members of the community bring to their work as science teachers are intrinsic to their identities as science teachers. Conversely, the identities that they have as science teachers are intrinsic to the negotiation and reification of the meanings that underpin their work as a community.

\subsubsection{Meaning - Identity: Epilogue}

The space 'in-between' meaning and identity is a space that is rich in opportunities for reflection and discourse around episteme, techne and phronesis. As such, it is a space of professional learning for this school-based community of science teachers. Within this space, teachers negotiate the meanings that they bring to their work through a combination of stories, defending the integrity of their subject against perceived threats, accepting uncertainties, and arguing over what they perceive as important to them as both individuals and as a community. These negotiations also reinforce the identity that the teachers have of themselves as teachers of science. They understand 
the language that they are speaking. They trust each other, as they share a common background in science and have negotiated a common sense of meaning. Most importantly, they value the work that they do as a community. This is the work of educating students in science; work that they identify as their own, work that they know is important. And this is work that within the school, they alone are equipped to undertake. For science is their subject, and only they can teach it.

\subsubsection{IDENTITY - PRACTICE}

For this community of science teachers, practice is the lived experience of the meanings that they have negotiated for their work, and the identities that they have as teachers of science. In the nexus between identity and practice, there are many examples of the identity that the teachers have developed influencing the practices that occur within the community. Practices that just a year before would have appeared unrealistic, or inappropriate, to the community emerge as exciting possibilities that can improve the teaching and learning that occurs within the science department. Some practices were challenged by those outside the community, and due to the strength of conviction that those practices engendered, they withstood the possibility of change. Other long-standing, practices are challenged by both individuals and the community, and are found wanting. In their place new practices are adopted in order to move the community forward. The dynamic interaction between identity and practice constantly presents new opportunities for professional learning in the 'in-between' space. In the personal reflections and/or public discourses around episteme, techne and phronesis, the members of the community accept those opportunities; with the result that professional learning is seen to occur.

\subsubsection{Identity - Practice: Episteme}

One aspect of the teachers' practice that undergoes a radical change is the curriculum. In Years 11 and 12, the state government's Secondary Assessment Board sets the curriculum and conducts externally assessed public examinations. The curriculum for Years 7 to 10 follows a recommended framework provided by the Secondary Assessment Board. The actual science content that is taught is the responsibility of the individual school. In December 2002, the curriculum of the school consisted almost 
entirely of a list of disconnected topics that were supposed to be covered within the school year. In theory, the topics were supposed to include the major scientific concepts that were appropriate for each year group. In reality, the number of topics was a source of frustration for teachers, and was seen to hinder the effective teaching of science:

Jenny answered for all of the Year 8 teachers. "We didn't get our last unit on machines done."

"So you struggled with time, did you?" enquired Jack.

Jenny's explanation as to why the last unit on machines was not covered reflected the difficulties in having some 14 topics to cover in a school year. "I think that 1 could have tightened up a few topics; I kind of went over, with a couple of the units early on. If I had kept to the time table..."

Stuart also expressed concerns about the large number of topics that were in the Year 8 syllabus at the time:

"The problem that I had was that you would just be getting into something with the kids, they would just be showing some understanding, and that is the point where you can stretch it and do all sorts of wonderful things, and bang, sorry, we've got to go off and do something different." (Vignette 4)

If understanding was one of the aims of teaching a large number of topics, then it had clearly failed. Both teachers and students had found the structure frustrating. If this was the case, if the topics had failed to be understood, then what could they be replaced with? And, just as importantly, how could the change be justified? The teachers' understanding of their subject, and the sense of identity that they have developed from it, comes into focus at this point.

According to Jack in Vignette 4, the core concepts of science, as expressed in chemistry, physics and biology should make up the curriculum from Years 7 to 10 . Jack also mentioned mathematics as a core concept that needed to be covered, but that idea did not gain wide acceptance, being replaced by a desire to engage the students in research. The important point to be made regarding Jack's opinion was not that he believed that his colleagues would cover the core concepts:

"We do cover all those" Jack said referring to the subject endpoints in physics, chemistry, and biology. "There is no doubt about that." (Vignette 4)

Rather, Jack trusted that his colleagues could teach the core concepts from a variety of directions. It was a trust shared by Rob: 
Jack: "I think we should have a flexible syllabus based on themes or something, and it is totally and utterly up to the teacher to decide on with those groups of students." (Vignette 4)

Rob: "We work out what we want to teach in each of those areas, and then leave it up to the teacher, to structure their unit themselves in Years 7 and 8 . If you want to do a whole 10-week block on chemistry, go for it. But if you want to split your chemistry unit up into a couple of units on chemistry, it's up to you. As long as we all cover the same endpoints, we'll be right." (Vignette 4)

This trust in the ability of the other teachers was a reflection of identity that they shared as teachers of science. Being experienced teachers, all trained in science, the trust was well founded. It was a reflection born of mutual respect and professional judgement in ones colleagues.

\begin{abstract}
Jack: "If people have any questions about depth or perception in terms of their work, they can talk to anybody and we can make a decision then and there. Is there a need to be so prescriptive? We can have common tests, particularly for the better kids that will cover the core units that every body does and if anyone wants to do anything else, that's fine. There needs to be some professional judgement there, so that these are covered." (Vignette 4)
\end{abstract}

Stuart: "So, Jack, you might do astronomy to cover physics, I might do light, that's fine, as long as we cover the same basic ideas. If people know where they have to get to, and then you leave it up to the professionalism of the teacher, I mean, we trust each other. For everyone around this table, the units and their endpoints would be enough. I think that you would be confident that everything would be covered." (Vignette 4)

Jenny: "This presentation demonstrated teamwork ... from the science personnel." (Vignette 6)

There was, however, recognition that such a system may not work for an inexperienced teacher coming into the community. Such a person would need to establish themselves as a member of the community before they enjoyed the same level of trust.

Jack: "For a new teacher coming in, being first year out might need a bit more guidance." (Vignette 4)

In the same way in which the relationship between identity and practice can open new opportunities for professional learning, the relationship can also be used to justify existing practices. This is especially the case if those practices are firmly held. Knowledge of the subject, and the influence of the derived identity of the teacher on practice, is graphically illustrated by Jenny's reaction to a proposal to move the school's internal examinations forward. The proposal to have the school examinations in early August left Jenny very unhappy. For her, the subject of chemistry possesses an internal coherence and logic that is beneficial for teaching and understanding. To go against this structure was to endanger the entire enterprise of being a chemistry 
teacher. When asked to consider changes, the following response showed the level of interconnection between identity and practice:

\footnotetext{
"I could (consider a new sequence), but that is not good chemistry ... I have a sequence worked out, I have done it for five years, and I have changed various bits and pieces, but it is good'. She had not appreciated the earlier examination this year, 'It was disastrous for me this year, because it was very difficult to set the paper because I had to make up a lot of my own organic questions, as I hadn't gone deep enough into the topic to be able to use any of the exam paper types of questions. So I had to write a lot of stuff myself." (Vignette 8)
}

Jenny's practice for the past five years had, without doubt, been successful in the area of pretertiary chemistry, given the examination results of her students and the Royal Australian Chemical Institute citations for teaching excellence that had come her way. Her identity is that of a teacher of chemistry, and as such, she is in a position to judge whether a practice is "good" chemistry or not. In this judgement, Maddie, who also teaches Year 11 chemistry, supports her:

"It is better to do electrochemistry first, and you can't do organic chemistry until you have done electrochemistry, because you have a lot of oxidation." (Vignette 8)

Episteme shapes the identity of the teachers in this community, and those identities shape the practices that the community sanctions. Through personal reflection and/or public discourse about episteme, professional learning can occur, leading to changes in practice and reinforcing the sense of identity that community members have. Alternatively, a tightly held practice based on a strongly held identity can be effective in forestalling changes to practice that are seen as inimical to good teaching and learning. Either way, episteme is a powerful influence on the shaping of the inbetween' space between identity and practice. Likewise, techne is an important focus for reflection and/or public discourse in this 'in-between' space.

\subsubsection{Identity - Practice: Techne}

The Science Expo (Vignette 6) was an outstanding success for all concerned. Parents were impressed by the research work that they had seen the students produce. Students had presented their findings to scientists, and found that they could relate classroom science to the world outside the classroom. The judges were impressed by the quality of science being undertaken within the school, a sentiment expressed by the comment made by one of the judges that the event demonstrated the "richness of the science experience that is available to students at the school" (Vignette 6). The 
science teaching community was also seen as successful in the classroom, and in the wider community.

School Newsletter, 29 October 2003: "It is clear that there are many experts in our local community who are willing to share their scientific know-how with our students. This can compliment our classroom teaching and make the study of science more relevant to our students. By engaging students now, hopefully we will encourage more to pursue careers in science,"(Vignette 6)

Clearly, the Science Expo had been a highlight for the science teachers in 2003, a fact confirmed by the decision to expand the event in 2004. The Expo was seen as a success, as it had given students the opportunity to apply the science that they had learnt in the classroom to questions that were of interest to them. The range of questions that they asked confirmed this. More importantly, the students were given the opportunity to discuss their methods and findings with 'real' scientists. While many found this daunting initially, they all grew in confidence as the evening went on.

The results of the Science Expo convinced the teachers that it was an event worth the extra effort in terms of organisation and commitment. Through this event the practice of the science teachers was changed. In terms of my proposition, what evidence is there that private reflection and/or public discourse around techne in the 'in-between' space between identity and practice has provided an opportunity for professional learning to occur? I believe that Vignettes 5 and 6 provide ample evidence of the occurrence of professional learning around techne, in particular, the introduction of a research-based topic into the curriculum. The catalyst for these changes was the leadership role taken on by Jenny.

In her letter to the school's administrative meeting (Vignette 5) Jenny gives a clear picture of what her identity as a science teacher means to her. She writes to the administration team that:

"It is my belief that conducting independent scientific investigation allows students an opportunity to address all of the ... key elements." (Vignette 5)

For Jenny, student research is an important part of her practice, a practice that has been recognised by various awards. Not only does she see student research as 
important for her own practice, but also as a way of improving the practice of her colleagues, as demonstrated in her dot points to the school administration:

- To raise public awareness of the importance and relevance of science to our lives today.

- To create models and exemplars of students work to assist teachers embarking upon this approach to curriculum delivery and the establishing of moderation standards. (Vignette 6)

Clearly, Jenny has reflected on her practice as a science teacher, and is prepared to share her thoughts in discourse with her colleagues. This discourse is to be found in Vignette 5, a Vignette that outlines the importance of techne after the discourses in Vignette 4 highlighted the importance of episteme in shaping teachers practice in the 'in-between' space between identity and practice.

In Vignette 4, Jack outlined what he saw as the "four basics" of the science curriculum; chemistry, physics, biology and mathematics. This discourse leads to the adoption of a Year 7 to 10 curriculum based on the core concepts of the first three scientific disciplines. Mathematics, however, was not seen as a core concept to be covered in the subject of science, with the result that there was a gap in the curriculum. Jenny suggested that a research topic should be placed into this gap. This suggestion was well received, with the main critique being how such a topic would work across all year levels and ability levels. This discourse around the techne involved with research topics was professional learning for the teachers, and it also lead to the acceptance of the Science Expo as a method of extending the work of the science teachers into the wider community.

Jenny's proposal could be considered in four sections. First, there was the actual organisation of the research topic:

\footnotetext{
"It could be organised by a couple of different methods. One way would be that you go unit one, research block, unit two, and unit three. That means that they have their research finished half way through the year ... The other option would be, or one of the other options would be that, you start out doing unit one, and you take a day a cycle, which is probably a better way to go, and that becomes the research day, and then next cycle has another research day." (Vignette 5)
}

Next, there were the expectations of what the students were to accomplish:

"There would have to be an expectation on those kids that they will have to complete it ... That is going to be part of their assessment that they have to complete." (Vignette 5) 
Third, there was a warning about the difficulties involved in running a research topic:

"Overseeing them, that is tedious work ... you know. It is very hard to coordinate." (Vignette 6)

Finally, there were the rewards to be gained by allowing students to undertake research on a topic of their choice.

"The very nature of research, it involves extending yourself out into the greater community.
And very often they (the students) have to do something that then has to be the data that is not
on the premises ... it is very rewarding when it works." (Vignette 5)

Taken together, these concerns for practice addressed the concerns that the teachers had about how the research topic could be adopted into the science curriculum for Years 7 to 10 . Jenny had explicitly addressed the issues, both positive and negative, that were of concern to the teachers, and so provided an opportunity for them to learn from her. The success of the Science Expo showed that the teachers had learnt from Jenny, and the result was their changed practice. This change in practice also had the effect of reinforcing their identities as teachers of science. The Science Expo had taken the science of the classroom into the wider community, and that community was appreciative of the science that was displayed. Jack was so enthused about the potential benefits of the Science Expo that he boldly proclaimed that science should be at the centre of the entire school's curriculum, with all other subjects radiating from science:

\footnotetext{
"We are going to gear the whole school around the Science Expo ... everything that we do in science could be the centre point, and every thing else comes into it. Computing to English to maths. The whole lot." (Vignette 5)
}

This self-assured confidence in the pre-eminence of science as the subject, an echo of Jenny and Dennis' statements in Vignette 12, had reached the Principal:

"I have heard that science is the focus and that every thing else radiates out from it." (Vignette 6)

She did not disagree with the sentiment expressed by the science teachers, perhaps in recognition of the kudos that the Science Expo had brought to the school, as shown in Vignette 12 .

The identity of the science teachers had been reinforced by the success of the Science Expo. They now saw themselves at the centre of the curriculum, and in a position to 
link what happened in their classrooms with the wider community. They had been publicly acknowledged as offering a rich science experience. They were seen as talented at their work, work that was valued by the school and the community. They had reached this position through a preparedness to reflect on their practice, and to learn from each other. The practice of the science teachers had clearly been enhanced through the opportunities for professional learning that Jenny had created in opening the public discourse on research as a component of the curriculum. The institutionalisation of Jenny's ideas on teaching scientific research was a reflection of this learning.

Institutionalisation of a practice, however, is not the end of the story. For changes in one practice can, and do, lead to changes in other practices. The teachers accepted the proposal for a research topic in Years 7 to 10 as a worthwhile change to the curriculum. The proposal was seen as valuable in linking the science of the classroom with science in the wider community, thus challenging students to apply their knowledge to new situations. This reasoning behind the benefits of the proposal to students with an aptitude for science was never challenged in the data. For students who struggled with science, for whatever reason, the benefits were challenged; almost the instant the proposal was raised:

Rob: "Would your weak kids be alright with this?" (Vignette 5)

This question is a reflection of phronesis, the moral dimension of the Aristotelian typology. Despite the enthusiasm for Jenny's proposal shown by the teachers, there was a great deal of concern about how all students would cope with being asked to use the form of the scientific method taught within the school to generate an answer, or answers, to a question that they had developed. For some students, such a task would prove too difficult, and could further alienate them from science. To deliberately alienate a student, any student, from science would go against the aims that the teachers had negotiated for their work: critical thinking, relevance, knowledge and theory, interest and understanding. Phronesis, a moral concern for the learning of all students, meant that alternatives had to be provided to the research topic proposal. It was an area of their practice that individual teachers had already perceived needed improvement: 
Zoe: "What we haven't necessarily always done very well is this within-school moderation. If you do head down that path, you do need to have quite effective ways of allocating kids to these classes." And, she continued, "l think that that has been the problem with science in the past. We do need to address that a bit better." No one disputed this criticism. (Vignette 7)

Jack: "But, you see, my view is that there should be some practicals that you do purely and simply for the enjoyment of science. You don't necessarily have to write up everything ... if I was looking at this, in terms of a less able science student, I'm not going to enjoy it in Year 9. You need something, you need some enjoyable science there that can, let's face it, and it's not enjoyable. So in 9, we need some whiz bang stuff." (Vignette 9)

Such statements open new opportunities for professional learning, as they bring issues for private reflection and/or public discourse in the 'in-between' space between identity and practice to the surface.

\subsubsection{Identity - Practice: Phronesis}

Students have different abilities in different subjects. As a consequence of this, different students often need to be engaged in learning using different teaching practices. One of the primary responsibilities that teachers have is to match the appropriate practice with the appropriate student in order to facilitate learning for that student. Having an understanding of, and empathy for, the abilities and attitudes of the students in a class is a vital prerequisite for teachers if they are to undertake this responsibility. The virtues of honesty, truth, trust, courage, care, fairness, and practical wisdom provide a language for understanding the professional learning that occurs when teachers consider their responsibilities to student learning in the 'inbetween' space between identity and practice. These virtues form a foundation for much of the discourse in Vignettes 5 and 7.

Having discussed the idea of a research topic in Years 7 to 10, there was a realisation that some students would not, in the teachers' opinion, benefit from the proposal:

Jill: "If your talking about their ability, no."(Vignette 5)

Stuart: "With kiddies like that you need to keep it fairly structured, you basically give them the question." (Vignette 5)

Rob: "Would the weaker kids be better off doing a project over a block of time? Or not a project, and just do another unit of work?" Jill's response, borne of experience in teaching lower ability classes over a number of years, was blunt. "Another unit of work." (Vignette 5)

Dennis: "Well the first unit, I'm just concentrating on practical work, and what I'm finding is interesting in that I'm getting to the stage now where I'm wondering what practical work, not necessarily to do with school, but anything practical that students do ... It's just those little 
things ... so I don't think we can expect the kids to have the same skills that they used to have, because $l$ don't think that they do." (Vignette 9)

For Dennis, the entire question came down to what was best for his students. His plea was direct, and reflected a great degree of care for his students:

Dennis: "And what about the weaker middle syllabus kids? ... Just something of a practical nature, I don't think that my kids would be capable of some of the maths." (Vignettes 5 and 9)

These statements all reflected the meanings that the teachers had negotiated as being important in their work as science teachers. For those students who were in the top syllabus, knowledge and theory were seen as important:

Rob: "The Year 10 science that I teach in top syllabus is really focussed on knowledge and theory, because they are the students who are going to go onto Year 11 and 12." (Vignette 1)

For students in the middle and bottom syllabuses, there was a different emphasis:

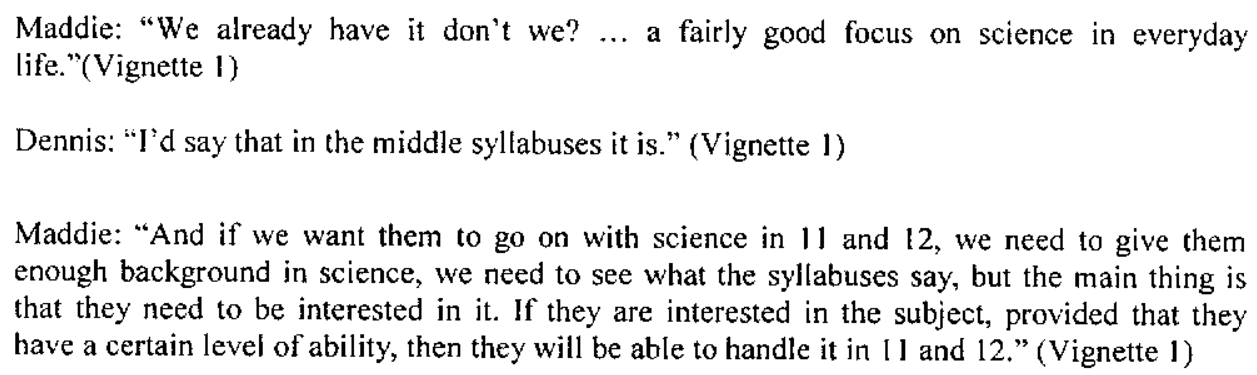

Maddie: "And if we want them to go on with science in 11 and 12, we need to give them enough background in science, we need to see what the syllabuses say, but the main thing is that they need to be interested in it. If they are interested in the subject, provided that they have a certain level of ability, then they will be able to handle it in II and 12." (Vignette 1)

Given the aims of the community, the work that students undertook needed to be capable of inspiring interest, regardless of the syllabus that they were studying. This important aspect of the teachers work was highlighted by Jenny's statement regarding the proposed research topic and students who struggled in science:

Jenny: "I would say that the weaker kids would probably not be as interested in the outcome." (Vignette 5)

The other teachers shared this opinion of the importance of engendering interest, in ways that could sometimes be considered trivial to a teacher but crucial to students:

Rob: "Are the weaker classes going to bother doing titrations?"

"They love to. They do them, they don't understand anything about the molarity, that doesn't matter. They think that they are doing science. In Year 10 they probably will end up doing titrations. They just have to fill in the boxes" Jack said, referring to the calculations that went with titrations. "Unless we just get onto the titrations and not worry about the theory, because they like putting lab coats on" he concluded. 
Rob had taken this path with some previous classes. "Just the mechanics of it, that's what I used to do with the other group. They could use the all the gear, but had no idea about the calculations. They can't do the maths and stuff, they can't write the equation."

Dennis was unequivocal about the value of the equation compared to the value of the practical. "They can still do the prac though. Forget about the equation."

Jenny was concerned for the wellbeing of her chemistry burettes, in the hands of lower ability students. "Yeah, you could give them the plastic burettes as well."

"Oh no, you have to give them the glass ones, how would they break the plastic ones?" asked Jack, who was fishing for a bite from Jenny. The bait was not taken.

"Swordfights?" offered Stuart, referring back to an earlier incident in which two burettes had been broken in a duel between two students.

"Mine have difficulty with lab coats and things like that" said Jenny, changing the conversation back to the need for some students to look like scientists before they thought they were doing science. It just wasn't science without a lab coat and, preferably, a pair of safety glasses.

"Lab coats?" asked a slightly incredulous Rob.

"You've got to look the part" explained Stuart.

There was a chorus of agreement. "You do" said Jack. "The better groups don't care about the lab coats."

"Oh yeah?" added Jenny, before continuing. "Who did I have doing titrations, and all he used to do was go out into the corridor, up and down, in his lab coat and his glasses, so that everyone could see him?" (Vignette 9)

Thus, for many students, alternatives involving practical work had to be developed in place of the research proposal. The alternatives decided on followed the basic idea of the research topic proposal. Both alternatives relied heavily on teachers knowing the interests and abilities of their students, and taking these into account when deciding on topics. For the weakest students, the teacher was given the autonomy to develop, in consultation with the students; a teacher-directed investigative topic that they believed would be of interest to their students. For the middle syllabus students, a structured research project was decided on. Under this proposal, students could research any reasonable question from within a teacher-selected topic. In this case, there was to be a high level of teacher assistance in the conduct of the research. The model for this assistance came from a teacher whom Stuart knew:

Stuart: "Basically, the way that she sets it up is to give the kids a $\log$ book, they have to come up with the question, when they have done that they have to get her to sign off on it and they sign off, work out the variables, everyone signs off, so that is all very structured." (Vignette 5) 
As a result of the discourse around the research topic proposal, teaching practices were developed that took into account the different student abilities found in the teachers' classes. The focus of each of the alternatives may vary, from "theory and knowledge" to "science in every day life" but each was formulated with the idea of building student interest in science. To engender interest was seen as a method of encouraging more students to take suitable science based courses in the Years 11 and 12 , and so strengthens the identity of the science teachers within the school. In making alternatives to the research topic available, however, the teachers also needed to carefully consider the premises on which they were basing the alternatives. These considerations had in fact been an ongoing process as Vignette 7 suggests.

All of the alternatives to the research topic, and indeed much of the work of science teaching, were based on two premises. The first was that students were in the appropriate syllabus for their ability. The second was that teachers knew their students' attitudes, interests and abilities well enough to be able to develop topics that were suitable for them. Vignette 7 demonstrates the importance of phronesis in critiquing these two premises, mainly through the efforts of one teacher, Dennis. Dennis' reflections and role in the ensuing discourse opened opportunities for professional learning in the 'in-between' space between identity and practice.

Rob, as Head of Department, was administratively responsible for the allocation of students in classes. The process through which this was done could be considered somewhat subjective:

\footnotetext{
Rob: "I don't know the process is, but obviously, do we get together and talk about it, or do you just give me your results and l just pick off the top ones in each class, or what happens?" (Vignette 7)

Jenny: "That's what I used to do, and hope that an OA (Outstanding Achievement award) coming from one class was equivalent to an OA from another." (Vignette 7)
}

Dennis, however, did not believe that such a system was equitable to boys. His belief was based on the opinion that criterion-based assessment disadvantaged boys, particularly in Years 7 to 9, where he taught. 
Dennis: "If you are looking at Years 7 and 8, when you look at the swing in assessment criteria and so on, how subjects have become touchy feely, it is no wonder that boys are disadvantaged in that area. You are looking at a lot of written work, and poster drawing and what ever is going on, then of course the boys are going to be disadvantaged compared to the girls." (Vignette 7)

Dennis believed that criterion-based assessment disadvantaged boys, as it was weighted towards the presentation of work, which girls were better at, and did not give boys the chance to be boys. Boys in the lower years of secondary school were not usually "touchy feely". And science, which should be a hands-on, messy, experimental subject, had been made into a "touchy feely" subject. Dennis identified as a science teacher, "it is alright for a science teacher" (as Dennis refers to himself in Vignette 12), but he was not assessing "science". He was assessing the presentation of students" work, the "written work, and poster drawing and whatever is going on". A more objective method of assessing science was needed. This dilemma that Dennis was expressing was a reflection of the status in which science was held within the wider school community. Science is an 'academic' subject that many see as difficult, but necessary. Scientific knowledge is highly valued in western society (Coulter \& Orme, 2000) and as such should be taught in a rigorous, content driven manner in order to prepare students for tertiary science. The fact that a declining number of students were going onto the pretertiary chemistry, physics and biology subjects was, to the teachers, an indication that such an approach was unsatisfactory. While there was a desire to maintain the content base of science across the year levels (Vignette 12), there was also a desire to engender more interest in the subject. However, to make the subject too "touchy feely" was a mistake in the view of science teachers such as Dennis.

Rob, raising the issue of the allocation of students to classes gave Dennis an opportunity to express his thoughts. In part, as a result of Dennis' concerns, a new system of allocating students to classes, based on the mathematics department's model of common tests, was introduced. These tests included both practical and theoretical sections, and were to be used in conjunction with class results to determine class allocations. This new practice also addressed Zoe's concerns about the allocation of students to classes:

Zoe: "What we haven't necessarily always done very well is this within-school moderation. If you do head down that path, you do need to have quite effective ways of allocating kids to these classes." (Vignette 7) 
Dennis' concern for his students, and his identification as a teacher of science, had led to changes in the practice of the community. Dennis, through his preparedness to raise issues, had provided an opportunity for professional learning that also addressed the concerns of another teacher. Class allocations, however, were not the end of Dennis' concerns for his students. In the area of providing every possible opportunity for his students to succeed in science, Dennis was also prepared to share his reflections in a way that produced changes in the practice of the teachers.

Dennis was concerned, in the first instance that many students in his Year 7 classes were simply not coping with the amount of work that was required of them:

Dennis: "What about the kids?" he would argue. "Teaching all four Year 7 classes, I see the same problems coming up with the students. Like organisational skills, you can see it's not just one, it is across all the classes." (Vignette 7)

Dennis was also concerned that the students who demonstrated ability were being held back because the majority of the lessons were being directed at the students of average ability:

\begin{abstract}
Dennis: "I've had some ideas in Year 7, that we can take out students that have, shall we say, difficulties, and put them into one class, they would probably end up doing less, but perhaps, if we concentrate on those students they might be ready, or better prepared for Year 8 . And then they can go back into normal classes. I was thinking that in the classes I teach, I reckon that you could probably fill up a class with students who are having a few difficulties of one sort or another. I also think too that some of the brighter kids, many of them just seem to be treading water. Because we tend to teach to that middle lot. There are classes in which we spend a fair amount of time on the middle students, the ones at the bottom; they need a lot of help, so you don't see them very often, and the good ones you just tend to leave. I wonder also if some of the good kids were getting bored, because of the repetition, having to do so much over and over again ... if you take out those high flyers they don't necessarily cover' more, but can you imagine what you could do with them by the time that they reach Years 9 and 10 for the Science Fair or whatever. You could do quite a lot with them by that stage." (Vignette 7)
\end{abstract}

Dennis' concern resonated with the other teachers, who could see the value in what he had said. Science - the subject - is important, but to teach it well is even more important. Jack was laconic in his response to Dennis' suggestion:

Jack: "Dennis made the point that they don't cover as much, but does that matter if what they do cover they cover well?" (Vignette 7)

As a result of Dennis' concern for the progress of all of his students, changes were made in the teachers' practices. In 2004, programs were put in place to assist students with ability to pursue research topics in small, specialised groups. Greater attention was also paid to looking out for students who were seen to be struggling, for 
whatever reason, in science. These efforts included special assistance with organisation skills and extra help with literacy and numeracy in the context of the science classroom. These changes were not what Dennis envisaged, but they were assessed as being realistic in addressing the needs that Dennis had identified. Phronesis, a concern with the moral dimension of teaching, had produced these changes. Dennis' reflections on his students' progress, and a preparedness to raise his reflections in a discourse with his colleagues, had provided an opportunity for the professional learning of all.

\subsubsection{Identity - Practice: Epilogue}

The 'in-between' space between identity and practice is a space of great opportunity for professional learning. In the case of the teachers involved in this research, those opportunities were taken through a combination of personal reflection and public discourse, around the Aristotelian typology of episteme, techne and phronesis. In each case of reflection and discourse, the identity that the teachers have as teachers of science is reciprocal to their practice as both individuals and as a community. Identity influences practice and practice influences identity in the 'in-between' space.

The teachers trust in the subject knowledge of their colleagues, and their identification as teachers of science. Jenny, who categorically states what she believes "good" chemistry to look like, most graphically shows this identification with the subject. Flowing from this trust, they understand that the core concepts that need to be covered in chemistry, physics and biology are being covered, despite the crowded nature of the syllabus. They are also prepared to raise difficulties with the syllabus that affect their ability to teach. This trust in the subject knowledge serves as a foundation for all of their work. Identity with the subject exercises a large influence on the practices of these teachers. Confidence in their identity also allows them to experiment with new science teaching strategies, the techne of teaching.

The evolution of the Science Expo and the research alternatives for some students demonstrates the learning that has occurred around the techne of teaching. The concept of a Science Expo originated with Jenny, who also possessed the energy and leadership to make the event happen. The fact that the other teachers supported 
Jenny's ideas, and carried them through to fruition, highlighted the importance of the research topic concept to the teachers. The research topic concept fulfilled the meanings of science education that the teachers had negotiated: critical thinking, relevance, knowledge and theory, interest and understanding. Moreover, the discourse on techne provided an opportunity to raise concerns regarding the moral dimension of teaching, phronesis.

Believing that some students were disadvantaged by the current assessment practices and subsequent class allocations, Dennis took the lead in highlighting his concerns. The science that he was being required to assess was "touchy feely" science, not the science that he identified with. To Dennis, science was more concerned with experimentation and practical work that leads to potential answers for research questions, and less with the presentation of that work. Boys in particular, were disadvantaged by the assessment that he was required to do. Through the raising of his concerns, assessment practices were changed to better reflect Dennis' conception of science; a conception with which no-one disagreed. Similarly, Dennis' reflections on the most appropriate ways in which to help all students achieve their potential in science were accepted, leading to changes in the practice of the teachers.

Their identification as teachers of science has a reciprocal relationship with the practices of these science teachers. Through personal reflection and/or public discourse, these teachers have opened up opportunities for professional learning that have, potentially, reinforced their identity and enhanced their practices, both individual and corporate. Powerful professional learning opportunities can be seen to exist in the 'in-between' space between identity and practice.

\subsubsection{PRACTICE - MEANING}

The meanings that the community has negotiated for its work are not static. And the practices of the community are not static. Meanings and practices cannot remain static for one very simple reason: The community does not operate in educational isolation from internally, or externally, imposed changes. Changes in personnel, changes in school level administrative decisions, changes in government policy, changes in societal expectations and demands, changes in how science education is 
conceptualised, all these impact the work of the community. In response to these pressures, amongst others, the community negotiates and renegotiates its sense of meaning. In doing this the community also renegotiates its practices, an ongoing dynamic process that produces opportunities for professional learning for both individuals and the community. Those opportunities for professional learning can, I believe, be described in terms of the Aristotelian typology of episteme, techne and phronesis. Further, these opportunities for professional learning can also be situated in the 'in-between' space between practice and meaning. It is the purpose of this section of the data analysis to examine the professional learning that occurs in this "inbetween' space.

The meanings of science education that have developed through negotiation can be summarised as involving critical thinking, relevance, knowledge and theory, interest and understanding. These meanings that this community of science teachers has negotiated for itself are heavily dependant on the discipline of science. Being almost exclusively trained in science, the teachers share a common language and view of the role and importance of science in the world. These teachers regard themselves as exclusive in terms of possessing knowledge about science and how it is to be taught. Given the high status that society generally accords science as opposed to other, 'less academic' subjects, these teachers see themselves as occupying a higher place in the hierarchy of subjects, higher than say, woodwork. As Dennis stated so succinctly:

"It is alright for a science teacher to teach woodwork ... but you would not have the woodwork teacher teaching science." (Vignette 12)

The position that they occupy is one that they are more than willing to defend, as discussed in the section of this analysis on meaning and identity. It would be an error, however, to believe that this community of teachers is unable or unwilling, to continue to negotiate how the meanings of science education impact on their practice as teachers of science. For in renegotiating their meanings, these teachers also seek to improve their practice, and vice-versa. As always, knowledge of the subject, episteme, is crucial in this dynamic process. 


\subsubsection{Practice - Meaning: Episteme}

The new science syllabus that was being written in 2002 was seen as being heavily content focussed, with an emphasis on core scientific concepts that students needed to understand at various levels of assessment. The reasoning behind this decision was the belief that there are core concepts that students need to understand if they are to progress in science based courses in both Years 11 and 12 and beyond. The "pigeonholing" of the new syllabuses that Zoe and Stuart, amongst many other science teachers across the state, had been involved in writing was met with unconcealed anger:

Stuart: "I've just been told this morning that the science syllabus writing has been pigeonholed somewhere. I haven't been told officially and I'm on it."

Jack: "Sensational, Jesus, science have got their act together haven't they? Wonderful!"

Zoe: "It is enormously frustrating for us. Endless days working on a Life Science syllabus that doesn't look like it is going to exist anymore, despite everything that we have done."

Jack: "They are wallies, absolute wallies, incompetent morons. The reason that they are at the Secondary Assessment Board is that they can't teach." (Vignette 2).

The anger was not principally focussed on the cancellation on the new science syllabus. There was a deeper cause to the resentment that many of the teachers felt. The decision of the state government to introduce the Essential Learnings Framework was seen as the real threat to the integrity of science as a subject, and the identity of the teachers who taught it:

\footnotetext{
Zoe: "The Assessment Board isn't driving the agenda anymore, it is all this Essential Learning stuff coming from the Minister, and whoever advises the Minister."

"They must be an ex-teacher who can't teach, that's why they are there with the Minister" fired Jack from across the table.
}

Zoe continued, despite Jack's anger. "They have decided that the Essential Learnings are the only thing that they want in schools up to grade 10 , by $2005 . "$

Stuart's anger had turned to sarcasm. "That's very interesting because the bloke who actually set up the New Basics in Queensland, which is similar to the Essential Learnings, it's almost exactly the same, he did a review of the New Basics in Queensland and came up with the brilliant conclusion that they made a serious mistake by chopping out disciplines, like science and maths."

"And he developed it" stated Jack rhetorically.

"He developed it Jack, you ask the TCE Coordinator about it." The school's Tasmanian Certificate of Education (TCE) Coordinator has the role of disseminating information to and from the Secondary Assessment Board. 
"Geez, have we got something to look forward to." (Vignette 2)

To "chop out the disciplines" was a direct threat to these teachers of science, teachers who centred the meaning of their work on their negotiated sense of the discipline and how it should be taught. The Essential Learnings Framework was, to these teachers, an attempt to reduce the status of their subject to that of a subject in which:

Rob: "We'll have everybody doing projects, and saying that they are doing science."

(Vignette 12)

As a result, the teachers chose to effectively ignore the Essential Learnings Framework until the second semester of 2003, when the school decided to adopt the Essential Learnings as the future Framework for the development of the school's curriculum. In making her decision to follow the Essential Learnings Framework, the Principal explicitly sought to address the concerns of many of the teachers of science:

"So things like the rigour of the disciplines is something that we don't want to tamper with." (Vignette 7)

Jenny, however, did not appear to share the concerns of the other science teachers for the future of the discipline. In promoting her ideas for the inclusion of a research topic in the syllabus in December 2002, Jenny saw an opportunity to negotiate the Essential Learnings into science:

\footnotetext{
"You know where this would perfectly, it would fit in that Essential Learnings thing, because the whole idea of that Essential Learnings is that they (the students) have got data that is applicable to them, and that they can analyse it and display and talk about it. And that is the whole focus of the Essential Learnings. So you'll be doing something for the science department that they'd be interested in." (Vignette 5)
}

These courageous words, spoken in the discourse of the science staff meeting, were the precursor to both the introduction of a change in practice, and a renegotiation of meaning. In this particular case, the change of practice preceded the renegotiation of meaning by approximately ten months.

Early in 2003, the curriculum for Years 9 and 10 was altered to include a research topic for more able students and a teacher-directed unit of work for less able students. The remainder of the curriculum was based on the core concepts contained within physics, chemistry and biology, with a sprinkling of geology. This curriculum was seen to address the important meanings of science education that the teachers had negotiated for their work: critical thinking, relevance, knowledge and theory, interest 
and understanding. Indeed, these meanings are clearly discernable in the introduction of Jenny's October 2003 letter to the school's administration in which she sought permission to organise the Science Expo:

The purpose of the expo is:

- To showcase the scientific research work being conducted by grade 9 and 10 students at the school

- To allow students an opportunity to "speak to" their research before judges and the general public (their parents and friends).

- To raise public awareness of the importance and relevance of science to our lives today.

- To demonstrate the ways in which the school is addressing the new curriculum Framework for Essential Learnings through science.

- To create models and exemplars of students work to assist teachers embarking upon this approach to curriculum delivery and the establishing of moderation standards.

- To provide a set of research dossiers from which to select entries for the Open Research Section of the Tasmanian Science Talent Search. (Vignette 6)

In "addressing the new curriculum framework" Jenny was also opening an opportunity for professional learning to occur, by opening a discourse into renegotiating the meanings of science education in the language of the Essential Learnings. This language is centred on the five Essential Learnings and their constituent Key Elements (see Appendix 3). The five Essential Learnings, and their Key Elements, which seek to explicitly describe what is considered important for students to learn in their education are:

Thinking.

- Inquiry

- Reflective thinking

Communicating.

- Being literate

- Being numerate

- Being information literate

- Being arts literate

Personal Futures.

- Building and maintaining identity and relationships

- Maintaining wellbeing

- Being ethical

- Creating and pursuing goals

Social responsibility.

- Building social capital

- Valuing diversity

- Acting democratically

- Understanding the past and creating preferred futures World futures.

- Investigating the natural and constructed world

- Understanding systems

- Designing and evaluating technological solutions.

- Creating sustainable futures. 
Taken from Introduction to the Outcomes and Statements, Department of Education, Tasmania (2003a, p. iii).

In her letter, Jenny justified the concept of the Science Expo in the language of the Essential Learnings Framework,

It is my belief that conducting independent scientific research allows students an opportunity to address all of the above key elements.

- In order to decide upon a topic for research, students must demonstrate some curiosity and sense of inquiry in relation to some scientific phenomenon and reflect deeply upon the best pathway to pursue to answer their questions.

- When communicating with one another during the process or with the public when completed, students need to utilise all listed modes of communication.

- Numeracy, in relation to their quantitative evaluations

- Literacy, in verbal and written communication

- Information technology, in compiling their dossiers

- Arts, in presenting their summary poster as background for the presentation.

- In personal terms, while conducting the research students need to set firm goals (both short and long-term) and pursue them, be ethical in presenting 'true' results, avoid plagiarism and maintain good relationships with co-workers.

- In social terms students need to value the diversity of their working groups and allow equal representation. They must show understanding and act democratically toward one another. Only in this way can a future that will hold benefit for all, emerge.

- With view to our world, hopefully they will come to understand the systems already in place, their benefits and limitations and how these can be modified to create more sustainable futures. (Vignette 6)

The success of the Science Expo in presenting the research work of the students to the wider community gave the teachers cause to reflect on the Essential Learnings

Framework. As the Principal stated in the school's Newsletter:

By exhibiting the products of their own investigations, students are fulfilling the main criteria of the Essential Learnings Framework about to be adopted by Tasmanian Schools. We are glad to have an opportunity to showcase the manner in which we approach Essential Learnings. (Vignette 6)

The teachers found that the practice of explicitly teaching scientific research for public presentation and comment could be described in terms of the Essential Learnings Framework, and consequently could be negotiated into the meanings that the teachers brought to their work. If the language of the Essential Learnings Framework had not been negotiated into the practices of the teachers, then it is doubtful that the teachers would ever have accepted the Essential Learnings Framework. Without meaning or context, the language of the Essential Learnings Framework would have failed to influence the practice of the teachers. 
The Science Expo appeared to convince the science teachers that the Essential Learnings Framework was not an instrument by which an "ex-teacher who can't teach" could maliciously attempt to "chop out the disciplines". Indeed, the language of the Essential Learnings Framework and the Key Elements could be used to justify an accretion of importance to science, and hence to the science teachers. As Jack explained, the day before the Expo:

\footnotetext{
"We are going to gear the whole school around the Science Expo. If we are going to take the Essential Learnings to the nth degree, everything that we do in science could be the centre point, and every thing else comes into it. Computing to English to maths. The whole lot." (Vignette 6)
}

Professional learning can be seen to have occurred in the 'in-between' space between meaning and practice, as the teachers grappled with negotiating the language of the Essential Learnings Framework into their newly adopted practices. Initially, the Essential Learnings Framework was seen as an assault on the subject of science. The experience of the Science Expo gave the language of the Essential Learnings Framework a context within the teachers' practice of teaching student-based research. Given this experience, the language of the Essential Learnings Framework came to be negotiated into the meanings that the teachers had developed for their work. As the result of these negotiations, which were a struggle, both the meanings and practices of the teachers' work in science education continued to evolve. And the teachers' belief in the pre-eminence of science, the subject, was reinforced.

\subsection{Practice - Meaning: Techne}

As this analysis has demonstrated, this community of science teachers is more than willing to learn from each other. They are prepared to learn more about the knowledge base of their subject, science. They are prepared to learn more about the teaching of their subject. And they are prepared to learn more about the moral aspects, and implications, of their work. Only once any of the teachers, even obliquely, referred to the fact that they were learning from each other. It would appear from the data that the teachers' perception of their own learning was latent, buried beneath the busy, sometimes chaotic, life of a secondary science teacher. To the teachers, learning appeared to be implied in the context of the relationships that they shared one with the other. The school and the state government's Teacher Registration Board, however, had a different perspective on where and how teacher 
learning occurred. Vignette 3 highlights the dichotomy between the teacher community's view of learning and the organisational view of teacher professional learning.

Neither the school, nor the Teachers Registration Board had made explicit what was meant by the term 'professional learning'. Zoe was quick to highlight the problems that this lack of definition would cause for people:

Zoe: "The essential nature of what you do is going to have to be spelt out too. Like, l'm on a syllabus-writing committee, which takes a fair bit of time, does that count?" (Vignette 3)

The Teachers Registration Board was completely silent on the definition issue. The school had dropped its previous policy of 12 'out of hours' professional development per year for each teacher. The replacement policy was also vague as to what was meant by professional learning:

\begin{abstract}
Rob: "Our department meetings, our science ones, are to be more along the lines of professional learning, rather than information dissemination. As Department Head, I have to disseminate information through notes in pigeon-holes, rather than waste time in our meetings going through stuff. The Principal is going to speak to the whole staff, there's an expectation that the meetings will be from 3.15 to 4.15 minimum, and during that time we do some professional learning, and that may be logged onto our little sheets to satisfy teacher registration. That might mean that we take turns in presenting something. You only need to talk about something that you might do in class, an experiment that you might do." (Vignette 3)
\end{abstract}

Stuart had previously worked in a school in which the departmental meetings were organised along the lines described by Rob. For Stuart, the experience was beneficial as it addressed issues relating to the techne of teaching in the 'in-between' space between meaning and practice, even though he did not use those terms. For him, such a meeting structure was common sense:

\begin{abstract}
Stuart: "We sort of did that sort of system a couple of years ago, where each person took a meeting, and one person who was new to science teaching brought in their Year 8 prac books, and then people went through and discussed; why did you give this person a $C$ and this person a $\mathrm{B}$, which helped moderate things very nicely. One person did something on teaching about models, using models in science and some of the problems that you run across in using models. It doesn't need to be much, and if it is addressing problems that people have already mentioned, well, it helps everybody. Rather than passing around the latest stationery catalogue. Who wants to buy this Lego?" (Vignette 3, my emphasis)
\end{abstract}

It was this structure of the departmental meeting that Jenny was to use in her quest to incorporate a research topic, and later the Science Expo, into the syllabus. The key to understanding how professional learning can occur around the techne of teaching in the 'in-between' space between meaning and practice is to be found in Stuart's 
statement that "if it is addressing problems that people have already mentioned, well, it helps everybody". To mention a problem is to identify what the problem actually is. Even if the answer(s) to the problem is not immediately obvious. To mention a problem, then, is a question of having an understanding of the meanings that one brings to one's work. Stuart offers two examples of "problems" that had been mentioned in the life of the science teachers in his previous school.

The first "problem" was one of assessment; "why did you give this person a $\mathrm{C}$ and this person a $\mathrm{B}$ ?" One meaning that could be identified from this question is the purpose of the assessment. Is the work to be assessed for its presentation of the material, or its scientific content, or some combination of both? It was just such a concern that caused Dennis to question the role of assessment in Year 7 in Vignette 7. The second "problem" was the use of models in science, and the misconceptions that can arise from their use. For example, the Rutherford-Bohr Model of the atom is useful for younger students in terms of understanding Mass and Atomic Numbers in relation to the Periodic Table, but unsuitable for pretertiary physics and chemistry students. The meanings that one could identify from the use of models are: the relative importance attached to theory; the level of interest for different students; and the tensions that this can cause for teachers in lower secondary heterogeneous classes. This tension is discussed in Vignettes 5, 7 and 9. For some students, the RutherfordBohr Model of the atom is more than sufficient, and to go any further is to risk losing their interest. For other students, the Quantum Mechanical Model is appropriate to their level of understanding and interest, and anything less would be to limit their understanding.

In identifying a "problem" in their practice, teachers are involved in reflection about their practice, and how that practice relates to the meanings that they have negotiated for their work. When discussing those "problems" with their colleagues teachers are engaging in public discourse about the techne of teaching. In these ways, teachers are engaging in professional learning. The Vignettes that I have developed from the recorded meetings are replete with examples of teachers raising issues with their colleagues, and then reflecting on those issues in order to either negotiate new meanings about their work, to continue to refine their individual and corporate identities, or to continue to refine their teaching practices. It would be wrong, 
however, to regard the scheduled meetings as the only place where professional learning occurs.

The dichotomy between the teacher perspective of their learning and the organisational perspective of teachers learning is not just a matter of definitions. It is also a question of situation. Vignette 3 highlights the difficulty that the school, as an organisation, faced in trying to plan for the professional learning of its teachers. For the school, the most effective method of encouraging professional learning was to expect that professional learning will occur at set times, as well as being evidenced in an unstated manner:

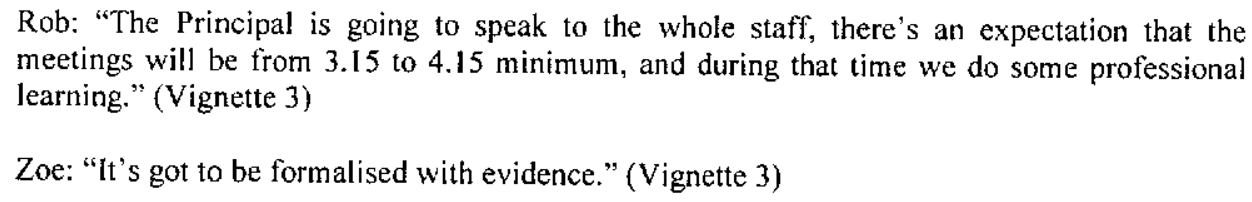

While the data clearly shows that professional learning, as I have described it for the purposes of this thesis, was occurring at the staff meetings, there are other situations in which it takes place:

Stuart: "Some of the best stuff occurs when you are talking to people over lunch. Like that conversation the other day about vectors, and making sure that the kids were doing the same style with their vector work." (Vignette 3)

This is another example of a "problem" being identified that could be resolved by engaging in discourse with other teachers. Such a lunchtime meeting is clearly looking at the techne of teaching, in this case the convention in which work on vectors was to be presented. It is also part of the ongoing negotiation of meaning regarding the knowledge and theory that is taught within science classes. This lunchtime meeting ensured that the teaching of the convention for labelling vector diagrams was consistent across all teachers. Not only that, but the professional learning from that lunchtime was acknowledged as "some of the best stuff".

Professional learning can happen in any place, and at any time, when teachers have the time, and willingness, to engage in reflection and discourse about their work. Further, the spontaneous nature of such opportunities makes it difficult, or impossible, to formally evidence that learning has occurred in a way that may satisfy the administrative requirements of an organisation such as the school. For the school then, 
the dilemma is the recognition of the professional learning that teachers undertake outside the formal structures of the school organisation, not just at the formally sanctioned times set aside by the school. This is a dilemma that the Principal recognised, but was yet to deal with:

Stuart: "The Principal said last night, 10 minutes here and there is not going to count, even though she said that she recognises that it is probably more beneficial than the other stuff."

Zoe noted that such a statement was an attempt to put administrative structures around teachers" professional learning in order to facilitate management and accountability. "That is more for administrative reasons than for devaluing the informal learning." (Vignette 3)

The issues of where professional learning physically occurs, and how to evidence it appear to be the major concerns of the school as an organisation. Such a view is understandable given the organisational and administrative requirements under which all schools operate. Those concerns, however, are not really the concerns of the teachers in this study, except where they are being asked to conform their professional learning into the organisational parameters of the school. At this point, the lack of a concise definition as to what constitutes professional learning makes it difficult for the teachers to know if their activities meet with the requirements of either the school or the Teachers Registration Board.

\subsubsection{Practice - Meaning: Phronesis}

Reflection and/or discourse around phronesis in the 'in-between' space between practice and meaning provide an important opportunity for professional learning. The reason for this importance is highlighted by the dramatic growth that has occurred in the past decade about understanding how children learn. This increased understanding suggests that there are many ways of knowing, and that deeper understandings can arise from possessing a number of ways of knowing. This has moral implications for teachers, and schools, as the Tasmanian Department of Education (2003b) states:

The belief that competence develops differentially across multiple domains implies that school curricula and modes of operation should respect and cater for diversity of all kinds. If educators and learners learn to respect diverse ways of being capable, then a much broader spectrum of learners can come to think of themselves as being capable (p. 7).

These changes in understanding mean that teachers need to renegotiate some of their practices, and the assumptions that underlie them. Such renegotiations are a reflection 
of the moral dimension of teaching, phronesis, and can challenge both the meanings of the work that teachers have negotiated for themselves and the practices that may have served them well earlier in their careers.

Vignette 9 provides an example of this renegotiation of practice within the meanings of the community and the changing realities of how students learn. Specifically, the issue revolves around the amount of theory, relative to practical work, that struggling students in Years 9 and 10 should be expected to work with in the chemistry topics. Dennis was the first to highlight the observation that students now appeared to lack practical skills that were once assumed:

\begin{abstract}
Dennis: "Well the first unit, I'm just concentrating on practical work, and what I'm finding is interesting in that I'm getting to the stage now where I'm wondering what practical work, not necessarily to do with school, but anything practical that students do. When it comes to tightening and untightening clamps, clearly they haven't got any idea which way they turn. It's just those little things ... so I don't think we can expect the kids to have the same skills that they used to have, because I don't think that they do." (Vignette 9)
\end{abstract}

This observation was to resonate in the ensuing discussion as to the content and skills that should be included in the Year 9 and 10 chemistry topics. The discussion was driven by two major concerns. The first concern was for the nature of the subject, which is a powerful influence on the both the identity of the teachers and the meanings that they bring to their work. The second concern was a deep personal concern about what students should learn, and why they should learn it.

Jenny, as the teacher of pretertiary chemistry, had very definite views as to what was important for students to learn. Stuart, who tended to teach the middle to top syllabus classes, wanted to give students every opportunity to succeed, according to their ability. Jill, who tended to teach the lower ability classes, had a deep concern that students should not be discouraged from science by an over emphasis on content.

Jenny: "A very quick review of what they have done, and then you go into writing formulae for various other types of reactions. You know, acid plus carbonate to produce carbon dioxide that kind of thing, writing an equation from it as opposed to a word."

Stuart agreed. "Your middle syllabus kids, say you did acid plus carbonate, you can do the word equation, you can do the experiment, you can separate out the salt from the water. If you want to try and push on in the direction of writing the chemical equation, that's fine."

Jill was sceptical about the progress that some students would make with equations. "Do you see the bottom kids doing it that way?" she asked. 
"Certainly getting the products of the reaction" said Stuart, as that was as far as he would have taken a lower ability class with the reactions. "Although there is the problem that if we chop out the theory too much some students may be disadvantaged in the longer term."

Jill was quick to point out that such a standard would, in her opinion, quickly lose a large number of students. "That equation work is alright for the top syllabus, but for the middle and bottom syllabus kids, they haven't made enough progress in Year 8."

Jenny was quick to defend her position. "I'm going on what's here."

Rob pointed out that, as the content was currently written, "The bottom kids would be spending three weeks reviewing the chemistry that they did in Year 8."

"And loving it" Jill remained cynical as to how the less able students would find the first three weeks of Year 9 chemistry. In this Jack supported her.

Looking over the list of content for chemistry in Years 9 and 10, Jack had two major concerns. The first was a concern for the perceived lack of interest in the content that the students would display.

"But, you see, my view is that there should be some practicals that you do purely and simply for the enjoyment of science. You don't necessarily have to write up everything ... if I was looking at this, in terms of a less able science student, I'm not going to enjoy it in Year 9. You need something, you need some enjoyable science there that can, let's face it, and it's not enjoyable. So in 9, we need some whiz bang stuff." (Vignette 9)

This exchange highlights the moral dilemmas that teachers face in developing a syllabus for their students. All of the teachers agree with the importance of practical work. It is the extent to which theory should be pursued, based on that practical work that is the issue. For some lower ability students, an overemphasis on the theory of chemistry would be counterproductive, potentially leading them to disengage from science. Such students, not having made progress in earlier years for various reasons, would simply be set up to fail the chemistry topic again in Years 9 and 10. This is the crux of Jill's position. For other students, the opportunities to learn how to write chemical equations need to be kept open for as long as possible, as all students learn at different rates. To curtail their opportunities at an early stage would also be indefensible. This is the crux of Stuart's position. For some students, however, learning to write chemical equations is an appropriate aim, as it gives them access to the symbolic language of chemistry. To deny them access to this language, particularly if their future interests lie in that general direction would clearly be indefensible. This is the crux of Jenny's position. It was a position that she had stated before, in discussions on the science content of other schools:

"Well, what I'm saying is that both are lightweight in comparison to what we do in grade 10 In chemistry, but you see I guess that a lot of the high schools haven't the problem of knowing that their kids are going on to their own school in grade 11, so they don't care if they don't know about molar calculations. Because it is not their problem. They go off to a 
pretertiary college somewhere else where people there are teaching physical sciences have got to deliver ... (our students) will end with a less high standard if they go to a school where they haven't done the same."

"A certain amount of knowledge should be compulsory, because they were coming in and they know nothing. And it is a big, big problem. We hear it at moderation all the time. I mean it is so big a problem that they are talking about having a subject called introduction to physical science as a non-pretertiary."

"That is a sad state of aftairs for the rest of the state's 7 to 10 schools, [ think. It's an indictment of very poor levels of achievement, and then they can't do their matriculation within the two years of senior college because they've got to do Physical Science in Year 12 and then they've got to come back for 13 too for physics and chemistry, So we 're not helping them, I would have thought. So, from my point of view, the knowledge should be very subject specific, so that in all schools they are doing exactly the same." (Vignette 12)

"So we're not helping them" is a plea that applies to the entire discussion, and is an example of the concern for phronesis that these teachers have for their students. The net result of the discussion was that, for those students who struggled with chemistry, a program of practical work was developed that related to, or extended, their life experiences. Two examples of this type of work were given in Vignette 9. One involved investigating the $\mathrm{pH}$ of soaps and shampoo, and the other involved making soap. For all other students, writing chemical equations was incorporated into the syllabus, but teachers were to be careful in monitoring the progress of students who struggled with the concepts. The top students were expected to attempt the balancing of chemical equations. Under such a system, the concerns of Jenny, Stuart and Jill were all addressed. Each student was given an opportunity to go as far as their ability would allow them to go.

Reflection and/or discourse around phronesis in the 'in-between' space between practice and meaning provided an important opportunity for professional learning. The meanings that the teachers had negotiated for their work: critical thinking, relevance, knowledge and theory, interest and understanding had been maintained, admittedly with different emphasis for different ability students. In explicitly addressing the abilities of different students from the perspective of phronesis, the teachers formalised what had been individual practices into the collective practice of the community. 


\subsubsection{Practice - Meaning: Epilogue}

The space 'in-between' practice and meaning is a dynamic space in which professional learning occurs. Teachers do not operate in isolation, and the pressures to change are constant. Governments and schools mandate changes in policy areas such as curriculum and teacher registration requirements. Colleagues can develop new insights and practices regarding the teaching and learning of a subject. Individuals moving through their careers develop new interests, skills and attitudes. All of these influences produce creative tensions within a community that can produce the private reflections and public discourses around which professional learning can occur.

The nature of the subject has a large impact on teachers' responses to both internal and externally sourced changes. The subject shapes teachers identities and the meanings that teachers negotiate for their work. Any change that is perceived to attack the subject, therefore, is also perceived to be an attack on teachers' identity and sense of meaning. Such a perception would elicit a strong response, as teachers sought to defend their individual, and corporate, sense of meaning. Thus, the initial response to the Essential Learnings Framework was savage. The Essential Learnings Framework was seen as an attempt by "wallies (and) incompetent morons" to "chop out the disciplines". As such, the Framework was to be studiously ignored, despite the fact that the Principal had decided that the Essential Learnings Framework would be introduced into the school in 2004. Jenny, however, in moving to establish the Science Expo as a regular part of both the school calendar and the science syllabus, provided a way in which the language of the Essential Learnings could enter the public discourse of the science community. As this discourse evolved, painfully at times, the teachers came to negotiate the Essential Learnings Framework into the meanings that they had previously developed for their work. Those enhanced meanings translated into the student research work that the teachers undertook with their students. This process of negotiation and eventual reification permitted the science teachers to mount a successful Science Expo that was promoted by the Principal as an example of how the Essential Learnings Framework could produce outstanding results in science education. 
Subject knowledge is one aspect of teaching. Another equally important aspect is the ability to teach that subject knowledge to another person. The techne of the teachers in this community, along with their sense of episteme and phronesis, is something that continued to evolve through the two years that the data were collected. The Vignettes are testament to this evolution. When required to evidence this evolution to the school or the newly created Teachers Registration Board, however, they are not able to identify specific cases in which they have undertaken 'professional learning'. From the organisational perspective of the school and Teachers Registration Board, professional learning was something that could be mandated to occur at specific times, such as programmed staff meetings, and then it could be evidenced for accountability. This belief in organisational efficiency and accountability possessed one fatal flaw: Professional learning was never defined, leading to the situation in which the organisation was attempting to evidence an activity that is, apparently, nebulous. This lack of clarity caused the teachers in the community to look to their own experiences in dealing with the new accountability regime. Professional learning, for the teachers, involved identifying issues in their work that could then be discussed and, hopefully, resolved. The identification, discussion and resolution of these issues could be carried out in both formal and informal settings. The teachers experienced difficulty in providing evidence when trying to make their conceptualisation of professional learning conform to the organisational requirements. For the teachers, there appeared to be an intuitive recognition of what worked and what did not. How to reconcile these different conceptualisations was never resolved in the two years of data collection.

The moral dimension of teaching, phronesis is captured by Jenny's phrase "So we're not helping them". This concern for students underpins much of the discussion about the amount of theory that should be included in the syllabus. For some teachers, to limit the amount of theory is to "short-change" students who have the ability, and aptitude to, undertake pretertiary courses in the physical sciences. For others teachers, students need to have the opportunity to attempt the more abstract theory, in the belief that different students develop at different rates. To limit their opportunities is to potentially disadvantage them in the longer term. For yet another group of teachers, an over emphasis on theory is to risk alienating students for whom science is already difficult. None of the teachers disagree with the basic pedagogy of basing the theory 
component on practical work. What is questioned is the depth to which some students are able or willing, to learn the theory that underpins the practical work, and how this can impact on their participation in science. In raising and addressing these concerns, the teachers formalised what had been individual practices into the collective practice of the community, for the benefit of their students.

\subsubsection{COUNTERPOINT}

This analysis of the data is premised on the belief that each of the science teachers are, in fact, fully participating members of the community of science teachers. To be a member of a community is to share many common characteristics. These characteristics include an engagement with the purpose(s) of the community, a shared sense of engagement in a common enterprise and a shared repertoire of practice (Wenger, 1998). To be a participating member of the community, with these shared characteristics, is to permit a teacher access to the professional learning opportunities that are offered within the community. A member of the community has access to the spaces 'in-between' that are located between meaning and identity, identity and practice, and practice and meaning. Is this access available, however, to non-members of the science teaching community?

I believe that a teacher who is not a member of the community is effectively excluded from these spaces, and consequently from the opportunities for professional learning. The experience of Dick in Vignette 11 illustrates the problems faced by a teacher who, organisationally, was regarded as a teacher of science, but who was not recognised as such by the members of the science teaching community. Dick joined the teaching staff in January 2003, having completed a Bachelor degree in Adult and Vocational Education, a course that did not include a science component. He was employed as a science and mathematics teacher until May 2003, at which time he lost his Year 8 science class, teaching only mathematics until the end of the year. The school did not employ him in 2004.

The lack of access that Dick experienced in relation to the professional learning of the community can be described in terms of the proposition that I have expounded. In terms of his understanding of the episteme, techne and phronesis of science teaching, 
Dick was unable to participate in the shared meanings, practices and identities that the teachers had negotiated for themselves. Dick's lack of training in science and in secondary education meant that he was unable, through no fault of his own, to engage in the reflection and discourse that underlie the processes of negotiation and reification. The lack of engagement is highlighted in two extracts from Vignette 11, both of which focus on subject knowledge, or episteme. The first extract shows the importance of the vocabulary of science. The second extract highlights the importance of understanding the community's reification of science as a subject.

\subsubsection{Counterpoint: Episteme}

The first lack of access to professional learning regards the vocabulary of the community of science teachers. Science possesses a precise vocabulary, with words such as 'work' and 'weight' having entirely different meanings for those trained in science from those in the wider population. An understanding of the vocabulary of science is crucial, therefore, to identifying with the practices of the community. Dick, due to his lack of training, lacks a rudimentary understanding of this vocabulary:

\footnotetext{
"I bought a Year 7 book, a whole lot of them" Dick said, "I had the idea of photocopying that and testing them on ... on ... on ...."

"Apparatus" offered a somewhat bemused Jenny.

"The names of the bits and pieces and going over safety again" continued Dick (Vignette 11)
}

An inability to communicate at such a rudimentary level in the language of the community will obviously limit participation within the community. Knowledge of the subject, episteme, is therefore crucial in providing the vocabulary that will allow a teacher to begin to access the professional learning opportunities available within the community through public discourse and personal reflection.

The second lack of access regards an understanding of how the community has defined science. Dick is new to both science teaching and the subject, and has a different reification of the word 'science' from the other members of the community:

Dick: "Have you heard about the creation science van that travels around schools, to give a scientific presentation of creation?"

"Scientific presentation would be one definition of it" was Stuart's curt response. 
"One description of it" was Jack's sarcastic contribution to the discussion. Stuart continued:

"The creation science bus is fairly dogmatic. If you disagree with ..."

At this point Dick was back-pedalling rapidly from his initial question, "I've never seen one, I just heard about it." The damage had already been done.

Stuart finished his sentence. "It's not terribly scientific, if you don't go along with them, then, you're wrong. There is no space for disagreement with those people." The meeting moved on to the next agenda item. (Vignette II)

The members of the community hold very strong views as to the meaning of science, views negotiated over a long period of time, and there is clearly no place for creation science within their shared view. The acerbic response to the creation science bus suggestion, and Dick's rapid retreat from his question, indicate that the community's understanding of science is something that is tightly held, and not easily renegotiated. The community's understanding of science belongs to the members of the community, and forms the basis of both their work and identity. Dick, based on his understanding of science, does not appear to share that identity, thus limiting his opportunities for engagement with other teachers. This lack of engagement, based on the episteme of the subject, also limits his ability to learn the craft of science teaching, techne.

\subsubsection{Counterpoint: Techne}

Initially, the members of the science community were keen to assist Dick. There were many offers of assistance with lesson materials, notes and ideas for experiments. Dick had the opportunity to observe other teachers at work, and to observe other teachers work with his class. This assistance extended to the knowledge content of the topics that Dick was to teach. In short, there was no shortage of assistance with the episteme and techne of teaching:

The return of the students in the following week gave Dick the opportunity to see Stuart and Rob at work in their classrooms, before he took his first science class. He made notes on how the teachers organised and managed their classes. The majority of his notes, however, referred to the content that was being taught, to the extent of taking the student's notes from the board. In Stuart' class, these notes initially included revision on the properties of acids and bases and their uses. The notes made in Stuart's class were to form Dick's lesson plans ... Over the following seven weeks, Stuart and Rob continued to support Dick's teaching. Both occasionally took Dick's class in order to model classroom management, both helped with the development of lesson plans, and both went through resources and experiments with him. (Vignette 11) 
Despite these efforts to assist Dick with task of teaching Year 8 science, it soon became clear to Rob, Stuart and the students that Dick was not, and did not look like developing into, an effective science teacher.

Their (Rob and Stuart's) direct observations of his teaching, and concerns raised by students, however, forced Rob to act on Dick's perceived failure to develop as a teacher. (Vignette 11)

Dick's lack of subject knowledge largely excludes him from any form of negotiation about the meaning of what it is to teach Year 8 science. Without possessing this sense of personal meaning, Dick found that it was extremely difficult to contextualise the assistance that was offered. Without a context, the lesson plans, experiments and observations lacked coherence. This was summarised by Rob:

\footnotetext{
"He doesn't understand the core concepts well enough to teach them. He goes off with explanations that are not correct, and the kid's eyes glaze over. They know he doesn't know."(Vignette 11)
}

The members of the community were very forthcoming with what to teach, and how to teach, but effectively ignored the relationships needed to bring Dick into membership of the community. The moral dimension of teaching, phronesis, was ignored due to a preoccupation with the content and teaching of the subject - the here and now of teaching. This is not a criticism of the science teachers and their actions. They sought to assist Dick as well as they could, and in ways which they had traditionally assisted new science teachers. What they did not realise was that Dick, who was not trained in the sciences, lacked a basic episteme and techne of science teaching that would permit him to access the professional learning available within the community.

\subsubsection{Counterpoint: Phronesis}

As we have seen, Dick's lack of training in the sciences, and in secondary education, made it impossible for him to access the professional learning opportunities presented by the science community. This lack of access has implications for the moral dimension of teaching, as it restricted Dick's ability to develop as a teacher of science. Dick could not identify with the meanings and practices of the community, and hence 
lacked a context in which he could develop an identity as a teacher of science. Dick failed to develop an identity as a teacher of science in three ways, identification through practice, identification through imagination, and identification through the work of the science teaching.

For Dick to identify as a science teacher through practice would be difficult to justify. Dick could certainly identify, as a teacher, a moral responsibility for the students in his class. However, for Dick to identify as a teacher of science with those students would be far more problematic. Given his lack of subject knowledge, the result of his efforts was a recognition by his students that "he doesn't know" the subject. In such a case, to claim a responsibility for others may not be appropriate. In his imagination, Dick identified as a science teacher. The reality for the community was, however, that Dick was not identified as a science teacher. Finally, to identify with the work of this community of science teachers implied a basic understanding of science as a discipline. Not only did Dick not possess this, he admitted a fear of some aspects of the subject:

Dick's response did not inspire confidence. "Chemical formulae and that used to scare me." (Vignette 11)

While the other teachers in the community freely acknowledged that there were some areas of science where they could continue to learn more, none had ever expressed a fear of any topic. To a large extent, this attitude was based on the trust that they shared. When Dick expressed concerns about his subject knowledge, the initial response was to provide large amounts of content material, rather than attempting to provide a context within which Dick could commence his teaching career. The lack of a science background prevented Dick from placing the material in context, resulting in Rob's statement that "he doesn't understand the core concepts well enough to teach them. He goes off with explanations that are not correct, and the kid's eyes glaze over". Clearly, the identity of the science teaching community did not become a part of Dick's identity. Organisationally, in the view of the school, Dick was a science teacher. In the view of the community of science teachers, he was never a teacher of science. 


\subsubsection{Counterpoint: Epilogue}

The space 'in-between' practice and meaning is a space in which professional learning can occur. This statement must be qualified, however, as only applying to those members of the community of science teachers. For non-members, there is a restriction in their access to the professional learning that a community of science teachers offers. Specialist subject teachers shape their meanings, identities and practices around their subject. Without an understanding of science, non-science trained teachers are unable to participate in negotiations regarding these meanings, identities and practices. If the practices of the community are the experience of its meaning and identity, then the practices of the community are inaccessible to the nonscience trained teacher.

Dick could not participate in the department because of his lack of an understanding of science. This raised three difficulties. First, Dick was unable to participate in the community due to his lack of the science-based language of the community. Second, an inability to engage in the negotiation and reification of the work of the community limited the capacity for Dick to develop the robust professional relationships needed for professional learning. The community offers a context in which to learn from the experiences of others, to allow others to learn from one's own experiences, and to critique one's own practice. That context relies heavily on the quality of the relationships that exist within the community. Third, the lack of context for teaching science meant that the response to Dick's teaching difficulties by giving copious quantities of lesson plans and tips for experiments ignored the real dilemma that Dick faced. The other science teachers did not identify Dick as a member of the science teaching community. To develop an identity, not just as a teacher, but also as a science teacher, is a long-term proposition. For to develop an identity as a science teacher is to have an understanding of the subject, together with the ability to negotiate both personal meanings and community meanings in science education. And the ability to negotiate meanings is to be able to access all of the professional learning opportunities that science departments offer. 


\subsection{SUMMARY}

I have proposed that professional learning occurs in the spaces 'in-between' the metaphors of understanding community: meaning, practice and identity. Professional learning occurs in these spaces 'in-between' when members of the community engage in virtues-based personal reflection and/or public discourse around the episteme, techne and phronesis of the specific 'in-between' space. Thus community members can locate their reflections and/or discourses, and hence professional learning, in the spaces 'in-between' between identity and meaning, or between meaning and practice, or between practice and identity.

From the data presented in the Vignettes, it would appear that my proposition provides a rigorous framework for analysing the data. The data contains many examples of private reflection and/or public discourse around episteme, techne and phronesis in each of the three spaces 'in-between'. The employment of these three components of the Aristotelian typology and the language of virtues can be used to describe the vital aspects of a teacher's work in education. These examples also highlight the importance of meaning, practice and identity in defining and describing the community of science teachers who formed the focus of this study. For it is within the community that teachers negotiate and reify the meanings of science education, and in the process develop their individual identities and practices. From this analysis, I am now in a position to outline the conclusions of my thesis and describe how these conclusions are important in expanding the knowledge base of professional learning in a school-based community of science teachers. 


\section{CHAPTER 12 - CONCLUSION AND IMPLICATIONS}

\subsection{INTRODUCTION}

My research has focussed on the professional learning of one community of science teachers for a period of two years. Over this time I have observed and recorded the members of that community negotiating what it means to them, both individually and corporately, to be teachers of science. Those negotiations have at times proceeded rapidly; at other times they have been convoluted and glacial in their progress. The negotiations, based on the virtues of teacher professionalism, have taken the form of private reflection and/or public discourse and have consistently sought to improve the teachers' quality of practice. As such, I believe that the data I have recorded, and the paradigmatic analysis of the data that I have undertaken, provides new insights into the professional learning that occurs within a school-based community of science teachers.

This final chapter has three functions. The first function is to restate the boundaries of my study. This is important, as it refocusses attention on the community, while acknowledging the relationships that the community has with external organisations and communities. The second function is to detail my insights into school-based professional learning, and describe how these insights add to the knowledge base surrounding professional learning within schools. The third function of this chapter is to discuss the potential implications of my research, and pose further research questions that my work has raised.

\section{2 BOUNDARIES}

When discussing the notion of boundaries as they relate to the membership of teachers in communities, it is important to keep in mind one salient fact: teachers never exclusively belong to one particular community. The teachers in this research may belong to the community of science teachers, and draw a substantive part of their meaning and identity from that particular community, but they also possess parallel memberships with other communities. These include membership of other subject 
communities, the wider school community and sections of the wider education community. It remains, however, that the subject community with which a teacher most strongly identifies is the one that confers, to the individual, the strongest "sense of common identity in relation to space, epistemology and pedagogy" (Blenkin et al. 1997 , p. 222). This fact is crucial in being able to identify, from the data, the membership status of the teachers within the community. This knowledge, in turn, helps to set the boundaries of the community.

Wenger (1998, p. 152) describes full community membership in terms of the identity and competence that an individual has in relation to the community. Membership is "an experience and a display of competence that requires neither an explicit self image nor self-identification" with a community. An individual who is a full member in a community will:

Handle [themselves] competently ... experience competence ... [and be] recognised as competent. [They will] know how to engage with others ... [and] understand why they do what they do because they understand the enterprise to which participants are accountable. Moreover, [they] share the resources they use to communicate and go about their activities. These dimensions of competence ... become dimensions of identity (Wenger, 1998, p. 152).

Under such a definition, it could be argued from the data that the full members of the community are Rob, Stuart, Jack, Zoe, Jenny, and Dennis. All six teachers demonstrate, through their participation in the meetings, the various criteria of membership identified by Wenger. All six display competence in the areas of episteme, techne and phronesis, and all are prepared to experience the competence of their colleagues. All six have an identity heavily dependent on the subject, and so are able to communicate their knowledge in the precise language of science. These six teachers form the nucleus of the community.

An individual who is not a full member of the community can occupy one of a number of other spaces in relation to the community, although their position can change over time. An individual can be on the periphery of the community, with the capacity to participate with the full members of the community. Maddie and Jill appear in this position, participating rarely in the negotiations of the community, but being valued for the contributions that they do make. Given the part-time nature of 
Jill's employment, her limited participation is understandable, as meetings were not always held on the days on which she was at school. Maddie, in her senior administrative role as the school's Director of Studies, is in a similar position, unable to attend some meetings due to her other commitments. For these reasons, and keeping in mind their science training, it would be reasonable to expect that their position on the periphery is due to factors beyond their control. An individual can also be marginalised, and remain on the boundary of the community, with little participation in the life of the community. Louise would be an example of marginalisation, due in part to her lack of a tertiary background in science, and also due to her other school commitments, which prevented her from attending many meetings. An individual can also be outside the community, completely unable to participate in the negotiations of the community. Dick would be a prime example of a teacher unable to participate in the community. Thus the boundaries of the community for the purposes of this research, in terms of its members, are delineated. It must be noted, however, that community boundaries are never fixed.

The boundary between the community of science teachers and external organisations, such as the school and government authorities, is another important aspect of my research. It could be argued from the data that the community of science teachers is successful in the work that it undertakes. The glowing references from one of the judges at the Science Expo, in which she extolled the "richness of the science experience that is available to students at the school" (Vignette 6), and the words of the Principal at the same event, "We are glad to have an opportunity to showcase the manner in which we approach Essential Learnings" (Vignette 6), are testament to this high regard. From these instances, it may also be inferred that the school, as a whole, is effective. As Harris et al. (1997, p. 149) note, it is a "commonplace observation [that effective departments] need to be 'nested' inside schools which are themselves managed effectively".

While this may be the case, departments that are, apparently, operating effectively in effective schools did "not feel that they were operating in structures and cultures that were particularly supportive of their specialist endeavours" (Harris et al. 1997, p. 150). The reason for this feeling is, I believe, to be found in using the notion of the department as an occupational community, as discussed by Van Maanen and Barley 
(1984). Paule (1989) presents schools as organisations composed of multiple occupational communities. The specialist endeavours referred to by Harris et al. are the teaching of the subjects within departments. The subject plays such a crucial role in the shaping of the social identities of the teachers of that subject, and the community provides the scene for the development of both personal and professional relationships. Any external imposition on the community could therefore be viewed as a threat to the self control that occupational communities seek for themselves in their work (Van Maanen \& Barley, 1984). The Vignettes provide many examples of the tensions that exist between this community and external organisations. Examples include Jack's memorable outburst against the Secondary Assessment Board in Vignette 2, the exasperation of Jenny in dealing with the school's professional development accountability structure in Vignette 3 , and the concerns of non-science trained teachers teaching science in Vignette 12.

While the relationships between the community of science teachers, the school, government authorities and the wider education community are undoubtedly important, they are not the focus of this thesis. The science teachers, throughout the data, make many references to external organisations and communities, an indication of the depth, and importance, of the relationships between this community and those external to it. My thesis is not, however, about a detailed exploration of the relationships between the community of science teachers and those external to it. Such an exploration could easily become another thesis. My thesis is focussed on examining the location and processes of professional learning within the school-based community of science teachers. With the boundaries of my community of science teachers delineated, and the importance of relationships between the community and those external to it acknowledged, I am now in a position to detail my insights into school-based professional learning, and describe how these insights add to the knowledge base surrounding professional learning within schools.

\subsection{INSIGHTS AND CONCLUSIONS}

In the analysis of the data that I presented in the previous chapter, I advanced a proposition based on the situated nature of professional learning and the importance 
of virtues-based private reflection and/or public discourse centred on the Aristotelian typology of episteme, techne and phronesis. My proposition stated that professional learning occurs in the spaces 'in-between' the metaphors of understanding community: meaning, practice and identity. Professional learning occurs in these 'inbetween' spaces when members of the community engage in virtues-based personal reflection and/or public discourse around the episteme, techne and phronesis of the specific 'in-between' space. While I believe that the data analysis supports this proposition, the purpose of this section of the conclusion is to detail the reasoning behind my belief in the fidelity of the proposition in understanding professional learning in a school-based community of science teachers. This reasoning involves three principal conclusions from my research. These are; the location of professional learning; the importance of virtues in teacher professional learning; and the importance of understanding community in understanding teacher professional learning within a school-based community of science teachers.

The data, and subsequent analysis of the narratives, highlights the importance of the situational context of the professional learning that is evidenced in the Vignettes. My research can, I believe, situate professional learning in the 'in-between' spaces between identity and meaning, or between meaning and practice, or between practice and identity. Thus professional learning is to be found in the relational spaces inbetween' the metaphors of community that I have identified, and justified, in chapter 4. Further, the facilitation of private reflection and/or public discourse in the inbetween' spaces is made possible because of the foundational nature of virtues in those reflections and/or discourses around episteme, techne and phronesis, as I identified in chapter 2 . Such insights are important, as they link several of the key theoretical considerations of teacher professional learning that were considered in the literature reviews on teacher professionalism, teacher professional learning and the subject department in chapters 2,3 and 4. There are three theoretical considerations to consider in this conclusion. These are: the intellectual and moral dimensions of teacher professional learning; the importance of the virtues as a language for teacher professional learning; and the importance of a community possessing the capacity to renegotiate its identity, practices and sense of meaning. 
Clandinin and Connelly (1995), describe teacher professional learning as occurring in two places, the in-class and out-of-class work places. These places are both intellectual and moral "landscapes" inhabited by teachers. The in-class place is seen as one in which teachers teach and the curriculum that is important to students is made. The out-of-class place, which is the focus of this research, is one that is filled with visions of what is 'right' in terms of the students' education. As such it is a place that develops certain expectations as to which actions and behaviours will fulfil those visions. It is this process of negotiating that is a major point of contestation over teacher professional learning in this out-of-class place.

At a superficial level, the out-of-class place described by Clandinin and Connelly (1995) is characterised by the structures, programs and policies that are found in all schools, and clearly evidenced in the Vignettes, as well as the attitudes, knowledge, experience and skills of the teachers. This superficial characterisation is not, however, all that impacts upon the out-of-classroom work of teachers. There is also the constant stream of knowledge that enters the school through the metaphorical "conduit". This information, presented in the form of meetings, policy pronouncements, in-service activities and textbooks, is considered to be an abstract "rhetoric of conclusions", knowledge that is disconnected from its historical, theoretical underpinnings and the conversations from which it developed. This imported information, that teachers are expected to understand, discuss and deploy, includes a multitude of topics such as "assessment plans ... school improvement plans, schemata, forces, research conclusions, research prescriptions and policy prescriptions" (Clandinin \& Connelly, 1995, pp. 10-11). The implementation of the Essential Learnings Framework, and the introduction of the Teacher Registration Board's registration requirements are examples of this "rhetoric of conclusions". This information is also to be taken, by teachers, as a given that must be followed; to question the information that flows into the out-of-class place is to question the authority of those who have developed the knowledge. Jack's description of the Secondary Assessment Board is an example of such a challenge:

"They are wallies, absolute wallies, incompetent morons. The reason that they are at the Secondary Assessment Board is that they can't teach." (Vignette 2) 
In addition to this flow of information, Clandinin and Connelly (1995) describe this knowledge as invariably possessing a moral orientation, an orientation that teachers are expected to act on.

It is in response to the belief that teachers are to do something with the morally oriented "rhetoric of conclusions" that impinges on their out-of-class workplace that teacher professional learning becomes most apparent. Teacher professional learning involves teachers living moral stories in both the in-class and out-of-class places, and then being prepared to retell and relive a story that improves their practice, incorporating the abstract knowledge that is being constantly delivered into their schools. The preparedness of Jenny to use the language of the Essential Learnings Framework in her desire to implement a research topic into the syllabus is an example of a being prepared to retell a moral story using the new language. The acceptance of the new language was a result of her courage to express the new language in terms of the community's already negotiated aims for science education. The capacity to derive understanding from the Essential Learnings Framework permitted the community to improve the quality of its practice. This desire to express fundamental, educative human desires in their work can be seen as the expression of professional learning by teachers (Clandinin \& Connelly, 1995). Alternatively, those who control the knowledge in the "conduit" could have viewed the initial rejection of the Essential Learnings Framework as an example of negativity and teacher conservatism.

As the analysis chapter demonstrated, there are many examples of the teachers in this community acting to express the virtues in order to improve the quality of their individual, and corporate, practice as teachers:

Stuart: "If people know where they have to get to, and then you leave it up to the professionalism of the teacher, I mean, we trust each other." (Vignette 4)

Dennis: "And what about the weaker middle syllabus kids?" (Vignette 5)

Jack: "See that is the sort of debate you could go into with the better kids." (Vignette 10) 
Given that school-based academic departments can act to "influence the decisions and shape[s] the actions of those who inhabit it [the department]" (Siskin, 1994, p. 5), there is a convergence between this defining intellectual aspect of the academic department and the moral aspect of the out-of-class place in shaping the professional learning of the teachers who inhabit the spaces 'in-between' the metaphors of community. There is a deep connection between this aspect of the department and the importance of the department's 'in-between' space. This connection is in the notion that the department as a "knowledge category" (Siskin, 1994, p. 5) also operates in the 'in-between' space, and as such the department is in relationship with the people, reflections and discourses that occur in that 'in-between' space. It is the relationships that exist between people, as well as the "knowledge category" of the department that define the 'in-between' space as both a moral and intellectual space. Recognising the foundational importance of relationships in the private reflections and/or public discourse around the episteme, techne and phronesis of teacher professional learning in the 'in-between' spaces between meaning and practice, practice and identity, and identity and meaning is a key conclusion of my research.

This relational definition of the 'in-between' space as both moral and intellectual also provides a very strong link to two other important aspects of teacher professional learning: teacher professional learning is both an intellectual and moral undertaking, as discussed in chapter 2 on teacher professionalism; and the notion of a moral and intellectual space is closely linked to the concepts of teacher professionalism that are described by Sockett (1993).

Sockett (1993, pp. 16-17) outlines four "dimensions" of teacher professionalism. These dimensions are: the professional community, professional expertise, professional accountability, and the profession's ideal of service. The first dimension is the professional community. As teachers do not work in isolation, but within a variety of formal and informal education communities such as departments, committees, grade levels and so on, teachers are called on to develop moral relationships that rely on different levels of trust, collegiality and collaboration. Although the levels of relationship vary within and between the different communities, there is a common identity of belonging to a profession that seeks to develop learning that has some form of educational end in view, and seeks to develop 
the best practices to pursue that end. The Vignettes clearly demonstrate the importance, often unstated, that the members of the community place on their relationships. For example, the teachers of this science community have negotiated a common understanding of science education that involves critical thinking, relevance, knowledge and theory, interest and understanding, even though these aims were never published. It was simply trusted that members of the community accepted these aims, even if individuals expressed them in different words.

There is a difficulty, however, where these relationships do not exist. As Vignette 11 described, Dick lacked the ability to communicate in the language and perspective of science, due to his lack of training in the subject. The members of this community of science teachers hold very strong views about the meaning of science, views negotiated over a long period of time. The community's understanding of science is something that is tightly held, and not easily renegotiated. The community's understanding of science belongs to the members of the community, being based on the relationships that they cultivate. Their understanding forms the basis of both their work and identity.

The second of Sockett's (1993) dimensions is professional expertise. Teachers are concerned with knowledge of two forms. The first is the knowledge base that forms the subject disciplines, and the acquisition of skills that are integral to those disciplines. The second is the pedagogical knowledge of teaching. Taken together, these forms of knowledge form a professional expertise that is contained in a professional teacher's practice. More importantly, this professional expertise can be discussed using a moral language, underlining the importance of the individual in the task of teaching.

Jenny demonstrates a degree of the virtue of practical wisdom in expressing her concerns to proposed school level changes that would impact on her pretertiary chemistry course. Practical wisdom is not a virtue that is developed in an instant, and in this case is heavily dependant on a thorough understanding of the subject. For both Jenny and Maddie there is a clear sequence of topics that are to be covered if the subject is to be taught well. Anything other than that sequence is not "good" chemistry. To know that sequence is to possess both a solid understanding of the 
subject, and a preparedness to develop, over an extended period of time the most appropriate way to teach the subject.

Regarding pedagogical knowledge, the discussions on developing a research topic for students reflect a recognition within the department that students of different abilities require different levels of support if they are to achieve to their potential. For the weakest of students, research was not seen as a suitable pedagogy. For students in the middle syllabus, research was seen as appropriate, provided that the necessary levels of support were provided at all stages of the research work. For students with more ability in science, research was seen as a valuable experience that could be used to extend the students out of the classroom. The care that the teachers show for their students' progress is based on their individual and corporate understanding of their students' abilities and attitudes. These different abilities and attitudes required different pedagogies if the students were to progress in science. In developing and using these different pedagogies, the teachers demonstrated not just the virtue of care, but also the virtue of practical wisdom. Throughout the Vignettes there are many other examples of the virtues of trust, courage, honesty and fairness. These examples were examined in more detail in the Vignette discussions.

The third of Sockett's (1993) dimensions is professional accountability. Professional teachers are morally responsible for the needs of students, parents and the state. These responsibilities can be viewed specifically, such as meeting a performance standard, or generally, through the meeting of ethical standards appropriate to a professional teacher. The question of professional accountability is clearly evident in the story of Dick in Vignette 11. Dick was not trained in the sciences, but was employed by the school to teach a Year 8 science class. Organisationally, Dick was a member of the science department, and as such it was expected that the science department would assist him in the early stages of his teaching. While this assistance was more than willingly given, Dick was not seen as a member of the community of science teachers. He was, however, held accountable to the standards of that community. Clearly, the community saw itself as accountable to students, their parents, and to the subject. The standards of accountability that the community of science teachers exercised were not to be found in any school-produced document, and the community acted well in advance of the school's probation policy for new teachers. Dick was employed by the 
school but was held accountable by the community. This accountability was an indication of the depth of belief that the community has in the importance of its understanding of what it means to be a teacher of science, and the confidence that this understanding gives to the actions of the community.

The fourth dimension that Sockett (1993) discusses is the ideal of service. Professions work within some moral vision of human betterment, a set of ideals that sets the moral purpose of the profession. Teachers should be committed to education as an ideal of service of some kind, an ideal that would require constant inquiry. One of the aims for science education that this community of teachers has negotiated is the need for students to be taught the value of critical thinking, as a way of making informed choices in the use of science. In the making of informed choices students have the opportunity to use their knowledge of science for the betterment of society. This belief in the importance of teaching for critical thinking is not just an academic exercise; it is an increasingly important part of the teaching practice of the teachers. This is demonstrated in the discourse from Vignette 10:

Jack: "That's a wonderful idea, but I have also said that I would like to see the better groups do a GM discussion... See that is the sort of debate you could go into with the better kids."

To teach for critical thinking in such a way demonstrates the virtues of teacher professionalism. To raise, and then explore, difficult questions is an exercise in courage, as people must be prepared to argue their case, and be prepared to consider arguments that may not concur with their beliefs. Critical thinking is also an exercise in intellectual honesty and fairness in dealing with both arguments and their proponents. Such a concern for teaching and encouraging the application of critical thinking is in stark contrast to a utilitarian view of science education which is raised, then only to be dismissed as a point not even worthy of discussion. As Rob asked:

\footnotetext{
"Is our aim in science to teach them enough stuff to get them through Year 11 and 12 Science, or is it to give them skills to design and develop experiments?" (Vignette 1)
}

Clearly, the teachers in this community understand that science education is both a moral and intellectual undertaking that can only be fully pursued if they themselves are prepared to constantly learn and refine what it means to them to be teachers of science. Even though trust is the only virtue that is explicitly named (Vignette 4) there is clear evidence that virtues underpin the private reflections and public 
discourse of the members of the community. Virtues are an unspecified language of the community. Virtues are a language of the professional learning that occurs within the community. The importance of virtues in personal reflection and/or public discourse about episteme, techne and phronesis of teacher professional learning is one of the key conclusions of my research.

It is with this understanding of the importance of virtues to teacher professional learning that I examine the third, and final, of my conclusions: the importance of a school-based community of science teachers possessing the capacity to renegotiate its identity and sense of meaning.

The understanding of community that forms the foundation for this research was developed from the work of Wenger (1998) on communities of practice, Siskin (1994) on school academic departments, and Van Maanen and Barley (1984) on occupational communities. Taken together, these three authors provide a framework for understanding the community of science teachers. Such an understanding is important, for if "we wish to promote teacher led professional development ... we need to understand how to create workplace environments that respect, support and nourish the efforts of those involved" (Mayer-Smith, 2003, p. 96). Subject departments, as discussed by McCullough et al. (2000) are the primary context for teacher professional learning as they are the primary site for the development of both personal and professional relationships and the member teachers' social identity as a teacher of their subject.

For secondary school teachers this means that those trained in a discipline can describe themselves in terms of their subject because they share, along with similarly trained teachers, a set of values, norms and perspectives based around their subject discipline. Siskin (1994) found that a teacher's academic discipline is fundamental to the individual teachers', often subconscious, "choice of words, the structure of their arguments, or the goals that they hold" (p. 153). The subject, in the secondary school, has a very real role in influencing how teachers "construct their norms of community, their standards of practice-their professional identity and behaviour" (p. 154). Thus, an occupational community is made up of people who consider themselves "to be" the members of an occupation, rather than those people who "are" members of the same 
occupation (Van Maanen \& Barley, 1984, p. 295). For the science teachers in this research, there is a clear demarcation between being a science teacher and being a teacher of another subject:

"We'll have everybody doing projects, and saying that they are doing science" concluded Rob.

"We are seeing the dumbing down of science" observed Jack. (Vignette 12)

Later in the same Vignette, there is the clear implication of a hierarchy of subjects:

Maddie's response was clear and unambiguous. "Maths and science teachers would be teaching maths and science. You would not have the woodwork teacher teaching science."

For the teachers in this community, there is a very clear identity as teachers of science, an identity that separates them, in their own minds, from teachers of other subjects.

Subjects are an important factor in this development of teacher identity, for subjects give departments their reason for existence (Siskin, 1994). Effective subject departments, moreover, are characterised by "a clear and shared sense of vision ... [which] embraced the nature of the subject and how it should be organised for teaching purposes" (Harris et al. 1997, p. 151). Thus departments can be seen as communities as well as subunits of the school organisation. Importantly, Wenger $(1998$, p. 74$)$ in his work on communities of practice makes the point that membership of a community is not a synonym for "belonging to an organisation, or having personal relations with some people". Membership of a community grants the member access to the professional learning of the community, as the member can participate in the ongoing negotiation of both an individual, and communal, sense of identity and meaning.

This negotiation of meaning involves two interdependent processes - participation and reification (Wenger, 1998). The active involvement between the members of a community in an enterprise is seen as participation. Participation is a "complex process that combines doing, talking, thinking, feeling and belonging. It involves our whole person, including our bodies, minds, emotions and social relations" (Wegner, 
1998 , p. 56). Participation has a strong link to the relationships and identities developed by the members of a community. The telling of stories around science and science education in Vignette 10 are examples of participation in action in the discourse of the community.

The implication of Wenger's (1998) definition of participation for this study of the science department is immense. A teacher coming into the department who is trained in a subject would, over time, be able to participate in shaping the practice of the community, as well as being transformed into a member themselves. Likewise, the conversations that teachers have with science teachers outside their own community can provide a stimulus for conversations within the community. In these ways, a community can continue to negotiate its sense of meaning built on the participation of new members, and the ideas of others, who share the same view of the world through the lens of their particular subject. The result of participation is to open new opportunities for professional learning to occur. Two such examples occur in Vignette 5. In the first example, Jenny introduces the idea for a Science Expo, based on discussions that she had with a colleague. In the second, Stuart tells of a colleague's method of developing her students' research skills. Such examples highlight the importance of participation in the professional learning of teachers in a school-based community. Participation by itself is not, however, sufficient to see negotiation occurring within a community. Reification, or the making of the abstract into a concrete form, is the second of Wenger's processes involved in the negotiation of meaning.

Reification contributes to negotiation by creating a focus for negotiation (Wenger, 1998). There is a danger, however, in not recognising the duality inherent in participation and reification. To give precedence to participation over reification, and vice versa, is to risk endangering the entire enterprise. As Wenger states:

If participation prevails - if most of what matters is left unreified - then there may not be enough material to anchor the specificities of coordination and to uncover diverging assumptions. If reification prevails - if everything is reified, but with little opportunity for shared experience and interactive negotiation then there may not be enough overlap in participation to recover a coordinated, relevant or generative meaning (p. 65). 
Participation and reification, the constituents of negotiation, are clearly seen in two examples from the Vignettes. These Vignettes interpret both the development of a new event in the life of the community, the Science Expo and secondly, a change in the science syllabus that was to be taught in Years 7 to 10 . In Vignettes 5 and 6 , the development of the Science Expo is chronicled from an idea that Jenny presented to the teachers through to the overwhelming success that it became for both the department and the school as a whole.

The Science Expo idea that Jenny proposed was reified through the participation of the teachers in the community. As a result of negotiation, the teachers also gained an understanding of the language of the Essential Learning Framework and an appreciation of how their classroom practices could be described in the new language. As a result, the initial hostility to the Essential Learnings Framework was broken down, and an opportunity for professional learning was created.

In the case of Vignette 4, the initial conversation into the development of the syllabus for Years 7 to 10 , there was little progress until Jack intervened in his usual, forthright way:

Jack: "I think that we should probably change the whole system. I'm probably throwing a spanner in the works here. I would pull geology out of grade 10 , so that we could spend more time on physics, chem., maths and biology." (Vignette 4)

As a result of this act of participation, and the trust that it demonstrated on Jack's behalf, the conversation moved forward. The net result was a syllabus that the teachers believed was less crowded, and more amenable to pursuing topics in greater depth, rather than a mass of topics that caused frustration. Through negotiation, the teachers had produced a syllabus that reflected their concern for teaching the foundational concepts of physics, chemistry and biology, as well as giving the flexibility that allowed them to introduce a unit of work on research, or suitable alternative for those students who struggled with science. Through negotiation, the teachers had opened an opportunity for professional learning that reinforced their aims for science education, and their identity as teachers of science. 
In summary, there are the three key conclusions to my research that, I believe, extend the knowledge base as it applies to our understanding of professional learning in school-based communities. The first of these conclusions is that the location of professional learning is in the relational spaces 'in-between' the metaphors of community: meaning, practice and identity. The second conclusion that I draw from my research is that a language of virtues is foundational to the private reflections and/or public discourses around episteme, techne and phronesis that constitute teacher professional learning. The third, and final, conclusion that I can draw from my research is the importance of an explicit understanding of the notion of community when attempting to describe the location of teacher professional learning. Taken together, these conclusions provide the foundation of my understanding of the professional learning that occurs in a school-based community of science teachers. In reaching these conclusions, however, several implications of this research emerge, along with new questions to be asked.

\subsection{IMPLICATIONS}

There are two major implications that arise from this research. By implication, 1 refer to the questions that my research has exposed, but which fall outside the boundaries of my work. As questions, they deserve to be asked and hopefully, answered in the interests of adding to the knowledge base around teacher professional learning. The first of these implications is concerned with the location of the boundaries of subjectbased communities and organisationally recognised subject departments. The second, closely related, implication is the question of access to professional learning opportunities for those teachers who are not members of the subject-based community in which they teach.

In this research, the boundaries of the science community, as I delineated them, are closely aligned with the organisational boundaries of the school's science department. In many ways the words 'community' and 'department' were synonymous. The science department was charged by the school to teach science, and was more than capable of undertaking this function due to fact that the department was also a community that consisted almost entirely of highly experienced, trained science 
teachers. What are the implications for science education within a school, however, where there is a dissonance between the subject department and the subject-based community? This is an important question to ask for two reasons. First, if all members of the department do not share the aims of the community there is a potential for idiosyncratic teaching of the subject. Second, there are an increasing number of nonscience trained teachers teaching science in Australia. Goodrum et al. (2001) stress that there are insufficient science teachers being trained in Australia, resulting in a shortage of science teachers. The net result is that there could well be large numbers of teachers teaching science who, because of their lack of a science background, are members of science departments, but who are not members of the science teaching community. This situation leads directly to the second implication of my study: access to professional learning within communities.

Given that the single most important factor in the improvement of teaching and learning is the teacher, it has been stated that professional development should be a high priority for science teachers (Goodrum et al. 2001). In particular, it is suggested that "professional development must involve all of the science staff within the school ... professional learning must be school-based and directly related to the classroom" (pp. 174-175). This statement reflects the growing realisation that teacher professional learning is "situated, specific and practical in character" (McCullough et al. 2001, p. 90). My research may indicate that recommendations for school, or departmentallybased professional learning may fail to take into account the importance of the community that science trained teachers inhabit, and the role of that community in the professional learning of teachers. My research indicates that the assumption that nonscience trained teachers can actively engage in school-based professional learning within the community of science trained teachers may not be warranted, leading to questions about the efficacy of relying too heavily on departmentally-based professional learning for teachers of science who are not trained in the sciences (Melville, 2004).

In concluding this thesis, I return to my starting point for this research. In section 1.1, the Introduction to chapter 1, I stated my intuitive belief that the subject department is a more appropriate focus for the study of teacher professional learning than the whole school. The department, I believe, offered a situation in which relationships, 
knowledge and identity with a subject would provide opportunities for professional learning to occur. The data that I have collected and analysed in this thesis supports my intuition. My research leads me to conclude that teacher professional learning is situated, not in terms of time or space, but in terms of the relational spaces that are found in the 'in-between' spaces between meaning and practice, practice and meaning, and meaning and identity. Professional learning occurs in these spaces when teachers engage in virtues-based private reflection and/or public discourse around the episteme, techne and phronesis of science teaching. This finding has two important implications for those responsible for the management and leadership of schools. The first implication raises the question of how to conceptualise subject-based departments - as subunits of the wider school organisation, or as communities with their own peculiar meanings, practices and identities. The second implication asks: what is the role that subject-based departments can play in the professional learning of teachers who are not trained in the subject that they are expected to teach? Both implied questions are worthy of further consideration, for both have ramifications for the teaching of science in Australian schools. 


\section{REFERENCES}

American Bar Association. (1986). In the spirit of public service: A blueprint for the rekindling of lawyer professionalism. Chicago: American Bar Association.

American Institutes for Research. (1999). Designing effective professional development: Lessons from the Eisenhower program. Washington DC: US Department of Education.

Angus, L. (1986). The study of organisations and schools. In Schooling, the school effectiveness movement and school reform. Melbourne: Deakin University Press.

Aoki, T.T. (2003). Locating living pedagogy in teacher "research": five metonymic moments. In E.H. Hasebe-Ludt \& W. Hurren. (Eds.), Curriculum intertext. (pp. 19). New York: Peter Lang.

Aquinas, T. (1936). Summa theologica / Aquinas ethicus. (L. Shapcote, Trans.). London: Burns and Oates.

Aristotle. (1985). Nicomachean ethics / Aristotle. (T. Irwin, Trans.). Indianapolis: Hackett.

Asia-Pacific Economic Cooperation Secretariat. (2000). Towards knowledge-based economies in APEC. Retrieved from http://www.apec.sec.org.sg/oad/pubs.kbe.exe

Aspin, D. (2002). An ontology of values and the humanisation of education. Values in Education: College Year Book 2002. Canberra: Australian College of Educators.

Astuto, T.A., Clark, D.L., Read, A-M., McGree, K. \& Fernandez, L.deK.P. (1993). Challenges to dominant assumptions controlling educational reform. Andover, MA: Regional Laboratory for the Educational improvement of the Northeast and islands.

Australian Council of Professions. (1993). Professional services, responsibility and competition policy: A discussion paper prepared for the Permanent Advisory Committee. Canberra, ACT: Australian Council of Professions.

Australian Vice-Chancellors' Committee. (2004). Joint National Health and Medical Research Council / Australian Vice-Chancellors' Committee Statement and Guidelines on Research Practice. Retrieved from http://www.avcc.edu.au/news/public_statements/ publications/glrespra.htm

Bacharach, S.B., Bauer, S.C., \& Shedd, J.B. (1986). The learning workplace: the conditions and resources of teaching: organizational analysis and practice. Washington DC: National Educational Association. 
Ball, D.L. (1993). With an eye on the mathematical horizon: Dilemmas of teaching elementary school mathematics. The Elementary School Journal, 90, 449-466.

Becher, T. (1996). The Learning Professions. Studies in Higher Education, 21 (1), 4355.

Bellah, R.N., Madsen, N., Sullivan, W.M., Swidler, A., \& Tipton, S.M. (1985). Habits of the heart: Individualism and commitment in American life. Berkeley, CA: University of California Press.

Bhabha, H. (1994). The location of culture. New York: Routledge.

Biggs, J. (1987). Student approaches to learning and studying. Camberwell, VIC: Australian Council for Educational Research.

Blackler, F. (1993). Knowledge and the theory of organisations: Organisations as activity systems and the reframing of management. Journal of Management Studies, 30 (6), 863-884.

Blenkin, G.M., Edwards, G., \& Kelly, A.V. (1997). Perspectives on educational change. In Harris, A., Bennett, N., \& Preedy, M. (Eds.), Organisational effectiveness and improvement in education (pp. 216-230). Buckingham, UK: Open University Press.

Bok, S. (1978). Lying: Moral choice in public and private life. New York: Pantheon.

Boston, K. (2002). The road from Corio Bay: The Australian College of Educators and teacher professionalism. Unicorn, $28(2), 8-15$.

Bransford, J.D., Brown, A.L., \& Cocking., R.R. (Eds.). (1999). How people learn: Brain, mind, experience and school. Washington DC: National Academy Press.

Brock, P. (1999). Ethics and professional teaching standards, In The professional ethics of teaching-initial and continuing teacher professional development, Occasional Papers No. 2 (pp. 1-20). Sydney, NSW: New South Wales Department of Education and Training.

Brock, P. (2000). Standards of professional practice for accomplished teaching in Australian classrooms - A national discussion paper. Canberra: Australian College of Education, Australian Curriculum Studies Association, Australian Association for Research in Education.

Bruner, J. (1986). Actual minds, possible worlds. Cambridge, MA: Harvard University Press.

Buckskin, P. (2002). Conflicting values in the education of indigenous Australians. Values in Education: College Year Book 2000 (pp. 152-163). Canberra, ACT: Australian College of Educators. 
Burns, R.B. (1995). Introduction to research methods (2 ${ }^{\text {nd }}$ Ed.). Melbourne, VIC: Longman Australia.

Bush, T. (1997). Collegial models in organisational effectiveness. In A. Harris, N. Bennett, \& M. Preedy (Eds.), Organisational effectiveness and improvement in education (pp. 68-79). Buckingham, UK: Open University Press.

Bybee, R.W. (1993). Reforming science education: Social perspectives and personal reflections. New York: Teachers College Press.

Calkins, L.M. \& Harwayne, L.M. (1991). Living between the lines. Portsmouth, N.H: Heinemann.

Carr, N. (2002). Worldview, wisdom and wonder: a quest for transformation through education. Values in Education: College Year Book 2002 (pp. 173-183). Canberra: Australian College of Educators.

Carter, SL. (1998). Civility: Manners, morals and the etiquette of democracy. New York: Basic Books.

Cawsey, C. (2002). Naming, measuring and modelling the values of public education. Values in Education: College Year Book 2002 (pp. 71-84). Canberra, ACT: Australian College of Educators.

Cibulka, J., Coursey, S., Nakayama, M., Price, J., \& Stewart, S. (2000). Schools as learning organisations: A review of the literature. Retrieved September 5, 2000, from http://www.ericsp.org/pages/digests/profdevlitrev.htm

Cibulka, J. \& Nakayama, M. (2000). Practitioners guide to learning communities. Retrieved September 5, 2000, from http://www.ericsp.org/pages/digests/guide.htm

Clandinin, D. J., \& Connelly, F. M. (1995). Teachers' professional knowledge landscapes. New York: Teachers College Press.

Coble, C.R., \& Koballa, T.R. Jr., (1996). Science education. In J. Sikula., T.J. Buttery \& E. Guyton (Eds.), Handbook on research in teacher education (pp. 459-484). New York: Simon and Schuster/Macmillan.

Cohen, D. \& Hill, H. (2000). Instructional policy and classroom performance: the mathematics reform in California. Teachers College Record, 102 (2), 294-343.

Committee for the Review of Teaching and Teacher Education. (2003). Interim report: Attracting and retaining teachers of science, technology and mathematics. Canberra, ACT: Department of Education, Science and Training.

Connell, R.W. (1985). Teachers' work. London: Allen and Unwin.

Connelly, F.M. \& Clandinin, D. J. (Eds.). (1990). Stories of experience and narrative inquiry. Educational Researcher, 19 (5), 2-14. 
Connelly, F.M. \& Clandinin, D. J. (Eds.). (1999). Shaping a professional identity. New York: Teachers College Press.

Connors, L. (2002). The values that characterise public schooling: A Thermopylae well worth defending. Values in Education: College Year Book 2002 (pp. 59-70). Canberra, ACT: Australian College of Educators.

Cook, M. (2003, March 5). Testing times for science and mathematics. The Age. Retrieved November 11, 2004, from http://www.theage.com.au/articles/2003/03/10/1047144912034.html

Cooper, R.K. \& Sawaf, A. (1997). Executive EQ. London: Orion Business Books.

Costa, A. (1981). Teaching for intelligent behaviour. Educational Leadership, 39 (1), 29-32.

Costello, R. (1991). Government policy for the future development of teachers. In P. Hughes. (Ed.), Teachers' professional development. Hawthorn, VIC: Australian Council for Educational Research.

Coulter, D. \& L. Orme. (2000). Teacher Professionalism: The Wrong Conversation. Education Canada, 40 (1), 4-7.

Council for Science and Technology. (2000). Science teachers: A report on supporting and developing the profession of science teaching in primary and secondary schools. London: British Council for Science and Technology.

Creswell, J.W. (2003). Research design (2 ${ }^{\text {nd }}$ Ed.). Thousand Oaks, CA: Sage.

Czarniawska, B. (2004). Narrative in social science research. London: Sage.

Darling-Hammond, L. (1990). Teacher professionalism, why and how? In A. Lieberman. (Ed.), Schools as collaborative cultures: Creating the future now (pp. 25-50). London: Falmer.

Darling-Hammond, L., \& Sykes, G. (Eds.). (1999). Teaching as the learning profession: Handbook of policy and practice. San Francisco: Jossey-Bass.

Darling-Hammond, L. (2000). Teacher quality and student achievement: a review of State Policy evidence. Education policy analysis archives, 8 (1). Retrieved from http://www.epaa.asu.edu/epaa/v8n1

Davis, M., \& Elliston, F. (Eds.). (1986). Ethics and the legal profession. New York: Prometheus Books.

de Bono, E. (1970). Lateral thinking. New York: Harper and Row.

Denzin, N.K., \& Lincoln, Y.S. (2003). Strategies of qualitative inquiry (2 ${ }^{\text {nd }}$ Ed.). Thousand Oaks, CA: Sage. 
Department of Education, Tasmania. (2003a). Introduction to the outcomes and statements. Hobart, TAS: Department of Education.

Department of Education, Tasmania. (2003b) Learners and learning provision. Hobart, TAS: Department of Education.

Eisner, E (1988). The primacy of experience and the politics of method. Educational Researcher, 20, 15-20.

Elson-Green, J. (2002). Pedagogy needs place in education reform. Campus Review, $12(32), 1$.

Eraut, M. (1994). Developing professional knowledge and competence. London: Falmer.

Eraut, M. (1995). Professional knowledge within a client-centred orientation. In T.R. Guskey \& M. Huberman. (Eds.), Professional development in education (pp. 227254). New York: Teachers College Press.

Eraut, M. (1997). Perspectives on defining the 'The learning society'. Journal of Education Policy, $12(6), 551-558$.

Evans, R. (1996). The human side of school change. San Francisco: Jossey-Bass.

Fenstermacher, G.D. (1990). Some moral considerations of teacher profession, In J.l. Goodlad., R. Sonder \& K.A. Sorotnik. (Eds.), The moral dimensions of teaching. San Francisco: Jossey-Bass.

Fisher, D.L. \& Fraser, B.J. (1991). School climate and teacher professional development. South Pacific Journal of Teacher Education, 19 (1), 17-33.

Fitzgerald, D. (2002). And the winner is... Unicorn, 28 (1), 30-33.

Forgasz, P. (2002). On teaching values in Jewish schools. Values in Education: College Year Book 2002 (pp. 103-114). Canberra, ACT: Australian College of Educators.

Forster, M. \& Masters, G. (2002). Accepting the challenge: assessing the moral and ethical outcomes of schooling. Values in Education: College Year Book 2000 (pp. 140-151). Canberra, ACT: Australian College of Educators.

Freidson, E. (1994). Professionalism reborn, theory, prophecy and policy. Cambridge, UK: Polity Press.

Fullan, M. (1991). What's worth fighting for?: Working together for your school. Hawthorn, VIC: Australian Council for Education Administration.

Fullan, M. (1992). What's worth fighting for? Buckingham, UK: Open University Press. 
Fullan, M. (1994). Teacher leadership: A failure to conceptualise. In D.R. Walling. (Ed.), Teachers as leaders: Perspectives on the professional development of teachers. Bloomington: Phi Delta Kappan.

Fullan, M. (2002). The role of leadership in the promotion of knowledge management in schools. Incorporated Association of Registered Teachers of Victoria, Seminar Series 117, October 2002.

Goodrum, D., Hackling, M., \& Rennie, L. (2001). The status and quality of teaching and learning of science in Australian schools. Canberra, ACT: Department of Education, Training and Youth Affairs.

Gray, J., Hopkins, D., Reynolds. D., Wilcox. B., Farrell. S. \& Jesson, D. (1999). Improving schools: performance and potential. Buckingham, UK: Open University Press.

Grossman, P., Wineburg, S., \& Woolworth, S. (2000). What makes a teacher community different from a gathering of teachers? Center for the Study of Teaching and Policy: University of Washington.

Guba, E., \& Lincoln, Y. (1989). Fourth generation evaluation. Beverley Hills, CA: Sage.

Gulledge, S.A. (1998). Before and after pictures: the makeover of professional relationships through PDS collaboration. Paper presented at the annual meeting of the National Association for Research in Science Teaching, San Diego, CA.

Gusfield, J.R. (1975). Community: A critical response. New York: Harper and Row.

Habermas, J. (1972). Knowledge and human interests. J. Shapiro (Trans.). London: Heinemann.

Habermas, J. (1974). Theory and practice. J. Viertal (Trans.). London: Heinemann.

Hargreaves, A. (1992). Cultures of teaching: a focus of change. In A. Hargreaves \& M. Fullan. (Eds.), Understanding teacher development. London: Cassell Education.

Hargreaves, A. (1994). Changing teachers, changing times: Teachers' work and culture in the post-modern world. London: Cassell.

Hargreaves, A. (1998). The emotional practice of teaching. Teaching and Teacher Education, 14 (8), 835-854.

Hargreaves, D. H. (2000). The knowledge creating school. In B. Moon, J. Butcher \& E. Bird (Eds.), Leading professional development in education (pp. 224-240). London: RoutledgeFalmer.

Harris, A., Bennett, N., \& Preedy, M. (Eds.). (1997). Organisational effectiveness and improvement in education. Buckingham, UK: Open University Press. 
Hawley, W. \& Valli, L. (1999). The essentials of professional development: A new consensus. In L. Darling-Hammond \& G. Sykes. (Eds), Teaching as the learning profession. handbook of policy and practice (pp. 151-180). San Francisco: Jossey- Bass.

Helms, J.V. (1998). Science - and Me: Subject matter and identity in science teachers. Journal of Research in Science Teaching, 35 (7), 811-834.

Hord, S.M. (1997a). Professional learning communities: what are they and why are they important? Issues ... about Change 6(1) Retrieved 7 March, 2001, from http://www.sedl.org/change/issues/issues61.html

Hord, S.M. (1997b). Professional learning communities: Communities of continuous inquiry and improvement. Austin, TX: Southwest Educational Development Laboratory.

Huberman, M. (1990). The model of an independent artisan in teachers' professional relations. In J.W. Little \& M.W. McLaughlin (Eds.), Teachers' work (pp. 11-50). New York: Teachers College Press.

Huberman, M. (1992). Teacher development and instructional mastery. In A. Hargreaves \& M. Fullan (Eds.), Understanding teacher development (pp. 122142). New York: Teachers College Press.

Huberman, M. (1995). Professional careers and professional development-some intersections. In T.R. Guskey \& M. Huberman (Eds.), Professional development in education (pp. 193-224). New York: Teachers College Press.

Huffman, J.B., Hipp, K.A., Pankake, A.M. \& Moller, G. (2001). Professional learning communities: leadership, purposeful decision making, and embedded staff development. Journal of School Leadership, 11, 448-463.

Ingvarson, L. (2002). Building a learning profession. Commissioned research series Paper number 1. Canberra, ACT: Australian College of Educators.

Isaac, S., \& Michael, W.B. (1995). Handbook in research and evaluation ( $3^{\text {rd }}$ Ed.). San Diego, CA: Educational and Industrial Testing Services.

Kennedy, M. (1998). Form and substance in inservice teacher education. Research monograph No. 13. Arlington, VA: National Science Foundation.

Kennedy, K. (2002). Searching for values in a globalised world: can civic education provide an answer? Values in Education: College Year Book 2002 (pp. 25-37). Canberra, ACT: Australian College of Educators.

Kenny, A. (1978). The Aristotelian ethics. Oxford: Oxford University Press. 
Kidder, R. (1994). Shared values for a troubled world: Conversations with men and women of conscience. California: Jossey-Bass.

Kilbourn, B. (1998) For the love of teaching. Ontario: The Althouse Press.

Lampert, M. (1985). How do teachers manage to teach? Perspectives on problems of practice. Harvard Education Review, 55 (2), 178-194.

Leithwood, K., Leonard, L., \& Sharratt, L. (1998). Conditions fostering organisational learning in schools. Education Administration Quarterly, 34 (2), 243-276.

Lincoln, Y.S., \& Guba, E.G. (1985). Naturalistic inquiry. Beverly Hilis, CA: Sage.

Little, J.W. (1982). Norms of collegiality and experimentation: workplace conditions of school success. American Educational Research Journal, 19, 325-340.

Little, J.W. (1990). Conditions of professional development in secondary schools. In M.W. McLaughlin., J.E. Talbert., \& N. Bascia (Eds.), The contexts of teaching in secondary schools: Teachers' realities (pp. 187-223). New York: Teachers College Press.

Loucks-Horsley, S. (1998). The role of teaching and learning in systematic reform: A focus on professional development. Science Educator, 7, 1-6.

Loucks-Horsley, S., Hewson, P.W., Love, N., \& Stiles, K.E. (1998). Designing professional development for teachers of mathematics and science. Thousand Oaks, CA: Corwin.

Louis, K.S., \& Smith, B. (1992). Cultivating teacher engagement: Breaking the iron law of social class. In F.M. Newmann (Ed.), Student engagement and achievement in American secondary schools (pp. 119-152). New York: Teachers College Press.

Lovat, T., Schofield, N., Morrison, K. \& O'Neill, D. (2002). Research dimensions of values education: a Newcastle perspective. Values in Education: College Year Book 2002 (pp. 125-139). Canberra, ACT: Australian College of Educators.

Lovat, T. (1994). The implications of bioethics for teachers and teacher researchers. British Educational Research Journal, 20, 187-196.

Lovat, T. (1995). Bioethics teaching and the researcher teacher: considerations for teacher education. Action in Teacher Education, 16, 71-78.

Lyotard, J.F. (1984). The postmodern condition: A report on knowledge (G. Bennington \& B. Massumi, Trans.). Minneapolis: University of Minnesota Press (original work published 1979).

Maslow, A. (1965). Eupsychian management. Homewood, Ill: Richard Irwin and Dorsey Press. 
Mayer-Smith, J. (2003). The experience and challenges of teacher leadership in learning technology reform for science education. J. Wallace \& J. Loughran (Eds.), Leadership and professional development in science education: New possibilities for enhancing teacher learning (pp. 81-98). London \& New York: RoutledgeFalmer.

McCullough, G., Helsby, G., \& Knight, P. (2000). The politics of professionalism. London: Continuum.

McLaughlin, M.W. \& Talbert, J.E. (1993). Contexts that matter for teaching and learning. Stanford, CA: Centre for Research on the Context of Secondary School Teaching, Stanford University.

Melville, W.S. (2004). Science teachers' occupational community and the implications for non-science trained teachers. Paper presented at the annual meeting of the National Association for Research in Science Teaching, Vancouver, Canada.

Midgley,C. \& Wood, S. (1993). Beyond site-based management: empowering teachers to reform schools. Phi Delta Kappan, 75 (3), 245-252.

Misko, J. (2002). On-line learning in the knowledge based society: a VET perspective. Unicorn, $28(3), 65-70$.

National Center for Research on Teacher Education. (1991). Final report: National Center for Research on Teacher Education. East Lansing: Michigan State University.

National Research Council. (1996). The national science education standards Washington DC: National Academy Press.

Newell, C., \& Rimes, J. (2002). Beyond pious platitudes: values, spirituality and curriculum. Values in Education: College Year Book 2002 (pp. 92-102). Canberra, ACT: Australian College of Educators.

Nias, J. (1975). The nature of trust. In Elliot, J., Bridges, D., Ebbutt, D., Gibson, R. \& Nias, J. (Eds.), School accountability (pp. 21 1-224). London: Grant Mcintyre.

Noddings, N. (1984). Caring: A feminine approach to ethics and moral education. Berkeley: University of California Press.

Noddings, N. (1989). Woman and evil. Berkeley: University of California Press.

Noddings, N. (1992). The challenge to care in schools: An alternative approach to education. New York: Teachers College Press.

Noddings, N. (1995). Philosophy of education. Boulder: Westview. 
Noddings, N. (1996). On community. Educational Theory, 46 (3).

Nonaka, I. \& Takeuchi, H. (1995). The knowledge-creating company. Oxford: Oxford University Press.

Ong, W. (1982). Orality and literacy: The technologising of the word. London: Routledge.

Ontario College of Teachers, (1999). Standards of practice for the teaching profession. $\quad$ Retrieved 28 March, 2001 from http://www.oct.on.ca/english/professional_affairs/plf_final.htm

Organisation for Economic Co-operation and Development. (1994). Quality in Teaching. Paris: OECD Centre for Educational Research and Innovation.

Organisation for Economic Co-operation and Development. (2001). Teacher Demand and Supply. Paris: OECD Centre for Educational Research and Innovation.

Ozga, J. (1992). Teacher professionalism. Paper presented to the annual conference of British Educational Management and Administration Society, Bristol, UK.

Quisumbing, L. \& de Leo, J. (2002). Values education in a changing world: some UNESCO perspectives and initiatives. Values in Education: College Year Book 2002 (pp. 164-172). Canberra, ACT: Australian College of Educators.

Parquette, M. (1987). Voluntary collegial support groups for teachers. Educational Leadership. November, 1987, 36-39.

Paule, L, (1989). Oregon school improvement and professional development project: Final report. Portland, OR: Northwest Regional Educational Laboratory, Assessment and Evaluation Program.

Peters, R. (1972). Ethics and education. London: Allen \& Unwin.

Polkinghorne, D.E. (1995). Narrative configuration in qualitative analysis. In J.A. Hatch \& R. Wisniewski. (Eds.), Life, history and narrative (pp. 5-24). London:Falmer.

Regnier, P. (1994). The illusion of technique and the intellectual life of schools. Phi Delta Kappan, September, 1994.

Ricoeur, P. (1991). From text to action: Essays in hermeneutics. (K. Blamey \& J.B. Thompson, Trans.). Evanston: Northwestern University Press (original work published 1986).

Ridden, P. (1996). Caught in the middle - leading from the centre. the importance of teacher perceptions. The Practising Administrator, 2, 25-28. 
Rosenholtz, S. (1989). Teacher's workplace: the social organization of schools. New York: Longman.

Rowan, B., (1991). The shape of professional communities in schools. Paper presented at the annual meeting of the American Educational Research Association, Chicago, IL.

Ritchie, S.M., \& Rigano, D.L. (2002). Discourses about a teacher's self-initiated change in praxis: storylines of care and support. International Journal Science Education, 24 (10), 1079-1094.

Ryan, C. (1996). New ways of approaching professional development. Independent Education, 26 (3), 7-9.

Salman, S. (2002). Values in education: an Islamic perspective. Values in Education: College Year Book 2002 (pp. 115-124). Canberra, ACT: Australian College of Educators.

Salomon, G. (1994). Whole individuals in complex settings: Educational research reexamined. Address at the annual conference of the Australian Association for Research in Education, Newcastle, Australia.

Schifter, D. \& Fosnot, C.T. (1993). Reconstructing mathematics education: Stories of teachers meeting the challenge of reform. New York: Teachers College Press.

Schultz, A. (1998). Caring in schools is not enough. Educational Theory, 48 (3), 373393.

Scribner, J.P. (1998). A qualitative analysis of teacher professional learning and teacher work in urban high schools. Paper presented at the annual meeting of the American Educational Research Association, San Diego, CA.

Senge, P.M. (1990). The fifth discipline: The art and practice of the learning organisation. New York: Currency Doubleday.

Shapero, A. (1985). Managing professional people. New York: Free Press.

Short, K. (1990). Creating a community of learners. In K.Short \& K. Pierce (Eds.), Talking about books: Creating literate communities (pp. 33-51). Portsmouth, N.H: Heinemann. 
Shulman, L.S. (1987). Knowledge and teaching: Foundations of new reform. Harvard Educational Review, 57 (1), 1-22.

Shorter Oxford English Dictionary. (1980). Oxford: Oxford University Press.

Silva, D.Y., Gimbert, B., \& Nolan, J. (2000). Sliding the doors: locking and unlocking possibilities for teacher leadership. Teachers College Record, 102 (4), 779-804.

Siskin, L.S. (1994). Realms of knowledge: Academic departments in secondary schools. London: The Falmer Press.

Smith, D.G. (2003) Preface: Some thoughts on living in-between. In E.H. HasebeLudt \& W. Hurren. (Eds.). Curriculum intertext (pp. xv-xvii). New York: Peter Lang.

Smith, J.K. \& Blase, J. (1988). Educational leadership: a moral and practical activity. NASSP Bulletin, 72 (510), 1-4 and 6-10.

Smith, P. (2002). Expert teachers, challenged learners. Independence, 27 (1), 24-27.

Sockett, H. (1993). The moral basis of teacher professionalism. New York: Teachers College Press.

Sockett, H. (1996). Teachers for the $21^{\text {st }}$ century: redefining professionalism. NASSP Bulletin, 80 (580), 22-29.

Stenhouse, L. (1975). An introduction to curriculum research and development. London: Heinemann.

Squires, G. (1999). Teaching as a professional discipline. London: Falmer.

Sykes, G. (1999). Teacher and student learning: Strengthening their connection (pp. 151-180). In L. Darling-Hammond \& G. Sykes (Eds.), Teaching as the learning profession: Handbook of policy and practice. San Francisco: Jossey-Bass.

Sykes, G. (2001). Professional development for teachers: Principles, practices and contexts. Draft paper prepared for the Learning First Alliance, Michigan State University.

Tarlington, R. \& O'Shea, F. (2002). Values Education: a Catholic perspective. Values in Education: College Year Book 2002 (pp. 85-91). Canberra, ACT: Australian College of Educators.

Toh, S.H. (2002). Citizenship education for a culture of peace: themes, challenges and possibilities. Values in Education: College Year Book 2002 (pp. 38-58). Canberra, ACT: Australian College of Educators. 
Torstendahl, R. (1990). Introduction: Promotion and strategies of knowledge-based groups. In R. Torstendahl \& M. Burrage. (Eds.), The formation of professions. London: Sage.

United States National Board for Professional Teaching Standards. (1989). Policy position. Retrieved 29 March, 2001 from http://www.nbpts.org/about/index.html

United States National Board for Professional Teaching Standards. (1989).

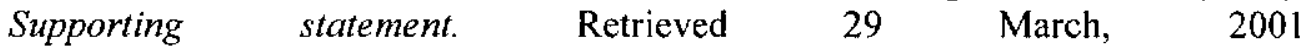
http://www.nbpts.org/about/index.html

Van Maanen, J. \& Barley, S.R. (1984). Occupational communities: Culture and control in organisations. Research in Organisational Behaviour, 6, 287-365.

Wallace, J. (1997). Leading curriculum change: a sourcebook of ideas for heads of department and program coordinators. Perth, WA: Curriculum Leadership Project.

Wallace, J., \& Wildy, H. (1995a). The changing world of school leadership, working in the professional organisation today. The Practising Administrator, 1, 14-17.

Wallace, J., \& Wildy, H. (1995b). Working in the science department: Developing a professional community. Science Educator, 4 (1), 1-6

Wallace, J., \& Wildy, H. (1997). Improving science education through accountability relationships in schools. Science Educator, 6, 11-15.

Wasley, P. (1991). Teachers who lead. New York: Teachers College Press.

Wells, D. (1998). Losing our virtue. Grand Rapids: William B. Eerdmans Publishing.

Wenger, E. (2003). Communities of practice. Cambridge, UK: Cambridge University Press.

Westheimer, J. (1998). Among school teachers: Community, autonomy, and ideology in teachers' work. New York: Teachers College Press.

Wildy, H., \& Wallace, J. (1994). Relearning to teach physics: In the midst of change. Research in Science and Technological Education, 12 (1), 63-75.

Wildy, H., \& Wallace, J. (1995). Understanding teaching or teaching for understanding: Alternative frameworks for science classrooms. Journal of Research in Science Teaching, 32 (2), 143-156.

Wildy, H., \& Wallace, J. (2004). Science as content: science as context: working in the science department. Research in Science Education 30 (2), 99-112.

Wilson, S., \& Berne, J. (1999). Teacher learning and the acquisition of professional knowledge: An examination of research on contemporary professional 
development. In Iran-Najed \& P.D. Pearson (Eds.), Review of Research in Education (24) 173-209. Washington: American Educational Research Association.

Wolcott, H.F. (1988). Ethnographic research in education. In R.M. Jaeger (Ed.), Complementary methods for research in education (pp. 187-206). Washington DC: American Educational Research Association.

Wolcott, H.F. (1990). On seeking - and rejecting - validity in qualitative research. In E.W. Eisner \& A. Peshkin. (Eds.), Qualitative inquiry in education: The continuing debate. New York: Teachers College Press. 


\section{APPENDICES}

\section{APPENDIX 1: STUART'S GUIDELINES FOR POLICY DEVELOPMENT}

- The policy needs to clearly articulate what we consider to be important in the teaching and learning of science in this school. This would need to take into account the school's mission statement and ethos, mandated government requirements for science education and current thinking in the field of science education.

- The policy should direct the development of the science program, and act as a standard against which changes can be referred to and so evaluated.

- The policy should give practical guidance to teachers of science as to what is expected of them, and what they can expect of the science faculty, in their teaching of science in this school.

- The policy must clearly state how assessment is to be conducted and reported on, and give particular emphasis to the setting and maintenance of within school standards.

- The policy should contain a mechanism whereby it can be reviewed over time to ensure that it still provides a suitable basis for the development of science in this school.

- The policy should be the result of professional discussion amongst science teachers and other interested individuals. It should not be imposed upon science teachers, or written in a way that makes it inaccessible to teachers or administrators.

- The policy needs to ensure that health and safety issues are addressed. 


\section{APPENDIX 2: DRAFT SCIENCE POLICY}

The purpose of science education at the school is to develop students' scientific literacy.

Scientific literacy is a high priority for the community. Scientific literacy helps students to be interested in and understand the world around them, to encourage in the discourses of and about science, to be sceptical and questioning of claims made by others about scientific matters, to be able to identify questions and draw evidencebased conclusions, and to make informed decisions about the environment and their own health and well-being.

Fundamental to the high priority of scientific literacy for all our students is the way in which science is implemented at the school.

Science and science education have a high priority in the school curriculum and re valued by the school and the wider community.

The science curriculum is dynamic. It is relevant to the student's needs, concerns and personal experiences.

The teaching and learning of science is centred on inquiry. Students investigate, construct and test ideas and explanations about the natural and man-made worlds.

The teaching-learning environment is characterised by enjoyment, fulfilment, ownership, and of engagement in learning, and mutual respect between teacher and students.

Assessment is seen as a tool to guide the development of a student's strengths and highlights areas for student improvement.

Excellent facilities, equipment and resources support teaching and learning. Appropriate class sizes make it possible to employ a range of teaching strategies and 
provide opportunities for the teacher to get to know each child as a learner and give feedback to individuals.

Teachers are life-long learners who are supported, nurtured and resourced to build the understandings and competencies required of contemporary best practice.

Teachers of science have a recognised career path based on sound professional standards endorsed by the profession.

Science teaching is perceived as exciting and valuable, contributing significantly to the development of persons and to the economic and social well-being of the nation. 


\section{APPENDIX 3: ESSENTIAL LEARNINGS FRAMEWORK, VALUES AND PURPOSES}

The five Essential Learnings, and their associated key elements, for the Tasmanian

Department of Education's curriculum framework are:

Thinking.

- Inquiry

- Reflective thinking

Communicating.

- Being literate

- Being numerate

- Being information literate

- Being arts literate

Personal Futures.

- Building and maintaining identity and relationships

- Maintaining wellbeing

- Being ethical

- Creating and pursuing goals

Social responsibility.

- Building social capital

- Valuing diversity

- Acting democratically

- Understanding the past and creating preferred futures

World futures.

- Investigating the natural and constructed world

- Understanding systems

- Designing and evaluating technological solutions.

- Creating sustainable futures.

The Essential Learnings are guided by the core values of:

- Connectedness

- Resilience

- Achievement 
- Creativity

- Integrity

- Responsibility

- Equity

The Purposes of the Essential Learnings are to ensure that students are:

- Learning to relate, participate and care

- Learning to live full, healthy lives

- Learning to create purposeful futures

- Learning to act ethically

- Learning to learn

- Learning to think, know and understand

Taken from Introduction to the Outcomes and Statements, Department of Education, Tasmania (2003, p. iii). 


\section{APPENDIX 4: TOPICS FOR THE YEARS 8 TO 10 SCIENCE SYLLABUS}

The topics for Year 7 Science were never listed and distributed to the whole department, as Dennis taught all except one of the Year 7 classes. Dennis and Jenny, who taught the other Year 7 class, developed the sequence of Year 7 topics between them.

\section{YEAR 8 SCIENCE OVERVIEW}

\section{Chemistry}

Metals: 5 Properties, reactivity series, displacement reactions, corrosion, bonding.

Non-metals: Properties, comparison to metals.

Chemical and physical reactions.

Rates of reaction: temperature, concentration and catalysts.

Consumer chemistry project.

Physics

Energy forms: heat, light, nuclear, chemical, sound, etc.

Flame tests, spectrometry.

Potential and kinetic.

Energy converters.

Mass / energy conservation.

Uses of electrical energy.

Electric circuits / diagrams / symbols.

Uses of multimeters.

Series and parallel.

Ohm's law.

Circuit breakers / fuses / power meters.

Biology

Human body systems.

Main focus on reproduction, respiratory, circulatory, digestive.

Minor focus on skeletal, muscular, nervous, excretory, endocrine.

Geology

Minerals and ores.

Colour, cleavage, crystal, lustre, streak, Moh's hardness.

Mining methods.

Mineral processing.

Distribution of metals in Tasmania.

Environmental impact of mining.

Prospecting methods. 
Geological mapping.

\section{YEAR 9 SCIENCE OVERVIEW}

Chemistry

Periodic table trends

Electron configuration

Ion formation / valencies

Ionic and covalent bonds

Solubility reactions / rules

Physics

Sun / stars facts and figures, structure, life cycle

Solar system / Milky Way information

Other objects in the Universe

Space exploration

Planetarium visit

Biology

Photosynthesis

Nitrogen / carbon / water cycles

Food chains / webs

Interdependence in habitats

Forest ecology

Geology

Geological timeline

Radioactive dating

Contour mapping

Dipping beds

Geological cross section

Correlation

\section{YEAR 10 SCIENCE OVERVIEW}

Review

Review Year 9 chemistry for 2 weeks

Writing formulae / balancing equations

Chemistry

Mole / molarity calculations

Titrations (dilute / concentrated vs. strong / weak)

Alternative work:

- Volatility of different fuels

- Thermal capacity of different fuels

- Energy content of different foods

- Alcohol distillation 
- Calorimeter work

Physics

Force / mass / weight

Vector diagram (right angled)

Equations of motion (conversion of units)

$\mathrm{CO}_{2}$ rocket project on motion

Displacement vs. time / velocity vs. time / acceleration vs. time graphs

Biology

Cell structures / functions

Mitosis / meiosis

DNA

Inherited characteristics

Genetic crosses

Genetic engineering

Optional unit

Can be project based, extension of a topic, or a new topic 


\section{APPENDIX 5: TEACHER CONSENT FORM}

Professional learning in a school-based community of Science teachers.

\section{TEACHER CONSENT FORM}

This research project is being undertaken as part of my Doctor of Philosophy degree course with Curtin University of Technology. The research is concerned with how teachers of science undertake professional learning through the dialogue that they use in science staff meetings.

In order to undertake this program, it is intended to record each of the regular science staff meetings that are held through the school year. For each of these meetings it is proposed to analyse the recordings through a series of questions that will be designed to look at the critical aspects of teacher professional learning, and to track the development of that learning for the particular group of science teachers. The main value of this program is to examine the professional learning that occurs within a close community of science teachers, as opposed to the professional learning at the school level, which has tended to be the focus in other studies.

The transcripts of the recordings, and the recordings themselves, will form the only data source for the study. I will take every means possible to ensure the anonymity of both the school and each person involved. For example, only fictional names will be used for both the participants and the school, and the school will not be identifiable from the text.

If you have any concerns regarding this request, please feel free to contact myself, or either of my Co-Supervisors, whose names appear at the foot of this page.

I hereby give my consent to being recorded at a science staff meeting.

NAME:

SIGNATURE:

DATE:

This research has received ethical clearance from Curtin University of Technology. 